\title{
The sympathetic nervous system and human energy metabolism in relation to obesity
}

Citation for published version (APA):

Blaak, E. E. (1993). The sympathetic nervous system and human energy metabolism in relation to obesity. [Doctoral Thesis, Maastricht University]. Datawyse / Universitaire Pers Maastricht. https://doi.org/10.26481/dis.19931216eb

Document status and date:

Published: 01/01/1993

DOI:

10.26481/dis.19931216eb

Document Version:

Publisher's PDF, also known as Version of record

\section{Please check the document version of this publication:}

- A submitted manuscript is the version of the article upon submission and before peer-review. There can be important differences between the submitted version and the official published version of record.

People interested in the research are advised to contact the author for the final version of the publication, or visit the DOI to the publisher's website.

- The final author version and the galley proof are versions of the publication after peer review.

- The final published version features the final layout of the paper including the volume, issue and page numbers.

Link to publication

\footnotetext{
General rights rights.

- You may freely distribute the URL identifying the publication in the public portal. please follow below link for the End User Agreement:

www.umlib.nl/taverne-license

Take down policy

If you believe that this document breaches copyright please contact us at:

repository@maastrichtuniversity.nl

providing details and we will investigate your claim.
}

Copyright and moral rights for the publications made accessible in the public portal are retained by the authors and/or other copyright owners and it is a condition of accessing publications that users recognise and abide by the legal requirements associated with these

- Users may download and print one copy of any publication from the public portal for the purpose of private study or research.

- You may not further distribute the material or use it for any profit-making activity or commercial gain

If the publication is distributed under the terms of Article $25 \mathrm{fa}$ of the Dutch Copyright Act, indicated by the "Taverne" license above, 
THE SYMPATHETIC NERVOUS SYSTEM AND

HUMAN ENERGY METABOLISM

IN RELATION TO OBESITY 


\section{CIP-GEGEVENS KONINKLIJKE BIBLIOTHEEK, DEN HAAG}

Blaak, Ellen Elisabeth

The sympathetic nervous system and human energy metabolism in relation to obesity / Ellen Elisabeth Blaak.

Maastricht: Universitaire Pers Maastricht.-I1 1.

Proefschrift Maastricht.- Met lit. opg.- Met

samenvatting in het Nederlands

ISBN 90-5278-107-9

trefw.: energiemetabolisme/overgewicht

Vormgeving:

Omslagillustratie:

Druk:
Ellen Blaak

Rick van Westerop

Datawyse Maastricht/Krips Repro Meppel 


\title{
THE SYMPATHETIC NERVOUS SYSTEM AND HUMAN ENERGY METABOLISM IN RELATION TO OBESITY
}

\section{PROEFSCHRIFT}

\author{
ter verkrijging wan de graad van doctor \\ aan de Rijksuniversiteit Limburg te Maastricht, \\ op gezag van de Rector Magnificus, Prof. dr. H. Philipsen, \\ vollgens het besluit van het College van Dekanen, \\ in het openbaar te verdedigen op donderdag, 16 december 1993 \\ om 14.00 uur
}

door

Ellen Elisabeth Blaak

geboren te Vught op 17 december 1964

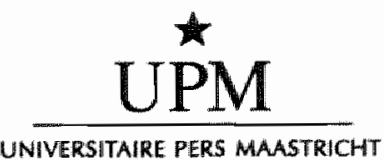


Promotor:

Co-promotor:

Beoordelingscommissie: $\quad$ Prof. dr. A.C. Nieuwenhuijzen Kruseman (voorzitter)

Prof. dr. A. Astrup (University of Copenhagen, Denmark)

Prof. dr. H. Kuipers

Prof. dr. H.A.J. Struijker Boudier

Prof. dr. M.J. Stock (St. George's Hospital Medical

School, London, United Kingdom)

Het verschijnen van dit proefschrift werd mede mogelijk gemaakt door de financiële steun van de Nederlandse Hartstichting en de Stichting Dr. Ir. J.H.J. van de Laar 
Aan mijn moeder

Ter nagedachtenis aan mijn vader 


\section{Contents}

Chapter 1 Introduction

Chapter 2 Role of alpha and beta-adrenoceptors in the sympathetically mediated thermogenesis

Chapter 3 The effect of hand heating by a warm air box on oxygen consumption of the contralateral arm

Chapter 4 Total forearm blood flow as indicator of skeletal muscle blood flow: effect of subcutaneous adipose tissue blood flow

Chapter 5 Effect of beta-adrenergic stimulation on forearm skeletal muscle metabolism in man

Chapter 6 Effect of beta-adrenergic stimulation on whole body energy expenditure and forearm skeletal muscle metabolism in obese men: a comparison with lean men

Chapter 7 Beta-adrenergically mediated thermogenic and heart rate response: effect of obesity and weight loss

Chapter 8 Beta-adrenergic stimulation and skeletal muscle metabolism in rellation to weight reduction in obese men

Chapter 9 Beta-adrenergic stimulation and abdominal subcutaneous fat blood flow in lean, obese and reduced-obese subjects 
Samenvatting

Abbreviations

153

Nawoord

155

Curriculum vitae

List of publications 



\section{CHAPTER 1}

\section{Introduction}

\section{General}

Human obesity, which is generally defined as the disproportional increase in fat mass when compared to the fat free body mass, has become the most common nutritional disorder in the developed world. Its prevalence in the Dutch population may vary between $5-50 \%$, depending on the definition of overweight (6). Obesity has been reported to be associated with major health hazards including coronary heart disease and noninsulin dependent diabetes mellitus (2). A great amount of research has been performed on the efficacy of different weight reducing regimens in the treatment of obesity. Although the remedies for obesity seem simple- i.e. eat less and exercise more-, in general the outcome of the treatment of obesity is disappointing and experience indicates that for most individuals the weight-reduced obese state is a limited accomplishment since weight regain occurs within measurable time. To develop an effective strategy for the treatment of obesity and more particular for the long term management of weight control, more knowledge is required on the regulatory mechanisms in the control of energy metabolism. At present, it is clear that the sympathetic nervous system plays a role of importance in the control of human energy and substrate metabolism. The catecholamines, norepinephrine and epinephrine, have a central role in the regulation of energy expenditure and substrate utilization since they increase cellular oxygen uptake and stimulate the conversion of complex fuels into readily available substrates by processes of lipolysis, glycogenolysis and gluconeogenesis $(17,28,29,31,35)$, as indicated in figure 1 for epinephrine. Norepinephrine and epinephrine have been reported to be potent stimuli for increasing metabolic rate (thermogenesis, 36,37). Moreover, the demonstration that B-blockade may inhibit diet-induced thermogenesis (39) or resting energy expenditure (42) suggests that several components of energy metabolism may be partly controlled by the sympathetic nervous system. Metabolic effects of the sympathetic nervous system in certain tissues, may be exerted directly via sympathetic nerve stimulation, may occur indirectly as a consequence of stimulation of humoral factors (e.g. secretion of catecholamines from the adrenal medulla, and insulin and glucagon from the pancreas, fig 1) or may be associated with the sympathetically-induced cardiovascular effects, influencing the perfusion of metabolically active tissues. In the following paragraphs literature on adrenoceptor populations, tissues and metabolic processes involved in the sympathetically mediated thermogenesis is reviewed. Finally, special attention is given to the metabolic processes that may be involved in the development or maintenance of the obese state. 
Muscle

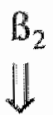

\begin{tabular}{l}
\hline glycolysis $\uparrow$ \\
glycogenolysis $\uparrow$ \\
glucose transport $\downarrow$ \\
\hline
\end{tabular}

Liver

$B_{2}$

U.

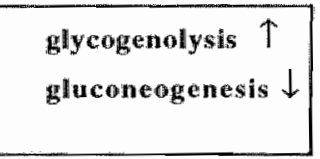

Adipose tissue
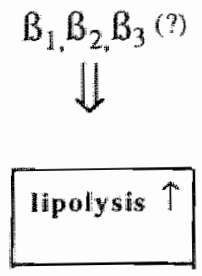

lipolysis $\downarrow$

\section{Pancreas}

$\alpha$

$\downarrow$

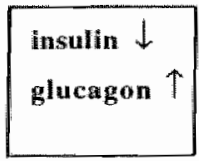

$\alpha_{2}$

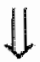

$\sqrt{2}$

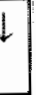

Fig 1. Scheme of the effects of epineptrine on tissue metabolism

\section{Involved adrenoceptor populations}

The traditional adrenoceptor subtypes can be classified as $\alpha_{1}{ }^{-}, \alpha_{2}, \beta_{1}-$, and $\beta_{2}$ adrenoceptors. In addition, a human $\mathbb{B}_{3}$-adrenoceptor has recently been cloned (12). Several studies have shown that the resting metabolic rate or diet-induced thermogenesis can be inhibited by B-blockade $(1,39,42)$. Thorin et al (39) found that the glucose-insulin induced thermogenesis was similarly reduced by the selective $B_{1}$-antagonist metoprolol as by the non-selective $B$-blocker propranolol, which suggests that only the $B_{1}$ adrenoceptor is involved in thermogenesis. Astrup et al (4) showed that skeletal muscle plays an important role in the ephedrine-stimulated thermogenesis. This may indicate a role for $B_{2}$-adrenoceptors in human energy metabolism since the adrenoceptor population of skeletal muscle mainly consists of $B_{2}$-adrenoceptors (26). In addition, atypical agonists (perhaps $B_{3}$ ) have been reported to increase thermogenesis in rats (19) and in man (16). In humans, a B-agonist with atypical selectivity increased weight loss in obese subjects on a restricted diet (9), but this effect was not seen in all studies (8). Furthermore, although functional studies of human adipocytes suggested involvement of $B_{3}$-adrenoceptors in lipolysis (18), in another study $B_{3}$-adrenoceptors could not be identified in human adipose tissue (23). Thus, there is still much debate on the significance of $B_{3}$-adrenoceptors in human energy metabolism. 
Also, further research is necessary on the significance of $\alpha$-adrenoceptors in human thermogenesis. An early study in rats (13) showed that $\alpha$-adrenoceptors may be involved in the sympathetically mediated thermogenesis since the norepinephrine-induced thermogenesis was markedly inhibited by $\alpha_{1}$-adrenoceptor blockade. However, human studies showed that $\alpha$-adrenoceptor blockade did not affect diet-induced thermogenesis $(10,33)$.

To obtain more information on the role of $\alpha_{1}-, \alpha_{2}-, \beta_{1}-, B_{2^{-}}$and $B_{3}$-adrenoceptors in human energy metabolism a study intended to investigate the role of the different adrenoceptor subclasses in the sympathetically mediated thermogenesis, is described in chapter 2.

\section{Site of localization and underlying metabolic processes}

The localization of the thermogenesis induced by the sympathetic nervous system is still a matter of dispute. In adult rats, the norepinephrine-induced thermogenesis has been shown to occur mainly in brown adipose tissue (38). Astrup et al (4) showed that in humans ephedrine-induced thermogenesis is not located in brown adipose tissue. They concluded that $50 \%$ or more of the increase in whole body energy expenditure may be located in skeletal muscle. Furthermore, it requires more research to elucidate the metabolic pathways underlying the increase in metabolic rate as result of sympathetic stimulation. It has been shown that catecholamines may affect hepatic and skeletal muscle glucose turnover $(29,35)$. In addition, catecholamines are potent lipolytic hormones and play an important role in the mobilization of fat stores in man (17). To obtain more information on the role of skeletal muscle and different metabolic processes in the sympathetically mediated thermogenesis the underneath described methods had to be validated.

Skeletal muscle metabolism was studied by means of the determination of arterio-venous concentration differences of various metabolites across forearm muscle in combination with a measurement of muscle blood flow (forearm model). However, canulation of an artery may not always be succesful and may sometimes result in complications. Therefore, sampling of arterialized blood from a heated dorsal hand vein has often been used as an alternative. Astrup et al (5) have criticized the method of hand heating by a warming blanket, showing that it may affect core temperature and hemodynamics and may thereby introduce errors in the skeletal muscle flux calculations. However, it may be possible that the warming blanket, in which there is direct contact of the heating device and skin has a more pronounced effect on metabolism than the more often used warm air box (15). For this reason, we have investigated how hand heating by a warm air box would affect core temperature and hemodynamics of the contralateral arm (chapter 3).

A generally applied method for estimating skeletal muscle blood flow in forearm balance studies is venous occlusion plethysmography (43). This method only measures total blood flow through the forearm and not the flow through the individual parts such as muscle, fat tissue and skin. Although skeletal muscle may account for $60 \%$ or more of the forearm tissues, a significant contribution of other forearm tissues to total forearm 


\section{Chapter 1}

blood flow cannot be excluded. In chapter 4 , the contribution of forearm subcutaneous adipose tissue blood flow ( ${ }^{133}$ xenon washout technique, 24) to total forearm blood flow is evaluated in lean and obese males. Subsequently, the importance of skeletal muscle metabolism in the sympathetically mediated thermogenesis was studied in healthy male volunteers by means of the determination of arterialized-deep venous concentration differences of oxygen and various metabolites across forearm muscle in combination with an estimation of skeletal muscle blood flow (chapter 5).

\section{Obesity}

According to the classic energy balance equation, obesity develops when the equilibrium between energy intake and expenditure shifts towards a positive balance. There is some evidence that a low energy expenditure may contribute to the development of obesity and that the metabolic rate during rest is, to some extent, genetically determined (30). Furthermore, a blunted thermogenic response after the ingestion of food has been reported in obese subjects $(3,32)$, although this finding is not consistent $(22,40)$. In several studies, a diminished metabollic rate in obese subjects has been suggested to be associated with a lowered activation of the sympathetic nervous system after a meal or glucose load (3) or a diminished rise in metabolic rate after the infusion of catecholamines (21).

At present, it is becoming still more evident that energy balance can only be achieved in the case of macronutrient balance and evidence is accumulating that carbohydrate, fat and protein balances are regulated separately (14). Achievement of macronutrient balance in turn requires that the net oxidation of each macronutrient equals the average amount of the same macronutrient in the diet. Recent lines of evidence suggest that the development of obesity is not per se associated with a disbalance in energy intake and expenditure but may be associated with abnormalities of fuel metabolism. A low ratio of fat to carbohydrate oxidlation has been reported to be associated with subsequent weight gain in Pima Indians (44) and non-obese white men (34). In these studies, however, it cannot be excluded that the initial high respiratory quotient may be the result of an already existent positive energy balance in subjects predisposed to weight gain. The results of these prospective studies are, however, supported by studies in post-obese subjects, showing an increased 24-h respiratory exchange ratio in the post-obese group in comparison with lean and obese subjects during fasting and during a high fat diet (25). Beside these studies in pre- or post-obese subjects, there are also studies which indicate an impaired fat oxidation in obese subjects. It has been reported that lipid oxidation (expressed per $\mathrm{kg}$ fat mass) decreased with increasing degree of obesity (27) and that obese men combusted less fat during an exercise load than lean men (41). The close association between the sympathetic nervous system, energy expenditure and intermediary metabolism, especially the crucial role of the sympathetic nervous system in the utilization of fat stores, suggests that any alteration in the activity of the sympathetic nervous system may lead to a metabolic abnormality in obesity.

To investigate whether the sympathetically mediated thermogenesis and sympathetically- 
induced changes in metabolic pathways and skeletal muscle metabolism are altered in obesity, a comparison of these processes was made in lean and obese healthy males by means of the above described forearm model (chapter 6 ).

The possibility exists that there are small subtle differences in the sympathetically mediated thermogenesis between lean and obese subjects, that may be hard to detect but may favor the maintenance (or development) of fat stores in the long term. Therefore, the B-adrenergically mediated thermogenesis was described in a large group of males with a wide range of percentage body fat to detect whether there may be a relationship between obesity and the $B$-adrenergically mediated thermogenesis when including extremely lean and extremely obese subjects (chapter 7).

Metabolic abnormalities leading to the development of obesity may be hard to detect when the obese state has already developed, since by then no separation can be made between causes and consequences of obesity. To obtain an indication whether observed differences in sympathetically mediated thermogenesis (chapter 7) and substrate metabolism between lean and obese subjects (chapter 6) may be primary or secondary to the obese state, these metabolic processes were restudied after weight reduction (chapter 7,8 ).

Adipose tissue blood flow may play an important role in adipose tissue metabolism by delivering substrates, lipolytic hormones and carrier proteins, responsible for the transport of fatty acids in the bloodstream, to the tissue $(7,11)$. The fact that blood flow is under strong autonomic regulation suggests a mechanism whereby the sympathetic nervous system plays an important role in the control of the mobilization of fat stores both by stimulating the breakdown of triglycerides and by affecting adipose tissue perfusion. In literature, there are indications that the blood flow response in adipose tissue (after glucose ingestion) may be impaired in obesity (20). In chapter 9 , it has been investigated whether obesity may be associated with a diminished abdominal fat blood flow response as result of $B$-adrenergic stimulation.

\section{Outline of the thesis}

The studies described in the present thesis were intended to obtain more information on the role of the sympathetic nervous system in human energy metabolism with emphasis on processes that may be of importance in the development and maintenance of the obese state. The first steps in this project were to elucidate the adrenoceptors involved in the sympathetically mediated thermogenesis (chapter 2) and to evaluate several techniques used to study skeletal muscle metabolism (chapter 3,4). Subsequently, the importance of skeletal muscle in the sympathetically mediated thermogenesis was investigated in healthy male volunteers (chapter 5). In chapter 6 and 7, a comparison was made between the B-adrenergically mediated changes in skeletal muscle metabolism and whole body energy expenditure in lean and obese males. Since adipose tissue blood flow may play an important role in the mobilization of fat stores, the effect of beta-adrenergic stimulation on abdominal subcutaneous fat blood flow was studied in lean and obese males (chapter 9). To obtain an indication whether observed differences in the 
beta-adrenergically mediated changes in energy and substrate metabolism and abdominal fat blood flow between lean and obese subjects may be a cause or a consequence of the obese state, these processes were restudied after weight reduction (chapter $7,8,9$ ).

\section{References}

1. Acheson $K_{.,}$E. JEquier, and J. Wahren. Influence of B-adrenergic blockade on glucose-induced thermogenesis in man. J. Clin. Invest. 72:981-986, 1983.

2. Anderson K.M., and W.B. Kannel Obesity and disease. In: Obesity. Bjömtorp P." and B.N. Brodoff editors. J.B. Lippincout Company, Philadelphia. 465-473, 1992.

3. Astrup A., T. Andersen, N.J. Christensen, J. Bülow, I. Madsen, L. Breum, and F. Quaade. Impaired glucose-induced thermogenesis and arterial norepinephrine response persists after weight reduction in obese humans. Am. J. Clin. Nutr. 51: 331-337 1990.

4. Astrup A., J. Butlow, J. Madsen, and N.J. Christensen. Contribution of BAT and skeletal muscle to thermogenesis indluced by ephedrine in man. Am. J. Physiol. 248 (Endocrinol. Metab. 11): E507E515, 1985.

5. Astrup, A., L. Simonsen, J. Butow, and NJ. Christensen. Measurement of forearm oxygen consumption: role of heating of the contralateral hand. Am. J. Physiol. 255 (Endocrinol Metab. 18): E572-E578, 1988.

6. Blokstra A., and D. Kromhout. Trends in obesity in young adults in The Netherlands from 1974-1986. Int. J. Obes. 15: 513-521, 1991.

7. Bülow J., and J. Madsen. Influence of blood now on fatty acid moblization Irom lipolytically active adipose tissue. Pflugers Arch. 390: 169-174, 1981.

8. Chapman B.J., D.L. Farquahar, S.M. Galloway, and I.F. Munro. The effects of a new B-adrenoceptor agonist BRL 26830A in refractory obesity. Int. J. Obes. 12: 119-123, 1988.

9. Connacher A.A., R.T. Jung, and P.E.G. Mitchell. Weight loss in obese subjects on a restricted diet given BRL26830A, a new atypical B-adrenoceptor agonist. Brit. Med. J. 296: 1217-1220, 1988.

10. DeFronzo R.A., D. Thorin, J.P. Felber, D.C. Simonsen, D. Thieband, E Jequier, and A. Golay. Effect of $B$ - and $\alpha$-adrenergic blockade on glucose-induced thermogenesis in man. J. Clin. Invest. 73: $633-639,1984$.

11. Edens N.K., R L. Leibel, and J. Hirsch. Mechamism of free fatty acid reesterification in human adipocytes in vitro. J. Lip. Res. 31: 1423-1431, 1990.

12. Emorine L,J., S. Marullo, M. Briend-Sutren, G. Patey, K. Tate, C. Delavier-KIutchko, and D.A. Strosbcrg. Molecular characterization of the human $B_{3}$-adrenergic receptor. Science 245: 1118-1121, 1989.

13. Foster D.O. Participation of alpha-adrenoceptors in brown adipose tissue thermogenesis in vivo. Int. J. Obes. 9: 25-29, 1985.

14. Flatt J.P. Dietary, fat, carbohydrate balance, and weight maintenance: effects of exercise. Am. J. Clin. Nutr. 45: 296-306, 1987

15. Gallen, I.W., and I.A. MacDonald. Effect of two methods of hand heating on body temperature, forearm blood flow, and deep venous oxygen saturation. Am. J. Physiol. 259 (Endocrinol. Metab. 22): E639-E643, 1990.

16. Henny $C_{\text {, }}$ Y. Schutz, A. Buckert, M. Meylan, E. Jequier, and J. Felber. Thermogenic effect of the 
new B-adrenoreceptor agonist RO-16-8714 in healthy malle volunteers. Int. J, Obes. 11: 473-483, 1987.

17. Hjemdah1 P., and B. Linde. Influence of circulating NE and Epi on mdipose tissue wascular resistance and lipolysis in humans. Am. J. Physiol. 245 (Heart Circ. Physiol. 14): H447 H452, 1983.

18. Hollenga C.H., F. Brouwer, and J. Zaagsma. Three B-adrenoceptor subtypes mediate lipolysis in human adipocytes. Thesis: Beta-3, beta-2 and beta-1 adrenoceptors in human and animal adipocytes, Groningen, The Netherlands, 1990.

19. Holloway B.R., R. Howe, B.R. Rao, D. Stribling, R.M. Mayers, M.G. Briscoe, and J.M. Jackson. ICI D7114 a novell selective B-adrenoceptor agonist selectively stimulates brown fat and increases whole body oxygen consumption. Brit. J. Pharmacol. 104: 97-104, 1991.

20. Jansson P., A. Larsson, U. Smith, and P. Lónnroth. Glycerol production in subcutaneous adipose tissue in lean and obese humans. J. Clin. Invest. 89: 1610-1617, 1992.

21. Jung R.T., P.S. Shetty, W.P.T. James, M. Barrand, and M. Callingham. Reduced thermogenesis in obesity. Nature (London) 279: 322-323, 1979.

22. Katzeff H.L., M. O'Connell, E.S. Horton, E. Danforth, J.B. Young and L. Landsberg. The sympathetic nervous system in human obesity. Int. J. Obes. 9 (suppl. 2): 131-137, 1985.

23. Langin D., M.P. Portillo, J. Saulnier-Blache, and M. Lafontan. Coexistence of three B-adrenoceptor subtypes in white fat cells of various mammalian species. Eur. J. Pharmacol. 199: 291-301, 1991.

24. Larsen O.A., N.A. Lassen, and F. Quaade. Blood flow through human adipose tissue determined with radioactive xenon. Acta Physiol. Scand. 66 (3): 337-345, 1966.

25. Lean M.E.J., and W.P.T. James. Metabolic effect of isoenergetic nutrient exchange in relation to obesity in women. Int. J. Obes. $12: 15-27,1988$.

26. Ligget S.B., D.S. Suresh, and P.E. Cryer. Characterisation of B-adrenergic receptors of human skeletal muscle obtained by needle biopsy. Am. J. Physiol. 254 (Endocrinol. Metab. 17): E795-E798, 1988.

27. Lillioja S., J. Foley, C. Bogardus, D. Mott, and B.V. Howard. Free fatty acid metabolism and obesity in man: in vivo and in vitro comparisons. Metabolism 35: 505-514, 1986.

28. MacDonald I.A., T. Bennet, and I.W. Fellows. Catecholamines and the control of metabolism in man. Clin. Sci. 68: 613-619, 1985 .

29. Raz I., A. Katz, and M.K. Spencer. Epinephrine inhibits insulin-mediated glycogenesis but enluances glycolysis in human skeletal muscle. Am. J. Physiol. 260 (Endocrinol. Metab. 23): E430-E435, 1991.

30. Ravussin E., S. Lillioja, W.C. Knowler, L. Cristin, D. Freymond, W.G.H. Abbot, V. Bayce, B.V. Howard, and C. Bogardus. Reduced rate of energy expenditure as a risk factor for body weight gain. New Engl. J. Med. 318: 467-472, 1988

31. Rizza R.A., P.E. Cryer, M.W. Haymond, and J.E. Gerich. Adrenergic mechanisms for the effects of epinephrine on glucose production and clearance in man. $\$. Clin. Invest. 65: 682-689, 1980.

32. Segal K.R., A. Edano, and M.B. Tomas. Thermic effect of a meal over 3 and 6 hours in lean and obese men. Metabolism 39: 985-992, 1990.

33. Seaton T., S.Welle, S. Alex, U. Lilavivat, and R. Campbell. The effect of adrenergic blockade on glucose induced thermogenesis. Metabolism 33: 415-419, 1984.

34. Seidell J.C., D.C. Muller, J.D. Sorkin, and R. Andres. Fasting respiratory exchange ratio and resting metabolic rate as predictors of weight gain: the Baltimore Longitudinal study on aging. Int. J. Obes. 16: $667-674,1992$.

35. Sherwin R.S., and L. Sacca. Effect of epinephrine on glucose metabolism in humans: contribution of the liver. Am. J. Physiol. 247 (Endocrinol. Metab. 10): E157-E165, 1984. 


\section{Chapter I}

36. Sjoström L. Y. Schutz, F. Gudinchet, L. Hegnell, P.G. Pittet, and E. Jëquier. Epinephrine sensitivity with respect to metabolic rate and other wariables in women. Am. I. Physiol. 245 (Endocrinol. Metab. 8): E431-EA42, 1983.

37. Staten M.A., D.E. Matthews, P.E. Cryer, and D.M. Bier. Physiological increments in epinephrine stimulate metabolic rate in humans. Am. J. Physiol. 253 (Endocrinol. Metab. 16): E322-E328, 1987.

38. Stock MJ., and N.J. Rothwell. Factors influencing brown fat and the capacity for diet-induced thermogenesis. Int. J. Obes. 9: 9-15, 1985.

39. Thorin D., A. Golay, C. Simonsen, E. Jéquier, and J.B. Felber. The effect of selective B-adrenergic blockade on glucose-induced thermogenesis in man. Metabolism 35: 524-528, 1986.

40. Vernet O., C.A. Nacht, L. Christin, Y. Schutz, E. Danforth, and E. Jếquier. B-adrenergic blockade and intravenous nutrient-induced thermogenesis in lean and obese women. Am. J. Physiol. 253 (Endocrinol. Metab. 16): E65-E71, 1987.

41. Wade A.J., M.M. Marbut, and J.M. Round. Muscle fibre type and aetiology of obesity. Lancet 335: $805-808,1990$.

42. Welle S., R.G. Schwartz, and M. Statt. Reduced metabolic rate during B-adrenergic blockade in humans. Metabolism 40: 619-622, 1991.

43. Whitney, R.J. The measurement of volume changes in human limbs. J. Physiol. 121: 1.27, 1953 .

44. Zurlo F. S. Lillioja, A. Esposito-Del Puente, B.L. Nyomba, I. Raz, M.F. Saad, B.A. Swinburn, W.C. Knowler, C. Bogardus $s_{\text {, and }} \mathrm{E}$. Ravussin. Low ratio of fat to carbohydrate oxidation as predictor of weight gain: study of 24-h RQ. Am. J. Physiol. 259 (Endocrinol. Metab. 22): E650-E657, 1990. 


\title{
CHAPTER 2
}

\section{Role of alpha and beta adrenoceptors in the sympathetically mediated thermogenesis}

\author{
E.E. Blaak, M.A. van Baak, K.P.G. Kempen, and W.H.M. Saris.
}

Department of Human Biology, University of Limburg, Maastricht, The Netherlands.

Am. J. Physiol. 264 (Endocrinol. Metab. 27): E11-E.17, 1993

\section{Abstract}

This study was intended to investigate the role of $\alpha$ - and B-adrenoceptor populations in the sympathetically mediated thermogenesis in healthy lean males. In the first study, the $B_{1}-, B_{2}-$ and ' $B_{3}$ '- agonist isoprenaline was infused in increasing doses with and without simultaneous infusion of the $\beta_{1}$-blocker atenolol (ISO and ISO+AT, respectivelly). There was an increase in whole body resting energy expenditure (EE) after infusing ISO+AT $(\mathrm{P}<0.001)$ and an almost twofold higher increase after infusion of ISO only $(\mathrm{P}<0.001)$. Stimulation of the $B_{2}$-adrenoceptors by a selective agonist (salbutamol) resulted in a significant increase in $\mathrm{EE}(\mathrm{P}<0.001)$. The effect of stimulation of $\alpha_{1}$-adrenoceptors on EE was measured by infusing increasing doses of the $\alpha_{1}$-agonist phenylephrine. EE did not change, while mean arterial pressure (MAP) increased $(\mathrm{P}<0.001)$ and $\mathrm{HR}$ decreased $(\mathrm{P}<0.01)$. In addition to this study, the $\alpha_{1^{-}}, \alpha_{2^{-}}, B_{1^{-}}, B_{2^{-}}$and ' $B_{3^{\prime}}$-agonists norepinephrine and epinephrine were infused with simultaneous infusion of the $B_{1}{ }^{*}$ and $B_{2}$-blocker propranolol. In both studies, there was no effect on $\mathrm{EE}$, while MAP increased $(\mathrm{P}<0.01)$. In conclusion, in healthy male lean volunteers both $B_{1}$ - and $B_{2}$-adrenoceptors are involved in the sympathetically mediated thermogenesis, while the $\alpha_{1}{ }^{-}$and $\alpha_{2^{-}}$and ' $B_{3}{ }^{\text {"- }}$ adrenoceptors do not play a role.

\section{Introduction}

The sympathetic nervous system plays a role in the regulation of energy expenditure. Several studies have shown that there is an increase in energy expenditure as result of infusion of norepinephrine or epinephrine $(17,29,30)$. Also, there are indications that the facultative component of the diet-induced thermogenesis is mediated by an increased sympathetic tone $(3,27)$.

It is still uncertain which type of adrenoceptor mediates the sympathetically-induced thermogenesis. Several studies have shown that the diet-induced thermogenesis can be inhibited by $\beta$-blockade $(1,4,33)$. Thorin et al $(33)$ showed in a glucose-insulin clamp 
study that only $B_{1}$-adrenoceptors are involved in the sympatheticaliy mediated thermogenesis, whereas Astrup et al (4) also suggested involvement of $B_{2}$-receptors. Additionally, atypical $B$-agonists $\left(B_{3}\right.$ ?) increased thermogenesis in rats $(16)$ and in man (14). In man, a $B$-agonist with atypical selectivity increased weight loss in obese subjects on a restricted diet (8), although this effect was not seen in all studies (5). Furthermore, in a recent study (19) ' $B_{3}$ "-adrenoceptors could not be characterized in human white adipose tissue.

Less is known on the role of the $\alpha$-adrenergic receptors in the sympathetically mediated thermogenesis. In rats, norepinephrine-induced thermogenesis was markedly inhibited by $\alpha_{1}$-receptor blockade (13). However, in man $\alpha$-receptor blockade by phentolamine did not influence diet-induced thermogenesis $(10,28)$. So far no studies have been done to investigate the effect of $\alpha$-adrenoceptor stimulation on resting energy expenditure.

The localization of the thermogenesis induced by the sympathetic nervous system is still it matter of dispute. Studies in adult rats and mice have shown that the major site for nonshivering or diet-induced thermogenesis is brown adipose tissue (31). However, Astrup et al (2) showed that in humans, ephedrine-induced thermogenesis is not located in brown adipose tissue. They concluded that up to $50 \%$ of the increase in whole body oxygen consumption may take place in skeletal muscle.

This study was intended to investigate the role of $\alpha_{1^{-}}, \alpha_{2}, B_{1}-, B_{2^{-}}$, and ' $B_{3}$ 'adrenoceptors in the sympathetically mediated thermogenesis. The adrenoceptor population of skeletal muscle mainly consists of $\mathbb{B}_{2}$-adrenoceptors (20). Therefore, it might be possible to obtain an indication of the different tissues contributing to the sympathetically mediated thermogenesis on basis of the involved adrenoceptor populations.

\section{Subjects and methods}

\section{General}

The study design consisted of five protocols. In these studies the effects of several $\alpha$ - and B-adrenoceptor agonists and antagonists on energy expenditure at reșt were investigated, as summarized in figure 1. During all experiments, energy expenditure was continuously measured by an open-circuit ventilated hood system (Oxycon Beta, Jaeger, Breda, The Netherlands). The experiments were performed after a 12-h fast (overnight) and room temperature was kept between $23-25^{\circ} \mathrm{C}$. Energy expenditure was calculated according to the abbreviated formula of Weir (35). The experiments started at 8.00 A.M and the subjects came to the laboratory by car or bus. The study protocol was approved by the Ethics Committee of the University of Limburg and all volunteers were asked for written consent. Before participation, all subjects underwent a medical examination. 


\section{Isoprenallne}

In the first protocol ten healthy male volunteers participated, aged $25.2 \pm 1.7 \mathrm{y}$ (means \pm SEM) and with a BMT of $22.3 \pm 0.5 \mathrm{~kg} / \mathrm{m}^{2}$. The subjects were studied on two different occasions with 3-7 days in between. At the beginning of the experiment, catheters were inserted in a left and right forearm vein. At one experimental day, the $B_{1}{ }^{-}, B_{2}-$, and $\left(B_{3}{ }^{\prime}\right)$ agonist isoprenaline (ISO) was infused in one arm and saline in the other arm. At the other experimental day, ISO was infused in one arm and the $B_{1}$-antagonist atenolol (AT) in the other arm. The study design was single-blind and the order of treatments was randomized. After $30 \mathrm{~min}$ baseline measurement, a continuous infusion of saline or atenolol $\left(0.1 \mathrm{mg} / \mathrm{kg}_{\text {Body weight }} \mathrm{h}\right)$ was started. Before the infusion of AT was started, a priming dose of AT $\left(0.07 \mathrm{mg} / \mathrm{kg}_{\mathrm{B}}\right)$ or saline was given within 5 minutes. After $60 \mathrm{~min}$, in the other arm the infusion of ISO was started in doses of $5,10,20$ and $40 \mathrm{ng} / \mathrm{kg}$ Bw. min, each dose for $30 \mathrm{~min}$. The dose in the text is related to ISO sulphate, $69 \%$ of which corresponds to ISO free base. During the experiment heart rate (HR) was recorded every five minutes. When HR had risen 30 beats/min or more, the infusion was stopped.

\section{Salbutamol}

In the second study, $B_{2}$-adrenoceptors were stimulated by the selective $B_{2}$-agonist salbutamol in 7 healthy male volunteers (age: $24.3 \pm 1.8 \mathrm{y}, \mathrm{BMI}: 23.0 \pm 0.6 \mathrm{~kg} / \mathrm{m}^{2}$ ). At the beginning of the experiment a catheter was inserted in a forearm vein. After $30 \mathrm{~min}$ baseline measurement, the $\mathrm{B}_{2}$-agonist salbutamol was infused in increasing doses of 70 , 140 and $280 \mathrm{ng} / \mathrm{kg}_{\mathrm{B}}$. min, each dose for $30 \mathrm{~min}$. To exclude a possible $B_{1}$-effect, the highest dose of salbutamol was continued for $30 \mathrm{~min}$ in the presence of a continuous infusion of the $B_{1}$.blocker AT (bolus: $0.07 \mathrm{mg} / \mathrm{kg}_{B}$, infusion: $0.1 \mathrm{mg} / \mathrm{kg}_{\mathrm{B}}$. $\mathrm{h}$ ) During the experiments heart rate (HR) was recorded every five minutes. When HR had risen 30 beats/min or more, the infusion was continued in the presence of atenolol.

\section{Phenylephrine}

The effect of stimulation of $\alpha_{1}$-receptors on resting energy expenditure was measured in six healthy male volunteers (age: $24.0 \pm 2.1 \mathrm{y}, \mathrm{BMI}: 21.7 \pm 0.9 \mathrm{~kg} / \mathrm{m}^{2}$ ) by infusion of the $\alpha_{1}$-agonist phenylephrine. Before the experiment a catheter was inserted in a forearm vein for the infusion. After $30 \mathrm{~min}$ baseline measurement, phenylephrine was infused in increasing doses of $0.5,1$ and $2 \mu \mathrm{g} / \mathrm{kg}_{\mathrm{BW}}$.min, each dose for $30 \mathrm{~min}$. During the experiments, HR and mean arterial pressure (MAP) were recorded every five minutes. The infusions were stopped when HR had decreased to 35 beats/min or MAP had risen more than $30 \mathrm{~mm} \mathrm{Hg}$.

\section{Norepinephrine and epinephrine plus propranolol}

In the last two protocols, the $\alpha_{1}, \alpha_{2}, B_{1}, B_{2^{-}}$, and ' $B_{3}$ '-atgonists norepinephrine (NE, $\mathrm{n}=6$, age: $24.3 \pm 2.1 \mathrm{y}, \mathrm{BMI}: 22.9 \pm 0.6 \mathrm{~kg} / \mathrm{m}^{2}$ ) and epinephrine (E, $\mathrm{n}=6$, age: $24.6 \pm 1.9 \mathrm{y}$, 


\section{Chapter 2}
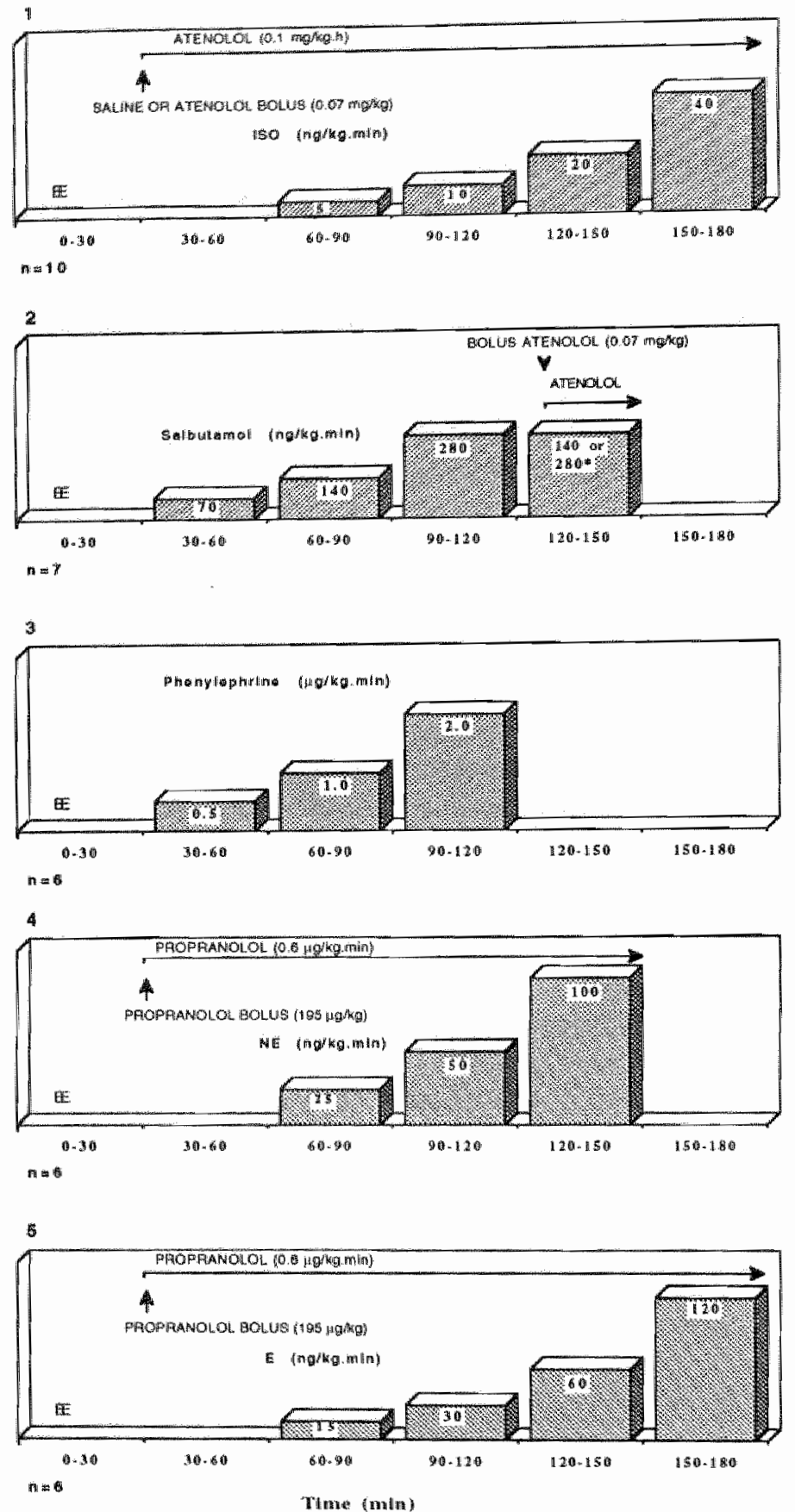

Fing 1. Study design of the five protocols.

$\mathrm{EE}=$ resting energy expenditure. *Atenolol was infused with the highest dose of salbutamol (140 or 280 $\mathrm{ng} / \mathrm{kg} \cdot \mathrm{min})$ 
BMI: $22.7 \pm 0.5 \mathrm{~kg} / \mathrm{m}^{2}$ ) were infused in the presence of the $B_{1}$ - and $B_{2}$-blocker propranolol in healthy lean male volunteers. Before the experiments, two catheters were inserted in a left and right forearm vein for the infusion. After $30 \mathrm{~min}$ control measurement, a priming injection of propranolol was given $\left(195 \mu \mathrm{g} / \mathrm{kg}_{\mathrm{BW}}\right)$, after which a continuous infusion of propranolol was started $\left(0.6 \mu \mathrm{g} / \mathrm{kg}_{\mathrm{BW}} \cdot \mathrm{min}\right)$. After one hour, in addition $\mathrm{NE}(25,50$ and $\left.100 \mathrm{ng} / \mathrm{kg}_{\mathrm{BW}} \cdot \mathrm{min}\right)$ or $\mathrm{E}\left(15,30,60\right.$ and $\left.120 \mathrm{ng} / \mathrm{kg}_{\mathrm{B}} \cdot \mathrm{min}\right)$ were infused in the other arm (each dose for $30 \mathrm{~min}$ ).

\section{Statistics}

Data are represented as means $\pm \mathrm{SEM}$. For all protocols, statistical analysis was performed with repeated measurements ANOVA. A P-value smaller than 0.05 was regarded as statistically significant.

The total response to the infusion of isoprenaline or isoprenaline and atenolol was calculated as the integrated area under the curve. For both treatments, the areas under the curve were compared by a Student's paired t-test.

\section{Results}

\section{Generall}

During the infusion of increasing doses of ISO, salbutamol, phenylephrine, NE or E, several subjects were not subjected to the higher infusion rates, due to our criteria for stopping the infusion (see methods). In the first experiment, three subjects were not subjected to the last infusion period of isoprenaline ( $\left.40 \mathrm{ng} / \mathrm{kg}_{\mathrm{B} w} \cdot \mathrm{min}\right)$. Furthermore, data on the highest infusion rates in protocols 2 to 5 are not presented because these infusion rates were not started in most subjects.

After 10 min infusion of ISO, ISO+AT, phenylephrine, NE or E (both with propranolol), energy expenditure and heart rate had reached a steady state: i.e. five-minute values did not significantly change anymore until the end of the infusion period. Therefore, mean values over the last $20 \mathrm{~min}$ infusion were taken as representative for the administered dose. In the ISO and ISO+AT trial steady state values for the respiratory exchange ratio (RER) over five-minute intervals were achieved after $20 \mathrm{~min}$ infusion. For this reason, RER values of the last 10 min infusion were averaged. With infusion of NE and $E$ (both with propranolol) and with phenylephrine, RER-values were stable throughout the infusions. With infusion of the $B_{2}$-agonist salbutamol energy expenditure, heart rate and respiratory exchange ratio (RER) reached a steady state within $20 \mathrm{~min}$.

\section{Isoprenaline}

There was a significant increase in resting energy expenditure as result of the infusion of the non-selective $\mathrm{B}$-agonist isoprenaline. This increase was at $5 \mathrm{ng} / \mathrm{kg}_{\mathrm{B} W} \cdot \mathrm{min}: 7 \%$, at 10 $\mathrm{ng} / \mathrm{kg}_{\mathrm{BW}} \cdot \mathrm{min}: 13 \%$, at $20 \mathrm{ng} / \mathrm{kg}_{\mathrm{BW}} \cdot \min : 16 \%$ and at $40 \mathrm{ng} / \mathrm{kg}_{\mathrm{BW}} \cdot \min : 25 \%$. As result of 

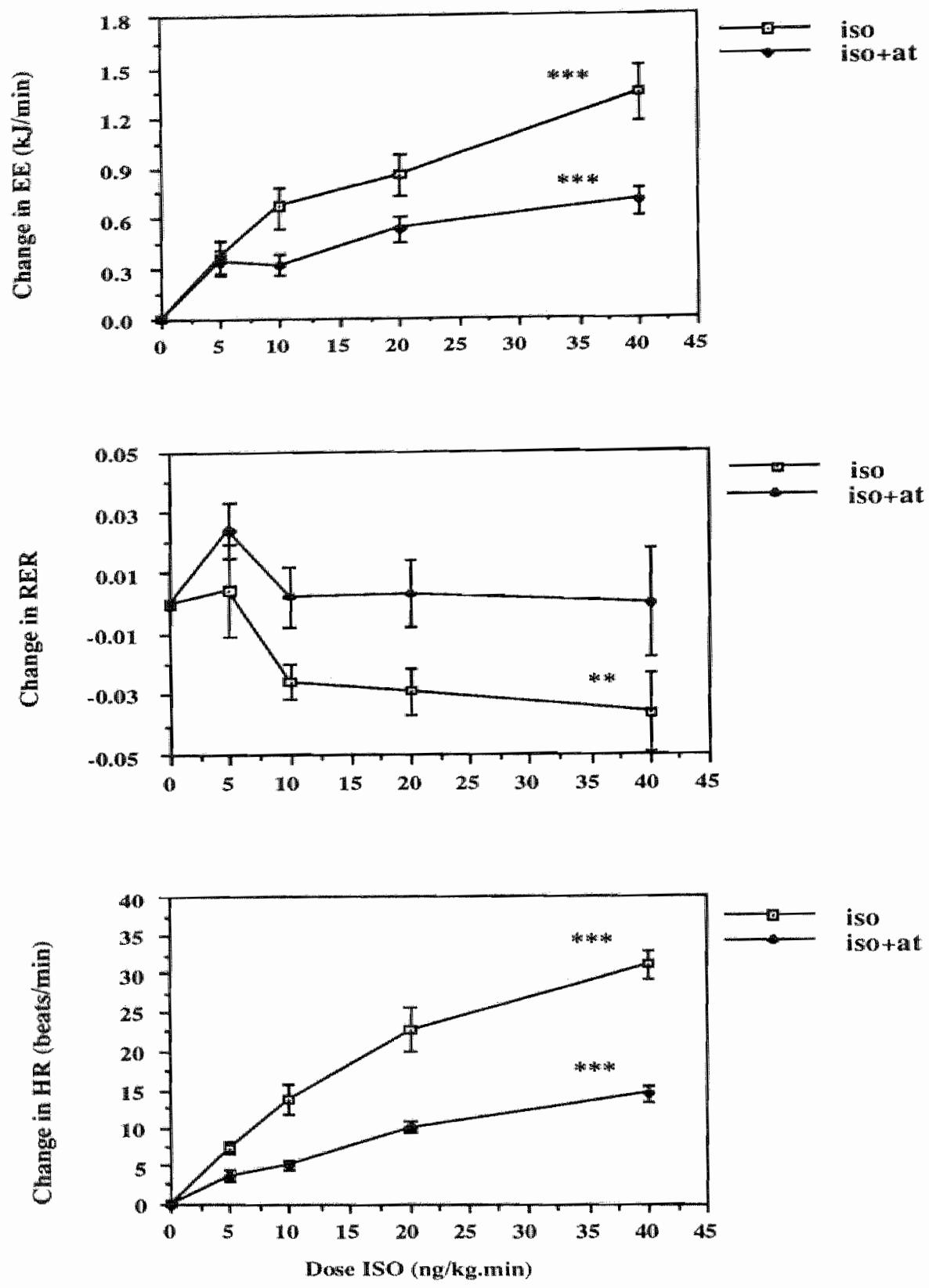

Fig 2. Changes in encrgy expenditure (EE), respiratory exchange ratio (RER) and heart rate (HR) as result of infusion of the $B_{1}, B_{2}$ - and ' $B_{3}$ "agonist isoprenaline with or without simultaneous infusion of the $B_{1}$-blocker atenolol (resp. ISO and ISO+AT). Means $\pm S E M, n=10$; at infusion rate $40 \mathrm{ng} / \mathrm{kg} \cdot \mathrm{min}: \mathrm{n}=7$; Repeated measurements ANOVA: $*=\mathrm{P}<0.01, * * *=\mathrm{P}<0.001$. 
the simultaneous infusion of ISO and the $\mathbb{B}_{1}$-blocker $\mathrm{AT}$, there also was a significant increase in resting energy expenditure (compared to infusion of AT only), which was haif the increase with infusion of isoprenaline only for the increasing doses respectively $8,6,10,14 \%$, fig 2 ). The integrated increase in resting energy expenditure was significantly higher with infusion of $1 S O$ than with ISO+AT $(\mathrm{P}<0.001)$. Infusion of the $B_{1}$-blocker atenolol for $30 \mathrm{~min}$ did not affect resting energy expenditure (control: $5.14 \pm 0.12$ vs AT: $5.06 \pm 0.10 \mathrm{~kJ} / \mathrm{min}$ ).

The pre-infusion respiratory exchange ratio (RER) was $0.83 \pm 0.01$ in the ISO trial and $0.85 \pm 0.01$ in the ISO+AT trial. With ISO, there was a marked increase in the respiratory exchange ratio within the first $5 \mathrm{~min}$ of infusion most probably caused by a change in ventilation, which decreased again within the next $10 \mathrm{~min}$. Steady state RER-values (the last 10 min infusion) significantly decreased with infusion of increasing doses ISO $(P<0.01)$, whereas with ISO+AT there was no change in RER. HR significantly increased with both treatments $(\mathrm{P}<0.001)$, and the increase with ISO+AT was half of the increase with ISO only. The integrated HR response was significantly higher with ISO than with ISO+AT $(\mathrm{P}<0.001)$, which indicates considerable $B_{1}$-blockade.

\section{Salbutamol}

Stimulation of the $\beta_{2}$-adrenoceptors by salbutamol increased energy expenditure by $14 \%$ at $70 \mathrm{ng} / \mathrm{kg}_{\mathrm{BW}}$. min and by $19 \%$ at $140 \mathrm{ng} / \mathrm{kg}_{\mathrm{BW}} \cdot \min (\mathrm{rg} 3$ ). Simultaneous infusion of the highest dose of salbutamol and the $B_{1}$-blocker atenolol resulted in a $2 \%$ lower energy expenditure than with infusion of salbutamol only $(6.66 \pm 0.39 \mathrm{vs} 6.54 \pm 0.35 \mathrm{~kJ} / \mathrm{min}$, NS), whereas HR significantly decreased $(92.0 \pm 5.8$ vs $81.2 \pm 3.2$ beats $/ \mathrm{min}, \mathrm{P}<0.05)$. Preinfusion RER was $0.85 \pm 0.02$ and steady state values did not change as result of the infusion. There was a significant increase in $H R$ as result of the $B_{2}$-adrenergic stimulation (for the two doses resp. 11 and 27 beats $/ \mathrm{min}, \mathrm{P}<0.001$, fig 3).
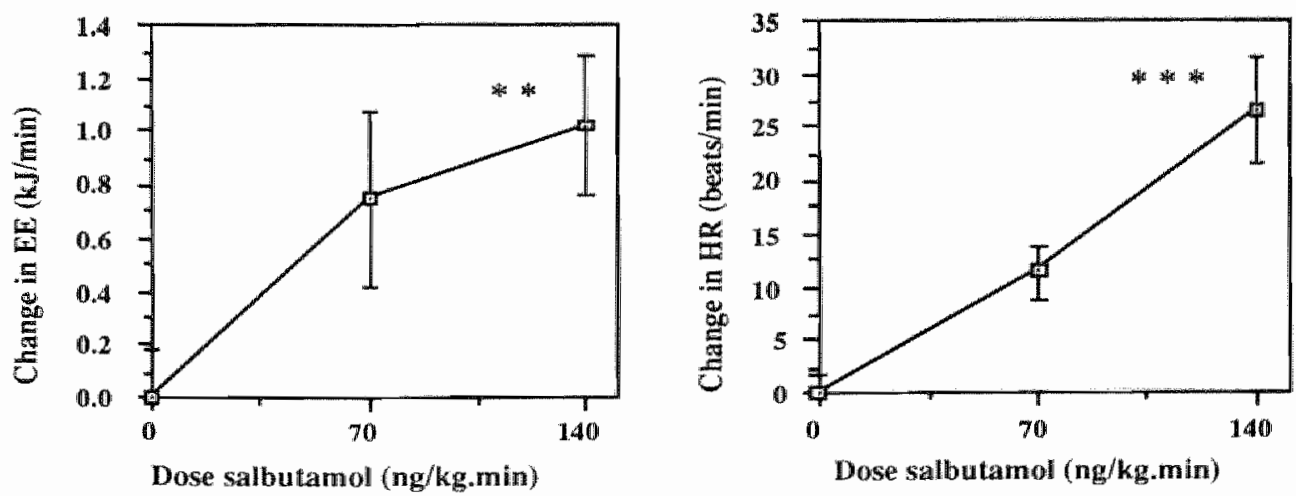

Fig 3. Changes in energy expenditure (EE) and heart rate (HR) as result of infusion of the $B_{2}$-agonist salbutamol. Means + SEM, n=7; Repeated measurements. ANOVA: ${ }^{*}=\mathrm{P}<0.01,{ }^{* * *}=\mathrm{P}<0.001$. 


\section{Phenylephrine}

Infusion of increasing doses of the $\alpha_{1}$-agonist phenylephrine did not change basall energy expenditure (fig 4), while there was a significant decrease in $H R(P<0.01)$ and a significant increase in MAP ( $\mathrm{P}<0.001)$. The basal RER was $0.84( \pm 0.02)$ and this value did not change as result of the infusion of phenylephrine.
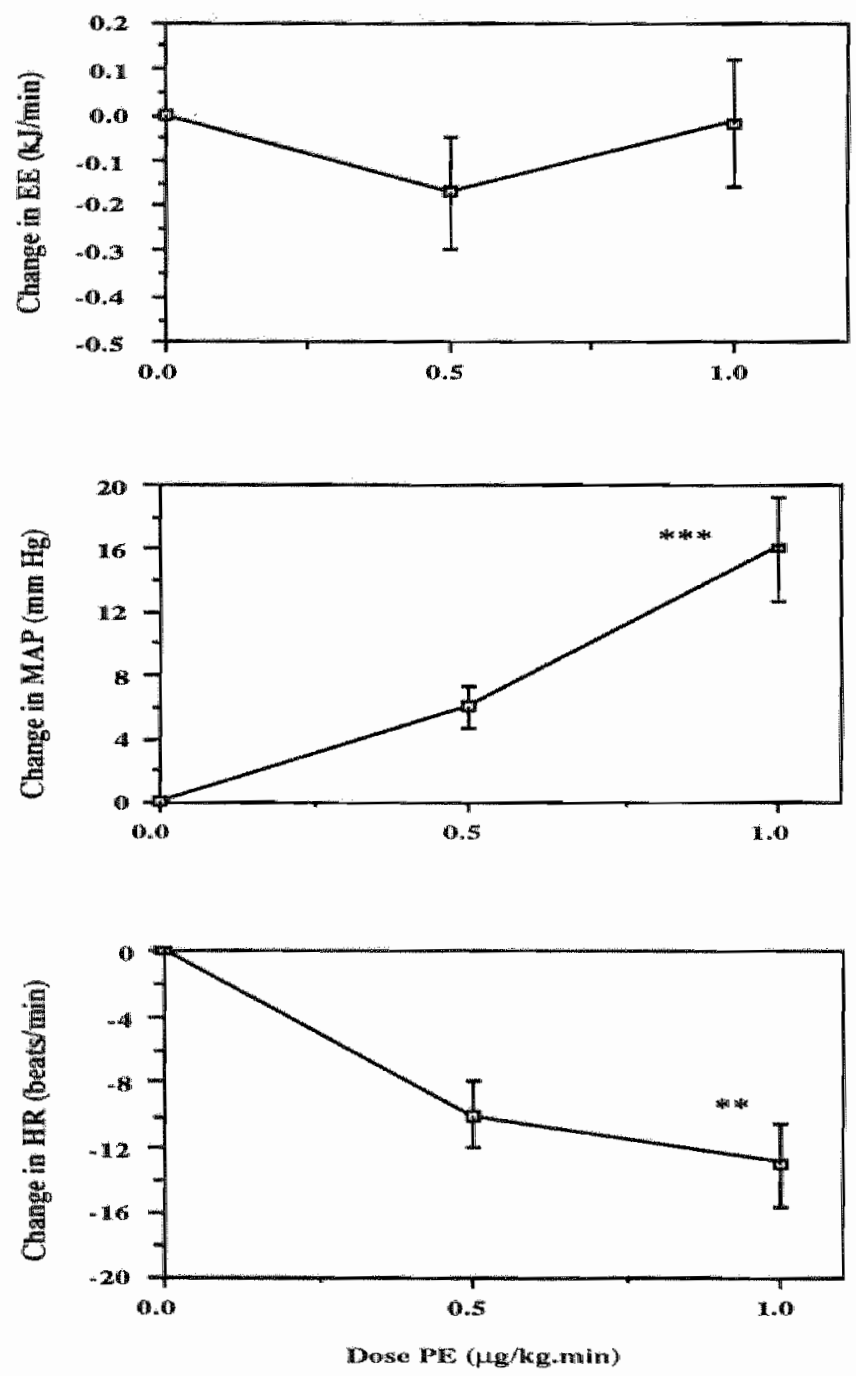

Fig 4. Changes in energy expenditure (EE), mean arterial pressure (MAP) and heart rate (HR) as result of infusion of the $\alpha_{1}$-agonist phenylephrine (PE). Means $\pm S E M, n=6$; Repeated measurements ANOVA: ${ }^{* *}=\mathrm{P}<0.01,{ }^{* * *}=\mathrm{P}<0.001$. 


\section{Norepinephrine and epinephrine plus propranolol}

As result of the infusion of the $B_{1}$ - and $B_{2}$-blocker propranolol, there was a very small, significant decrease in resting energy expenditure $(n=12,5.35 \pm 0.21 \mathrm{vs} 5.20 \pm 0.20 \mathrm{~kJ} / \mathrm{min}$, $P<0.01$ ), whereas RER did not change significantly. Simultaneous infusion of the $\alpha_{1}, \alpha_{2}$ and $B_{1}-, B_{2}-B_{3}$ '-agonists $N E$ or $\mathbb{E}$ and the $B_{1}$ - and $B_{2}$ - blocker propranolol did not change energy expenditure (compared to propranolol, fig 5). RER did not significantly change as result of the infusion of $\mathrm{NE}$ or $\mathrm{E}$ and propranolol (pre-infusion value 0.83-0.85). With both infusions there was an increase in MAP $(\mathrm{P}<0.001)$ and a decrease in HR (NE: $P<0.01$ and $E: P<0.001$ ). Table 1 summarizes the results of above mentioned protocols with respect to energy expenditure.

Table 1. Changes in energy expenditure (EE) as result of infusion of several $\alpha$ and $\mathrm{B}$ a sdrenoceptor agonist or antagonists.

Protocol EE $\quad$ Thange in EE

1: Isoprenaline $\left(B_{1}\right.$ and $\left.\mathbb{B}_{2}\right)$

increase

Isoprenaline with

atenolol $\left(B_{2}\right)$

increase

Atenolol ( $B_{1}$-blockade)

2: Salbutamol $\left(\mathbb{B}_{2}\right)$

at $140 \mathrm{ng} / \mathrm{kg}_{\mathrm{BW}} \cdot \min : 19 \%$

Salbutamoll with

atenolol $\left(\mathrm{B}_{2}\right)$

increase

no change

increase

increase

$2 \%$ lower than increase with

infusion of highest dose

salbutamol only at $40 \mathrm{ng} / \mathrm{kg}_{\mathrm{BW}} \cdot \mathrm{min}: 25 \%$
at $40 \mathrm{ng} / \mathrm{kg}_{\mathrm{BW}} \cdot \mathrm{min}: 14 \%$

al 40 g

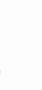

3: Phenyleptrine $\left(\alpha_{1}\right)$

no change

4: Norepinephrine with

no change

propranolol ( $\alpha$ and $B_{3}$ )

5. Epinephrine with

propranolol ( $\alpha$ and $\left.b_{3}\right)$

no change

Propranolol

decrease

$3 \%$ decrease in resting energy

$\left(B_{1}-\right.$ and $B_{2}$-blockade $)$ 


\section{Chapter 2}
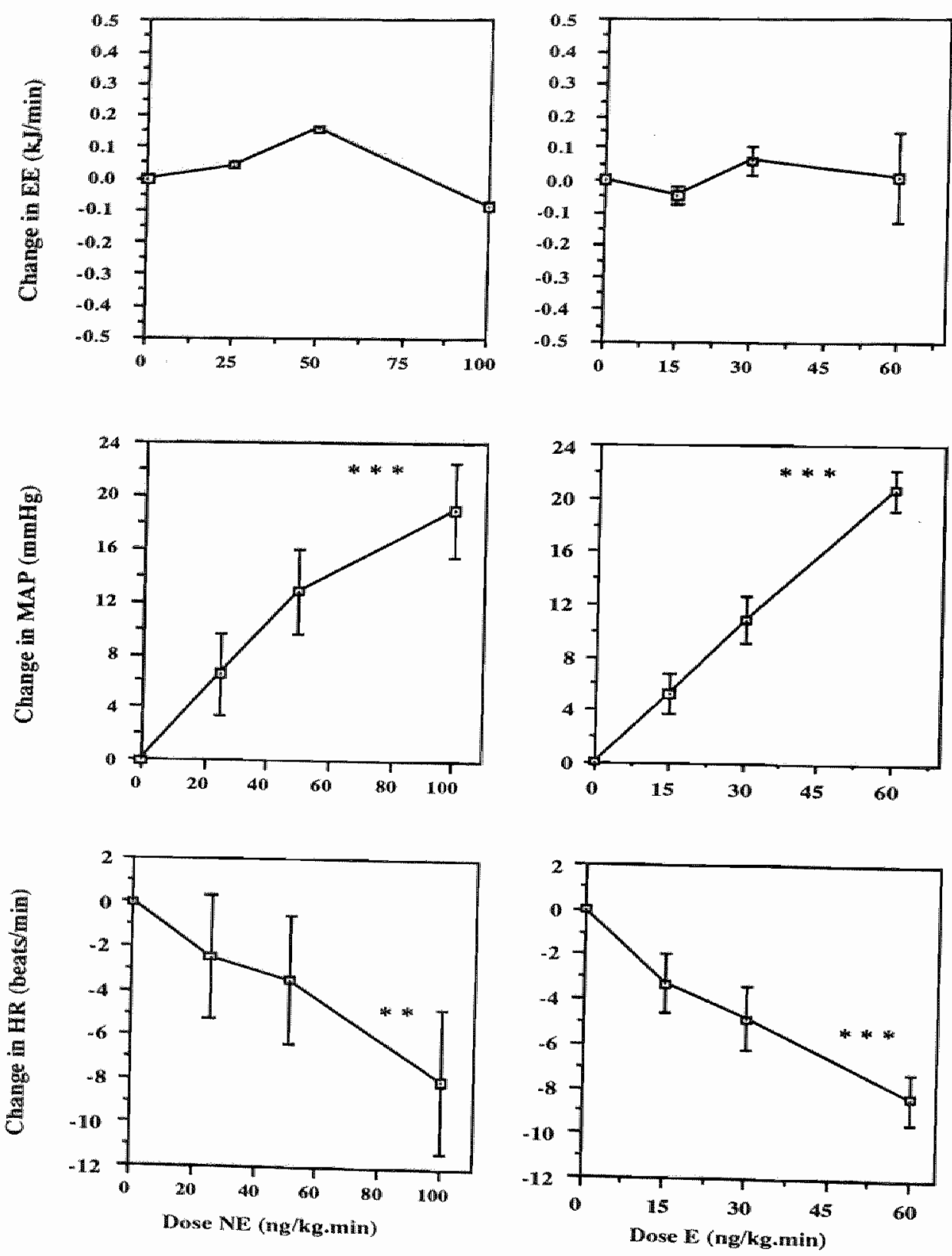

Fig 5. Changes in energy expenditure (EE), mean arterial blood pressure (MAP) and heart rate (HR) as result of infusion of the $\alpha_{1}, \alpha_{2}, B_{1}, B_{2}$ - and ' $B_{3}$ "-agonists norepinephrine (NE, left) and epinephrine (E, right) with simultaneous infusion of the $B_{1}$-and $B_{2}$-blocker propranolol. Means $\pm S E M, n=6$; Repeated measurements ANOVA: ** $=\mathrm{P}<0.01, * * *=\mathrm{P}<0.001$. 


\section{Discussion}

The objective of the present study was to investigate the role of the different adrenoceptor populations in the sympathetically mediated thermogenesis. In the literature, it has been reported that $B_{1}$ - and $B_{2}$-adrenoceptors may be involved in the adrenergically mediated thermogenesis $(4,33)$, whereas the role of the atypical " $B_{3}$ 'adrenoceptors remains controversial $(5,8)$. Less is known on the role of the $\alpha$ adrenoceptors in the sympathetically mediated thermogenesis.

In the present study, there was a significant increase in resting energy expenditure after simultaneous infusion of the $B_{1^{-}}, B_{2^{-}}$and ' $B_{3}{ }^{\prime}$ "agonist ISO in combination with the $B_{1^{-}}$ blocker AT and a twofold higher increase with infusion of ISO only. An increase in energy expenditure as result of infusing ISO has previously been reported. Cobbald et al (7) showed an increase in energy expenditure with an infusion of $100 \mathrm{ng} / \mathrm{kg}_{\mathrm{B} w}$. min. Mansell et al (22) reported increases in heart rate and energy expenditure with a 5 and 15 $\mathrm{ng} / \mathrm{kg}_{\mathrm{BW}} \cdot \min$ infusion, that seem to be slightly higher than our values. The increase in heart rate with ISO-infusion in our study is comparable to data of Martinsson et al (23). The administered dose of the $B_{1}$-blocking agent $A T$ was similar to those previously shown to be sufficient for an effective $B_{1}$-blockade $(9,34)$ and for a high $B_{1}$-selectivity (21). That there was a large $B_{1}$-adrenergic blockade was evident from the finding that heart rate increase was halved after $B_{1}$-blockade. From literature it is known that isoprenaline-induced tachycardia decreases to the same degree after $\beta_{1}$ - or $\beta_{2}$ - blockade, which indicates that both $B_{1}$ - and $B_{2}$-adrenoceptors contribute equally to this response (24). The involvement of the $B_{2}$-adrenoceptors in thermogenesis is confirmed in the second study, in which there was a significant rise in energy expenditure with infusion of the $B_{2}$-agonist salbutamol. Simultaneous infusion of the highest dose of salbutamol and the $\beta_{1}$-blocker atenolol resulted in a non-significant $2 \%$-lower energy expenditure than with infusion of salbutamol only, which shows that most of the rise in energy expenditure was due to $B_{2}$-adrenergic stimulation. From these findings we can conclude that both $B_{1}$ and $B_{2}$-adrenoceptors are involved in the sympathetically mediated thermogenesis.

Stimulation of $\alpha_{1}$-adrenoceptors did not change energy expenditure, which shows that these adrenoceptors are not involved in the adrenergically mediated thermogenesis. That there was a significant stimulation of $\alpha_{1}$-adrenoceptors is evident from the increase in MAP during the infusion periods. The role of the $\alpha_{2}$-adrenoceptors was determined by infusing NE or $E$ in the presence of the $B_{1}$ - and $B_{2}$-blocker propranolol. There was no change in $\mathrm{EE}$ and a significant increase in MAP, which shows that $\alpha_{2}$-adrenoceptors are not (directly) involved in thermogenesis. We cannot exclude the possibility that $\alpha_{2}$ adrenoceptors have indirect effects on thermogenesis by modulating $B$-adrenergic effects on metabolic processes (18). However, these effects are probably of the same magnitude as the effects of $\alpha_{1}$-adrenoceptor stimulation on thermogenesis and therefore very small. The above results are comparable to data previously reported in man, where $\alpha$ adrenoceptor blockade did not influence diet-induced thermogenesis $(10,28)$.

Reports on the involvement of ${ }^{\prime} B_{3}{ }^{2}$-adrenoceptors in thermogenesis in man are controversial $(5,8,19)$. Both an increased (8) and an unchanged (5) weight loss have been reported as result of adding a ' $B_{3}$ '-agonist to a restricted diet in obese subjects. In our 
study, stimulation of the non-classical ' $B_{3}$ '-adrenoceptors by infusing $N E$ and $E$ in the presence of the $B_{1}$ - and $B_{2}$-blocker propranolol did not change energy expenditure. It has been reported that $\mathrm{NE}$ appears the best endogenous agonist of ' $B_{3}$ '-adrenoceptors (11). The activation constant $\left(\mathrm{K}_{\mathrm{act}}\right)$ for c-AMP accumulation in eukaryotic cells (chinese hamster ovary cells) transfected with a human ' $B_{3}$ '-gene is for $N E 6.3 \pm 0.7 \mathrm{nmol} / \mathrm{L}$, whereas the sensitivity of $E$ is somewhat lower $\left(K_{\text {act }}: 49.2 \pm 5.3 \mathrm{nmol} / \mathrm{L}\right)$. The standard $B_{1}$ - and $B_{2}$-blocker propranolol had only very limited effects on the human ' $B_{3}$ '-adrenergic receptor (11). Hjemdahl et al (15) reported that B-adrenoceptor blockade (by propranolol) increases the plasma concentrations of $\mathrm{NE}$ and $\mathrm{E}$ during $\mathrm{NE}$ - or E-infusion. With infusion rates of $\mathrm{NE}$ and $\mathrm{E}$ (and propranolol) comparable to our highest infusion rates plasma concentrations above the 'physiological' range are achieved (NE> $10 \mathrm{nM}, E>4 \mathrm{nM}$ ). From the above considerations, we can conclude that in healthy lean males physiological concentrations of circulating catecholamines $\mathrm{NE}$ and $\mathrm{E}$ have no effect on thermogenesis mediated by ' $\beta_{3}$ '-adrenoceptors. However, we cannot completely exclude involvement of ' $B_{3}$ '-adrenoceptors in situations with a high local release of NE. From the literature, it is known that isoprenaline also displays very strong ' $\beta_{3}{ }^{\prime}$-agonistic activity $\left(\mathrm{K}_{\text {act }}: 3.9 \pm 0.4\right.$ $n M, 11)$. An effect of isoprenaline on thermogenesis via $B_{3}{ }^{\prime}$-adrenoceptor seems very unlikely, because even very high concentrations of the catecholamines are not able to stimulate ' $B_{3}$ '-mediated thermogenesis. Thus, since in healthy lean males the ' $B_{3}{ }^{\prime}$ adrenoceptors probably do not a play a role in the ISO-induced increase in energy expenditure and since the ISO-induced increase in energy expenditure is halved as result of $B_{1}$-blockade, the contribution of the $B_{1}$ - and $B_{2}$-adrenoceptors to thermogenesis seems to be of similar magnitude.

As result of $\beta_{1}$ - and $\beta_{2}$ - adrenergic blockade by propranolol, there was a very small ( $3 \%$ ) significant decrease in resting energy expenditure. This indicates the involvement of the $B$-adrenergic system in resting energy expenditure. In literature both an unchanged (37) or decreased (36) resting energy expenditure have been reported as result of $\beta$-adrenergic blockade. This discrepancy may be due to methodological difficulties in detecting such a small difference. Additionally, Christin et al (6) reported following propranolol infusion a negative correlation between the decrease in resting energy expenditure and the abdomen to thigh ratio, which suggests that differences in study population may also contribute to the inconsistent results in the literature.

Astrup et al. (2) showed that in humans, ephedrine-induced thermogenesis is not located in brown adipose tissue as in rats, but suggested that up to $50 \%$ of the increase in whole body oxygen consumption may take place in skeletal muscle. The quantitative significance of skeletal muscle and other tissues in the adrenergically-mediated thermogenesis cannot be established from the present study. However, the fact that $B_{2}$ adrenoceptors are involved in the sympathetically mediated thermogenesis makes it very likely that skeletal muscle is an important site of the localization, because the adrenoceptor population of skeletal muscle mainly consists of $\beta_{2}$-adrenoceptors (20). Additionally, skeletal muscle accounts for $40-50 \%$ of body weight in normal weight volunteers (25) and is therefore, quantitatively, the most important tissue mass of the body. The involvement of $\beta_{1}$-adrenoceptors shows that other tissues, such as adipose tissue, must also play a role. The energy cost of the elevated cardiac and respiratory work as result of sympathetic stimulation is generally considered to account for only a low 
percentage of its stimulatory effect on metabolic rate (29).

The present study offers no explanation for the processes that cause the sympathetically mediated energy expenditure. The decrease in steady state values of the respiratory exchange ratio with increasing doses of isoprenaline, which seems to be due to metabolic effects of ISO (12), suggests an increased rate of lipolysis. Furthemore, adrenargic stimulation has been reported to result in a fall in plasma $\mathrm{K}^{+}$concentrations $(2,26)$. This, together with the sympathetically-induced increase in oxygen consumption (2), suggests stimulation of active $\mathrm{Na}^{+} \mathrm{K}^{+}$transport in skeletal muscle or other tissues. Sympathetic stimulation of the $\mathrm{Na}^{+} \mathrm{K}^{+}$pump activity takes place predominantly via $\mathrm{B}_{2}$-adrenoceptors, but $B_{1}$-adrenoceptors may also play a part (26). Futile cycles have also been reported to be responsible for a part of the sympathetically mediated thermogenesis (32). These cycles could have a major role in increasing the sensitivity of processes that control the rates of degradation and synthesis of fuel stores.

In conclusion, in healthy lean males $B_{1}$ - and $B_{2}$-adrenoceptors are involved in the sympathetically mediated thermogenesis, whilst the $\alpha_{1}, \alpha_{2}$ - and " $B_{3}$-acrenoceptors are not. The involvement of $B_{2}$-adrenoceptors makes it very likely that part of the sympathetically mediated increase in thermogenesis takes place in skeletal muscle, but other tissues containing $B_{1}$-adrenoceptors must also be involved.

\section{References}

1. Acheson K., E. Jéquier, and $J$. Wahren. Influence of B-adrenergic blockade on glucose-induced thermogenesis in man. J. Clin. Invest. 72: 981-986 1983.

2. Astrup A., J. Büllow. J. Madsen, and N.J. Christensen. Contribution of BAT and skeletal muscle to thermogenesis induced by ephedrine in man. Am. J. Physiol. 248 (Endocrinol. Metab. 11): E507E515, 1985.

3. Astrup A., J. Billow, N.J. Christensen, J. Madsen, and F. Quade. Facultative thermogenesis induced by carbohydrate: a skeletal muscle component mediated by epinephrine. Am. J. Physiol. 250 (Endocrinol. Metab. 13): E226-E229, 1986.

4. Astrup A., L. Simonsen, J. Bülow, J. Madsen, and N.J. Christensen. Epinephrine mediates facultative carbohydrate-induced thermogenesis in human skeletal muscle. Am. J. Physiol. 257 (Endocrinol Metab. 20): E340-E345, 1989.

5. Chapman B.J., D.L. Farquahar, S.M. Galloway, and J.F. Munro. The effects of a new B-adrenoceptor agonist BRL. $26830 \mathrm{~A}$ in refractory obesity. Int. J. Obes. 12: 119-123, 1988.

6. Christin L., E. Ravussin, C. Bogardus, and B.V. Howard. The effect of propranolol on free fatty acid mobilization and resting metabollic rate. Metabolism 38: 439-444, 1989.

7. Cobbald A.F., J, Ginsburg, and A. Pato. Circulatory, respiratory and metabolic responses to isopropylnoradrenaline in man. I. Physiol. 151: 539-550, 1960.

8. Connacher A.A., R.T. Jung, and P.E.G. Milchell. Weight loss in obese subjects on a restricted diet given BRL26830A, a new atypical B-adrenoceptor agonist. Brit. Med. J. 296: 1217-1220, 1988.

9. Conway FJ. Human pharmacokinetic and pharmacodynamic studies on atenolol ICI 66082. Brit.J. Clin. Pharmacol, 3: 267-272, 1976.

10. DeFronzo R.A., D. Thorin, J.P. Felber, D.C. Simonsen, D. Thiebaud, E. Jéquier, and A. Golay. 
Effect of 1 - and $\alpha$-adrenergic blockade on glucose-induced themogenesis in man. J. Clin. Invest. 73 : $633-639,1984$.

11. Emorine L.J., S. Marullo, M. Briend-Sutren, G. Patey, K. Tate, C. Delavier-Klutchko, and D.A. Strosberg. Molccular chatracterization of the human $\mathbb{B}_{3}$-adrenergic receptor. Science $245: 1118-1121$, 1989 .

12. Fellows I.W., T. Bennet, and I.A. MacDonald. The effect of adrenaline upon cardiovascular and metabolic functions in man. Clin. Sci. 69:215-222, 1985.

13. Foster D.O. Participation of alpha-adrenoceptors in brown adipose tissue thermogenesis in vivo. Int. J. Obes. 9: 25-29, 1985 .

14. Henry C. Y. Schutz, A. Bucker, M. Mcylan, E. Jequier, and J. Felber. Thermogenic effect of the new B-adrenoreceptor agonist RO-16-8714 in healthy male volunteers. Int. J. Obes. 11: 473-483, $198 \%$.

15. Hjemdahl P., T. Akerstedt, T. Pollare, and M. Gillberg. Influence of B-adrenoceptor blockade by metoprolol and propranolol on plasma concentrations and effects of noradrenaline and adrenaline during i,y. infusion. Acta Physiol. Scand. (Suppl) 515: 45-53, 1983.

16. Hothoway B.R., R. Howe, B.R. Rao, D. Stribling, R.M. Mayers, M.G. Briscoe, and J.M. Jackson. ICI D7114 a novel selective B-adrenoceptor agonist selectively stimulates brown fat and increases whole body oxygen consumption. Brit. J. Pharmacol. 104: 97-104, 1991.

17. Katzeff H.L., M. OConnell, E.S. Horton, E. Danforth, J.B. Young, and L. Landsberg. Metabolic studies during over- and undernutrition: thermogenic and homonal responses to norepinephrine. Metabolism 35: 166-175, 1986.

18. Lafontan M., M. Berlan, J. Galitzky, and J.L. Montastruc. Alpha-2 adrenoceptors in lipolysis: $\alpha_{2}$ antagonists and lipid mobilizing strategies. Am. J. Clin. Nutr. 55: 219S-227S, 1992.

19. Langin D., M.P. Portillo, J. Saulnier-Blache, and M. Lafontan. Coexistence of three B-adrenoceptor subtypes in white fat cells of various mammalian spectes. Eur. J. Pharmacol. 199: 291-301, 1991.

20. Ligget S.B., D.S. Suresh, and P.E. Cryer. Characterisation of B-adrenergic receptors of human skeletal muscle obtained by needle biopsy. Am. J. Physiol. 254 (Endocrinol. Metab. 17): E795-E798, 1988.

21. Lipworth B.J., L.C. McFarlane, W.I. Coutie, and D.G. McDevitt. Evaluation of the metalbolic responses to inhaled salbutamol in the measurement of $B_{2}$-adrenoceptor blockade. Eur. I. Clin. Pharmacol. 37: 297-300, 1989.

22. Mansell P.I., I.W. Fellows, A.T. Birmingham, and I.A. MacDonald. Metabolic and cardiovascular effects of infusions of low doses of isoprenaline in man. Clin. Sci. 75: 285-291, 1988.

23. Martinsson A., K. Lindvall, A. Melcher, and P. Hjehmdahl. B-adrenergic receptor responsiveness to isoprenaline in humans: concentration-effect, as compared with dose effect evaluation and influence of autonomic reflexes. Brit. J. Clin. Pharmacol, 28: 83-94, 1989.

24. Motomura S., H.R. Zerkowski, A. Daul, and E. Brodde. The physiologic role of $B_{2}$-adrenoceptors in the human heart. In vitro and in vivo studies. Am. Heart J. 119:608-619, 1990.

25. Owen O.E., G.A. Reichard, G. Boden, M.S. Patel, and V.E. Trapp. Interrelationships among key tissues in the utilization of metabolic substrates. Adv. Mod. Nutr. 2: 517-550, 1978.

26. Reid J.L., K.F. Whyte, and A.D. Struthers. Epinephrine-induced typokalemia: the role of betaadrenoceptors. Am. J. Cardiol. 57: 23F-27F, 1986.

27. Schwartz R.S. L.F. Jaeger, and R.C. Veith. Effect of clonidine on the thermic effect of feeding in humans. Am. J. Phystol. 254 (Regulatory Integrative Comp. Physiol. 23): R90-R94, 1988.

28. Seaton T., S.Welle, S. Alex, U. Lilawivat, and R. Campbell. The effect of adrenergic blockade on 
glucase induced thermogenesis. Metabolism 33: 415-419, 1984.

29. Sjöström L., Y. Schutz, F. Gudinchet, L. Hegnell, P.G. Pittet, and E. Jéquier. Epinephrine sensitivity with respect to metabolic rate and other variables in women. Am. J. Physiol. 245 (Endocrinol. Motab. 8): E431-E442, 1983.

30. Staten M.A. D.E. Mathews, P.E. Cryer, and D.M. Bier. Physiological increments in epinephrine stimulate metabolic rate in humans. Am. J. Physiol. 253 (Endocrinol. Metab. 16): E322-E328, 1987.

31. Stock MJ., and N.J. Rothwell. Factors influencing brown fat and the capacity for diet-induced thermogenesis. Int. J. Obes. 9:9-15, 1985.

32. Tagliaferro A.R., S. Dobbin, R. Curi, B. Leighton, L.D. Meeker, and E.A. Newsholme. Effects of diet and exercise on the in wiwo rates of triglyceride-fatty acid cycle in adipose tissue and muscle of rat. Int. J. Obes. 14: $957.971,1990$.

33. Thorin D., A. Golay, C. Simonsen, E. Jequier, and J.B. Felber. The effect of selective B-adrenergic blockade on glucose-induced thermogenesis in man. Metabolism 35: 524-528, 1986.

34. Thörne $A_{\text {, }}$, and $J$. Wahren. B-Adrenergic blockade does not influence the thermogenic response to a mixed meal in man. Clin. Physiol. 9: 321-332, 1989.

35. Weir J.B. New methods for calculating metabolic rate with special reference to protein metabolism. J. Physiol 109: 1-9, 1949.

36. Welle S., R.G. Schwartz, and M. Statt. Reduced metabolic rate during B-adrenergic blockade in humans. Metabolism 40: 619-622, 1991.

37. Zwilich C., B. Martin, F. Hofeldt, A. Charles, V. Subryan, and K. Burman. Lack of effect of beta sympathetic blockade on the metabolic and respiratory responses to carbohydrate fceding. Metabolism 30: $451-455,1981$. 



\title{
CHAPTER 3
}

\section{The effect of hand heating by a warm air box on oxygen consumption of the contralateral arm}

\author{
E.E. Blaak, M.A. van Baak, K.P.G. Kempen, and W.H.M. Saris.
}

Department of Human Biology, University of Limburg, The Netherlands

J. Appl. Physiol. 72(6): 2364-2368, 1992

\begin{abstract}
Arterialization of venous blood is often used in studying forearm metabolism. Astrup et al (Am J Physiol 255: E572-E578, 1988) showed that heating of the hand by a warming blanket caused a redistribution of blood flow in the contralateral arm and thus introduced errors in forearm skeletal muscle flux calculations. The present study was undertaken to investigate how hand heating by a warm air box $\left(60^{\circ} \mathrm{C}\right)$ would affect metabolism and blood flow in the contralateral arm before and during $3 \mathrm{~h}$ after a glucose load. Eleven healthy volunteers $(5 \mathrm{M}, 6 \mathrm{~F})$ underwent an oral glucose tolerance test $(70 \mathrm{~g})$ on two different occasions, one test with and one without heating of the contralateral hand, in random order. Heating the hand for $30 \mathrm{~min}$ before glucose intake did not affect skin temperature, rectal temperature, deep venous oxygen saturation, forearm blood flow or oxygen consumption of forearm skeletal muscle. Although, after the glucose load, heating significantly increased forearm blood flow $(P<0.05)$, the integrated response after glucose was not significantly different between control and heating experiments (means \pm SEM: $67 \pm 43$ and $117 \pm 41 \mathrm{ml} / 100 \mathrm{ml}$ tissue). With both conditions, there was an increase in skin temperature ( $\mathrm{P}<0.001$, integrated response control: $369 \pm 79$ and heating: $416 \pm 203$ ${ }^{\circ} \mathrm{C} \cdot \mathrm{min}$ ) and $\mathrm{O}_{2}$-consumption of forearm muscle (control: $290 \pm 73, \mathrm{P}<0.01$ and heating: $390 \pm 130 \mu \mathrm{mol} / 100 \mathrm{ml}, \mathrm{P}<0.05)$ after glucose intake. These responses did not significantly differ between the conditions. Also, there were no significant differences in the other variables after the glucose load between the control and heating experiment. In conclusion, heating by a warm air box has no effect on deep venous oxygen saturation and little effect on forearm blood flow of the contralateral arm. Therefore, it is a better method for obtaining arterialized biood in forearm balance studies than the warming blanket.
\end{abstract}




\section{Introduction}

Studies on intermediary metabolism of ten involve the measurement of arterio-venous concentration differences of metabolites over tissues combined with determinations of tissue blood flow. However, arterial sampling carries the risk of complications. Therefore, sampling of arterialized venous blood, obtained from a heated dorsal hand vein, has often been used as an alternative. The increase in temperature causes an increase in blood flow in the digital arteries of the hand as result of both vasodilatation of forearm skeletal muscle and dilatation of the arterio-venous anastomoses in the skin. This results in arterialization of the venous blood in the superficial dorsal hand veins. The use of an arterialized superficial hand vein as an alternative for arterial sampling has shown to be valid for the determination of metabolites $(1,6), \mathrm{pH}$ and $\mathrm{pCO}_{2}(7)$.

Astrup et al (3) have criticized the method of hand heating, showing that it increased core temperature. In addition, it caused a redistribution of the blood flow in the contralateral arm. Heating increased subcutaneous adipose tissue blood flow and probably decreased skeletal muscle flow. In forearm balance studies, the most frequently used method for measuring forearm blood flow is venous occlusion plethysmography. It has the disadvantage that only total blood flow of the extremity can be measured and not the flow of the individual tissue parts, such as muscle, fat tissue and skin. If heating causes a redistribution of the contralateral blood flow through the different forearm tissues, this would potentially introduce errors in the flux calculations used in the measurement of forearm skeletal muscle balance. Furthermore, Astrup et al (3) reported that heating, as result of mixing of superficial with deep venous blood, increased deep venous oxygen saturation and masked the rise in forearm oxygen consumption after an oral glucose load, which was therefore no longer detectable. This phenomenon could be an explanation for the contradictory results of Jackson et al (11), who reported an unchanged glucoseinduced forearm skeletal muscle oxygen consumption when heating the contralateral hand, while Astrup et al (2) previously reported a diphasic increase in oxygen consumption after glucose intake.

However, for obtaining arterialized blood, Astrup et al (3) enclosed the hand in a warming blanket. It is possible that this method, in which there is direct contact of the heating pad and the hand, has a more pronounced effect on blood flow and deep venous oxygen saturation than the more often used warm air box (9). Therefore, the present study was undertaken to investigate how hand heating by a warm air box would affect deep venous oxygen saturation, blood flow and glucose-induced oxygen consumption of the contralateral forearm.

\section{Subjects and Methods}

\section{Subjects}

Five males and six females with a mean age of 28.5 y (range 22.41) participated in this study. Their mean body weight was $66.9 \pm 3.1$ (SEM) and mean height was $175.6 \pm 2.9$ 
cm (SEM). The subjects were healthy and took no medication. "The study was reviewed and approved by the Ethics Comittee of the University of Limburg.

\section{Experimental design}

The subjects were studied on two different occasions with 3-7 days in between. The tasts were started at 1.00 P.M. All individuals were fasted for at least five hours and had only performed very light activities during moming hours. At the two test days, they underwent an oral glucose tolerance test $(70 \mathrm{~g})$, one test with (hearing experiment) and one without heating of the contralateral hand (control experiment). For the former the hand was placed in a heated box, which circulated air with a temperature of $60{ }^{\circ} \mathrm{C}$. The order of the tests was randomized. After a 30 min baseline period, the heating of the hand was started, which lasted until the end of the study. The glucose load was given 30 min after the initiation of heating or after one hour baseline period (control experiment). Forearm blood flow, deep venous oxygen saturation of hemoglobin, forearm skin and body temperature were followed from one hour before until three hours after the glucose load.

\section{Clinical and biochemical methods}

During the experiment, the subjects were wearing light clothes and were resting supine in a room that was maintained at $23-25^{\circ} \mathrm{C}$. A teflon catheter was inserted retrogradely in an antecubital vein, so that its tip would be close to the muscle bed of the forearm. In the heating experiment, after 30 min the contralateral hand was placed in a heated box $(60$ $\left.{ }^{\circ} \mathrm{C}\right)$.

Forearm blood flow was measured with venous occlusion plethysmography (13) with a mercury strain gauge (Periflow 0699, Jansen Scientific Instruments, Belgium). The strain gauge was placed around the forearm, which contained the deep venous catheter. Because this method measures percentage change in volume, the blood flow is related to $100 \mathrm{ml}$ of forearm tissue. Prior to measuring blood flow, the hand circulation was occluded by inflating a pediatric sphygnomanometer cuff, placed around the wrist, to a pressure of $200 \mathrm{~mm} \mathrm{Hg}$ for a period of three minutes. In this way, forearm blood flow could be assessed without interference from the hand circulation. The venous occlusion cuff, placed around the upper arm, was automatically inflated (and deflated) to a pressure of $40 \mathrm{~mm} \mathrm{Hg}$. Forearm blood flow was recorded approximately every 4 seconds (depending on the heart rate) for $1.5 \mathrm{~min}$ and the consecutive (stable) values during the last min were averaged.

Blood samples were taken from the deep venous catheter after forearm blood flow was assessed, while the hand circulation was still occluded. Every 30 min a blood sample was taken with heparinized syringes for the determination of hemoglobin and the percentage saturation of hemoglobin with $\mathrm{O}_{2} \quad \operatorname{COSM}_{2}$ hemoximeter VA Howe Radiometer Copenhagen).

A temperature sensor was placed on the forearm distal to the strain gauge. This was used to record changes in skin temperature (every $15 \mathrm{~min}$ ) as indicator of changes to blood 


\section{Chapter 3}

flow in the skin. Also, every 15 min rectal temperature was recorded.

\section{Calculations and Statistics}

From the study of Astrup et al (3), it appeared that $\mathrm{O}_{2}$-saturation of hemoglobin $\left(\mathrm{SatO}_{2}\right)$ in arterial blood is within narrow ranges (96.4-97.9\%). Furthermore, Roddie et al (12) have demonstrated that arterial $\mathrm{SatO}_{2}$ does not change during body heating. Therefore, in the present study a fixed value of $97 \%$ was used. Oxygen content of blood was calculated assuming that 1 gram hemoglobin combines with $1.34 \mathrm{ml}$ oxygen when fully saturated. The exchange of oxygen across the forearm was calculated by multiplying the $A-V$ difference $(\mu \mathrm{mol} / \mathrm{ml})$ by the blood flow $(\mathrm{ml} / 100 \mathrm{ml}$ forearm tissue $\cdot \mathrm{min})$.

Statistical analysis was first performed with repeated measurements ANOVA, after which post-hoc testing was done with Bonferroni inequalities. The response to glucose was calculated as the integrated area of the response curve. For comparing the integrated response between the heating and control experiment, a Student's paired $t$-test was used. Data are represented as means \pm SEM. A P-value smaller than 0.05 was regarded as statistically significant.

\section{Results}

As shown in figure 1, throughout both experiments there were no significant changes in rectal temperature. Furthermore, heating the contralateral hand for 30 minutes did not influence skin temperature, while skin temperature significantly increased after glucose intake in both experiments $(P<0.001)$. The integrated increase in skin temperature after glucose was similar with and without heating of the contralateral hand (fig 1).

The mean baseline forearm blood flows were $1.8-2.0 \mathrm{ml} / 100 \mathrm{ml} \cdot \mathrm{min}$, which were similar to the values reported by Frayn et al $(2.0 \mathrm{ml} / 100 \mathrm{ml} \cdot \mathrm{min}, 8)$ and lower than values reported by Astrup et al $(2-3 \mathrm{ml} / 100 \mathrm{ml} \cdot \mathrm{min}, 3)$ and Gallen et al $(2.8-3 \mathrm{ml} / 100 \mathrm{ml} \cdot \mathrm{min}, 9)$. This difference might be due to our lower environmental temperature (8). Heating for 30 min did not change forearm blood flow (fig 1). After the glucose load, there was a significant increase in forearm blood flow when the contralateral hand was heated $(P<0.01)$, while in the control experiment a tendency to an increase was observed $(P=0.09)$. The integrated change in blood flow after glucose intake was not different between both treatments.

The changes in deep venous oxygen saturation $\left(\mathrm{SatO}_{2}\right)$ are shown in figure 2 . The mean initial values for $\mathrm{SatO}_{2}$ are respectively $55 \%$ (range $33-67 \%$ ) and $50 \%(28-67 \%$ ) in the control and heating experiment. No significant effect of heating on deep venous $\mathrm{SatO}_{2}$ could be detected, and at both experimental days the administration of glucose did not change $\mathrm{SatO}_{2}$.

The resting values for $\mathrm{O}_{2}$-flux of forearm skeletal muscle were respectively 6.5 (range $3.0-9.6$ ) and $7.1 \mu \mathrm{mol} / 100 \mathrm{ml} \cdot \mathrm{min}$ (range $3.0-11.7$ ) for the control and heating experiment, which is in agreement with values previously reported in literature $(2,4)$. The $\mathrm{O}_{2}$-flux of forearm skeletal muscle was not influenced by heating, while after the glucose load there was a significant increase in oxygen consumption on both experimental days 
(fig 2). The integrated $\mathrm{O}_{2}$-flux was not different with and without hand heating.
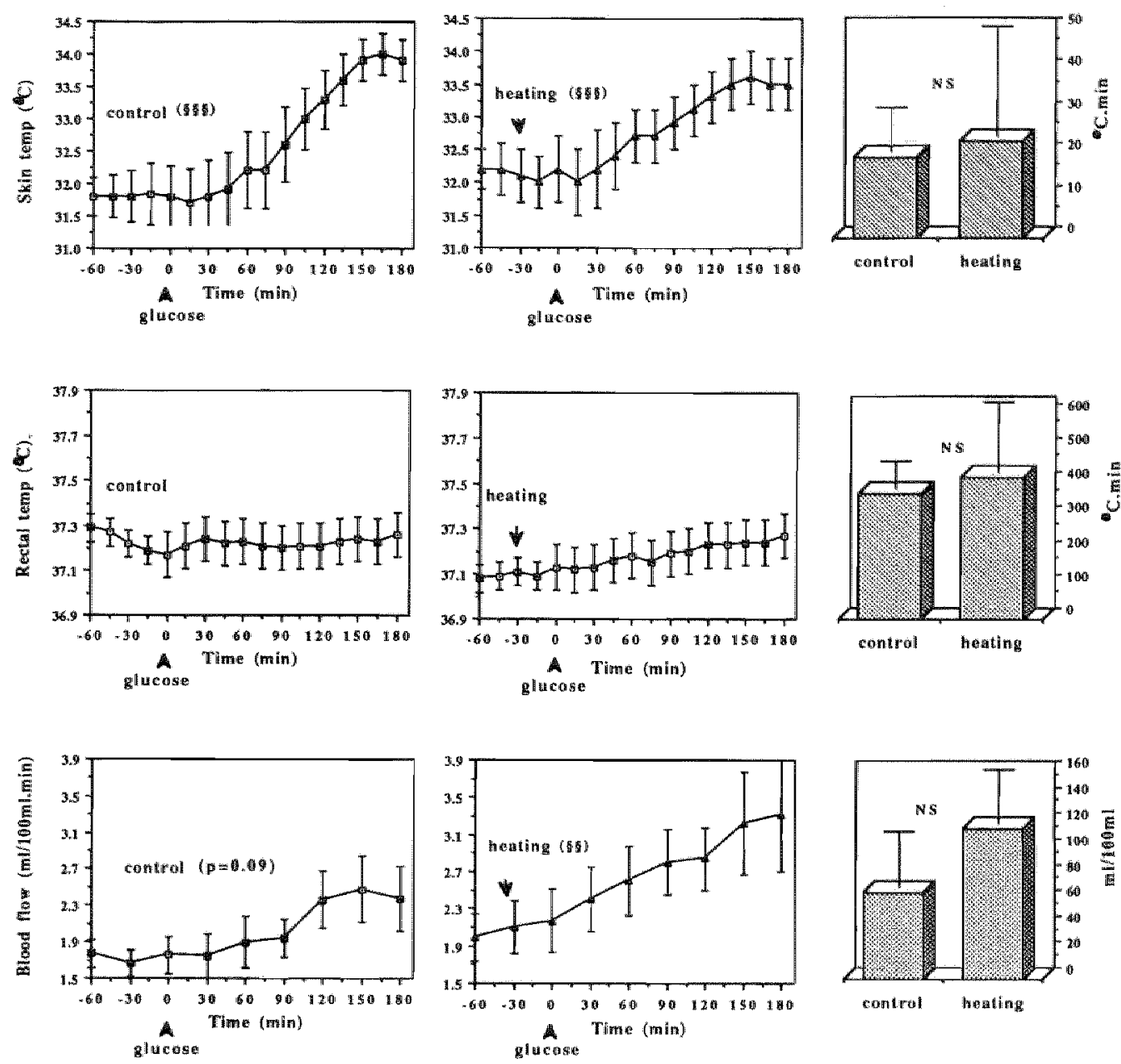

Fig 1. Changes in rectal temperature, skin temperature and forearm blood flow before and after glucose intake with (middle) or without (left) heating of the contralateral hand. Figure also shows the integrated area of the response curve to glucose (right). Means $\pm S E M ; n=11$; Repeated measurements ANOVA: $\S \xi=\mathrm{P}<0.01, \$ \$ \$=\mathrm{P}<0.001$. 

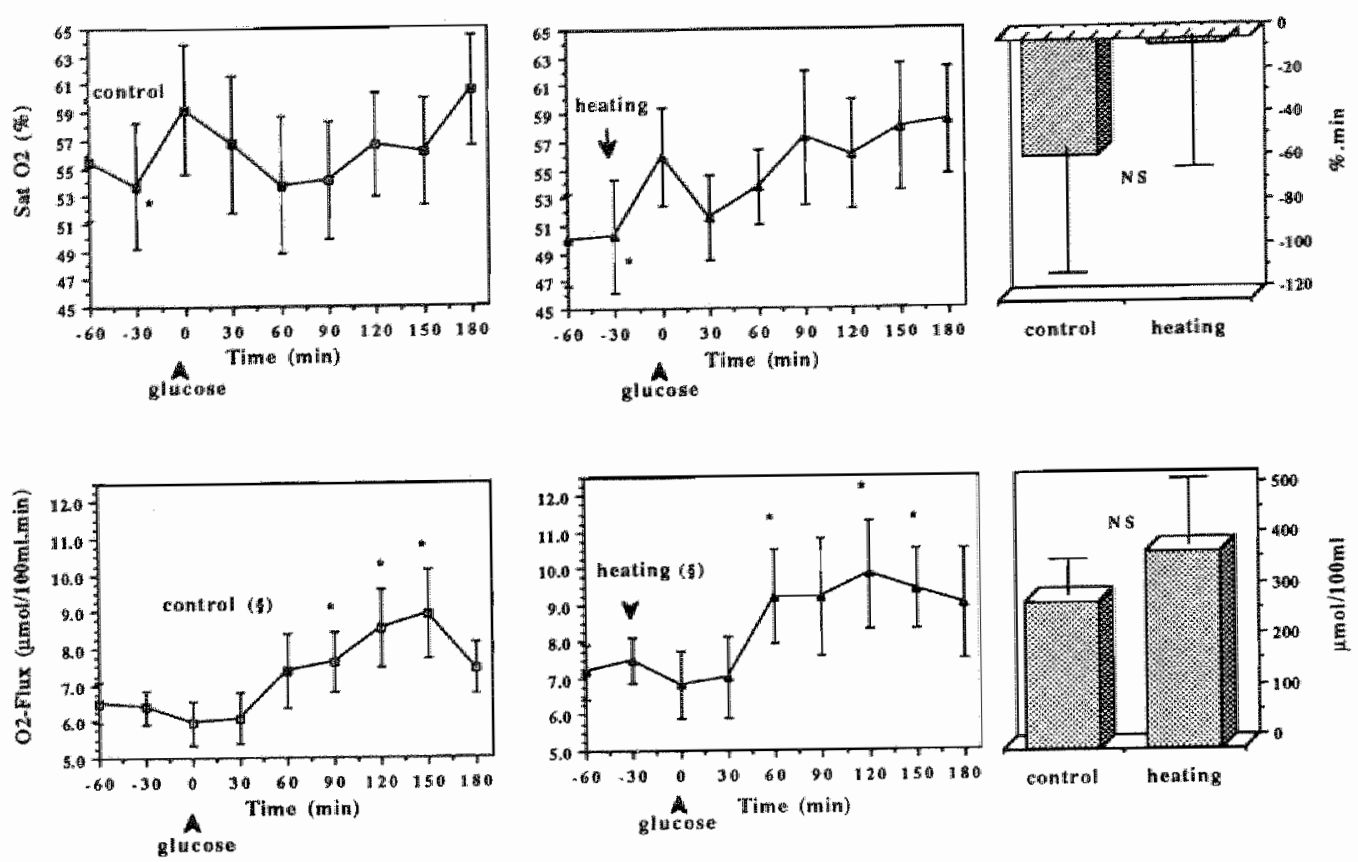

Fig 2. Changes in deep venous oxygen saturation $\left(\right.$ Sat $\left.\mathrm{O}_{2}\right)$ and forearm skeletal muscle oxygen consumption $\left(\mathrm{O}_{2}\right.$-flux) before and after glucose intake with (middle) or without (lleft) heating of the contralateral hand. Figure also shows the integrated area of the response curve to glucose (right); Means $\pm \mathrm{SEM} ; \mathrm{n}=11$; Bonferroni's paired t-test: time $\mathrm{x}$ ws 0 min: ${ }^{*}=\mathrm{P}<0.05$; Repeated measurements ANOVA: $\S=\mathrm{P}<0.05$.

\section{Discussion}

Because the sampling of arterial blood might cause complications, arterialized venous blood obtained from a dorsal hand vein is often used as an alternative. The heated hand technique provides a relatively painless method for sampling arterial blood, which can be used in almost all subjects. Astrup et al (3) criticized the method of hand heating in forearm skeletal muscle balance studies, because this caused a redistribution of the blood flow in the contralateral arm. Heating increased subcutaneous blood flow and probably also skin blood flow, leaving the total blood flow unchanged, which suggests that there was a reduced skeletal muscle blood flow. An increase in skin and subcutaneous blood flow as result of heating might cause mixing of superficial with deep venous blood. Also, in that study heating increased deep venous oxygen saturation and masked the increase in forearm skeletal muscle oxygen consumption after an oral glucose load. This would explain why Astrup et al (3) reported in their control experiment an increased and others (11) an unchanged glucose-induced oxygen consumption of the forearm. For obtaining arterialized venous blood Astrup et al (3) used a heating blanket, which might disturb body temperature, deep venous oxygen saturation and forearm blood flow to a greater 
extent than the more often used warm air box (9). Additionally, the basal deep venous oxygen saturation of hemoglobin (with occluded hand circulation) reported in that study seems to be very high $(75-82 \%)$ both in the heating as well as the control experiment, which suggests mixing of superficial to deep venous blood. It is possible that this is caused by an increased superficial blood flow due to a relatively high ambient temperature $\left(25-27^{\circ} \mathrm{C}\right)$. However, Gallen et al (9) reported with an even higher environmental temperature $\left(28^{\circ} \mathrm{C}\right)$, a mean deep venous oxygen saturation of $60 \%$ (occluded hand circulation). In our study, deep venous oxygen saturation was about 50 $\%$, which indicates deep venous sampling.

The present study was undertaken to investigate how hand heating by a warm air box would affect rectal temperature, deep venous oxygen saturation, forearm blood flow and glucose-induced oxygen consumption of the contralateral arm. For practical reasons, we did not measure arterialized oxygen saturation and used a fixed value of $97 \%$. In another study, we measured oxygen saturation of the arterialized blood with this heating procedure and obtained values of $95-96 \%$, which indicates good arterialization (unpublished observations). Also, in many other studies this procedure has been shown to result in sufficient arterialization of superficial venous blood $(1,6,9)$.

Heating the hand in the warm air box did not affect rectal temperature before or after the glucose load, while Astrup (3) reported an increase of rectal temperature of $0.6^{\circ} \mathrm{C}$ (in $3 \mathrm{~h}$ after glucose) when using the warming blanket. This difference between the warm air box and heating blanket has also been reported by Gallen et al (9).

In the present study, skin temperature of the contralateral arm did not change as result of half an hour heating, whereas Astrup et al (3) reported a significant increase in skin temperature with the warming blanket. Furthermore, in our study the integrated responses in skin temperature after the oral glucose load were similar in both conditions, while Astrup reported a significant higher response with the warming blanket than in the control experiment.

Total forearm blood flow was not affected by heating for half an hour with the warm air box, which is similar to results reported with the warming blanket $(3,9)$. After glucose intake, heating with the warm air box had a significant effect on blood flow, but the integrated response in blood flow after the glucose load was not different between both experimental days. This is in agreement with the results of Astrup (3), who also reported no significant difference in integrated blood flow response between the warm-blanket heating and control experiment.

Astrup (3) reported as result of heating with the warming blanket a significantly increased basal oxygen saturation and a significantly higher integrated response after glucose, which suggests contamination of superficial with deep venous blood. In our study, heating by the warm air box did not affect deep venous oxygen saturation before or after the glucose load, which indicates that superficial blood flow is less affected by heating with the warm air box than with the warming blanket. In the present study we did not determine blood flow through the different compartments of the forearm separately. However, Astrup (3) suggested a compensatory decrease in skeletal muscle blood flow as result of heating. Our results show no significant differences between the control and heating experiment for rectal temperature, skin temperature, deep venous oxygen 
saturation and total forearm blood flow, which suggests that the warm air box method causes much less disturbance in hemodynamic parameters than the warming blanket. The difference in hemodynamic effects between both methods of hand heating are likely to be due to differences in efficiency of heat transfer to the body. The heat transfer with the warming blanket may be greater than with the warm air box because conduction between surfaces is more efficient than transfer of heat from warmed air.

In the present study, oxygen consumption of the forearm was significantly increased to the same extent with or without hand heating. Thus, in contrast to the warming blanket used by Astrup et al (3), heating with the warm air box did not mask the glucose-induced oxygen consumption of the forearm. This would explain why Jackson et al (11), who also heated the hand with warming blankets, reported an unchanged forearm oxygen uptake after oral glucose. The increase in oxygen consumption of the forearm after glucose indicates that an important part of the glucose-induced thermogenesis might be located in forearm skeletal muscle. This is in agreement with other studies which reported an increased forearm oxygen consumption after a glucose load $(2,3)$ or after a mixed meal (5). Also, direct studies of splanchnic oxygen consumption in man failed to show any consistent change after glucose administration $(4,10)$, which suggests that splanchnic tissues are not important in this respect.

In conclusion, hand heating by a warm air box had a slight or no effect on body and skin temperature, deep venous oxygen saturation, total forearm blood flow and glucoseinduced oxygen consumption of the contralateral forearm. Thus, for obtaining arterialized blood the warm air box is recommended above the warming blanket, because it causes less hemodynamic disturbance than the heating blanket. We cannot exclude that the warm air box has a very slight effect on contralateral blood flow and deep venous oxygen saturation, which did not reach statistical significance in the present study, but may be more pronounced under different experimental conditions. Therefore, in forearm balance studies, where only total blood flow is measured, it is best to obtain arterialized blood with a minimum of local heating. The increased forearm oxygen consumption after glucose intake, suggests that a considerable part of glucose-induced thermogenesis might be located in forearm skeletal muscle.

\section{References}

1. Abumrad N.N., D. Rabin, M.P. Diamond, and W.W. Lacy. Use of the superficial hand vein as an alternative sampling site for the measurement of glucose and alanine kinetics in man. Mecabolism 30: $936-941,1981$.

2. Astrup A., J. Bülow, N.J. Christensen, J. Madsen, and F.Quaade. Facultative thermogenesis induced by carbohydrate: a skeletal muscle component mediated by epinephrine. Am. J. Physiol. 257 (Endocrinol. Metab. 13): E226-E229, 1989.

3. Astrup A., L. Simonsen, J. Bullow, and N.J. Christensen. Measurement of forearm oxygen consumption: role of heating of the contralateral hand. Am. J. Physiol. 255 (Endocrinol. Metab. 18): E572-E578, 1988.

4. Berry M., D.G. Clark, A.R. Grivell, and P.G. Wallace. The contribution of hepatic metabolism to diet- 
induced thermogenesis. Metabolism 34: 141, 1985.

5. Coppack S.W., R.M. Fisher, G.F. Gibbons, S.M. Humphreys, M.J. McDonough, J.L. Pons, and K.N. Frayn. Postprandial substrate deposition in human forearm and adipose tissue in vivo. Clin. Sci. 79 . $339-348,1990$.

6. Elia M., P. Folmer, A. Schlatmann, A. Goren, and S. Austin. Carbohydrate, fat and protein metabolism in muscle and in the whole body after a mixed meal ingestion. Metabolism 37:"542-551, 1988.

7. Forster H.V., J.A. Dempsey, J. Thomson, E. Vidruk, and G.A. doPico. Estimation of arterial pO2, $\mathrm{pCO}_{2}, \mathrm{pH}$ and lactate from arterialized venous blood. J. Appl. Physiol. 32: 134-137, 1972.

8. Frayn K.N., P.L.Whyte, A. Benson, D.J. Earl, and H.A. Smith. Changes in forearm blood flow at elevated ambient temperature and their role in the apparent impairment of glucose tolerance. Clin. Sci. 76: $323-328,1989$.

9. Gallen I.W., and I.A. MacDonald. Effect of two methods of thand heating on body temperature, forearm blood flow, and deep wenous oxygen saturation. Am. J. Physiol. 259 (Endocrinol. Metab. 22): E639-E643, 1990.

10. Hultman $\mathrm{E}$, and H. Castenfors. Effect of injection of hypertonic glucose on splanchnic blood how and oxygen consumption. Scand. J. Clin. Lab. Invest. 13: 503, 1961.

11. Jackson R.A., R.D. Doshania, M.I. Hawa, B.M. Sim, and L. DiSilvo. Impact of glucose ingestion on hepatic and peripheral glucose metabolism in man: an analysis based on simultaneous use of forearm and double isotope techniques. J. Clin. Endocrinol. Met. 63: 541-549, 1986.

12. Roddie I.C., J.T. Shepherd, and R.F. Whelan. Evidence from venous oxygen saturation measurements that the increase in forearm blood flow during heating is confined to the skin. J. Physiol. Lond.134: 444-450, 1956.

13. Whitney RJ. The measurement of volume changes in human limbs. J. Physiol. Lond. 121: 1-27, 1953. 


\title{
CHAPTER 4
}

\section{Total forearm blood flow as indicator of skeletal muscle blood flow: effect of subcutaneous adipose tissue blood flow}

\author{
E.E. Blaak, M.A. van Baak, G.J. Kemerink*\#, M.T.W. Pakbiers*, G.A.K. Haidendal*, \\ and W.H.M. Saris.
}

Department of Human Biology. University of Limburg, Maastricht, *Department of Nuclear Medicine and \#Department of Radiology, University Hospital Maastricht, The Netherlands.

Submitted to Clin. Sci.

\section{Abstract}

In studying forearm skeletal muscle substrate exchange, an often applied method for estimating skeletal muscle blood flow is strain gauge plethysmography. A disadvantage of this method is that it only measures total blood flow through a segment of forearm and not the flow through the individual parts such as skin, adipose tissue and muscle. In the present study the contribution of forearm subcutaneous adipose tissue blood flow (ATBF) to total forearm blood flow (TBF) was evaluated in lean (\% body fat 17.0 2.2 ) and obese males (\% body fat $30.9 \pm 1.6$ ) during rest and during intravenous infusion of the nonselective B-agonist isoprenaline (ISO). Measurements were obtained of body composition (hydrostatic weighing), forearm composition (magnetic resonance imaging) and of total forearm (venous occlusion plethysmography)-, skin (SBF, ]aser doppler)-, and subcutaneous fat blood flow ( ${ }^{133}$ xenon washout technique).

The absolute forearm area and the relative amount of fat (\% of forearm area) were significantly higher in obese as compared to lean subjects, whereas the relative amount of muscle and skin were similar. During rest, the percentage contribution of ATBF to TBF was significantly higher in lean than obese subjects (resp. 18 vs $11 \%, \mathrm{P}<0.05$ ). The percentage contribution of $\mathrm{ATBF}$ to TBF was significantly lower during ISO-infusion than during rest in lean subjects ( 10 vs $18 \%, P<0.05)$, whereas in obese subjects this value was similar during rest and during ISO (rest : $11 \%$, ISO: $13 \%$ ).

In conclusion, although the overall contribution of ATBF to TBF seems to be relatively small, the significance of this contribution may vary with degree of adiposity. Calculations on the contribution of ATBF and SBF to TBF indicate that the contribution of nonmuscular flow to TBF may be of considerable importance and may amount 35$50 \%$ of TBF in lean volunteers in the resting state 


\section{Chapter 4}

\section{Introduction}

To an increasing extent attention is paid to skeletal muscle metabolism at rest and during other conditions e.g. exercise, trauma and malnutrition. This interest is related to the relatively high muscle mass ( $\pm 40 \%$ of total body mass) and the significance of skeletal muscle in whole body energy expenditure and its role as a protein and carbohydrate store. The substrate exchange of skeletal muscle has been thoroughly investigated by measuring the arterio-venous concentration differences of substrates across the forearm in combination with a measurement of blood flow. An often applied method to obtain an indication of skeletal muscle blood flow is strain gauge venous occlusion plethysmography (28). The drawback of this method is that it only measures total blood flow through a segment of the forearm and not the flow through the individual parts such as skin, fat tissue and skeletal muscle. Although skeletal muscle may account for $60 \%$ or more of the forearm tissues (9), a significant contribution of the other forearm tissues to total forearm blood flow cannot be excluded. In the past, most research has been focussed on a separation of forearm muscle and skin blood flow by a combination of plethysmography and adrenalin iontophoresis $(11,17,31)$. In several more recent forearm studies $(4,23)$ also subcutaneous adipose tissue blood flow has been measured by means of the ${ }^{133}$ xenon washout technique. However, since exact data on forearm composition are lacking in these studies, a good indication of the contribution of subcutaneous adipose iissue flow to total blood flow cannot be obtained. In addition, subcutaneous fat blood flow has been reported to decrease with increasing degree of obesity (18), which implicates that the importance of fat blood flow for the magnitude of total forearm blood flow may vary between subjects.

In the present study the contribution of subcutaneous fat blood flow to total forearm blood flow was evaluated in lean and obese subjects. Measurements were performed on total forearm (venous occlusion plethysmography)-, skin (laser doppler)-, and subcutaneous fat blood flow ( ${ }^{133}$ xenon washout) during rest and during infusion of the $B_{1}$ - and $B_{2}$-agonist isoprenaline (ISO), which is a potent stimulator of muscle blood flow (8). The amount of forearm subcutaneous adipose tissue and muscle tissue were determined using magnetic resonance imaging (MRI).

\section{Subjects and methods}

In this study 8 lean and 8 obese male subjects participated. Subject's characteristics are

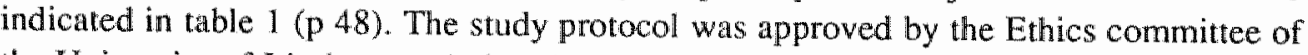
the University of Limburg and all volunteers were asked for written consent. The study protocol consisted of three measurements. Measurements of body composition and forearm composition were made with hydrostatic weighing and magnetic resonance imaging, respectively. After an overnight fast, blood flow measurements were performed on the total forearm, forearm skin and forearm subcutaneous adipose tissue during rest and during intravenous infusion of the $B_{1}$ - and $B_{2}$ agonist isoprenaline (ISO). Room temperature was controlled between 21 and $23^{\circ} \mathrm{C}$. 


\section{Body composition}

Body density was determined with hydrostatic weighing with simultaneous lung volume measurement (Volugraph 2000, Mijnhardt, The Netherlands). Body composition was calculated according to the formula of Siri (24).

\section{Forearm composiltion}

The amounts of subcutaneous fat, bone and muscle were determined by a cross-sectional analysis at the site of the greatest forearm circumference with magnetic resonance imaging (Gyroscan T5, Philips Medical Systems, The Netherlands). T1-weighted images were obtained by means of a Spin Echo Sequence at the greatest circumference of the forearm (repetition time $200 \mathrm{~ms}$, echo time $20 \mathrm{~ms}, 3$ slices of $10 \mathrm{~mm}$ thickness, $1 \mathrm{~mm}$ between slices). A surface coil was used during the imaging process. The acquisition time for imaging 3 slices of one forearm was about 40 seconds. In our MRI-images we could not accurately determine the amount of forearm skin nor distinguish the amount of muscle from tendinous structures. Therefore, the relationship between the area of forearm skin and the total area of muscle and subcutaneous fat was assumed to be as described by Cooper at al (9). In addition, the relationship between the amount of tendon and muscle was considered to be as assessed in the study of Cooper (9). Under the heading of muscle and fat are also grouped nerves and blood vessels within these tissue.

\section{Blood flow}

The blood flow through the total forearm-, forearm skin-, and forearm subcutaneous adipose tissue was investigated at the end of a $30 \mathrm{~min}$-period of supine rest. After this control period, an intravenous infusion of the $B_{1}$ - and $B_{2}$-agonist isoprenaline (ISO) was started for $30 \mathrm{~min}$. The blood flow measurements were repeated at the end of this infusion period. For each subject, a standardized dose of ISO corresponding to a plasma ISO concentration of $165 \mathrm{pg} / \mathrm{ml}$ was infused. This dose was extrapolated from data of a pre-study where plasma ISO concentrations were determined during infusion of increasing standardized doses, as described elsewhere (2). The mean infusion dose of ISO was $20 \mathrm{ng} / \mathrm{kg}_{\text {fat free mass }} \cdot \mathrm{min}$ in both lean and obese subjects.

\section{Total forearm blood flow}

Total forearm blood flow was measured by venous occlusion plethysmography (28) with a mercury strain gauge (Periflow 0669, Janssen Scientific Instruments, Belgium). The strain gauge was placed around the forearm at the site of the greatest circumference. Prior to measuring blood flow, the hand circulation was occluded by inflating a pediatric sphygnomanometer cuff, placed around the wrist to a pressure of $200 \mathrm{~mm} \mathrm{Hg}$. The venous occlusion cuff, placed around the upper arm, was automatically inflated (and deflated) to a pressure of $40 \mathrm{~mm} \mathrm{Hg}$. Forearm blood flow was recorded every four seconds (depending on heart rate) for $1.5 \mathrm{~min}$ and the consecutive (stable) values during the last min were averaged. Because this method measures percent change in volume, the 


\section{Chapter 4}

blood flow is related to $100 \mathrm{ml}$ of forearm tissue.

\section{Skin blood flow}

Preceding the measurements of total forearm blood flow, skin blood flow was determined by the laser doppler technique (Periflux PF3, Perimed Sweden) with an occluded hand circulation. The probe was placed on the ventral side of the forearm near the wrist joint. The laser doppler method is a relative method in which the blood flow in the microcirculation can be expressed in qualitative terms (21). For the calculation of quantitative skin blood flow it was assumed that resting skin blood flow was 5 $\mathrm{ml} / 100 \mathrm{ml}$ min in both lean and obese subjects, a value reported by Sejrsen at an ambient temperature of $19-22^{\circ} \mathrm{C}(25)$.

\section{Subcutaneous adipose tissue blood flow}

Subcutaneous adipose tissue blood flow was measured on the dorsal side of the forearm about $10 \mathrm{~cm}$ proximal to the wrist joint by the ${ }^{133}$ xenon washout method (18). A dose of $5.5 \mathrm{MBq}(150 \mu \mathrm{Ci})^{133} x$ enon, dissolved in saline, was injected subcutaneously with a very fine needle $(0.5 \times 16 \mathrm{~mm})$. The arm was placed in a fixed position close to a large field of view gamma camera. (Technicare, large field $438 \mathrm{HR}$, General Electrics, Utrecht). The registration of ${ }^{133}$ xenon was started 45 min after the injection at which moment the washout is usually mono-exponential. From the regression of count rate against time, the disappearance constant of ${ }^{133}$ xenon over the last $20 \mathrm{~min}$ of each measurement period was determined.

For the calculation of quantitative values of fat blood flow (per $100 \mathrm{ml}$ tissue), the relative solubility of xenon between tissue and blood, i.e., the partition coefficient, must be known. The major determinants for the adipose tissue-blood partition coefficient are the lipid content of adipose tissue and the hematocrit value of the blood perfusing it. In a study of Martin et al (19), the relationship between \% adiposity and lipid fraction (V) of adipose tissue was determined by means of underwater weighing of all portions of adipose tissue of human cadavers (range \% body fat 17.8-43.9) and was as follows:

(1) $V=0.327+0.0124 x \%$ adiposity $(\mathrm{r}=0.95, \mathrm{P}<0.005)$

Given that the solubility of xenon in a tissue equals the weighted mean of the solubility in the individual tissue components (30), the following equations for the solubility of xenon in blood and adipose tissue can be given on basis of data of Chen et al (6):

(2) $S_{B}=H t S C+(1-H t) S p$, whereby

$\mathrm{S}_{\mathrm{B}} \mathrm{S}_{\mathrm{C}}, \mathrm{S}_{\mathrm{p}}$ : solubility in blood, red blood cells, and plasma, respectively.

He: hematocrit

Assuming that the solubility of xenon in water and protein within adipose tissue equals that of plasma yields the following equation: 
(3) $S_{A}=V S_{L}+(1-V) S_{P}$, whereby

$S_{A}, S_{L}, S_{p:}$ solubility in adipose tissue, in lipid and in plasma, respectively

$V_{*}^{*} \quad$ lipid fraction of adipose tissue

The tissue-blood partition coefficient of xenon for adipose tissue $(\lambda)$ can then be expressed as:

(4) $\lambda=\frac{S_{A}}{S_{B}}=\frac{V\left(S_{L / S_{P}}-1\right)}{H t\left(S_{C} / S_{P}-1\right)}$, whereby

$\mathrm{S}_{\mathrm{P}}: \quad 0.0939 \mathrm{ml} / \mathrm{ml}$

$\mathrm{S}_{\mathrm{L}}: \quad 1.8276 \mathrm{ml} / \mathrm{g}$

$\mathrm{S}_{\mathrm{C}}: \quad 0.2710 \mathrm{ml} / \mathrm{ml}$.

On basis of equation 1 and 4 , the tissue blood partition coefficient was calculated for each individual. For the conversion of blood flow values from $100 \mathrm{~g}$ to $100 \mathrm{ml}$ fat tissue, the density of adipose tissue was assumed to be $0.9 \mathrm{~g} / \mathrm{ml}$ in both groups $(9,24)$.

\section{Calculations and Statistics}

A Student's paired t-test was used for analyzing within-group differences. Differences between lean and obese subjects were tested with an unpaired t-test. A P-value smaller than 0.05 was regarded as statistically significant.

\section{Results}

\section{Body composition}

The mean age, body mass index (BMI) and \% body fat were significantly lower in lean than obese subjects, as indicated in table 1.

\section{Forearm composition}

Figure 1 shows a magnetic resonance image deplicting a cross section of the forearm at the site of the greatest circumference. The total forearm area was signifcantly higher in obese than lean subjects (P<0.001, Table 1). Lean subjects had less subcutaneous fat than obese subjects, when expressed as absolute values (lean vs obese: $773 \pm 51$ ws $1629+97$ $\mathrm{mm}^{2}, \mathrm{P}<0.001$ ) or as percentage of total forearm area (Table 1). As expected, there was a significant positive relationship between $\%$ total body fat and $\%$ forearm $f a t ~(r=0.82$, $\mathrm{P}<0.001$ ). The absolute amount of muscle was higher in obese than lean subjects (lean $v \mathrm{~s}$ obese: $3483 \pm 128$ vs $4849 \pm 313 \mathrm{~mm}^{2}, P<0.01$ ), but the relative amount was not significantly different. The amounts of skin and tendon were lower in lean than obese subjects when expressed as absolute values (skin: $477 \pm 18$ vs $751 \pm 32 \mathrm{~mm}^{2}, \mathrm{P}<0.001$ and 


\section{Chapter 4}

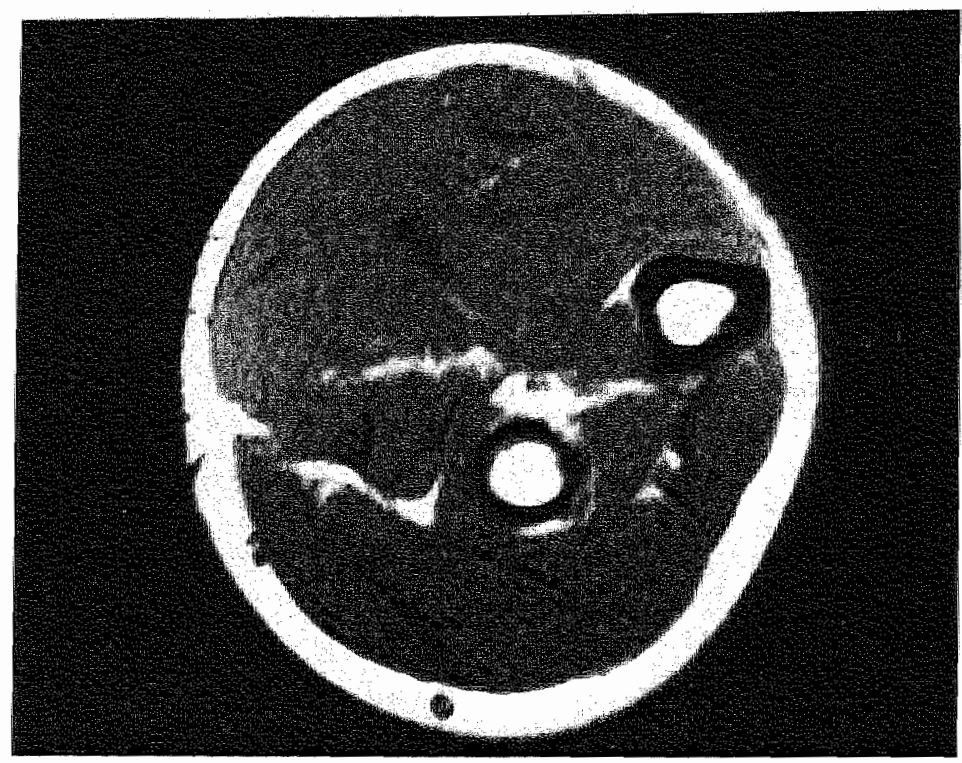

Fig 1. A magnelic resonance image showing a cross section of the forearm at the site of the greatest circumference. (Spin Echo, repetition time $200 \mathrm{~ms}$, echo time $20 \mathrm{~ms}$ ). The inner grey area represents muscle, whereas the suirounding white area represents subcutaneous fat tissue. The two inner circular structures represent bones: the inner white areas represent bone marrow and the surrounding black areas represent bome cortex.

Table 1. Body and forearm composition of lean vs obese subjects.

\begin{tabular}{lcc}
\hline & LEAN & OBESE \\
\hline Age $(\mathrm{y})$ & $25.0 \pm 1.6$ & $31.8 \pm 1.6 * *$ \\
BMI $\left(\mathrm{kg} / \mathrm{m}^{2}\right)$ & $23.2 \pm 1.4$ & $31.7 \pm 1.6 * * *$ \\
\% Body fat & $17.0 \pm 2.2$ & $30.9 \pm 1.9 * * *$ \\
Forcarm composition & & \\
total forearm area $\left(\mathrm{mm}^{2}\right)$ & & \\
\% subcutancous fat & $5537 \pm 151$ & $7925 \pm 306 * * *$ \\
\% muscle tissue & $14.0 \pm 1.1$ & $20.6 \pm 1.1 * *$ \\
\% skin & $62.8 \pm 0.9$ & $60.2 \pm 0.9$ \\
\% bone & $8.6 \pm 0.2$ & $9.2 \pm 0.3 * * *$ \\
\% tendon & $7.6 \pm 0.2$ & $4.5 \pm 0.3 * * *$ \\
& $6.1 \pm 0.2$ & $5.5 \pm 0.1 * *$ \\
\hline
\end{tabular}

Means \pm SEM ; lean $n=8$; obese $n=8$; Unpaired $t$-test: $* *=P<0.01, * * *=P<0.001$

$\mathrm{BMI}=\mathrm{Body}$ mass index, $\%$; percentage of total forearm area. 
tendon $336 \pm 13$ vs $449 \pm 29 \mathrm{~mm}^{2}, P<0.01$, respectively). When expressed as percentage of total forearm area the percentage tendon was significantly lower in the obese whereas the percentage skin was lower in lean subjects (Table 1). The absolute amount of bone was not different between lean and obese subjects, but expressed as a relative figure this value was lower in the obese.

\section{Blood fllow measurements}

Hematocrit values were similar in lean and obese men (table 2). The calculated lipid content of adipose tissue was significantly higher in obese than lean subjects and ranged in lean subjects from 0.40 to 0.62 and in obese subjects from 0.65 to 0.84 . The mean value for the partition coefficient was estimated to be $5.6 \mathrm{ml} / \mathrm{g}$ in lean subjects (range 4.4-6.5) and $7.2 \mathrm{ml} / \mathrm{g}$ in obese subjects (range 6.6-8.3, table 2).

Table 2. The contribution of forearm subcutaneous adipose tissue blood flow (ATBF) to total forearm blood flow (TBF) during rest and during the infusion of the $B_{1}$ - and $B_{2}$-agonist isoprenaline (ISO) in lean and obese subjects.

\begin{tabular}{lccc}
\hline & & LEAN & OBESE \\
\hline Hematocrit & & $47.3 \pm 2.5$ & $47.1 \pm 1.2$ \\
Lipid content adipose tissue & & $0.52 \pm 0.02$ & $0.71 \pm 0.02 * * *$ \\
Partition coefficient & & $5.6 \pm 0.2$ & $7.2 \pm 0.2 * * *$ \\
TBF (ml/100 ml forearm tissue-min) & rest & $1.43 \pm 0.13$ & $1.62 \pm 0.28$ \\
& ISO & $3.75 \pm 0.891$ & $2.44 \pm 0.301$ \\
ATBF (ml/100 ml adipose wissue min) & rest & $1.80 \pm 0.24$ & $0.83 \pm 0.12 * *$ \\
& ISO & $2.20 \pm 0.60$ & $1.38 \pm 0.30$ \\
Contribution ATBF to TBF & rest & $0.25 \pm 0.03$ & $0.17 \pm 0.02 *$ \\
(ml/100 ml forearm tissue;min) & ISO & $0.29 \pm 0.07$ & $0.28 \pm 0.06$ \\
\% contribution ATBF to TBF & rest & $18 \pm 2$ & $11 \pm 2 *$ \\
& ISO & $10 \pm 41$ & $13 \pm 3$ \\
\hline
\end{tabular}

Means \pm SEM, lean $n=8$, obese $n=8$; Unpaired t-test : lean ws obese $*=P<0.05, * *=P<0.01, * * *=P<0.001$; Student's paired t-iest ISO $\mathrm{vs}$ rest: $=\mathrm{P}<0.05$.

There was a significant increase in total forearm blood flow (TBF) as result of infusion of the $B_{1}$ - and $B_{2}$-agonist isoprenaline (ISO) in both groups, whereas this increase tended to be higher in lean subjects as compared to obese subjects $(\mathrm{P}=0.12$, Table 2$)$. During rest subcutaneous adipose tissue blood flow (ATBF) was significantly higher in lean than obese subjects. In both groups. ATBF did not change significantly as result of ISO- 


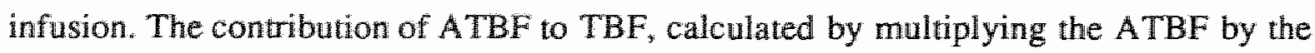
percentage of forearm fat tissue 100 , was significantly lower during rest in obese than lean subjects, whereas during ISO there was no longer a statistically significant difference between both groups. Expressed as percentage of total blood flow there was a significantly higher contribution of fat blood flow to total blood flow in lean subjects during test (18\%, range $14-27 \%)$ as compared to obese subjects $(11 \%$, range $5-20 \%)$. During ISO the \% contribution of fat flow to total blood flow was similar for both groups. The percentage contribution of ATBF to TBF was significantly lower during ISO-infusion than during rest in lean subjects, whereas in the obese these values were similar. There was a tendency towards a negative relationship between $\%$ body fat and the percentage contribution of $\mathrm{ATBF}$ to TBF $(r=0.41, \mathrm{P}=0.09$, fig 2 ).

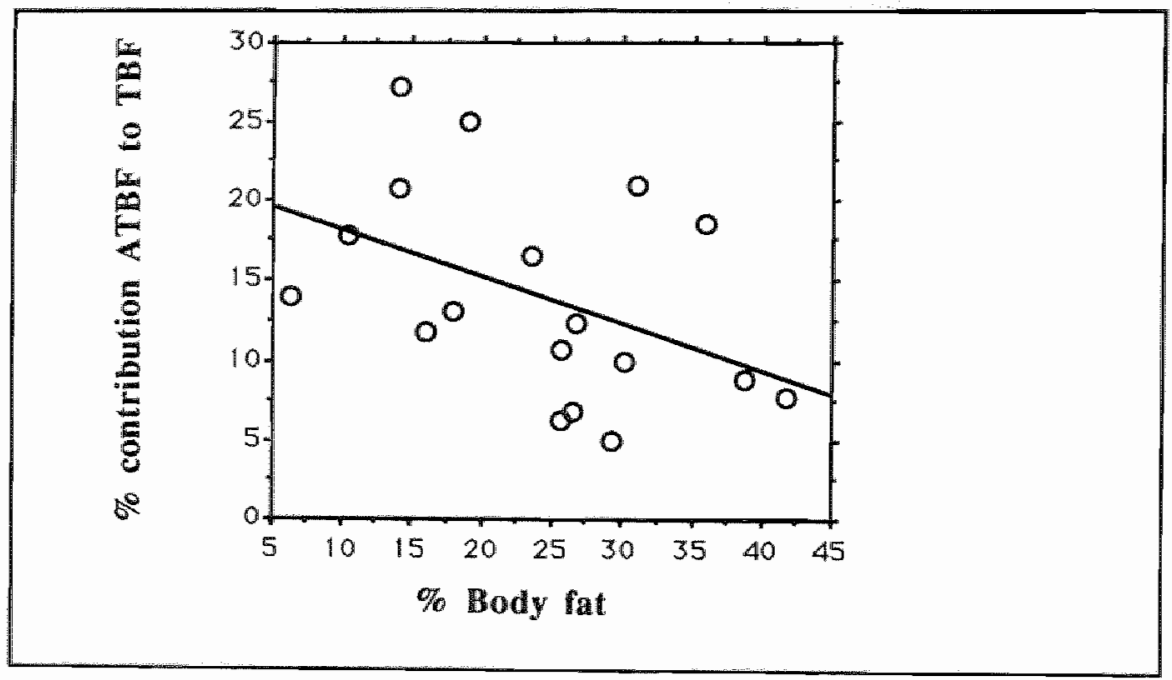

Fig 2. The relationship between percentage body fat and the percentage contribution of subcutaneous adipose tissue blood flow (ATBF) to total forearm blood flow (TBF) during rest. Standard error of estimate $=5.94 \%$

The relative units for skin blood flow (SBF) were similar in lean and obese subjects (lean vs obese : $5.9 \pm 0.6$ vs $5.2 \pm 0.6$ units) and in both groups there were no changes as result of ISO-infusion (lean vs obese ISO: $5.6 \pm 0.6$ vs $5.2 \pm 0.5$ units). Assuming a resting skin blood flow in lean and obese subjects in the range of 2.5 to $5 \mathrm{ml} / 100 \mathrm{ml} \cdot \mathrm{min}$ (see discussion), the contribution of skin and adipose tissue to total forearm blood flow can be estimated. The contribution of skin and and adipose tissue to TBF are then estimated to be $35-50 \%$ during rest and $18-25 \%$ during ISO in lean subjects, and in the obese $25-40 \%$ during rest and $23-33 \%$ during ISO. 


\section{Discussion}

In the present study the role of subcutaneous adipose tissue was evaluated in lean and obese subjects during rest and during infusion of the $B_{1}-$ and $B_{2}$-agonist isoprenaline. The data on the significance of subcutaneous adipose tissue blood flow are based on the following prerequisites:

- The individual values for the adipose tissue-blood partition coefficient of xenon estimated on basis of data of Martin et al (19) and Chen et al (6) are good estimations for the individual relative solubility of xenon between adipose tissue and blood.

- Total forearm blood flow can be measured with sufficient accuracy by means of strain gauge plethysmography.

- The total volume of muscle and subcutaneous fat can be differentiated with appropriate accuracy with magnetic resonance imaging.

\section{Tissue-blood partition coefficient}

For calculating absolute adipose tissue blood flow values from the washout curves of ${ }^{133}$ xenon, the tissue blood partition coefficient must be known. The highest solubility coefficients for xenon are found for lipids and hemoglobin, which implicates that the lipid content of adipose tissue and the hematocrit content of the blood perfusing it will be the major determinants for the adipose tissue-blood partition coefficient $(3,6)$. In the present study a correction was made for hematocrit values (see methods). Although the variation in lipid content of human subcutaneous adipose tissue reported by Martinsson et al (20) would only slightly affect the partition coefficient, Bülow et al (5) reported a much higher variation in lipid content. In both studies, however, exact data on the percentage adiposity of the subjects are not given. The relationship between the \% adiposity and the lipid content of total adipose tissue in the study of Martin et al (19) has, as far as we aware of, not previously been reported. Since subcutaneous adipose tissue comprises approximately two thirds of total adipose tissue (7), it may be assumed that the magnitude and the variation of the lipid content of total adipose tissue gives a reasonable representation of the lipid content in subcutaneous adipose tissue. Moreover, the range of the adipose tissue lipid fraction we found seems comparable to the range reported by Bülow et al (5) for subcutaneous tissue on the abdomen and thigh.

\section{Straln gauge plethysmography}

A major criticism when measuring with strain gauge venous occlusion plethysmography is that the measured blood flow at a single forearm segment may not be representative of total forearm blood flow (16). Indeed, this may be valid since muscle blood flow and the contribution of the different forearm tissues to total blood flow may vary along the forearm $(26,27)$. However, comparisons of strain gauge plethysmography with water plethysmography showed slightly lower values with strain gauge plethysmography (10) or a good agreement between both methods $(15,28)$. In addition, in a recent review (29) it was reported that the mean forearm blood flow of 25 plethysmographic forearm studies, 


\section{Chapter 4}

transformed to estimates of the percentage of cardiac output going to the total amount of muscle tissue, amounted $16.4( \pm 1.3) \%$ of cardiac output, whereas the mean percentage in six other studies based on other techniques (dye dilution or clearance rates for various tracers) was $19.1( \pm 2.2) \%$. Thus, it seems that in comparison with other techniques strain gauge plethysmography gives on average a reasonable estimate of forearm blood flow, which implicates that this method (when applied at the greatest forearm circumference) gives a blood low value that is representative for the main part of the forearm.

The resting total blood flow values measured in the present study are slightly lower than data from several other studies, obtained by means of strain gauge plethysmography (29). This may be explained by a higher ambient temperature in those studies than in the present experiment $\left(21-23^{\circ} \mathrm{C}\right)$. The importance of ambient temperature was illustrated in a study of Frayn et al (14), who reported much higher blood flow values at a temperature of 33 than $23^{\circ} \mathrm{C}$. Indeed, our blood flow values are comparable to the values measured in the latter study at $23^{\circ} \mathrm{C}$ ambient.

\section{Tissue volumes}

The determination of forearm composition was limited to volumes of subcutaneous fat, muscle and bone. By means of MRI (TI-weighted image) these tissue volumes could be easily differentiated. Since it was hard to differentiate between muscle and tendinous structures, the relationship between the absolute amount of muscle and tendons was assumed to be constant, which seems justified due to their functional relationship. Further, in our MRI-images it was not possible to obtain a clear image of the relatively thin human skin as found on the arm. Therefore, the relationship between the area of forearm skin and the total area of muscle and subcutaneous fat was assumed to be constant and was assumed to be as assessed with carcass analysis by Cooper and coworkers (9).

\section{Contribution forearm adipose tissue blood flow to total blood flow}

Taken the above discussion into account, it can be concluded that the contribution of ATBF to TBF is relatively small and amounts on average $15 \%$. The mean value we used for the subcutaneous adipose-blood partition coefficient is lower than the previously reported partition coefficient of $8 \mathrm{ml} / \mathrm{g}(5)$. Assuming an average partition coefficient of 8 $\mathrm{ml} / \mathrm{g}$ would make the mean contribution of ATBF to TBF only slightly higher (18\%).

The contribution of ATBF to TBF was significantly higher in lean than obese subjects (18 vs $11 \%$, respectively, $\mathrm{P}<0.05$ ). In addition, there was a tendency towards a negative relationship between $\%$ body fat and the \% contribution of ATBF to TBF during rest $(\mathrm{P}=0.09)$, which indicates that the contribution of $\mathrm{ATBF}$ may be $20 \%$ in very lean subjects. The contribution of ATBF to TBF was significantly lower during ISO-infusion than during rest in lean subjects ( 10 vs $18 \%$ ), whereas in the obese this value was similar during rest and during $1 S O$ (rest: $11 \%, 1 S O: 13 \%$ ). The above data indicate that although the overall contribution of $A T B F$ to TBF is relatively small, this contribution may vary between groups with a varying degree of adiposity. In addition, the significant lower 
percentage contribution of ATBF to TBF during ISO than during rest in lean subjects may indicate that in intervention studies where muscle blood flow is stimulated the measurements of forearm blood flow in the intervention period may not be comparable to the baseline measurement.

\section{Skin blood flow}

The circulation of skin is very sensitive to changes in environmental temperature. In our study ambient temperature was strictly controlled between $21-23^{\circ} \mathrm{C}$. Sejrsen et al (25) reported a resting skin blood flow of $5 \mathrm{ml} / 100 \mathrm{ml} \cdot \mathrm{min}$ at a comparable ambient temperature as in the present study. However, since in our study the hand circulation was occluded during the skin blood flow measurements and since the hand circulation is largely through skin (22) it may be that actual skin blood flow was lower in the present study. Assuming a resting skin blood flow of in the range of $2.5-5 \mathrm{ml} / 100 \mathrm{ml}$. min would give a contribution of SBF and ATBF to TBF ranging from 35-50\%. This calculation indicates that in normal weight volunteers nonmuscular blood flow may account for an important part of total blood flow in the resting state. Relative blood flow values, as assessed by laser doppler flowmetry, were similar during rest and ISO-infusion, which indicates that as result of ISO-infusion there were no big changes in skin blood flow. However, the laser doppler method measures the flow in the skin capillary vessels and probably also the flow in non capillary vessels (13), which implicates that changes in the diameter of the underlying subpapillary vessels may have biased the skin flow measurements. Since skin vessels mainly contain $\alpha$-adrenoceptors (1) a considerable change in contraction state of skin vessels as result of isoprenaline infusion (mainly Badrenergic stimulation, 2) seems not very likely. In addition, an effect of other neural mechanisms on the contraction state of skin vessels at the end of a 30 min period of ISOinfusion seems unlikely since intravenous ISO-infusion ( $\left.100 \mathrm{ng} / \mathrm{kg}_{\mathrm{BW}} \mathrm{min}\right)$ has been reported to cause a slight, transient vasodilatation of skin vessels which returned to resting values within $10 \mathrm{~min}$ after the initiation of the infusion (8). Implicit a similar skin blood flow during rest and ISO in lean men, it can be calculated that the contribution of $\mathrm{ATBF}$ and SBF to TBF during ISO is half of the contribution during rest. Moreover, even if there was a slight increase in SBF during ISO (i.e. $2 \mathrm{ml} / 100 \mathrm{ml}$.min) that was not detected by the laser doppler method, this would still give a considerably lower contribution of nonmuscular blood flow to TBF during ISO than during rest (at a resting SBF of $5 \mathrm{ml} / 100 \mathrm{ml} . \mathrm{min}$ : rest: $50 \%$, ISO:30\%).

Since the relative units for skin blood flow were similar in lean and obese subjects, it seems reasonable to assume that there were no large differences in absolute resting skin blood flow between both groups. However, since we cannot exclude slight differences in resting blood flow due to differences in the contraction state of skin vessels at the present ambient temperature, it seems not justified to compare the percentage contribution of ATBF and SBF to TBF in lean and obese subjects. Assuming no or only a slight difference in SBF during rest and ISO in obese subjects (as suggested by the laser doppler recordings), the contribution of SBF and ATBF to TBF seems to be comparable in both conditions. 


\section{Chapter 4}

In conclusion, the overall contribution of ATBF to TBF seems to be relatively small, but this contribution may vary between groups with a varying degree of adiposity. The lower o contribution of ATBF to TBF during ISO than during rest in lean males may indicate that in intervention studies where muscle blood flow is stimulated the measurement of forearm blood flow in the intervention period may not be comparable to the baseline measurement. The above calculations on the contribution of SBF and ATBF to TBF indicate that the contribution of nonmuscular flow to TBF may be of considerable importance and may amount $35-50 \%$ of TBF during rest in nomal weight volunteers.

\section{References}

1. Ahlquist R.D. A study of the adrenotropic receptors. Am. J. Physiol. 153: 586-600, 1948.

2. Blaak E.E. ,M.A. van Baak, G.J. Kemerink, M.T.W. Pakbiers, G.A.K. Heidendal, and W.H.M. Saris. Effect of beta-adrenergic stimulation on forearm skeletal muscle metabolism. Submitted to Am. J. Physiol. (Endocrinol. Metab.)

3. Bullow J. Adipose ussue blood flow during exercise. Dan. Med. Bull. 30 (2): 85-100, 1983.

4. Bülow J., A. Astrup, N.J. Christensen, and J. Kastrup. Blood flow in skin, subcutaneous adipose tissue and skeletal muscle in the forearm of normal man during an oral glucose load. Acta Physiol. Scand. 130: 657-661, 1987.

5. Bullow J., R. Jelnes, A. Astrup. J. Madsen, and P. Vilmann. Tissue/blood partition coefficient for xenon in various adipose tissue depots in man. Scand J. Lab. Invest. 47: 1-3, 1987.

6. Chen R.Y., F. Fan, S. Kim, K. Jan, S. Usami, and S. Chien. Tissue-blood partition coefficient for xenon: temperature and hematocrit dependence. J. Appl. Physiol. : Respirat. Environ. Exercise Physiol. 49 (2): 178-183, 1980 .

7. Chien S., M.T. Peng and K.T. Chen. Longitudinal studies on adipose tissue and üts distribution in human subjects. J. Appl. Physiol. 39: 825-830, 1975.

8. Cobbald A.F., J. Ginsburg, and A. Paton. Circulatory, respiratory and metabolic responses to isopropylnoradrenaline in man. J. Physiol. 151: 539-550, 1960.

9. Cooper K.E., O.G. Edholm, and R.F. Mouram. The blood flow in skin and muscle in human forearm. J. Physiol, 128: 258-267, 1955.

10. Clarke R.S.J., and R.F. Hellon. Venous collection in forearm and hand measured by strain gauge and volume plethysmography. Clin. Sci. 16: 103-117, 1957

11. Edholm O.G., R.H. Fox, and R.K. Macpherson. The effect of body heating on the circulation in skin and muscle. J. Physiol. 134: 612-619, 1956.

12. Edholm O.G., 5. Howarth, and J. McMichacl. Studies on peripheral circulation in osteitis deformans. Clin. Sci. 5: 249-260, 1945 .

13. Engelhart M., L.J. Peterson, and J.K. Kristensen. The local regulation of blood flow evaluated simultaneously by 133-xenon washout and laser doppler flowmetry. J. Invest. Dermatol. 91: 451-453, 1988.

14. Frayn K.N., P.L. Whyte, H.A. Benson, D.J. Earl, and H.A.Smith. Changes in forearm blood flow at elevated ambient temperature and their role in the apparent impairment of glucose tolerance. Clin. Sci. 76: $323-328,1989$.

15. Hyman C., and T. Winsor. The application of the segmental plethysmography to the measurement of 
blood flow through the limbs of human beings. Am. J. Cardiol. 6:667-671, 1960.

16. Jorfeldt L., and H. Rutberg. Comparison of dye-dilution and plethysmographic blood flow measurements: an evaluation of the inlluence of invasive techniques on blood flow and on arterial and femoral venous substrate variables in man. Clin. Sci. 79:81-87, 1990.

17. Kontos H.A., D.W. Richardson, and J.L. Patterson. Blood flow and metabolism of forearm muscle in man at rest and during sustained contraction. Am. J. Physiol. 21 1.(4): 869-876, 1966.

18 Larsen O.A., N.A. Lassen, and F. Quaade. Blood flow through human adipose tissue determined with radioactive xenon. Acta Physiol. Scand 66 (3): 337-345, 1966.

19. Martin A.D., D.T. Drinkwater, and J.P. Clarys. Adipose tissue density, estimated lipid fraction and wholle body adiposity in 6 male cadavars. Int. J. Sports Med. 25 (5, Suppl): \$5, 1993

20. Martinsson A. On the composition of human adipose tissue. Acta Med. Scand. 182: 795-803, 1967.

21. Öberg P.A. Laser Doppler Flowmetry. Biomed. Eng. 18 (2); 125-163, 1990.

22. Roddie I.C. Circulation to skin and adipose tissue. In: Handbook of Physiology. Am. Physiol. Soc, section 2, The cardiovascular system. ed. J.T. Shepherd and F.M. Abboud. Waverly Press Inc., Baltúmore, Maryland, 1983.

23. Simonsen L., J. Bulow, A. Astrup, J. Madsen, and N.J. Christensen. Diet-induced changes in subcutaneous adipose tissue blood flow in man: effect of B-adrenoceptor stimulation. Acta Physiol. Scand. 139: 341-346, 1990 .

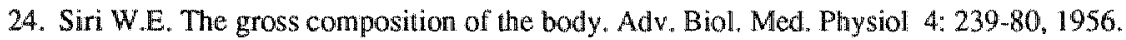

25. Sejrsen P. Blood flow in cutaneous tissue in man studied by washout of radioactive xenon. Circulation Res. XXV: $215-229,1969$.

26 Terjung R.L., and B.M. Engbretson. Blood flow to different rat skeletal muscle fiber type sections during isometric contractions in situ. Med. Sci. Sports Exerc. 20(5): S124-S130, 1988

27. Weber F., M. Anlauf, and M. Serdarevic. Noninvasive, quantitative determination of muscle blood flow by a combination of venous-occlusion plethysmography and computed tomography. Basic Res. Cardiol. 83: $327-341,1988$.

28. Whitney R.J. The measurement of volume changes in human limbs. J. Physiol. 121: 1-27, 1953.

29. Williams L.R., and R.W. Legget. Reference values for resting blood flow to organs of man. Clin Phys Physiol Meas 10 (3): 187-217, 1989.

30. Yeh S.Y, and R.E. Peterson. Solubility of krypton and xenon in blood, protein solutions, and tissue homogenates. J. Appl. Physiol. 20(5): 1041.1047, 1965.

31. Zelis R., D.T. Mason, and E. Braunwald. Partition of blood flow to the cutaneous and muscular beds of the forearm at rest and during leg exercise in normal subjects and in pationts with heart failure. Circulation Res XXIV: 799-806, 1969. 



\section{CHAPTER 5}

\section{Effect of beta-adrenergic stimulation on forearm skeletal muscle metabolism in man}

E.E.Blaak, M.A. van Baak, G.J. Kemerink*, M.T.W. Pakbiers*, G.A.K. Heidendal*, and W.H.M. Saris.

Department of Human Biology, Uniwersity of Limburg, Mastricht and * Department of Nuclear Medicine, University Hospital Maastricht, the Netherlands.

Submitted to Am. J. Physiol. (Endocrimol. Metab.)

\section{Abstract}

Forearm skeletal muscle metabolism was investigated in 9 healthy male lean volunteers (means $\pm S E M$; age: $25.2 \pm 1.7 \mathrm{y}$ ) after intravenous infusion of the $B_{1}{ }^{-}$, and $B_{2}$-agonist isoprenaline (ISO) with and without simultaneous intravenous infusion of the $\mathbb{B}_{1}$-blocker atenolol ISO+AT. After 30 min of supine rest, $\mathbb{S S O}$ (dose $16.5 \pm 1.2 \mathrm{ng} / \mathrm{kg}_{\mathrm{BW}} \cdot \mathrm{min}$ ) or ISO+AT infusion (bolus AT: $0.07 \mathrm{mg} / \mathrm{kg}_{\mathrm{B}} \mathrm{w}^{\cdot \mathrm{h}}$, dose: $0.1 \mathrm{mg} / \mathrm{kg}_{\mathrm{B} \mathrm{w}^{*}}$ ), skeletal muscle blood flow (SMBF) and arterialized-deep venous concentration differences of various metabolites across forearm were determined. The changes in SMBF were estimated from forearm total- (TBF, venous occlusion plethysmography), skin- (SBF, laser doppler) and fat tissue blood flow (ATBF, ${ }^{133}$ xenon-washout).

There was a rise in resting energy expenditure (EE) of $16 \%$ with $I S O$ and $8 \%$ with ISO+AT (ANOVA: P<0.001). Whole blood glucose, pyruvate, lactate and glutamine did not change, while alanine and glutamate decreased with $I S O$ or $1 S O+\mathrm{AT}^{*}(\mathrm{P}<0.001)$. With ISO, there was a threefold rise in plasma non-esterified fatty acids (NEFA, $P<0.001)$ and a twofold rise in plasma glycerol $(P<0.001)$ and whole blood 3-hydroxybutyrate $(\mathrm{BOH}, \mathrm{P}<0.001)$, while with $\mathrm{ISO}+\mathrm{AT}$ these values returned to baseline. TBF increased almost threefold with ISO and was elevated (above control) with ISO+AT (ANOVA:P<0.01). These changes were mainly caused by SMBF (Control vs ISO vs $I S O+A T: 1.5 \pm 0.6$ vs $5.8 \pm 1.6 \mathrm{vs} 3.2 \pm 1.2 \mathrm{ml} / 100 \mathrm{ml} \mathrm{min}, \mathrm{P}<0.01$ ). There was a significant increase in oxygen consumption of skeletal muscle (Control vs ISO vs ISO+AT: $4.4 \pm 1.1$ vs $10.1 \pm 2.0$ vs $6.6 \pm 1.5 \mu \mathrm{mol} / 100 \mathrm{ml} \cdot \mathrm{min}, \mathrm{P}<0.05$ ). With $1 \mathrm{SO}$, this was accompanied by an increased uptake of NEFA $(-27 \pm 23 \mathrm{vs} 228 \pm 80 \mathrm{nmol} / 100 \mathrm{ml} \mathrm{min}$, $\mathrm{P}<0.05)$ and $\mathrm{BOH}(\mathrm{P}<0.05)$ and with $\mathrm{ISO}+\mathrm{AT}$, lactate release increased (Control vs ISO+AT: $-22 \pm 21$ vs $-159 \pm 46 \mathrm{nmol} / 100 \mathrm{ml} \cdot \mathrm{min}, \mathrm{P}=0.05$ ). In conclusion, an important part of the $B_{1}$ - and $B_{2}$-mediated thermogenesis (with $1 S O$ ) is located in skeletal muscle, which may be explained by an increased fatty acid oxidation (with $B_{1}$ - and $B_{2}$ adrenergic stimulation). With ISO+AT (mainly $B_{2}$ ), the increased lactate release, which may be 


\section{Chapter 5}

accompanied by an increased glycogen breakdown and glucose oxidation, suggests that skeletal muscle maly also be of importance in the $B_{2}$-adrenergically mediated thermogenesis.

\section{Introduction}

The sympathetic nervous system plays a role in energy metabolism. Several studies have shown that infusion of the naturally occurring catecholamines increases energy expenditure $(19,35)$. Also, there are indications in literature that the facultative component of the diet-induced thermogenesis is mediated by an increased sympathetic tone (3). In a previous study we investigated the adrenoceptor populations involved in the sympathetically mediated thermogenesis. The results showed that in healthy lean male volunteers $B_{1}$ - and $B_{2}$ adrenoceptors are involved in the sympathetically mediated energy expenditure, while $\alpha_{1}-, \alpha_{2}$-and probably $\beta_{3}$-adrenoceptor populations do not play a role of importance (5).

It is still uncertain which processes are responsible for the sympathetically mediated thermogenesis and in which tissues these processes are localized. Catecholamines can influence hepatic and skeletal muscle glucose turnover $(28,29)$. Also, lipolysis in adipose tissue increases as result of B-adrenergic stimulation (18) and this may be indirectly related to the increased whole body energy expenditure (17). With regard to protein metabolism, a diminished or unchanged protein turnover have been reported as result of increasing levels of catecholamines (12,24). Furthermore, catecholamines cause a decrease in plasma $\mathrm{K}^{+}$concentration, which might be due to an increased activity of the $\mathrm{Na}^{+} \mathrm{K}^{+}$pump (2). The contribution of the different processes to the increased energy expenditure still has to be determined.

In rats, the main site for the sympathetically mediated thermogenesis is brown adipose tissue (BAT). In man, the role of BAT is probably minor, whereas skeletal muscle seems to be more important. Astrup et al (2) found as result of ephedrine stimulation an increased whole body oxygen consumption and suggested that at least $50 \%$ of this increase may be located in skeletal muscle.

The present study was intended to investigate forearm skeletal muscle oxygen consumption and metabolism in man after intravenous infusion of the $B_{1}$-and $B_{2}$-agonist isoprenaline (ISO) with and without simultaneous infusion of the $B_{1}$-b (AT). Changes in forearm skeletall muscle blood flow were estimated from the total forearm, skin and subcutaneous adipose tissue blood flow. Responses to ISO have usually been related to standardized doses. However, interindividual pharmacokinetic variation may lead to important differences in plasma concentrations attained. Martinsson ef al (26) reported that measurement of plasma concentrations of ISO improved the accuracy of the ISO-infusion test. Therefore, plasma concentrations of ISO were determined during infusion of standardized doses of ISO in each subject. The infusion dose of ISO used to stimulate forearm muscle metabolism was the dose that increased plasma $15 O$ concentration to a fixed value. 


\section{Subjects and methods}

In this study, 9 healthy male volunteers participated with a mean age of $25.2 \pm 1.7 \mathrm{y}$ and a mean BMI of $23.0 \pm 1.5 \mathrm{~kg} / \mathrm{m}^{2}$. The study protocol was approved by the Ethics committee of the University of Limburg and all volunteers were asked for written consent. The experiments were performed after an overnight fast and room temperature was kept between $21-23^{\circ} \mathrm{C}$. The study protocol consisted of two experiments with three weeks in between. First, a pre-study was performed to determine the plasma concentrations of the $B_{1}$ - and $B_{2}$-agonist isoprenaline (ISO) after intravenous infusion of increasing standardized doses (ISO-infusion test). In the second experiment, forearm skeletal muscle metabolism was investigated after intravenous ISO-infusion with and without simultaneous infusion of the $B_{1}$-blocker atenolol (AT).

\section{ISO-Infusion test}

In this experiment, isoprenaline was intravenously infused in increasing doses of 5,10 , 20 and $40 \mathrm{ng} / \mathrm{kg}_{\mathrm{BW}}$. min, each dose for $15 \mathrm{~min}$. The dose in the text is related to ISO sulphate, $69 \%$ of which corresponds to ISO free base. At the end of each infusion period, a venous blood sample was taken with heparinized syringes and was put into a glutathione containing tube in ice. The sample was immediately centrifuged at $3000 \mathrm{rpm}$ at $4{ }^{\circ} \mathrm{C}$ and stored at $-50^{\circ} \mathrm{C}$. In the plasma samples concentrations of isoprenaline, epinephrine and norepinephrine were determined by high performance liquid chromatography (32). During the experiments, heart rate was recorded continuously. When heart rate had risen 30 beats/min the infusion was stopped.

\section{Forearm muscle experiment}

\section{Design}

Forearm skeletal muscle metabolism was investigated after intravenous infusion of the $B_{1}$ - and $B_{2}$-agonist ISO with and without simultaneous infusion of the $B_{1}$-blocker $A T$. After $30 \mathrm{~min}$ supine rest (control), skeletal muscle blood flow and arterio-venous concentration differences of various metabolites across muscle were determined (see under clinical and biochemical methods). After the control period, the ISO-infusion was started for 60 min with AT added on to the last 30 min. The abovementioned measurements were repeated after 30 min ISO-infusion and after 30 min of simultaneous ISO and AT infusion. For each subject, the dose of ISO (per $\mathrm{kg}_{\text {Body weight }}$ ) corresponding to a plasma concentration of $165 \mathrm{pg} / \mathrm{ml}$ was infused, known to increase energy expenditure by about $15 \%$ (5). The mean infusion rate of ISO was $16 \mathrm{ng} / \mathrm{kg}_{\mathrm{BW}}$. min (range $\left.13-20 \mathrm{ng} / \mathrm{kg}_{\mathrm{BW}} \cdot \mathrm{min}\right)$. Before the simultaneous infusion of ISO and $\mathrm{AT}(0.1$ $\left.\mathrm{mg} / \mathrm{kg}_{\mathrm{BW}} \cdot \mathrm{h}\right)$ started, a priming dose of AT $\left(0.07 \mathrm{mg} / \mathrm{kg}_{\mathrm{BW}}\right)$ was administered within five minutes. The changes in forearm skeletal muscle blood flow were determined by measuring total forearm-, skin- and subcutaneous adipose tissue- blood flow. 


\section{Clinical methods}

Before the start of the experiment, three canulas were inserted. For sampling of arterialized blood, a canula was inserted into a superficial dorsal hand vein. For obtaining arterialized blood the hand was placed into a heated box at $60^{\circ} \mathrm{C}$. The hand was heated for at least 30 min before the first (baseline) blood sample was taken. In the same arm, a canula was inserted in a forearm antecubital vein for the infusion of ISO and AT. In the contralateral arm, a catheter was inserted in retrograde direction of an antecubital vein of the forearm for sampling of deep venous blood.

Forearm blood flow was measured by wenous occlusion plethysmography (41) with a mercury strain gauge (Periflow 0699, Janssen Scientific Instruments, Belgium). The strain gauge was placed around the forearm, which contained the deep venous catheter. Because this method measures percent change in volume, the blood flow is related to 100 $\mathrm{ml}$ of forearm tissue. Prior to measuring forearm blood flow, the hand circulation was occluded by inflating a pediatric sphygnomanometer cuff, placed around the wrist, to a pressure of $200 \mathrm{~mm} \mathrm{Hg}$. In this way forearm blood flow could be assessed without interference from the hand circulation. The venous occlusion cuff, placed around the upper arm, was automatically inflated (and deflated) to a pressure of $40 \mathrm{~mm} \mathrm{Hg}$. Forearm blood flow was recorded approximately every four seconds (depending on heart rate) for $1.5 \mathrm{~min}$ and the consecutive (stable) values during the last min were averaged.

Subcutaneous adipose tissue blood flow was measured on the dorsal side of the forearm about $10 \mathrm{~cm}$ proximal to the wrist joint by the ${ }^{133}$ xenon washout method (21). A dose of ${ }^{133}$ xenon was dissolved in saline (dose: $5.5 \mathrm{MBq}(150 \mu \mathrm{Ci})$ in $\left.0.1-0.15 \mathrm{ml}\right)$ and was subcutaneously injected with a very fine needle $(0.5 \times 16 \mathrm{~mm})$. The arm was placed in a fixed position close to a large field gamma camera (Technicare large field $438 \mathrm{HR}$, General Electrics, U trecht). The registration of the ${ }^{133}$ xenon disappearance was started 45 min after injection to be sure that the washout was monoexponential. From the regression of count activity against time, the disappearance constant of ${ }^{133}$ xenon over the last 20 min of each infusion period was determined in order to calculate fat tissue blood flow.

Before the measurement of total forearm blood flow, relative changes in skin blood flow were determined by the laser doppler technique (Periflux PF3, Perimed, Sweden) with an occluded hand circulation. The probe was placed on the ventral side of the forearm near the wrist joint. This method measures the flux of red cells in skin capillary vessels and probably also the flow in the underlying non capillary vessels (14) and is therefore only suitable to measure changes in blood flow, when there is no change in diameter of the skin blood vessels. A major change in skin vessel diameter can be excluded since intravenous isoprenaline infusion ( $100 \mathrm{ng} / \mathrm{kg} \cdot \mathrm{min}$ ) has been reported to cause a weak but transient vasodilatation of skin vessels, which returned to basal levels within 10 minutes after the initiation of the infusion (9).

During the entire experiment, whole body energy expenditure was determined by an open circuit ventilated hood system. Energy expenditure was calculated according the formula of Weir (40). 


\section{Biochemical methods}

Blood samples were taken simultaneously from the hand and the deep forearm wein after the blood flow measurement, while the hand circulation was still occluded. Triplicate samples of arterialized and deep venous blood were immediately deproteinized with ice cold sulphosalicylic acid (SSA, 3.5\% $\mathrm{w} / \mathrm{v}$ ) in a ratio of $1: 2$, respectively. The samples were centrifuged at $3000 \mathrm{rpm}$ at $4{ }^{\circ} \mathrm{C}$ In the supernatant concentrations of glucose, pyruvate, lactate, $B$-hydroxybutyrate ( $\mathrm{BOH}$ ), glutamate, alanine and glutamine were determined with enzymatic assays automated on the Cobas BIO centrifugal analyzer at $355 \mathrm{~mm}$ (13). All these assays were carried out using $0.2 \mathrm{M}$ tris-hydrazine buffer, $\mathrm{pH} 9.2$, except for pyruvate which was done with $1 \mathrm{M}$ phosphate buffer, pH 7. Plasma nonesterified fatty acids (NEFA) and glycerol were measured using standard enzymatic techniques automated on the Cobas Bio centrifugal analyzer. Plasma insulin was measured by a specific radio immunoassay.

The concentration of hemoglobin (Hb) in blood and the percentage saturation of $\mathrm{Hb}$ with $\mathrm{O}_{2}$ were measured with a hemoximeter (OSM2 hemoximeter, VA Howe Radiometer, Copenhagen). The hematocrit was determined using a microcapillary system.

\section{Callculations and Statlstics}

For the estimation of forearm skeletal muscle blood flow in the different periods, several assumptions were made:

- The forearm is of the composition described by Cooper al (11)

-The resting skin blood flow is $5 \mathrm{ml} / 100 \mathrm{ml} \cdot \mathrm{min}(30)$

-The tissue-blood partition coefficient of xenon is constant throughout the experiment and is $8 \mathrm{ml} / \mathrm{g}$ in normal weight subjects (7).

-For the conversion of the xenon blood flow values from $100 \mathrm{~g}$ to $100 \mathrm{ml}$ fat tissue, the density of adipose tissue was assumed to be $0.9 \mathrm{~g} / \mathrm{ml} \mathrm{(11)}$.

The exchange of metabolites across muscle (nmol/100 ml min) was calculated by multiplying the arterialized-venous difference of metabolites (umol/l) by muscle blood flow ( $\mathrm{mL} / 100 \mathrm{ml}$ muscle tissue.min). The exchange of $\mathrm{NEF}$ and glycerol was calculated by multiplying their plasma A-V difference by plasma flow (total blood flow (1-HV/100)). A positive flux indicates uptake. Arterialized blood has been validated against arterial blood for the determination of most metabolites (13), but it underestimates arterial $\mathrm{O}_{2}$ saturation of hemoglobin. Therefore, for calculating the oxygen consumption of skeletal muscle, the $\mathrm{O}_{2}$-saturation of hemoglobin in arteriall blood was assumed to be $97 \%$.

Data are represented as means \pm SEM. Statistical analysis was done with repeated measurements ANOVA. Post hoc testing was done with a Student's paired t-test and the P-values of the post-hoc comparisons were corrected according to Bonferroni's inequalities. 


\section{Chapter 5}

\section{Results}

\section{ISO-infusion test}

During the ISO infusions, all subjects had concentration-related increases in heart rate, plasma ISO and plasma norepinephrine (NE, table 1). The antecubital venous plasma concentration of ISO of the contralateral arm increased linearly as a function of the ISOinfusion rate $(r=0.99, \mathrm{P}<0.001)$. Furthermore, there was a small but significant increase in plasma NE (ANOVA: $\mathrm{P}<0.001$ ) and plasma epinephrine $(\mathrm{E})$ showed a doseindependent decrease during the infusions compared to baseline $(\mathrm{P}<0.01$, table 1$)$.

Table 1. Changes in heart rate (HR), plasma isoprenaline (ISO), norepinephrine (NE) and epinephrine (E) as result of infusion of the $B_{1}, B_{2}$-agonist $1 S O$.

\begin{tabular}{lrrrr}
$\begin{array}{l}\text { Infusion rate } \\
\left(\mathrm{ng} / \mathrm{kg}_{\mathrm{BW}} \cdot \mathrm{min}\right)\end{array}$ & $\begin{array}{r}\mathrm{HR} \\
\text { (beats/min) }\end{array}$ & $\begin{array}{r}\text { ISO } \\
(\mathrm{pg} / \mathrm{ml})\end{array}$ & $\begin{array}{r}\mathrm{NE} \\
(\mathrm{pg} / \mathrm{ml})\end{array}$ & $\begin{array}{r}\mathrm{E} \\
(\mathrm{pg} / \mathrm{ml})\end{array}$ \\
\hline 0 & $62 \pm 2$ & 0 & $176 \pm 16$ & $24 \pm 5$ \\
5 & $67 \pm 2$ & $62 \pm 5$ & $217 \pm 30$ & $15 \pm 4$ \\
10 & $72 \pm 3$ & $106 \pm 8$ & $226 \pm 29$ & $16 \pm 5$ \\
20 & $82 \pm 3$ & $195 \pm 34$ & $265 \pm 28$ & $16 \pm 4$ \\
40 & $97 \pm 6$ & $390 \pm 28$ & $287 \pm 35$ & $16 \pm 4$ \\
& $* *$ & & $*$ & $*$ \\
\hline
\end{tabular}

Means \pm SEM; n=9; ANOVA: * $<<0.01 * * 0<0.001$.

\section{Forearm muscle experiment}

\section{Whole body energy melabolism}

For whole body energy expenditure, after $10 \mathrm{~min}$ a steady state was reached and therefore the mean of the last 20 min of both infusion periods was taken as representative for the administered dose. There was a significant increase in whole body resting energy expenditure (EE) of $16 \%$ with ISO (Control vs ISO: $5.28 \pm 0.13$ vs $6.14 \pm 0.17 \mathrm{~kJ} / \mathrm{min}$, ANOVA and Bonferroni: $\mathrm{P}<0.001$, fig 1) and of $8 \%$ with ISO+AT (Control vs ISO+AT: $5.28 \pm 0.13$ vs $5.70 \pm 0.14 \mathrm{~kJ} / \mathrm{min}$, ANOVA and Bonferroni: $\mathrm{P}<0.001$, fig 1).

The respiratory exchange ratio (RER) reached a steady state after 20 min after a rapid initial increase at the start of infusion, as described before (5). There was a slight decrease in steady state values of RER with ISO infusion (from $0.83 \pm 0.01$ to $0.81 \pm 0.03$, $\mathrm{P}<0.01$ ), whereas with $\mathrm{SSO}+\mathrm{AT}$ this value did not change significantly.

Heart rate (HR) increased with ISO and was still increased above control with ISO+AT 
(control: $57.0 \pm 1.8$ vs ISO: $75.8 \pm 2.9$ vs ISO+AT: $64.4 \pm 1.7$, ANOVA: $\mathrm{P}<0.001$ )
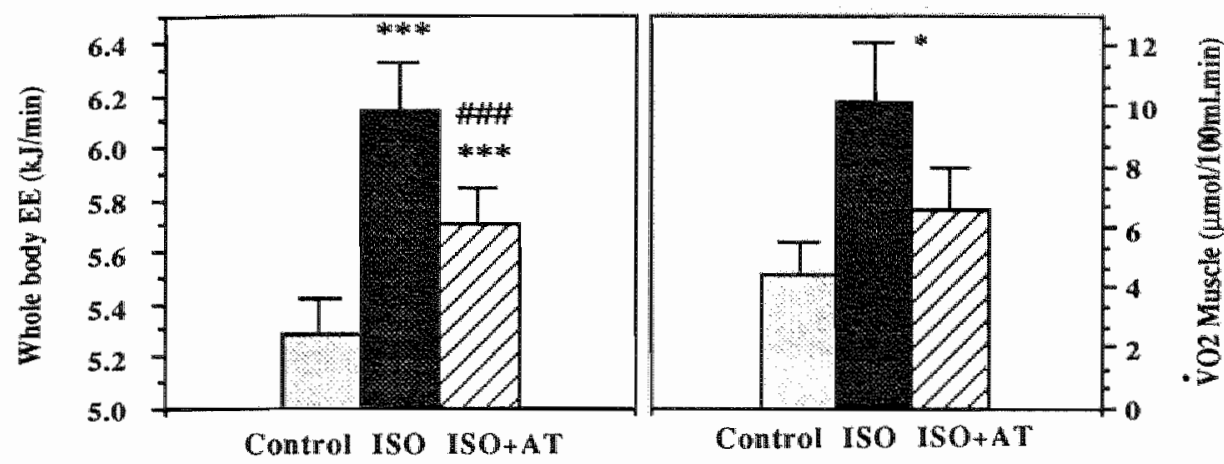

Fig 1. Whole body energy expenditure (EE) and skeletal muscle oxygen consumption ( $\mathrm{VO}_{2}$ Muscle) with infusion of the $B_{1}-B_{2}$-agonist isoprenaline (ISO) with and without the $B_{1}$-blocker atenolol (AT). $n=9$. Means \pm SEM; paired t-test (Bonferroni): Control vs ISO, ISO+AT: *P<0.05***P<0.001; ISO vs ISO + AT: HA 40.001 .

\section{Intermediary metabolites}

Table 2 indicates the changes in the arterialized concentrations of intermediary metabolites. There were no significant changes in circulating concentrations of glucose, pyruwate and lactate. The concentration of alanine decreased with ISO and even more with ISO + AT administration. The concentration of glutamate decreased to the same extent with ISO and ISO + AT infusion, whereas whole blood glutamine did not change. There was a threefold increase in plasma concentration of NEFA with ISO and a return to baseline values with ISO +AT infusion. Furthermore, plasma glycerol and whole blood $\mathrm{BOH}$ increased twofold with ISO and decreased again with ISO+AT. Plasma insulin increased twofold with ISO and was still significantly higher than control with ISO +AT.

\section{Skeletal muscle metabolism}

The oxygen saturation of hemoglobin in arterialized blood was $95.7 \pm 0.5 \%$ and did not change significantly with ISO and ISO+AT. For calculating the oxygen consumption of skeletal muscle, the $\mathrm{O}_{2}$-saturation of hemoglobin in arterial blood was assumed to be 97\%. Skeletal muscle oxygen consumption increased with ISO (ANOVA: $\mathrm{P}<0,05$, Bonferroni: $\mathrm{P}<0.05$, fig 1) and was not significantly elevated above control with ISO+AT,

With ISO, there was an almost threefold increase in total forearm blood flow (TBF, $\mathrm{P}<0.01$ ), which returns to values slightly above control with ISO+AT (fig 2). Skin blood flow (SBF) did not change with ISO or ISO+AT, whereas subcutaneous adipose tissue flow (ATBF) showed a tendency to increase $(\mathrm{P}=0.10)$. The changes in TBF were mainly 
Chapter 5

determined by changes in skeletal muscle blood flow (SMBF, fig 2)

Table 2. Changes in arterialized concentrations of metabolites as result of infusion of the $B_{1}{ }^{-}$and $B_{2}$ agonist isoprenaline (ISO) with and without simultaneous infusion of the $B_{1}$-blocker atenolol (AT).

\begin{tabular}{|c|c|c|c|c|}
\hline (tumol/l) & Controll & 150 & $I S O+A T$ & ANOWA \\
\hline pyrnwate & $80 \pm 6$ & $86 \pm 6$ & $88 \pm 5$ & \\
\hline lactate & $596 \pm 35$ & $647 \pm 54$ & $585 \pm 48$ & \\
\hline glucose & $4869 \pm 103$ & $5000 \pm 107$ & $4874 \pm 107$ & \\
\hline NEFA & $412 \pm 45$ & $1249 \pm 118 * *$ & $471 \pm 42$ & 0.001 \\
\hline glycerol & $70 \pm 4$ & $124 \pm 7 * * *$ & $70 \pm 3$ & 0.001 \\
\hline $\mathrm{BOH}$ & $110 \pm 40$ & $217 \pm 71 *$ & $164 \pm 67$ & 0.01 \\
\hline glutamate & $140 \pm 8$ & $114 \pm 7 * *$ & $119 \pm 8 *$ & 0.001 \\
\hline alanine & $282 \pm 16$ & $264 \pm 18 *$ & 249418 & 0.001 \\
\hline glutamine & $551 \pm 17$ & $557 \pm 22$ & $553 \pm 27$ & \\
\hline insulin (mU/) & $7.6 \pm 0.5$ & $14.4 \pm 1.1 * * *$ & $9.6 \pm 0.7 * \# \#$ & 0.001 \\
\hline
\end{tabular}

Means $\pm S E M ; n=9$; Student's paired t-test (Bonferroni): Control vs ISO, ISO +AT: *P<0.05, **P<0.01, *** $\mathrm{P}<001$; ISO vs ISO+AT: \#P<0.05, \#\# $<0.01$, \#\#\#<0.001. P-values of repeated measurements ANOVA are indicated in the right-hand column. NEFA= non-esterified fatty acids, $\mathrm{BOH}=\mathrm{B}$ hydroxybutyrate.

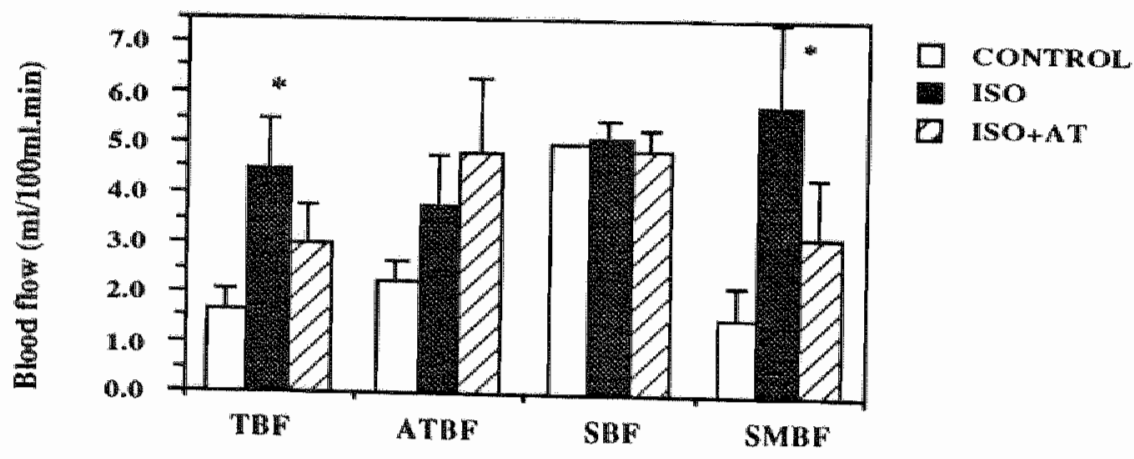

Fig 2. Forearm total blood flow (TBF), adipose tissue blood flow (ATBF), skin blood flow (SBF) and skeletal muscle blood flow (SMBF) with infusion of the $\mathbb{B}_{1}$ - and $\mathbb{B}_{2}$-agonist isoprenaline with and without the $B_{1}$-blocker atenolol (AT). $n=9$, Means \pm SEM; parred t-test (Bonferroni): Control vs ISO: ${ }^{*} P<0.05$. 
Figure 3 shows the fluxes of intermediary metabolites across skeletal muscle. There were no significant changes in glucose and pyruvate flux, whereas with ISO+AT lactate release increased $(\mathrm{P}=0.05)$. With ISO, there was an increased uptake of NEFA $(\mathrm{P}<0.05)$ and $\mathrm{BOH}(\mathrm{P}<0.05)$, which returned to baseline values with ISO+AT. Glycerol flux did not change significantly with ISO or ISO+AT. Furthermore, there were no changes in glutamate, glutamine and alanine flux with ISO or ISO+AT.
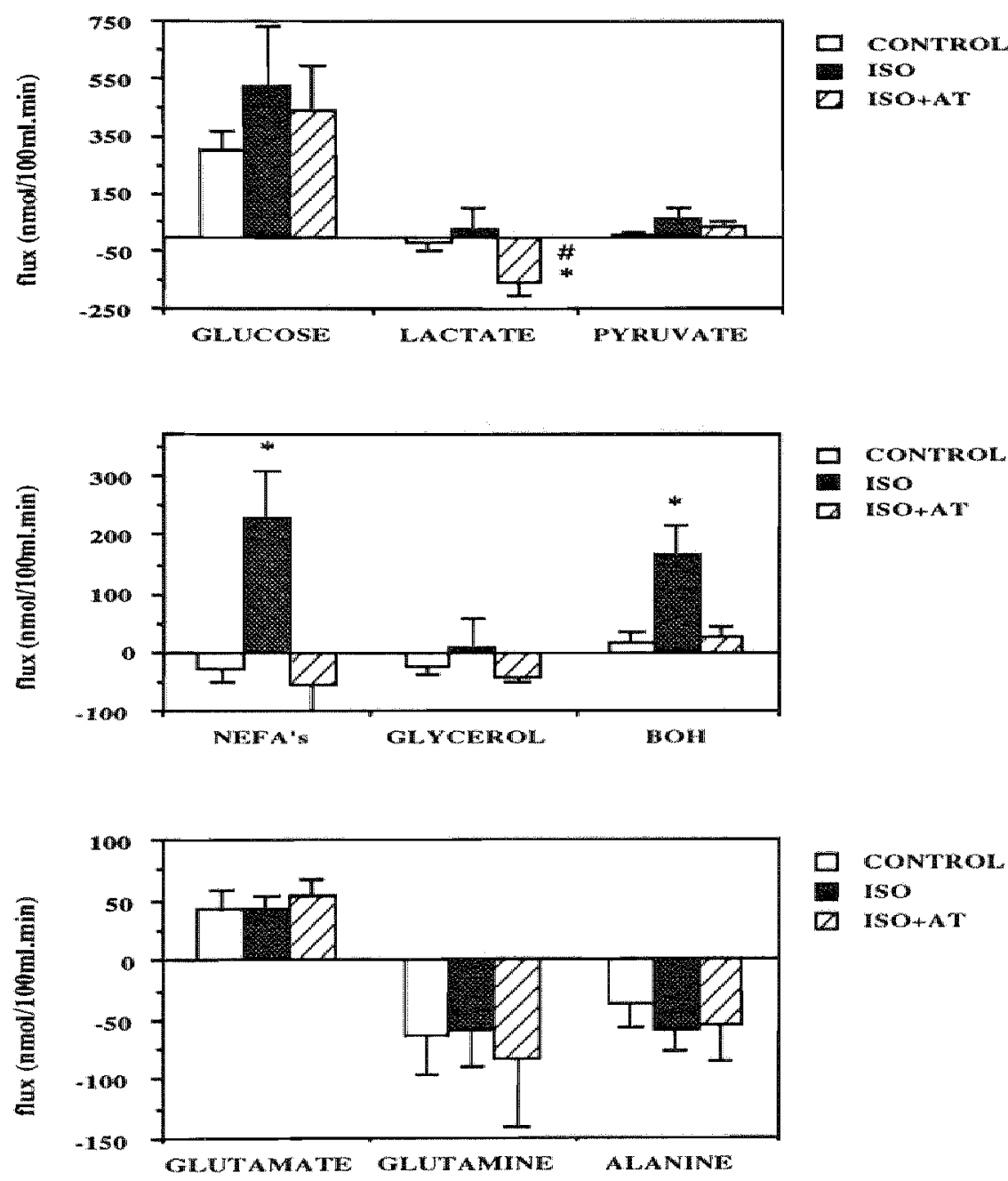

Fig 3. Skeletal muscle substrate fluxes with infusion of the $B_{1}$ - and $B_{2}$-agonist isoprenaline (ISO) with and without the $B_{1}$-blocker atenolol (AT). $n=9$, Means \pm SEM; paired L-test (Bonferromi): Control wS ISO, ISO +AT: *P<0.05, ISO vs ISO +AT: \#P<0.05. NEFA=non-esterified fatly acids, BOH=B-hydroxybutyrate 


\section{Discussion}

This study was intended to obtain more information on the metabolic processes responsible for the sympathetically mediated thermogenesis and especially on the role of skeletal muscle in this. Astrup et al (2) suggested that at least $50 \%$ of the increase in sympathetically mediated energy expenditure may be located in skeletal muscle.

However, in that study, total blood flow was determined in order to estimate changes in oxygen consumption of leg muscle. Since changes in sympathetic activity may influence the relationship between total leg blood flow and skeletal muscle blood flow, the blood flow measurement after sympathetic stimulation may not be comparable to the baseline measurement. In the present study, changes in skeletal muscle blood flow were estimated from the total forearm, forearm fat tissue and skin blood flow.

There was a $16 \%$ increase in whole body energy expenditure with $B_{1}$ - and $B_{2}$-adrenergic stimulation with ISO, which was accompanied by a significant increase in skeletal muscle oxygen consumption. This indicates that an important part of the sympatherically mediated energy expenditure is located in skeletal muscle. The results showed that changes in forearm total blood flow are mainly determined by skeletal muscle blood flow, which explains the consistency between our results and those of Astrup et al (2). With ISO +AT, there was an $8 \%$ increase in whole body energy expenditure. With the continued infusion of ISO (second 30-min period plus AT) without a baseline period in between there is a risk of tachyphylaxis of adrenoceptors. However, the increase in energy expenditure with infusion of ISO only in the present study is comparable to data on energy expenditure previously found during a stepwise ISO-infusion protocol (each step lasted $30 \mathrm{~min}, 5$ ), which does not support the phenomenon of tachyphylaxis. Since the administered dose of the $B_{1}$-blocker atenolol was sufficient for an effective $B_{1}$ blockade $(10,37)$ and a high $B_{1}$-selectivity $(5,22)$, the increase in energy expenditure during ISO+AT will be mainly due to $B_{2}$-adrenergic stimulation. Furthermore, in a previous study (5) we have confirmed the involvement of $B_{2}$-adrenoceptors in energy expenditure by infusing the $B_{2}$-agonist salbutamol. In that study, simultaneous infusion of the highest dose of salbutamol with a similar dose of $\mathrm{AT}$ as used in the present study resulted in a nonsignificant $2 \%$ lower energy expenditure than with infusion of salbutamol only, which confirmed that this dose of AT results in a selective $B_{1}$ adrenoceptor blockade. The increase in energy expenditure with ISO+AT is not accompanied by a significant increase in skeletal muscle oxygen consumption. This may be due to the relatively large variation in the measurement of skeletal muscle oxygen flux, which makes it unlikely to detect an $8 \%$-increase in whole body energy expenditure at skeleal muscle level.

With ISO, the most pronounced changes in metabolites were found for arterial NEFA and glycerol concentration, which increased three- and twofold, respectively. This indicates a 6-adrenergically mediated increase in lipolysis in adipose tissue. Furthermore, with ISO the increased whole blood BOH concentration indicates an increased ketogenesis in the liver due to an increased NEFA supply, which is consistent with literature (20). The sympathetically mediated increase in lipolysis has been reported to take place via $\mathbb{B}_{1}$ adrenoceptors $(15,33)$, whereas in vitro studies also indicate a role for the $B_{2}$ - 
adrenoceptors (25). In the present study, with ISO+AT ( $B_{2}$-adrenergic stimulation) arterialized plasma NEFA and glycerol and skeletal muscle fluxes of these metabolites returned to control values, which suggest that under the present conditions mainly $\mathbb{B}_{1}$ adrenoceptors are involved in the $\mathbb{B}$-adrenergically mediated lipolysis.

In the basal state, there was a small nonsignificant release of NEFA from muscle, because in some subjects the arterialized-deep venous difference of plasma NEFA was negative. Variations in NEFA forearm metabolism have been reported before, whereas there is no doubt that NEFA is extracted from arterial blood by forearm tissues at rest (4). The increased arterialized plasma NEFA and whole blood BOH concentrations with ISO are accompanied by an increased uptake of these metabolites and most likely an increased oxidation (increased oxygen consumption) by muscle. This agrees with other studies, which showed that the uptake of NEFA across the forearm is proportional to the quantity of NEFA delivered to the muscle bed (16) and that plasma NEFA concentration is an important regulator of its own oxidation (6). However, accumulated evidence suggests that NEFA uptake and transport may partly involve a carrier-mediated process, which indicates that muscle NEFA uptake could also be subject to regulation at the level of the plasma membrane $(1,38)$.

With ISO, there was no change in glucose concentration nor a significant change in muscle glucose uptake, despite a twofold increase in plasma insulin. This may be explained by the increase in NEFA and $\mathrm{BOH}$ oxidation leading to an increased intracellular concentration of citrate and acetylCoA, which in turn may inhibit the intracellular glycolytic enzymes phosphofructokinase and pyruvate kinase and thus decreases glycolysis and glucose oxidation. This old concept (glucose-fatty-acid-ketone body cycle, 27) has recently received new support (39). In addition, it is known that catecholamines and isoprenaline may inhibit peripheral insulin-mediated glucose uptake, which may be a consequence of an elevation an glucose-6-phosphate, causing an inhibition of hexokinase activity $(8,28)$.

Whole blood lactate concentration and muscle lactate flux did not change significantly with ISO, which may be due to the above mentioned inhibition of glycolysis. This is not in agreement with the increased plasma lactate concentration (31) and skeletal muscle lactate release (23) reported with epinephrine infusion. Differences between isoprenaline and epinephrine could be due to differences in threshold for responses and differences in the characteristics of these agonists. Isoprenaline stimulates $B_{1}{ }^{-}$and $B_{2}$ adrenoceptors, whereas epinephrine also stimulates $\alpha$-adrenoceptors and has a more pronounced effect on $B_{2}$ - than $B_{1}$-adrenoceptors. An indication in this direction comes from the finding that in our study skeletal muscle lactate release was increased with ISO+AT (mainly $B_{2}$ adrenergic stimulation), which agrees with the results reported with epinephrine infusion. This increased lactate release can be explained by an increased glycolysis, which may be accompanied by an increased glycogen breakdown as reported in intact human muscle with epinephrine stimulation (28) and in rat muscle after B-adrenergic stimulation (8). This $B_{2}$-adrenergic effect seems to be suppressed with ISO in wivo, which may be due to a higher NEFA oxidation with ISO than with ISO+AT. In addition, together with epinephrine-induced increase in glycolysis an increased content of tricarboxylic cycle intermediaires has been reported, which indicates an increased activity of the 


\section{Chapter 5}

tricarboxylic cycle (34).

Most studies in literature report an unchanged (24) or decreased (12) amino acid metabolism as result of epinephrine infusion. In our study, with ISO or ISO+AT the skeletal muscle flux of alanine, glutamate or glutamine did not change. This indicates that there were no major changes in amino acid oxidation as result of ISO or ISO+AT infusion and thus that the contribution of this process to the B-adrenergically mediated increase in energy expenditure is of minor importance. The whole blood concentration of alanine and glutamate decreased with ISO and ISO + AT. This decrease in amino acid levels has been reported before (12) and may be explained by an increased uptake of these amino acids by the liver, where they can be used for gluconeogenesis.

In summary, skeletal muscle seems to be an important site of localisation of the sympathetically mediated energy expenditure. With $B_{1}$ - and $B_{2}$-adrenergic stimulation (ISO), the increase in skeletal muscle oxygen consumption may be explained by an increased NEFA and $\mathrm{BOH}$ oxidation. With $B_{2}$-adrenergic stimulation (ISO+AT), the small increase in whole body EE could not be detected at skeletal muscle level. However, the increased glycolysis (increased lactate release), which may be accompanied by an increased glycogen breakdown and an increased activity of the tricarboxylic acid cycle (34), suggests that skeletal muscle may also be of importance in the $B_{2}$-adrenergic increase in energy expenditure. The rise in skeletal muscle oxygen consumption with ISO and the changes in skeletal muscle substrate fluxes would be sufficient to explain the total rise in whole body energy expenditure, taken total muscle mass into account. However, one has to be careful in drawing quantitative conclusions from the present study, since many variables were used to estimate skeletal muscle blood flow. Therefore, we cannot exclude that other tissues, such as adipose tissue through an increased NEFAtriglyceride recycling (36), are also responsible for part of the sympathetically mediated energy expenditure.

\section{References}

1. Abumrad N.A., C.R. Park, and R.R. Whitesell. Catecholamine activation of the membrane transport of long chain fatly acids in adipocytes is mediated by cyclic AMP' and protein kinase. J. Biol. Chem. 261: $13082-13086,1986$.

2. Astrup A., J. Ballow, J. Madsen, and N.J. Christensen. Contribution of BAT and skeletal muscle to thermogenesis induced by ephedrine in man. Am. J. Physiol. 248 (Endocrinol Metab 11): E507-E515. 1985.

3. Astrup A., J. Bülow, N.J. Christensen, J. Madsen, and F. Quaade. Facultative thermogenesis induced by carbohydrate: a skeletal muscle component mediated by epinephrine. Am. J. Physiol. 250 (Endocrinol. Metab. 13): E226-E229, 1986.

4. Ballzan M.A., R. Andres, G. Cader, and K.L. Zierler. Heterogeneity of forearm metabolism with special reference to free fatty acids. J. Clin. Invest. 41; 116-125, 1962.

5. Blaak E.E. M.A. van Baak, K.P.G. Kempen, and W.H.M. Saris. Role of alpha and beta adrenoceptors in the sympathetically-mediated thermogenesis. Am. J. Physiol. 264 (Endocrinol. Metab. 27): E11El7, 1993. 
6. Bonadonna R.C., L.C. Groop, K. Zych, M. Shank, and R.A. Defronzo, Dose-dependent effect of insulin on plasma free fatty acid tumover and oxidation in humans. Am. J. Physiol. 259 (Endocrinol. Metab. 22): E736-E750, 1990

7. Büllow J., R. Jelnes, A. Astrup, and J. Madsen. Tissue-blood partition coefficients for xenon in various adipose tissue depots in man. Scand. J. Clin. Lab. Invest. 47: 1-3, 1987.

8. Challis R.A.J., F.J. Lozeman, B. Leighton, and E.A. Newsholme. Effects of the B-adrenoceptor agonist isoprenaline on insulin-sensitivity in soleus muscle of the rat. Biochem. $J .233: 377-381,1986$

9. Cobbald A.F., J. Ginsburg, and A. Paton. Circulatory, respiratory and metabolic responses to epinephrine infusion in man. J. Physiol. 151: 539-550, 1960.

10. Conway F.J. Human pharmacokinetic and pharmacodynamic studies on atenolol $1 \mathrm{CI} 66082$. Brit. J. Clin. Pharmacol. 3: 267-272, 1976.

11. Cooper K.E., O.G. Edholm, and R.F. Mottram. The blood flow in skin and muscle of the human forearm. J. Physiol. 128: 258-267, 1955.

12. Del Prato $S_{*}$, R.A. De Fronzo, P. Castellino, J. Wahren, and A. Alvestrand. Regulation of amino acid metabolism by epinephrine. Am. J. Physiol. 258 (Endocrinol Metab 21): E878-E887, 1990.

13. Elia M., P. Folmer, A. Schlatman, A. Goren, and S. Austen. Carbohydrate, fat and protein metabolism in muscle and in the whole body after mixed meal ingestion. Metabolism: 37, 542-581, 1988.

14. Engelhart M., L.J. Peterson, and J.K. Kristensen. The local regullation of blood flow evaluated simultaneously by 133-xenon washout and laser doppler fowmetry. J. Invest. Dernatol. $91: 451.453$ 1988.

15. Frisk-Holmberg M., and J. Ostman. Differential inhibition of lipolysis in human adipose tissue by adrenergic beta receptor blocking drugs. J. Pharmacol. Exp. Ther. 200: 598-605, 1977.

16. Hagenfeldt L., and J. Wahren. Human forearm muscle metabolism during exercise. II. Uptake, release and oxidation of indiwidual FFA and glycerol. Scand. J. Lab. Invest. 21: 263-276, 1968.

17. Havel R.J., Carlson L.A., Ekelund L.G., and A. Holmgren. Studies on the relation between mobilization of free fatty acids and energy metabolism in man: Effects of Norepinephrine and Nicotinic Acid. Metabolism 13: 1402-1411, 1964.

18. HjemdahI P., and B. Linde. Influence of circulating NE and Epi on adipose tissue vascular resistance and lipolysis in humans. Am. J. Physiol. 245 (Heart Circ Physiol 14); H447-H452, 1983.

19. Katzeff H.L., M. O'Connell, E.S. Horton, E. Danforth, J.B. Young, and L. Landsberg. Metabolic studies during over- and undernutrition: thermogenic and hormonal responses to norepincphrine. Metabolism 35: 166-175, 1986.

20. Keller U., M. Lustenberger, J. Muiller-Brand, P.P.G. Gerber, and W. Stauffacher. Human ketone body production and utilization studied using tracer techniques: regulation by free fatty acids, Insulin, Catecholamines, and Thyroid Hormones. Diabeies/metabolism Rev. 5: 285-298, 1989.

21. Larsen O.A., N.A. Lassen, and F Quade. Blood now through human adipose tissue determ ined with radioactive xenon. Acta. Physiol. Scand, 66: 337-345, 1966.

22. Lipworth B.J., L.C. McFarlane, W.J. Coutie, and D.G. Mc Devitt. Evaluation of the metabolic response to inhaled salbutamol in the meastrement of $B_{2}$-adrenoceptor blockade. Eur. J. Clin. Pharmacol. 37: $297 \times 300,1989$.

23. Lundholm L.., and N. Swedmyr. Influence of adrenaline on blood flow and metabolism in human forearmi. Acta. Physiol. Scand. 65: 344-351, 1965.

24. Matthews D.E., G. Pesola, and R.G. Campbell. Effect of epinephrine on amino acid and energy metabolism in humans. Am. J. Physiol. 258 (Endocrinol. Metab. 21): E948-E956, 1990. 
25. Mariege P, G. De Pergolla, M. Berlan, and M. Larontan. Human fat cell beta-adrenergic receptors: beta-agonist-dependent lipolyuc responses and characterization of beta-adrenergic binding sites on human fat cell tipolytic responses with highly selective beta 1 -antagonists. I. Lipid. Res. 29: 587-601, 1988 .

26. Martinsson A, K. Lindvall, A. Melcher, and P. HJehmdall. B-adrenergic receptor responsiveness 10 isoprenatine in humans: concentration-effect, as compared with dose-effect evaluation and influence of autonomic reflexes. Brit. J. Chin. Pharmacol. 28: 83-94, 1989.

27. Randle P. . P.B. Garland. C.N. Hales, and E.A. Newsholme. The glucose-faty acid cycle. Its role in insulin sensitivity and the metabolic disturbances of diabetes mellitus. Lancet i: 785-789 1963.

28. Raz 1., A. Katz, and M.K. Spencer. Epinephrine inhibits insulim-mediated glycogenesis but enhances glycolysis in human skeletal muscle. Am. J. Physiol. 260 (Endocrinol Metab 247): E430-E435, 1991.

29. Sherwin R.S., and L. Sacca. Effect of epinephrine on glucose metabolism in humans: contribution of the liver. Am. J. Physiol. 247 (Endocrinol. Metab. 10): E157-E165, 1984.

30. Sejrsen P. Blood flow in cutaneous tissute studied by the washout of radioactive xenon. Circ. Res. $X X V: 215,229,1969$.

31. Sjostrom L., Y. Schuk, F, Gudinchet, L. Hegnell, P.G. Pittet, and E. Jequier. Epinephrine sensitivity with respect to metabolic rate and other variables in women. Am. J. Physiol. 245 (Endocrinol. Metab. 8): E431-E442, 1983.

32. Smedes F., J.C. Kraak, and H. Poppe. Simple and fast solvent extraction system for selective and quantitative isolation of adrenaline, noradrenaline and dopamine from plasma and urine. $J$. Chromatogr. 231: $25-39,1982$

33. Smith U. Adrenergic control of human adipose tissue lipolysis. Eur. J. Clin. Invest. 10: 343-344, 1980.

34. Spencer M.K., A. Katz, and I. Raz. Epinephrine increases tricarboxylic acid cycle intermediates in human skeletal muscle. Am. J. Physiol. 260 (Endocrinol Metab. 23): E436-E439, 1991.

35. Staten M.A., D.E. Matthews, P.E. Cryer, and D.M. Bier. Physiological increments in epinephrine stimulate metabolic rate in humans. Am. J. Physiol. 253 (Endocrinol. Metab. 16): E322-E328, 1987.

36. Tagliaferro A.R, S, Dobbin, R. Curi, B. Leighton, L. D. Meeker, and E.A. Newsholme. Effects of diet and exercise on the in vivo rates of the triglyceride-fatly acid cycle in adipose tissue and muscle of the rat. Int, J. Obes. 14, 957-971, 1990.

37. Thorne $A$., and $J$. Wahren. B-adrenergic blockade does not influence the thermogenic response to a mixed meal in man. Clin. Physiol. Lond. 9: 321-332, 1989.

38. Turcotte L.P., E.A. Richter, and B. Kiens. Increased plasma FFA uptake and oxidation during prolonged exercise in trained ws untrained humans. Am. J. Physiol. 262 (Endocrinol. Metab. 25) E791 E799, 1992.

39. Walker M, G.R. Fulcher, C. Catalano, G. Petranyi, H. Orskov, and K.G.M.M. Alberti. Physiological levels of plasma non-esterified fatty acids impair forearm glucose uptake in normal man. Clin. Sci 79: $167-174,1990$

40. Weir J.B. New methods for calculating metabolic rate with special reference to protein metabolism. J. Plhysiol. 109: 1-9, 1949

41. Whitncy, R.J. The measurement of volume changes in human limbs. J Physiol. 121: 1-27, 1953. 


\title{
Effect of beta adrenergic stimulation on whole body energy expenditure and forearm skeletal muscle metabolism in obese men: a comparison with lean men
}

\author{
E.E. Blaak, M.A. van Baak, G.J. Kemerink*, M.T.W. Pakbiers*, G.A.K. Heidendal*, and \\ W.H.M. Saris
}

Departnent of Human Biology, University of Limburg, Maastricht, and *Department of Nuclear Medicine University Hospital Maastricht, The Netherlands

Submitted to Am J Physiol (Endocrinol. Metab.)

\section{Abstract}

The effect of beta-adrenergic stimulation on whole body energy expenditure and forearm skeletal muscle metabolism was investigated in obese men. Wholle body energy expenditure was determined during rest and during intravenous infusion of increasing doses of the $B_{1^{-}}, B_{2^{-}}$agonist isoprenaline (ISO). Forearm skeletal muscle metabolism was investigated with ISO-infusion with and without simultaneous infusion of the $B_{1}$-blocker atenolol (AT) by measuring skeletal muscle blood flow and arterio-venous concentration differences of various metabolites. The results have been compared to those of a previous study with an identical protocol in lean subjects (5). The increase in whole body energy expenditure with ISO was similar in lean and obese subjects. With ISO, the rise in arterial or arterialized glycerol and non-esterified fatty acids (NEFA) was lower in obese than lean subjects, which may reflect a lower B-adrenergically mediated lipolysis in obesity. During infusion of increasing doses of ISO, the respiratory exchange ratio decreased significantly in lean subjects but not in the obese, which indicates a higher fat oxidation in lean. This is confirmed by the data on skeletal muscle metabolism, where NEFA uptake was increased in lean subjects, whereas the obese showed an increased glucose uptake and lactate release. The increase in muscle oxygen consumption with ISO was more pronounced in lean than obese subjects, which shows that skeletal muscle contributes more to $B_{1}-B_{2}$-adrenergic thermogenesis in the lean. With ISO+AT $\left(B_{2}\right.$ adrenergic stimulation) both groups showed an increased skeletal muscle lactate release. In conclusion, although the thermogenic response to isoprenaline was similar in lean and obese, the utilization of fat seems to be impaired in obese. 


\section{Introduction}

The issue whether obesity develops as result of a metabolic efficiency is still a matter of dispute. Although it has been reported that a predisposition to obesity may lie in a lowered resting energy expenditure (35), once the obese state has developed an elevated energy expenditure proportional to the increased lean body mass equals energy intake $(32,48)$. Obesity has also been associated with a diminished thermogenic response to catecholamines (22) or to ingestion of nutrients $(3,38)$, but these findings are not consistent $(11,23,44)$. Recent lines of evidence suggest that one of the factors contributing to the obese state may be an impaired utilization of fat as a fuel, which will result in the development and maintenance of large fat stores. A low ratio of fat to carbohydrate oxidation has been reported to be associated with subsequent weight gain in Pima Indians (50). Additionally, in Pima. Indian women free fatty acid turnover and lipid oxidation rates (expressed per $\mathrm{kg}$ body fat) decreased with increasing degree of obesity (28). Further, a recent study indicated that fatter men combusted less fat than lean men during an exercise load, which may be related to muscle fibre type (45).

The sympathetic nervous system plays an important role in the regulation of energy expenditure and fuel metabolism. In a previous study, we showed that the thermogenic response to sympathomimetics is mainly mediated via $B_{1}$ - and $B_{2}$-adrenoceptors (7). Furthermore, in healthy lean males an important part of the B-adrenergically mediated thermogenesis was located in forearm skeletal muscle, which increased oxygen consumption was accompanied by an increased fatty acid uptake ( $\beta_{1}$-mediated) and lactate release $\left(\beta_{2}\right.$-mediated, 5$)$. These results combined with the abovementioned findings on a possibly impaired sympathetically mediated thermogenesis and fatty acid utilization in obese have led to the present study. In this study, we investigated the effect of B-adrenergic stimulation on whole body energy expenditure and skeletal muscle substrate fluxes in obese men. The results have been compared to those of a previous study with an identical protocol in lean subjects (5). For stimulating metabolism the $\boldsymbol{B}_{1}$ " and $B_{2}$-agonist isoprenaline (ISO) was used with and without simultaneous infusion of the $B_{1}$-blocker atenolol (AT).

\section{Subjects and methods}

In this study, 8 obese male volunteers were selected on basis of their $\%$ body fat $(25-40)$ and age (between 20-40 y). Physical characteristics of the obese subjects and of the lean subjects of the previous study (5) are indicated in table 1. All subjects were in good health as assessed by a medical history and physical examination. Furthermore, both lean and obese subjects spent no more than 3 hours a week in organized sports activities. The study protocol was reviewed and approved by the Ethics Committee of the University of Limburg and all volunteers were asked for written consent. The experiments were performed after an overnight fast and room temperature was kept between $21-23^{\circ} \mathrm{C}$. The study protocol consisted of two experiments with two weeks in between. In the first experiment the $B_{1}$ - and $B_{2}$-agonist isoprenaline was infused in increasing standardized 
doses and during each infusion period whole body energy expenditure and plasma concentrations of ISO, norepinephrine and epinephrine were determined (ISO-infusion test). In the second experiment, forearm skeletal muscle metabolism was investigated during ISO-infusion with and without simultaneous infusion of the $B_{1}$-blocker atenolol (AT)(Forearm muscle experiment). To reduce the variability in the forearm muscle experiment, the dose of ISO infused in this experiment was individually determined in the ISO-infusion test and was the dose that increased plasma ISO to a fixed concentration of $165 \mathrm{pg} / \mathrm{ml}$.

Table 1. Physical characteristics of the subjects.

\begin{tabular}{lcc}
\hline & Lean & Obese \\
\hline Age $(\mathrm{y})$ & $25.2 \pm 1.7$ & $31.8 \pm 1.6 \quad * *$ \\
Weight $(\mathrm{kg})$ & $76.5 \pm 1.9$ & $108.4 \pm 8.1 \% * *$ \\
BMI $\left(\mathrm{kg} / \mathrm{m}^{2}\right)$ & $23.0 \pm 1.5$ & $31.7 \pm 1.6 * * *$ \\
Percent body fat $(\%)$ & $17.0 \pm 2.2$ & $31.3 \pm 1.8 * * *$ \\
\hline
\end{tabular}

means \pm SEM; obese: $n=8$, lean: $n=9$; Unpaired $t$-test **P<0.01, *** $P<0.001$.

\section{ISO-infusion test}

In this experiment, isoprenaline (ISO) was infused in increasing doses of 6,12,23 and 46 $\mathrm{ng} / \mathrm{kg}_{\text {fat free mass }}$. min, each dose for $30 \mathrm{~min}$. The dose is related to ISO sulphate, $69 \%$ of which corresponds to ISO free base. Body density was determined by hydrostatic weighing with simultaneous lung volume measurement (Volugraph 2000, Mijnhardt, the Netherlands). Body composition was calculated according to the formula of Siri (39). Whole body energy expenditure was measured by an open circuit ventilated hood system (Oxycon Beta, Mijnhardt, The Netherlands). The abbreviated formula of Weir (47) was used for calculating energy expenditure. After $15 \mathrm{~min}$ in each infusion period, a blood sample was taken with a heparinized syringe and was put into a glutathione containing tube in ice. The sample was immediately centrifuged at $3000 \mathrm{rpm}$ at $4{ }^{\circ} \mathrm{C}$ and the plasma was stored at $-50^{\circ} \mathrm{C}$. In the plasma samples concentrations of isoprenaline, epinephrine and norepinephrine were determined by high performance liquid chromatography (41). During the experiments, heart rate was recorded continuously. When the heart rate had risen 30 beats/min the infusion was stopped. 


\section{Forearm muscle experiment}

\section{Design}

Forearm skeletal muscle metabolism was investigated during infusion of the $B_{1}$ - and $B_{2}-$ agonist ISO with and without simultaneous infusion of the $B_{1}$-blocker atenolol (AT). After 30 min supine rest, skeletal muscle blood flow and arterio-venous concentration differences of various metabolites across muscle were determined (see under clinical and biochemical methods). After the resting period the ISO-infusion was started for $60 \mathrm{~min}$ with $\mathrm{AT}$ added on to the last $30 \mathrm{~min}$. The above mentioned measurements were repeated after 30 min ISO-infusion and after 30 min of simultaneous ISO and AT infusion. For each subject, the dose of ISO (per $\mathrm{kg}_{\mathrm{FFM}}$ ) leading to a plasma concentration of $165 \mathrm{pg} / \mathrm{ml}$ in the ISO-infusion test was infused. The mean infusion rate of ISO was 19.7 1.1 $\mathrm{ng} / \mathrm{kg}_{\text {FFM }}$.min (range $15.7-26.1 \mathrm{ng} / \mathrm{kg}_{\mathrm{FFM}} \cdot \min$ ). Before the simultaneous infusion of ISO and AT $\left(0.11 \mathrm{mg} / \mathrm{kg}_{\mathrm{FFM}}\right.$, $\left.\mathrm{h}\right)$ started, a priming dose of AT $\left(0.08 \mathrm{mg} / \mathrm{kg}_{\mathrm{FFM}}\right)$ was administered within five minutes. The changes in forearm skeletal muscle blood flow were determined by measuring total forearm-, skin- and subcutaneous adipose tissueblood flow and forearm composition.

\section{Clinical methods}

Before the start of the experiment, three canulas were inserted. One canula was inserted under local anesthesia in the radial artery of the forearm for sampling of arterial blood. In the same arm, a second canula was inserted in a forearm antecubital vein for the infusion of ISO and AT. In the contralateral arm, a third catheter was inserted in retrograde direction in an antecubital vein of the forearm for sampling of deep venous blood.

Total forearm blood flow (TBF) was measured by venous occlusion plethysmography (49) with a mercury strain gauge (Periflow 0699, Janssen Scientific Instruments, Belgium). The strain gauge was placed around the forearm, which contained the deep venous catheter. Because this method measures percent change in volume, the blood flow is related to $100 \mathrm{ml}$ of forearm tissue. Prior to measuring forearm blood flow, the hand circulation was occluded by inflating a pediatric sphygmomanometer cuff, placed around the wrist, to a pressure of $200 \mathrm{~mm} \mathrm{Hg}$. In this way forearm blood flow could be assessed without interference from the hand circulation. The venous occlusion cuff, placed around the upper arm, was automatically inflated (and deflated) to a pressure of $40 \mathrm{~mm} \mathrm{Hg}$. Forearm blood flow was recorded approximately every four seconds (depending on heart rate) during $1.5 \mathrm{~min}$ and the consecutive (stable) values during the last min were averaged.

Subcutaneous adipose tissue blood flow (ATBF) was measured on the dorsal side of the forearm about $10 \mathrm{~cm}$ proximal to the wrist joint by the ${ }^{133}$ xenon washout method (26). A dose of $5.5 \mathrm{MBq}(150 \mu \mathrm{Ci}){ }^{133} \mathrm{xenon}$, dissolved in saline $(0.1-0.15 \mathrm{ml})$, was injected subcutaneously with a very fine needle. The arm was placed in a fixed position close to a large field of view gamma camera (Technicare $438 \mathrm{HR}$, General Electrics/CGR large field, Utrecht, The Netherlands). The registration of the ${ }^{133}$ xenon disappearance was started $45 \mathrm{~min}$ after injection to be sure that the washout was monoexponential. From the regression of count activity against time, the disappearance constant of ${ }^{133}$ xenon over the 
last 20 min of each infusion period was determined in order to calculate fat tissue blood flow. It was assumed that the blood-fat tissue partition coefficient of xenon was 8 $\mathrm{ml} / \mathrm{gram}$ in obese subjects as in the previous study in lean subjects (5). Although it has been suggested that this coefficient in subcutaneous adipose abdominal tissue varies with the local skinfold thickness (9), a study in rats could not confirm this (31). However, variation in this coefficient within the range reported by Bülow et al $(8,9)$ would not change the conclusions of this study. For the conversion of the adipose tissue blood flow values from 100 gram to $100 \mathrm{ml}$ of tissue, the density of adipose tissue was assumed to be $0.9 \mathrm{~g} / \mathrm{ml}$ in both groups $(13,39)$.

Before the measurement of total forearm blood flow, skin blood flow was determined by the laser doppler technique (SBF, Periflux PF3, Perimed, Sweden) with an occluded hand circulation. The probe was placed on the ventral side of the forearm near the wrist joint. This method gives a linear measure of the flux of red cells in the blood vessels of the skin to a depth assumed to be approximately $1 \mathrm{~mm}$ (37) and probably is only suitable to measure changes in blood flow, when there is no change in diameter of the skin blood vessels (17). Since the skin vessels predominantly contain $\alpha$-adrenoceptors (2) a major change in contraction state of skin vessels as result of $B$-adrenergic stimulation seems unlikely. In addition, local sympathetically mediated changes in blood vessel diameter can be excluded since intravenous isoprenaline infusion (100 $\mathrm{ng} / \mathrm{kg} \cdot \mathrm{min})$ has been reported to cause a weak but transient vasodilatation of skin vessels, which returned to basal values within ten minutes after the initiation of the infusion (10). Resting skin blood flow was assumed to be $5 \mathrm{ml} / 100 \mathrm{ml} \cdot \mathrm{min}$, a value reported by Sejrsen et al (40) at an ambient temperature of $19-22^{\circ} \mathrm{C}$.

The amount of subcutaneous fat, bone and muscle of the forearm were determined by a cross-sectional analysis at the site of the greatest circumference with magnetic resonance imaging (Gyroscan T5, Philips Medical Systems, The Netherlands). In the previous study in lean subjects (5) forearm composition was not experimentally determined but was assumed to be as determined with carcass analysis by Cooper et al (13). To improve the comparability of the previous and present study, the average forearm composition of a group of lean subjects, determined with MRI, was used to recalculate muscle blood flow data of the previous study. In our MRI images, we could not determine the amount of forearm skin nor distinguish the amount of muscle tissue from tendinous structures. Therefore, the relationship between the amount of forearm skin and the total amount of muscle and subcutaneous fat was assumed to be constant and was assumed to be as described by Cooper et al (13). The amount of tendon was calculated in a similar way by relating its amount to the amount of muscle. Under the heading of fat and muscle are also grouped nerves and blood vessels within these tissues. Taken together, skeletal muscle blood flow (SMBF) was calculated by the following formula:

\section{$T B F=$ amount of muscle $x S M B F+$ amount of $\operatorname{skin} \times S B F+$ amount of fat $\times A T B F$,}

amount of tissue: \% of total forearm area/100

units blood flow: $\mathrm{m} / 100 \mathrm{~m} /$ tissue.min 

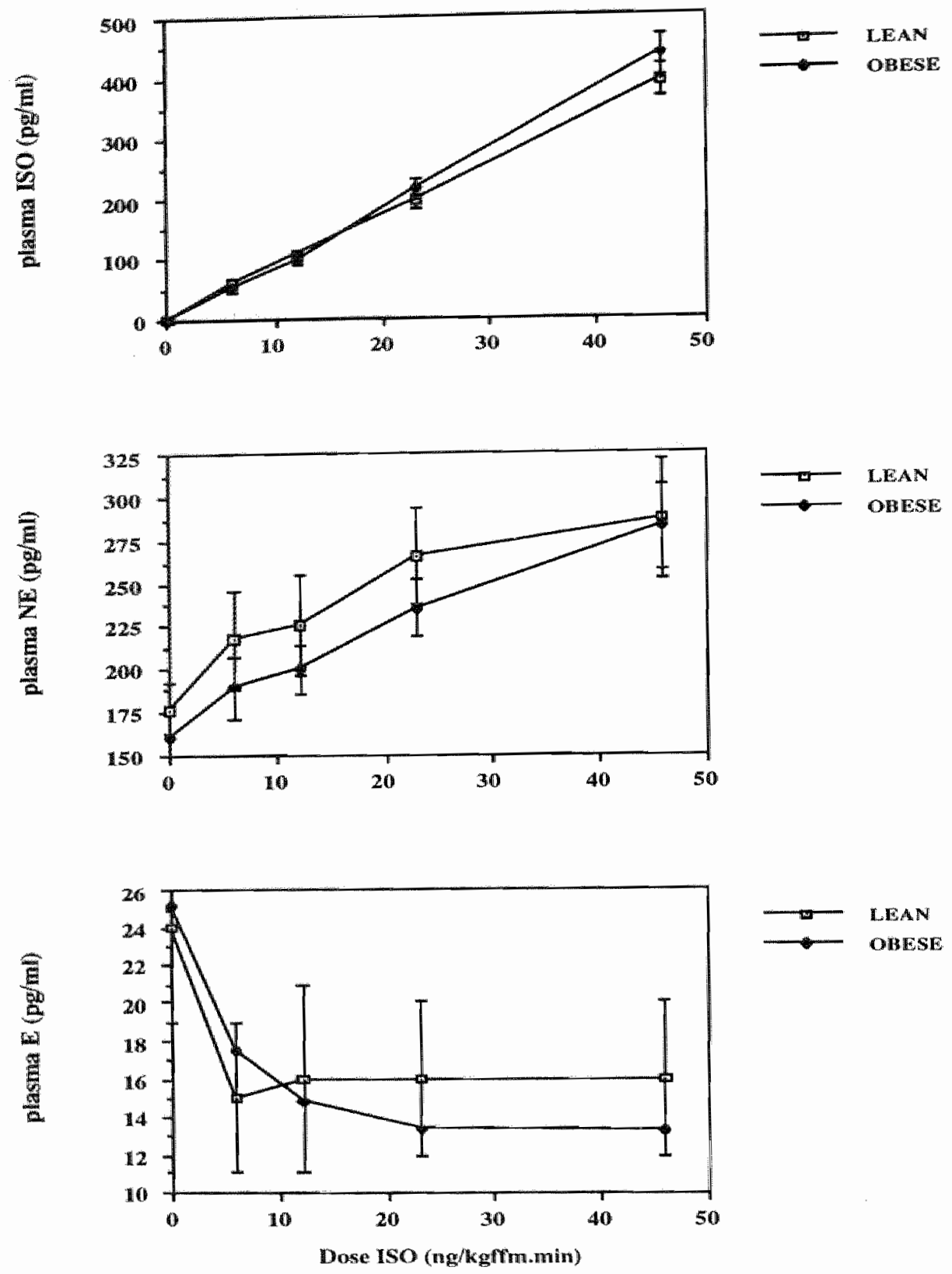

Fig 1. Changes in plasma isoprenaline (ISO), norepinephrine (NE) and epinephrine (E) with infusion of increasing doses of the $B_{1}, B_{2}$-agonist $1 S O$ in lean and obese subjects. Mearis $\pm S E M$; lean: $n=9$, obese: $\mathrm{n}=8$; Repeated measurements ANOVA: lean and obese, plasma ISO: $\mathrm{P}<0.001$, plasma NE: $\mathrm{P}<0.001$, plasma E: P $<0.01$. 


\section{Biochemical methods}

Blood samples were taken simultaneously from the artery and the deep forearm wein after the blood flow measurement, while the hand circulation was still occluded. Triplicate samples of arterial and deep venous blood were immediately deproteinized with ice cold sulphosalicylic acid (SSA, 3.5\% w/v) in a ratio of $1: 2$, respectively. The samples were centrifuged at $3000 \mathrm{rpm}$ at $4^{\circ} \mathrm{C}$. In the supernatant concentrations of glucose, pyruvate, lactate, $\$$-hydroxybutyrate $(\mathrm{BOH})$, glutamate, alanine and glutamine were determined with enzymatic assays automated on the Cobas Bio centrifugal analyzer at $355 \mathrm{~nm}$ (16). All these assays were carried out using $0.2 \mathrm{M}$ tris-hydrazine buffer, pH 9.2, except for pyruvate which was done with $1 \mathrm{M}$ phosphate buffer, pH 7.0. Plasma non-esterified fatty acids (NEFA) and glycerol were measured using standard enzymatic techniques automated on the Cobas Bio centrifugal analyzer.

The concentration of hemoglobin ( $\mathrm{Hb}$ ) in blood and the percentage saturation of $\mathrm{Hb}$ with $\mathrm{O}_{2}$ were measured with a hemoximeter (OSM2 hemoximeter, VA Howe Radiometer, Copenhagen). The hematocrit was determined using a microcapillary system.

\section{Calculations and Staflistics}

The exchange of metabolites across muscle (nmol/100 ml muscle tissue.min) was calculated by multiplying the arterio-venous difference of metabolites $(\mu \mathrm{mol} / 1)$ by muscle blood flow (ml/ $100 \mathrm{ml}$ muscle tissue min). The exchange of NEFA and glycerol was calculated by multiplying their plasma $\mathrm{A}-\mathrm{V}$ difference by plasma flow (muscle blood flow (1-Hu/100)). A positive flux indicates uptake.

Data are represented as means \pm SEM. Both in the lean and obese group the effects of ISO- and ISO+AT infusion were analyzed with repeated measurements ANOVA. To analyze changes within groups, post hoc testing was done with a Student's paired t-test and the P-values of the post-hoc comparisons were corrected according to Bonferroni's inequalities. Differences between lean and obese were tested with a one-way analysis of variance. A P-value smaller than 0.05 was regarded as statistically significant.

\section{Results}

\section{ISO-Infusion test}

Both obese and lean subjects showed dose-related increases in plasma ISO (for lean and obese: ANOVA: $\mathbf{P}<0.001$ ), and the mean plasma concentrations with the increasing standardized doses (expressed per $\mathrm{KgFFM}_{\mathrm{F}}$ ) were equal in the two groups (fig 1 ). Resting values of plasma norepinephrine (NE) or epinephrine (E) were not significantly different between lean and obese subjects (E: $24 \pm 5 \mathrm{vs} 25 \pm 5 \mathrm{pg} / \mathrm{ml}$, NE: $176 \pm 16 \mathrm{vs} 160 \pm 14 \mathrm{pg} / \mathrm{ml}$, respectively). Both groups showed similar plasma catecholamines responses during $15 \mathrm{O}$ infusion: an increase in plasma $N E(P<0.001)$ and a decrease in plasma $E(P<0.01$, fig 1$)$. 


\section{Chapter 6}
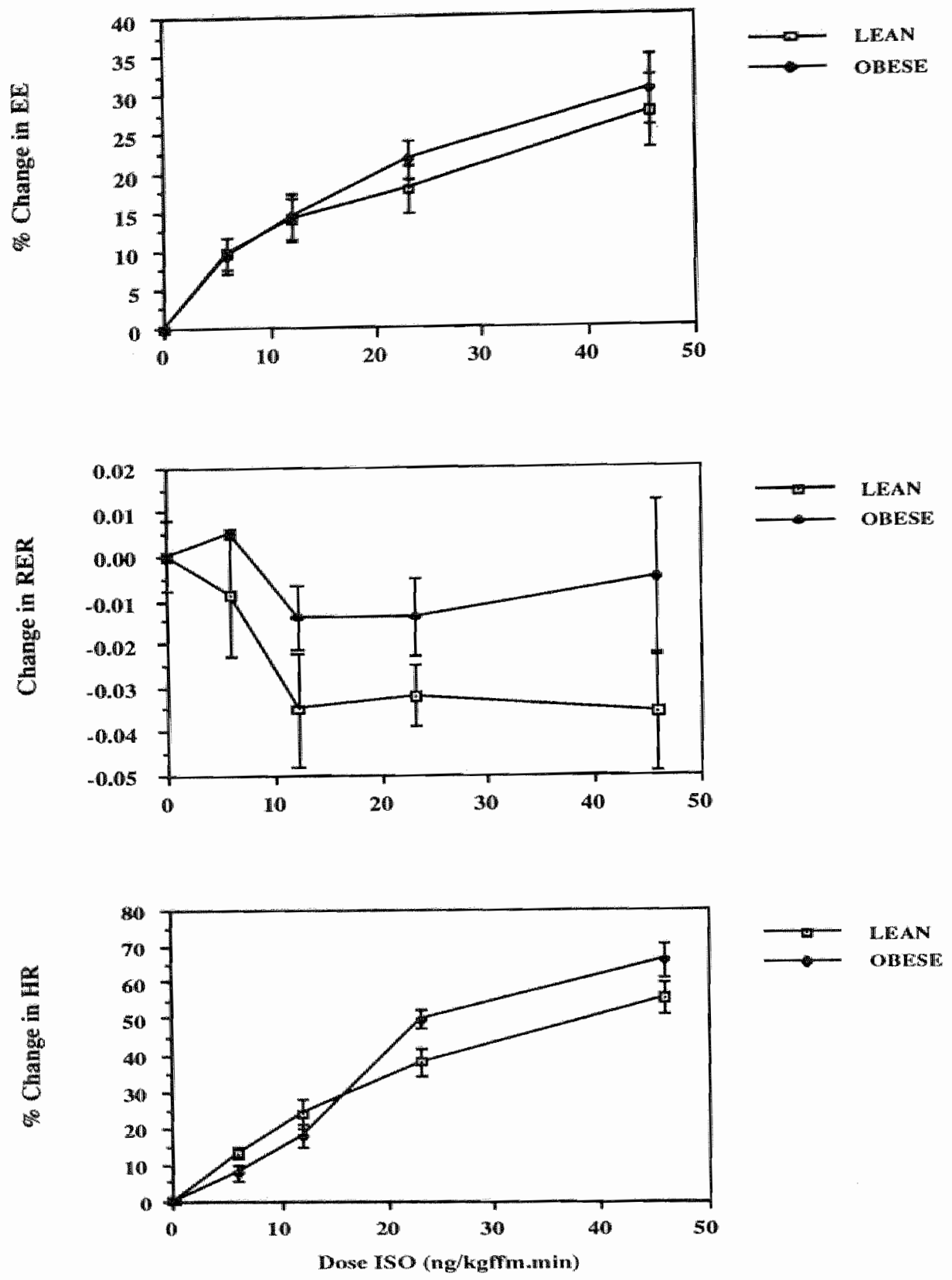

Fig 2. Changes in energy expenditure ( $E E$, as $\%$ change), respiratory exchange ratio (RER) and heart rate (HR, as \% change) with infusion of increasing closes of the $B_{1}{ }^{-}, B_{2}$-agonist isoprenaline (ISO) in lean and obese subjects. Means \pm SEM; lean: $n=9$, obese: $n=8$; Repeated measurements ANOVA: \% change EE and HR: P<0.001 for lean and obese, RER: lean P<0.01. 
Resting energy expenditure was significantly lower in the lean than the obese $(5.28 \pm 0.13$ vs $6.29 \pm 0.34 \mathrm{~kJ} / \mathrm{min}, \mathrm{P}<0.05$ ). There were no significant differences in the $15 \mathrm{O}$-induced increases in energy expenditure between lean and obese subjects (for both groups: $\mathrm{P}<0.001$ ), expressed either as absolute values ( $\triangle \mathrm{EE}$ lean vs obese: at $6 \mathrm{ng}: 0.48 \pm 0.10 \mathrm{vs}$ $0.57 \pm 0.12$, at $12 \mathrm{ng}: 0.71 \pm 0.10$ vs $0.89 \pm 0.51$, at $23 \mathrm{ng}: 0.92 \pm 0.16$ vs $1.35 \pm 0.15$, at $46 \mathrm{ng}$ : $1.41 \pm 0.20 \mathrm{vs} 1.72 \pm 0.20 \mathrm{~kJ} / \mathrm{min}$ ) or as \% increase (fig 2).

Resting values of the respiratory exchange ratio (RER) were similar in lean and obese $(0.83 \pm 0.01$ ws $0.83 \pm 0.01)$. During ISO-infusion this ratio decreased in lean subjects $(\mathrm{P}<0.01)$, whereas there was no significant change in the obese (fig 2 ).

Resting heart rate values were not significantly different in lean and obese subjects $(58.8 \pm 2.4$ vs $65.2 \pm 3.1$ beats/min, resp). Also, there were no significant differences in the ISO-induced increases in HR between lean and obese subjects (fig 2).

\section{Forearm muscle experiment}

\section{Heart rate}

The increase in heart rate (HR) at a plasma ISO concentration of $165 \mathrm{pg} / \mathrm{ml}$ did not differ significantly between lean and obese subjects, either expressed as absolute values (with ISO: $19.0 \pm 3.0$ vs $25.5 \pm 3.8$ beats $/ \mathrm{min}$, and with ISO+AT: $11.4 \pm 2.3 \mathrm{vs} 7.0 \pm 2.0$ beats $/ \mathrm{min}$, respectively) or as percentage increase (ISO: $33.0 \pm 2.5$ vs $36.9 \pm 5.0 \%$ and ISO+AT $13.2 \pm 1.7$ vs $11.7 \pm 3.0 \%$, respectively).

\section{intermediary metabolites}

Changes in arterial concentrations of metabolites within both groups are indicated in table 2 . In the resting state, glycerol concentration was significantly higher in obese than lean subjects, whereas lactate and NEFA concentration tended to be higher in obese subjects (NS). In both groups there were no changes in pyruvate, lactate and glucose concentrations with ISO. With ISO+AT these concentrations were still unchanged in lean, whereas in obese glucose concentrations decreased in comparison to control. With ISO, NEFA showed the most pronounced changes in both groups: a threefold increase in the lean and a twofold increase in obese subjects, while glycerol increased almost twofold in the lean and did not change in obese subjects. Both for NEFA and glycerol the changes with ISO are significantly higher in lean than obese subjects, which is indicated in fig 3. Whole blood alanine decreased in both groups whereas glutamate decreased only in the lean, In both groups, there were no changes in glutamine concentration. Basal plasma insulin was significantly higher in obese than lean subjects, so was the increase in insulin with ISO ( $\Delta$ plasma insulin: $21.1 \pm 7.0$ vs $6.8 \pm 0.9 \mathrm{mU} / 1, \mathrm{P}<0.05)$ and $I S O+\operatorname{AT}(\Delta$ plasma insulin: $6.8 \pm 2.4 \mathrm{vs} 2.0 \pm 0.5 \mathrm{mU} / 1, \mathrm{P}=0.05$ ). 


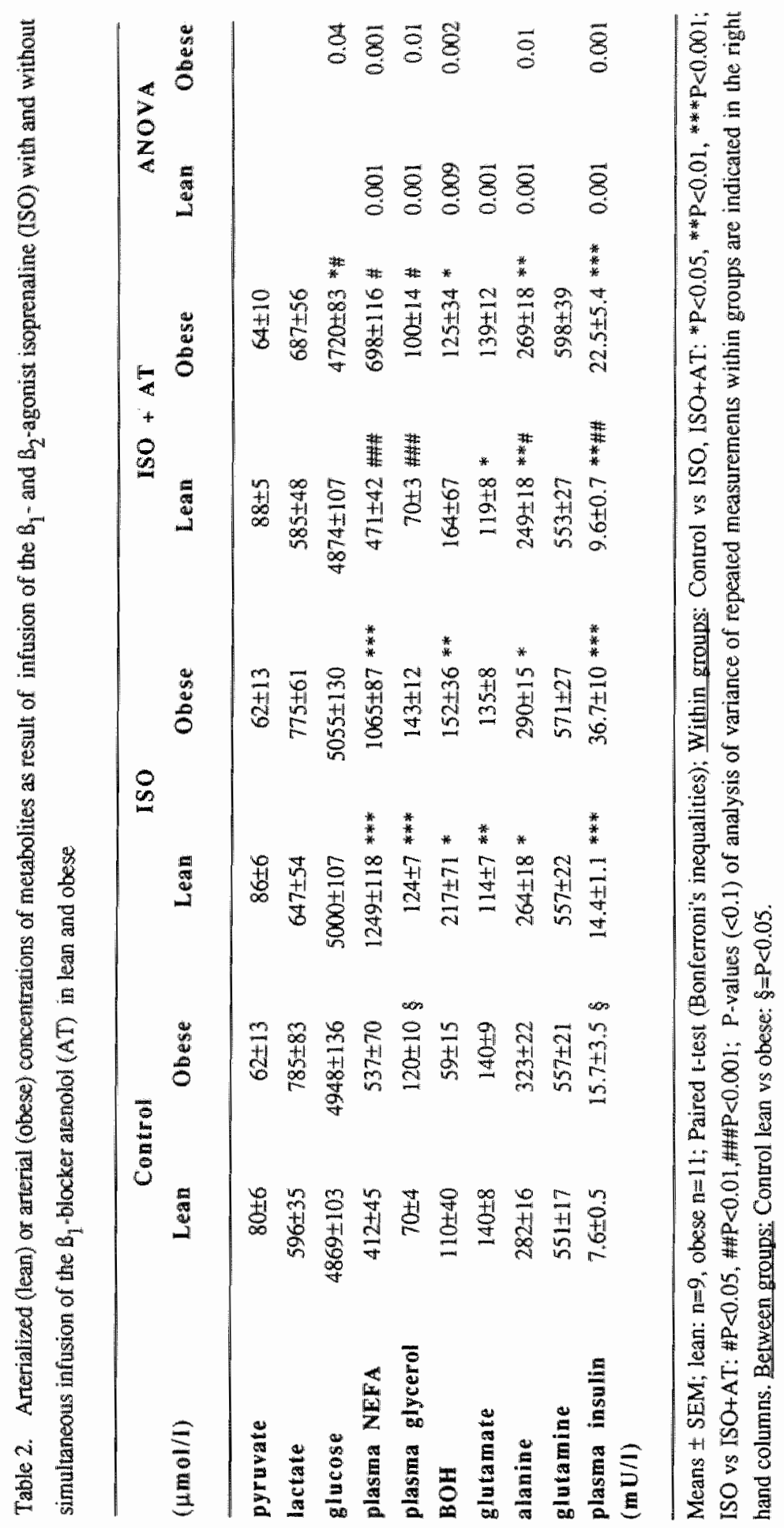



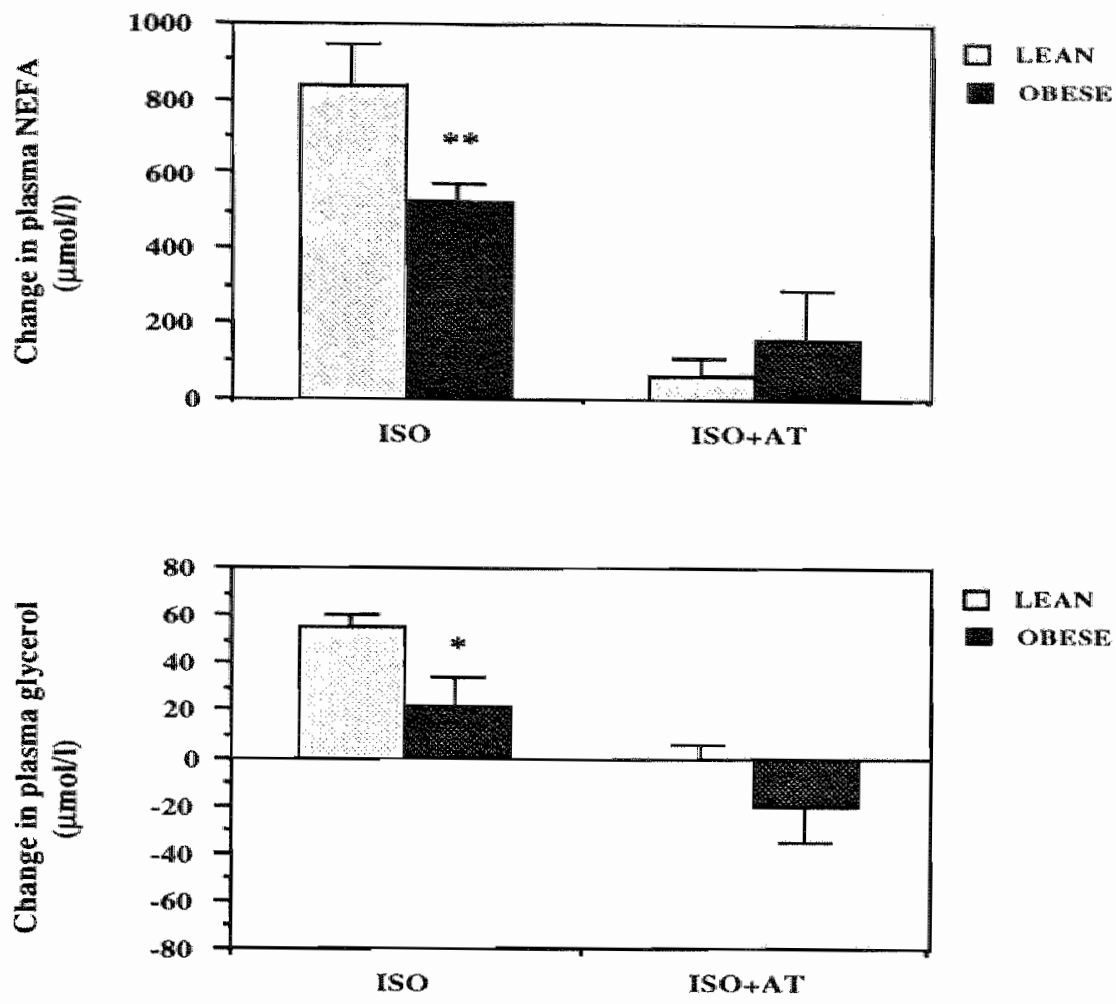

Fig 3. Changes in plasma non-esterified fatty acids (NEFA) and glycerol as result of infusion of the $B_{1}$-, $B_{2}$-agonist isoprenaline (ISO) with and without the $B_{1}$.blocker atenolol (AT) in lean and obese subjects. Means \pm SEM; lean: $n=9$, obese: $n=8$; one-way ANOVA: * $P<0.05$, * $P<0.01$.

\section{Composition forearm}

The composition of the forearm in obese and lean subjects, expressed as percentage of total forearm area, is indicated in fig 4 . Lean subjects had less subcutaneous fat than obese subjects when expressed as absolute values $\left(816 \pm 44\right.$ vs $\left.1629 \pm 97 \mathrm{~mm}^{2}, \mathrm{P}<0.001\right)$ or as percentage of total forearm area. The absolute amount of muscle was higher in obese than in lean subjects $\left(4849 \pm 313 \mathrm{vs} 3603 \pm 174 \mathrm{~mm}^{2}, \mathrm{P}<0.01\right)$, but the relative amount was not different. The absolute amount of bone was not different between the lean and the obese ( $402 \pm 31$ vs $366 \pm 33 \mathrm{~mm}^{2}$ ), but expressed as a percentage of total forearm area this value was lower in obese subjects. The estimated absolute amount of skin and tendons were higher in the obese as compared to lean subjects (skin: $751 \pm 32$ vs $500 \pm 20 \mathrm{~mm}^{2}$ $P<0.001$, and tendon: $449 \pm 29$ vs $367 \pm 18 \mathrm{~mm}^{2}, P<0.05$, respectively), whereas the relative amount of skin was higher and the relative amount of tendon was lower in obese as compared to lean subjects (fig 4 ). 


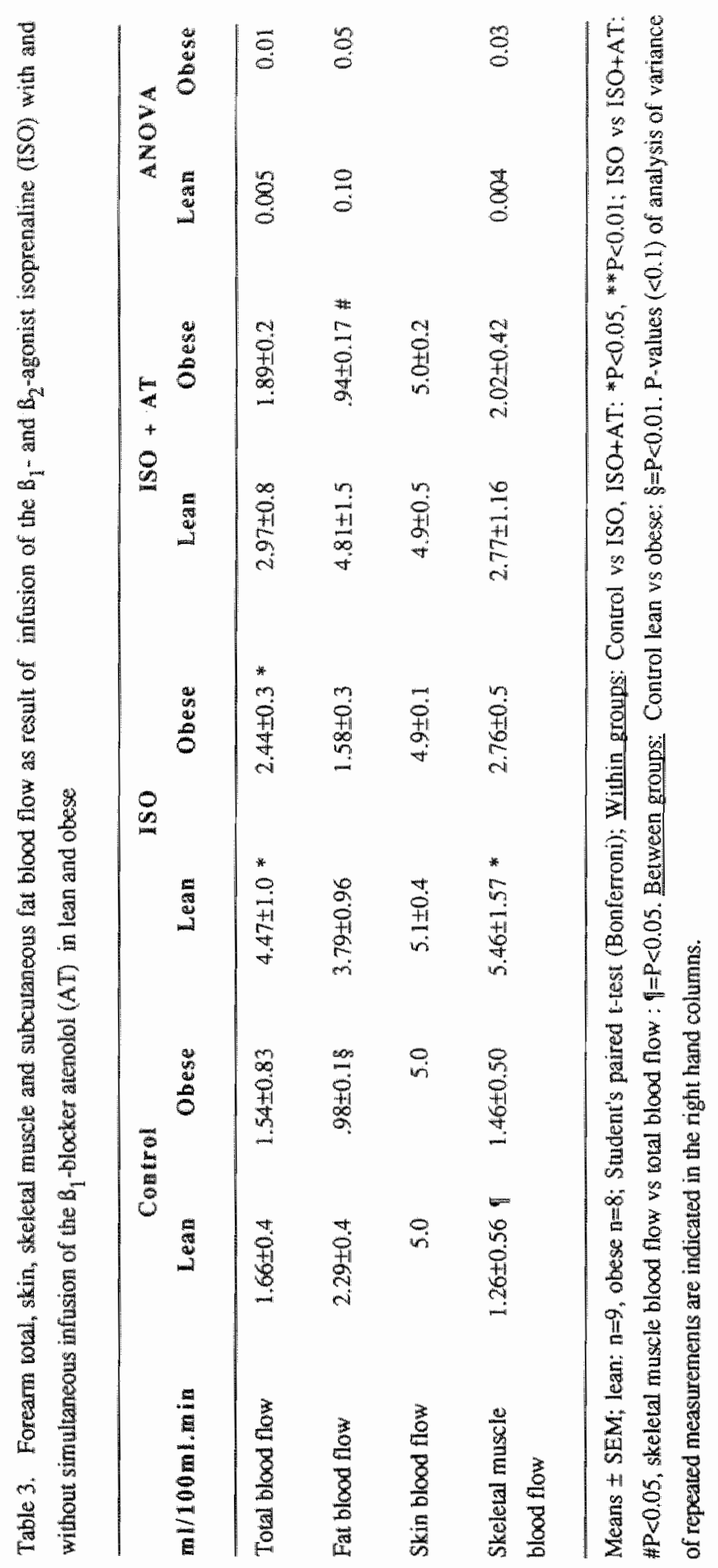




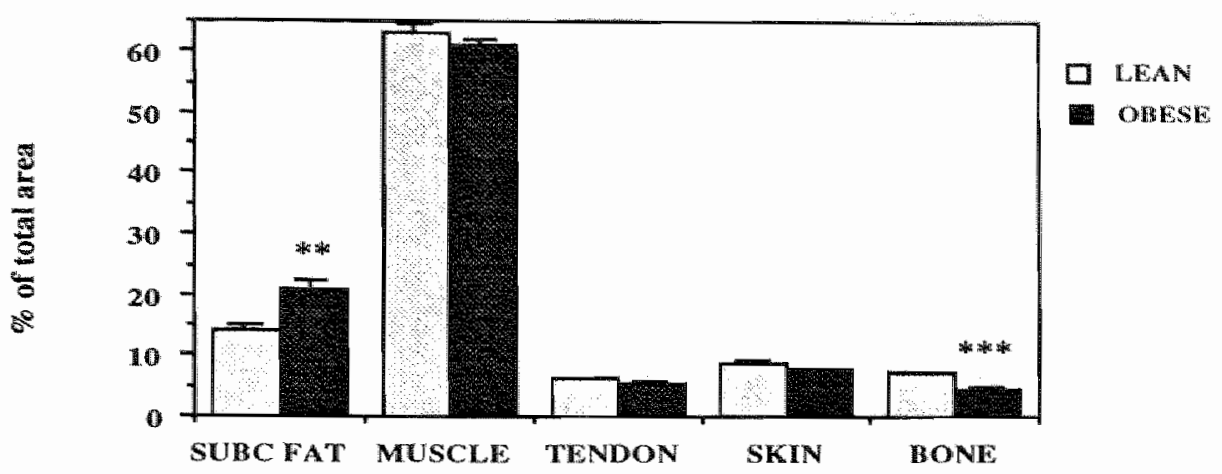

Fig 4. The forearm composition of lean and obese subjects, expressed as percentage of total forearm area. Total forearm area is $5709 \mathrm{~mm}^{2}$ in lean subjects and $8218 \mathrm{~mm}^{2}$ in obese subjects. Means $\pm S E M$, lean: $n=6$; obese: $n=8$; one-way ANOVA: **P<0.01,***P<0.001.

\section{Blood flow}

Table 3 shows the changes in blood flow through the different forearm tissues. Resting forearm and muscle blood flow were not different in lean and obese subjects, whereas the subcutaneous fat blood flow was significantly lower in the obese. The relative units for skin blood flow were similar in lean and obese subjects ( $5.8 \pm 0.6$ vs $5.2 \pm 0.6$, respectively) and there were no changes as result of ISO- or ISO+AT infusion. In both groups the changes in forearm blood flow were mainly determined by changes in skeletal muscle blood flow. Total blood flow tended to increase more with ISO in lean than obese ( $\triangle T B F$ lean ws obese: $2.87 \pm 0.87$ vs $0.90 \pm 0.3 \mathrm{ml} / 100 \mathrm{ml}$.min, $\mathrm{P}=0.06$ ), and the increase in skeletal muscle blood flow was significantly higher in lean subjects ( $\triangle S M B F$ lean ws obese: $4.12 \pm 1.25$ vs $1.26 \pm .48 \mathrm{ml} / 100 \mathrm{ml} \cdot \mathrm{min} \mathrm{P}<0.05$ ). With ISO+AT, fat blood flow retumed to control values in obese subjects, whereas in the lean there was a tendency towards an increase (between groups: $\mathrm{P}<0.05$ ).

\section{Skeletal muscle substrate fluxes}

Table 4 shows skeletal muscle substrate fluxes with ISO and ISO+AT. There are no significant differences in resting skeletal muscle substrate fluxes between lean and obese subjects, although glucose flux tended to be lower in the lean ( $\mathrm{P}=0.11)$. With ISO, muscle axygen uptake increased in the lean, whereas there was no significant change in the obese. With ISO+AT, the oxygen flux in both groups was not significantly different from control. In lean subjects, the rise in oxygen consumption with ISO was accompanied by a significantly higher muscle NEFA uptake, whereas in the obese glucose uptake and lactate release tended to increase. With ISO+AT, lactate release was still increased in the obese and also showed a strong tendency to increase in lean subjects (ANOVA: $P=0.07$ ). 


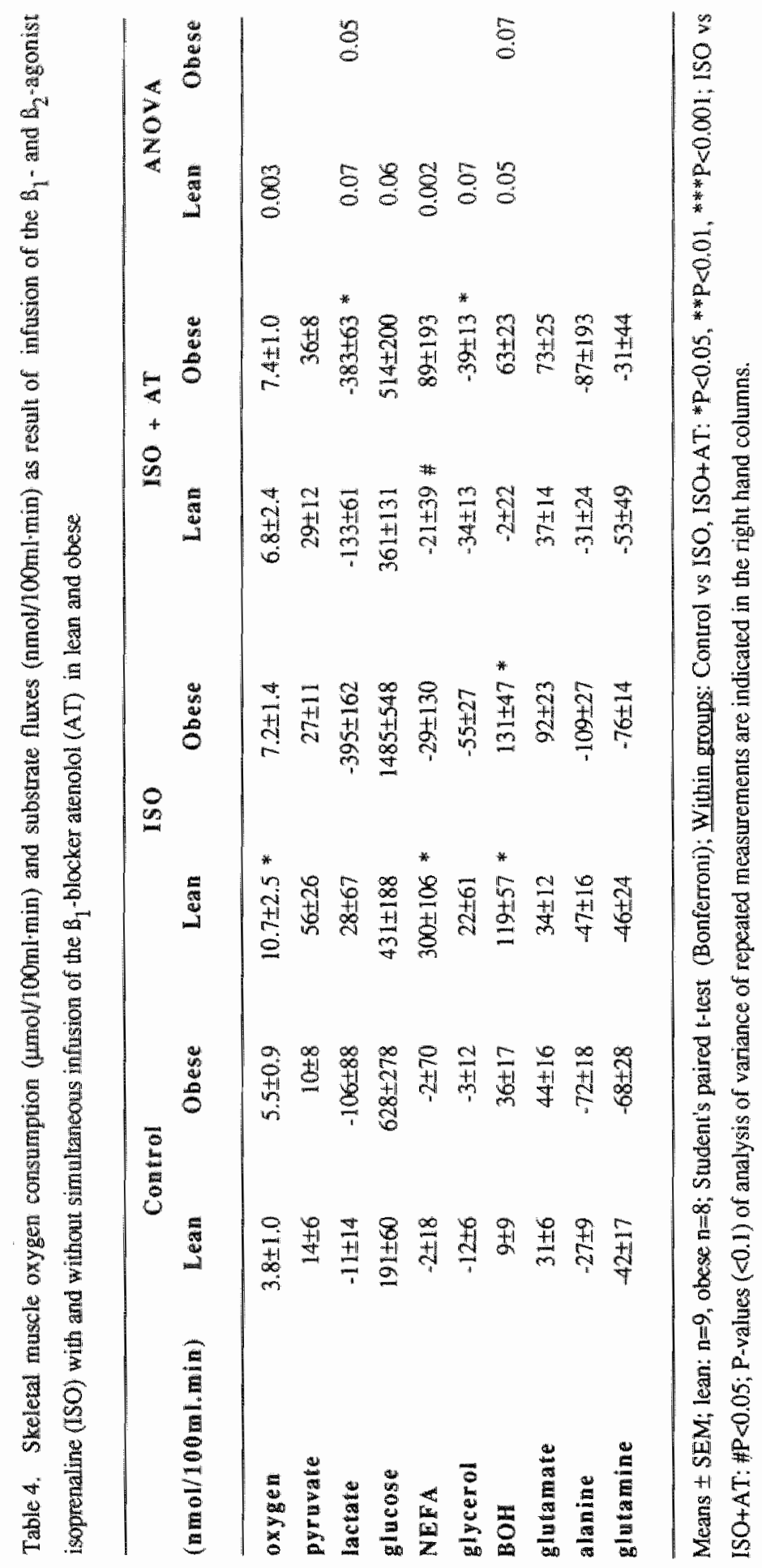


Glycerol flux did not change in the lean, whereas in obese subjects there was an increased release with ISO (Paired t-test, Bonferroni: $\mathrm{P}=0.06)$ and ISO+AT $(\mathrm{P}<0.05)$. The most pronounced differences in skeletal muscle metabolism between lean and obese with ISO or ISO+AT are summarized in figure 5.
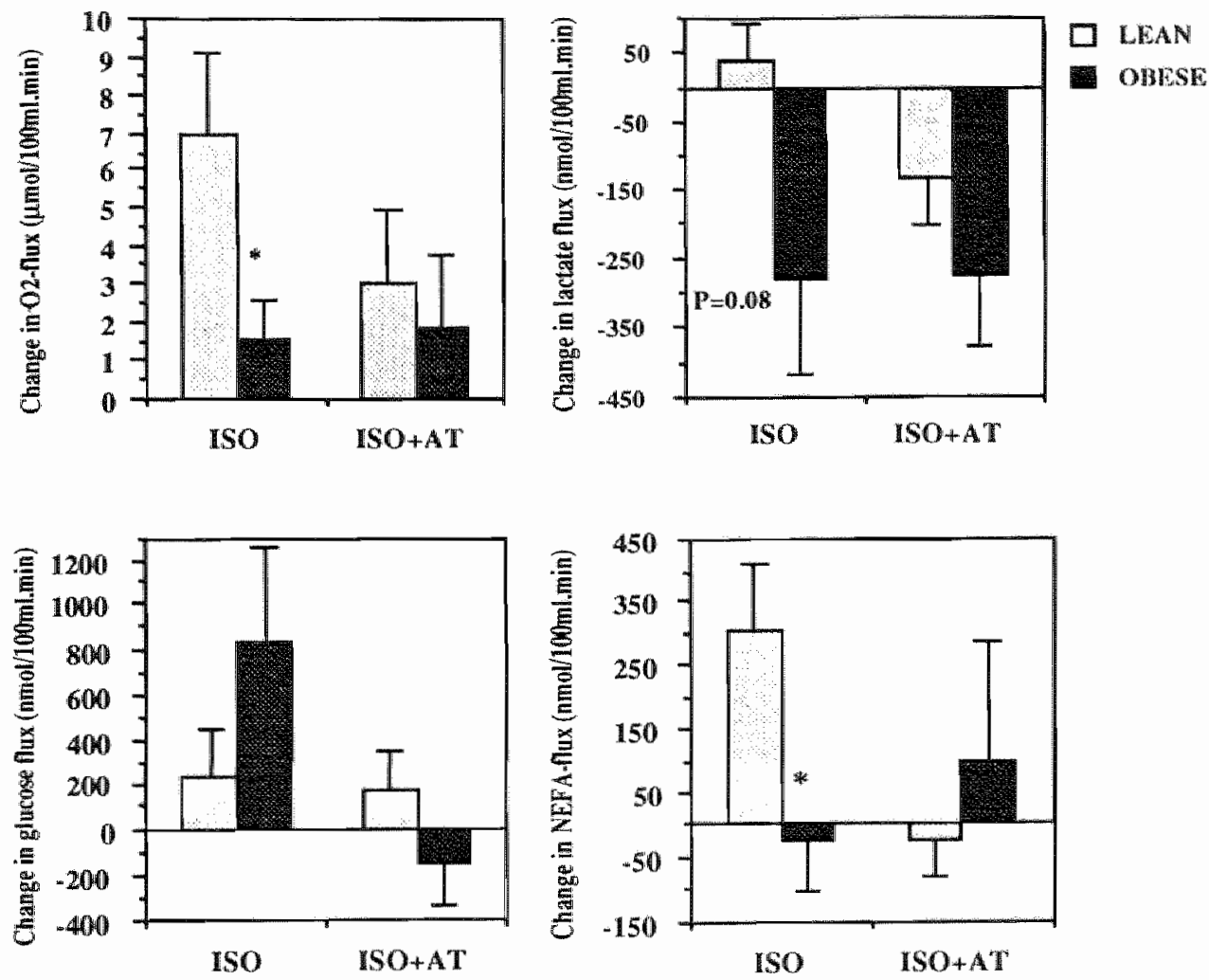

Fig 5. Changes in skeletal muscle oxygen, lactale, glucose and non-esterified fatty acids (NEFA) fiux as result of infusion of the $B_{1}-B_{2}$-agonist isoprenaline ( $\mathrm{SO}$ ) with and without the $B_{1}$ - blocker atconolol (AT) in lean and obese subjects. Means \pm SEM; lean: $n=9$, obese: $n=8$; one-way ANOVA: $P<0.05$. 


\section{Discussion}

\section{IIsoprenaline-induced thermogenesis}

Obesity thas been associated with a diminished thermogenic response during the infusion of sympathomimetics, but these findings are controversial $(11,22,23)$. In the present study the $B_{1}-, B_{2}$-mediated increase in energy expenditure was similar in lean and obese men, so were the mean plasma ISO concentration and the ISO-induced increase in plasma norepinephrine and decrease in epinephrine. This indicates a normal thermogenic responsiveness to sympathomimetics in obese, which is in line with findings of a recent study using epinephrine infusion (11). For practical reasons we did not measure energy expenditure during the skeletal muscle experiment in obese subjects. In the previous experiment in lean men the increase in energy expenditure with ISO and ISO+AT (at a plasma ISO of $165 \mathrm{pg} / \mathrm{ml}$ ) was $16.4 \pm 1.3$ and $8.0 \pm 1.0 \%$, respectively. Since the infused dose of the $B_{1}$-blocker atenolol was sufficient for an effective $\beta_{1}$-blockade and a high $B_{1}$ selectivity $(12,30)$, the increase in EE with ISO+AT can be mainly contributed to $B_{2}$ adrenergic stimulation. In addition, we showed in another study that both $B_{1}$ - and $B_{2}$ adrenoceptors are involved in the sympathetically mediated thermogenesis ( 7$)$. It is known from literature that obesity does not exert any effect on the kinetics of the water soluble $B_{1}$-blocker atenolol (18), which indicates that the achieved level of $B_{1}$-blockade must have been similar in lean and obese. Assuming a comparable level of $\beta_{1}$-blockade in lean and obese subjects, the similarity in ISO-induced thermogenesis and heart rate responses (with ISO and ISO+AT) suggests that the contribution of the $B_{1}$ - and $B_{2}$ adrenoceptors to the sympathetically mediated thermogenesis is of the same magnitude in both groups.

Although the whole body thermogenic response to ISO was similar in lean and obese subjects, there were pronounced differences in substrate metabolism with $B_{1}$ - and $B_{2}$ adrenergic stimulation. With $1 \mathrm{SO}$, both the mobilization of fat stores and the oxidation of fat appeared to be impaired in the obese as compared to lean subjects.

\section{Isoprenallne-Induced llpolysis}

The rise in arterial glycerol and NEFA during ISO-infusion is lower in obese than lean subjects, which may indicate an impaired B-adrenergic lipolysis in the obese. Secondly, since insulin is an important inhibitor of lipolysis, the higher insulin concentrations during ISO-infusion in obese subjects may also be an explanation for the lower lipolysis. Important in this respect is that we cannot exclude a difference in insulin sensitivity of adipose tissue between lean and obese subjects. Recent studies indicate that, in obese subjects, lipolysis in the resting situation (per unit fat mass) may be normally sensitive to insulin $(14,19)$. Nevertheless, adipose tissue hormone sensitive lipase and lipoprotein lipase fail to respond to insulin postprandially in obese as compared to lean subjects, which may indicate a stronger insulin resistance of adipose tissue after a meal in obese subjects (14). In addition to this, in lean volunteers it has recently been shown that the effects of insulin on lipolysis in vivo may be strongly counteracted by beta-adrenergic 
stimulation (21). Thus, whether the different degrees of hyperinsulinemia during $1 \mathrm{SO}$ infusion in lean and obese subjects could have been implicated in the differences in plasma NEFA and glycerol remains questionable.

A third factor that may contribute to differences in the ISO-induced release of glycerol and NEFA is the magnitude of the B-adrenergically mediated blood flow response. Adipose tissue blood flow may play an important role in the mobilization of fat stores by affecting the delivery of $1 S O$ and transport proteins for fatty acids to the tissue. In addition, a model has been proposed which suggests that the rate of reuptake and reesterification of fatty acids within adipose tissue may be controlled by adipose tissue perfusion (15). Recent experiments in our laboratory have shown that the ability to increase abdominal adipose tissue blood flow as result of $\mathbb{B}$-adrenergic stimulation is less in obese than in lean subjects (6), which might result in a higher fatty acid recycling within adipose tissue in obese subjects.

In contrast to the lower circulating NEFA and glycerol concentrations with sympathetic stimulation in obese than lean, basal glycerol levels were higher in the obese, which may indicate an increased basal lipolysis in obese. However, basal glycerol, expressed per $\mathrm{kg}$ fat mass, decreased with increasing degree of obesity $(r=0.7, P<0.001)$, which indicates an impaired lipolysis. This impaired lipolysis may be explained by the higher basal plasma insulin levels in obese subjects as compared to lean since recent studies suggest that basal lipolysis (per unit fat mass) in uncomplicated obesity is normally sensitive to insulin $(14,19)$. The abovementioned findings suggest that both in the resting state and after themogenic stimulation obese cannot make use of their (increased) fat stores as efficiently as lean subjects.

\section{Forearm muscle metabolism}

A factor that might disturb the results when comparing forearm skeletal muscle metabolism in lean and obese is that the contribution of the different forearm tissues to total forearm blood flow may be different. Therefore, skeletal muscle blood flow was estimated by determining total, subcutaneous fat and skin blood flow and by measuring forearm composition.

\section{$B_{1}$ - and $B_{2}$-adrenergic stimulation}

The impaired mobilization of fat stores during ISO infusion in obese is accompanied by a diminished oxidation of NEFA in comparison with lean subjects. During infusion of increasing doses of isoprenaline, there was a significant decrease in the respiratory exchange ratio in lean but not in obese subjects, which indicates a higher fat oxidation in lean subjects. This is confirmed in our data on skeletal muscle metabolism with $B_{1}$ - and $B_{2}$-adrenergic stimulation (ISO), where muscle NEFA uptake was significantly increased in the lean but not in the obese. The increased NEFA uptake in lean was accompanicd by an increased muscle oxygen consumption, which suggests an increased NEFA oxidation. In contrast, in obese subjects glucose seems to be the preferred substrate above fatt, which is reflected in an increased muscle glucose uptake and lactate release. The latter findings suggest an increased glycolysis which may be accompanied by an increased glycogenolysis, as reported with epinephrine infusion $(24,34)$. Taken together, in obese 
subjects skeletal muscle fatty acid uptake and/or oxidation with $B_{1}$-and $B_{2}$-adrenergic stimulation seems to be impaired, which is compatible with a recent study reporting a lower fractional fatty acid oxidation ( $\%$ of total plasma flux) with adrenaline infusion in obese than lean subjects (11). A factor contributing to the diminished fatty acid oxidation in obese may be simply the lower arterial concentrations of fatty acids in obese than lean subjects, which may result in a lower fatty acid uptake by muscle (20). Additionally, a recent study reported a lowered fatty acid oxidation during exercise in obese (45), which may be due to a lower proportion of slow-twitch, type 1, oxidative muscle fibres $(29,45)$. Thus, a factor contributing to the observed difference in fatty acid oxidation may be that obese subjects due to a relative low proportion of slow twitch oxidative fibres are unable to use fatty acids as efficiently as lean. Further, it has been shown that most responses to $B$-adrenergic stimulation are greater in slow-twitch oxidative than in their fast-twitch glycollytic type 2 counterparts (36). This might be an explanation why in obese the increase in skeletal muscle oxygen consumption with $B_{1}$-and $B_{2}$-adrenergic stimulation is less than in lean. Thirdly, it has been shown that the membrane transport of long chain fatty acids may be under $B$-adrenergic control (1), which implicates that differences in the activation of this transport between lean and obese subjects may contribute to the observed differences in muscle fatty acid uptake. However, at present evidence is lacking to support this speculation.

The diminished rise in metabolic activity of skeletal muscle during ISO in obese subjects was accompanied by a lowered rise in muscle blood flow in obese as compared to lean subjects. A blunted blood flow response in obese subjects has been reported before after oral glucose loading (4). The exact mechanism behind the lower blood flow response during ISO is not clear. In rats, it has been reported that the capacity for blood flow may be proportional to differences in oxidative capacity among fibre types (43). Taking these findings into account, it can be speculated that the lower capacity to increase blood flow in obese than lean subjects may be related to differences in muscle fibre pattern. Furthermore, it has been shown that insulin infused during euglycemic clamp studies may increase skeletal muscle blood flow in a dose-dependent fashion and that obese due to their insulin resistance exhibit a lower sensitivity to insulin's effect to increase blood flow (25). However, whether insulin has an important effect on skeletal muscle blood flow during B-adrenergic stimullation remains to be established.

\section{$B_{2}$-adrenergic stimulation}

With $B_{2}$-adrenergic stimulation (ISO+AT), in obese and lean subjects plasma NEFA and glycerol concentrations were no longer increased, which suggests that the sympathetically mediated increase in lipolysis is mainly mediated by $\mathbb{B}_{1}$-adrenoceptors. Both groups showed an increased lactate release, which may indicate, as mentioned above, an increased glycolysis and glycogenolysis $(24,34)$. In addition, with epinephrine infusion the increased glycolysis has reported to be accompanied by an increased content of tricarboxylic acid intermediates (42), which suggests an increased glucose oxidation. The changes in whole body thermogenesis with ISO in the obese and with ISO+AT in both groups were not reflected in changes in skeletal muscle oxygen consumption, whereas the changes in skeletal muscle substrate fluxes suggest that skeletal muscle is of 
importance in the $B_{2}$-mediated component of thermogenesis. This apparent discrepancy may be due to the relatively large standard error in the measurement of skeletal muscle oxygen flux, which makes it unlikely to detect a small increase in whole body energy expenditure at skeletal muscle level.

Taken together, in lean subjects the increase in muscle oxygen consumption with ISO was sufficient to explain the total rise in thermogenesis (assuming a total muscle mass of $40 \%$ of body weight $)$, which suggests that an important part of the $B_{1}$ - and probably $B_{2}$ adrenergic thermogenesis is localized in skeletal muscle. With ISO, the $B_{1}$-component seemed to be most important by indirectly increasing muscle fatty acid oxidation, which resulted in an inhibition of the $B_{2}$-mediated glycolytic component. This inhibition of the glycolytic pathway supports the operation of the glucose-fatty acid cycle, an old concept (33) which recently received new support $(27,46)$. In obese subjects, skeletal muscle seems to be less important in the ISO-induced thermogenesis. The consistent findings on skeletal muscle lactate flux with ISO and ISO+AT in obese indicate that the $B_{2}$-mediated component may be localized in skeletal muscle, whereas the increase in energy expenditure due to the $B_{1}$-component might be located in other tissues, such as adipose tissue through an increased triglyceride-fatty acid cycling.

In conclusion, although the thermogenic response to isoprenaline is similar in lean and obese, there are pronounced differences in substrate metabolism. In obese subjects, the ISO-induced increase in the mobilization of fat stores is impaired as compared to lean subjects. In addition, despite a twofold elevation in arterial NEFA concentrations there is no change in muscle NEFA uptake in obese subjects, which suggests an impaired ability of muscle to take up or oxidize fat. This lowered utilization of fat may favor the storage of triglycerides and the maintenance of large fat stores.

\section{References}

1. Abumrad N.A., C.R. Park, and R.R. Whitesell. Catecholam ine activation of the membrane transport of long chain fatty acids in adipocytes is mediated by cyclic AMP and protein kinase. J. Biol. Chem. 261: $13082-13086,1986$.

2. Ahlquist R.D. A study of adrenotropic receptors. Am. J. Physiol. 153: 586-600, 1948.

3. Astrup A., T. Andersen, N.J. Christensen, J. Bülow, J. Madsen, L. Breum, and F. Quaade. Impaired glucose-induced thermogenesis and arterial norepinephrine response persists after weight reduction in obese humans. Am. J. Clin. Nutr. 51:331-337, 1990.

4. Baron A.D., M. Laakso, G. Brechtel, B. Hoit, C. Wau, and S.V. Edelman. Reduced postprandial skeletal muscle blood flow contributes to glucose intolerance in human obesity. J. Clin. Endocrinol. Metab. 70: 1525-1533, 1990.

5. Blaak E.E., M.A. van Baak, G.J. Kemerink, M.T.W. Pakbiers, G.A.K. Heidendal, and W.H.M. Saris. Effect of beta-adrenergic stimulation on forearm skeletal muscle metabolism. Submitted to Am. J. Physiol. (Endocrinol. Metab.).

6. Blaak E.E., M.A. van Baak, G.J. Kemerink, M.T.W. Pakbiers, G.A.K. Heidendal, and W.H.M. Saris. Beta-adrenergic stimulation and abdominal subcutaneous fat blood flow in lean, obese and reduced- 
obese subjects. Submitted to Clin. Sci.

7. Blaak. E.E, M.A. van Baak, K.P.G. Kempen, and W.H.M Saris. Role of alpha and beta adrenoceptors in the sympathetically-mediated thermogenesis. Am. J. Physiol. 264 (Endocrinol. Metab. 27): E11E17, 1993.

8. Búllow I. Adipose tissue blood llow during exercise. Dan. Med. Bull. 30: 85-100, 1983.

9. Buflow I. R. Jelnes, A. Astrup, and I. Madsen. Tissue-blood partition coefficients for xenon in warious adipose ussue depots in man. Scand J. Clin. Lab. Invest. 47:1-3,1987.

10. Cobbald A.F. J. Ginsburg, and A. Paton. Circulatory, respiratory and metabolic responses to isopropylnoradrenaline in man. J. Physiol. 151: 539-550, 1960.

11. Connacher A.A., W.M. Bennet, R.T. Jung, D.M. Bier, C.C.T. Smith, C.M. Scrimgeour, and M.J. Rennie. Effect of adrenaline infusion on fatty acid and glucose turnover in lean and obese human subjects in the postabsorptive and fed states. Clin. Sci. 81: 635-644, 7991.

12. Conway F.J. Human phamocokinetic and pharmacodynamic studies on atenolol ICI 66082 . Brit. J. Clin. Pharnacol. 3: 267-272, 1976.

13. Cooper K.E., O.G. Edholm, and R.F. Mottram. The blood flow in skin and muscle of the human forcarm. J. Physioll. 128: 258-267, 1955.

14. Coppack S.W., R.D. Evans, R.M. Fisher, K.N. Frayn, G.F. Gibbons, S.M. Humphreys, M.L. Kirk, J.L. Potts, and T.D.R. Hockaday. Adipose tissue metabolism in obesily: lipase action in vivo before and after a mixed meal. Metabolism 41: 264272, 1992.

15. Edens N.K., R.L. Leibel, and J. Hirsch. Mechanism of free faty acid re-esterification in human adipocyles in vitro. J. Lipid Res. 31: 1423-1431, 1990.

16. Elia M., P. Folmer, A. Schlatman, A. Goren, and S. Austen. Carbohydrate, fat and protein metabolism in muscle and in the whole body after mixed meal ingestion. Metabolism: 37: 542-551, 1988.

17. Engelhart M., L.J.Petersen, and J.K. Christensen. The local regulation of blood flow evaluated simultaneously by 133-xenon washout and Laser Doppler Flowmetry. J. Invest. Dermatol. 91 : 451. $453,1988$.

18. Galletu F. M.L. Fasano, L.A. Ferrara, A. Groppi, M. Montagna, and M. Mancini Obesity and Betablockers: infuence of body fat on their knetics and cardiovascular effects. J. Clin. Phamacol. 29: $212-216,1989$.

19. Groop L.C., C. Bonadonnat, D.C. Simonson, A.S. Potrides, M. Shank, and R.A. DeFronzo. Effect of insulin on oxidative and nonoxidahive pathways of free faty acid metabolism in human obesity. Am. J. Plyysiol. 263 (Endocrinol. Metab. 26): E79-E84, 1992.

20. Hagenfeldt $L_{\text {.n }}$ and J. Wahren. Human foream muscle metabolism during exercise. II. Uptake, release and oxidation of individual FFA and glycerol. Scand. J. Lab. Inwest. 21: 2633.276, 1968.

21. Hagström-Toft E. P. Arner, U. Johannsson, L.5. Eriksson, U. Ungerstedt, and J. Bolinder. Effect of insulin on human adipose lissue metabolism in situ. Interactions with beta-adrenoceptors. Diabetologica 35: 664-670, 1992.

22. Jung R.T. P.S. Shetly. W.P.T. James, M. Barrand, and M. Callingham. Reduced thermogenesis in obesily. Nature (London) 279: 322-323, 1979.

23. Katzeff H.L., M. O'Connell, E.S. Horton, E. Danforth, J.E. Young, and L. Landsberg. The sympathetic nervous system in human obesity. Int. J. Obes. 9 (suppl. 2): 131-137, 1985.

24. Kirby C.R., and M.E. Tischler. B-adrenergic effects on carbohydrate metabolism in the unweighted rat soleus muscle. J. Appl. Physiol. 69(6): 2113-2119, 1990.

25. Laakso M., S.V. Edelman, G. Brechtel, and A.D. Baron. Decreased effect of insulin to stimulate 
skeletal muscle blood flow in obese man. A novel mechanisn for insulin resistance. J. Clin. Invest. 85: $1844-1852,1990$

26. Larsen O.A. N.A. Lassen, and F. Quaade. Blood how through human adipose tissue determined with radioactive xenon. Acta Physiol. Scand. 66: 337-345, 1966.

27. Lillioja S., C. Bogardus, D.M. Mot, A.L. Kennedy, W.C. Knowler, and B.V. Howard. Relationship between insulin-mediated glucose disposal and lipid metabolism in man. J. Clin. Invest. 75: 1106$1115,1985$.

28. Lillioja S., J. Foley, C. Bogardus, D. Mot, and B.V. Howard. Free fatty acid metabolism and obesity in man: in vivo and in vitro comparisons. Metabolism 35: 505 -514, 1986.

29. Lillioja S., A.A. Young, C.L. Culter, J.L. Ivy, W.G.H. Abbot, J.K. Zawadzki, H. Yki-Jarvinen, L. Christin, T.W. Secomb, and C. Bogardus. Skeletal muscle capilary density and fiber type are possible determinants of in viwo insulin resistance in man. I. Clin. Inwest. 80:415-424, 1987.

30. Lipworth B.J., L.C. McFarlane, W.J. Coutie, and D.G. McDewitt. Evaluation of the metabolic responses to inhaled salbutamol in the measurement of $B_{2}$-adrenoceptor blockade. Eur. J. Clin. Pharmacol. 37: 297-300, 1989

31. Madsen J. A. Malcow-Möller, and S. Waldorft. Continuous estimation of adipose tissue blood flow in rats by ${ }^{133}$ Xe elimination. J. Appl. Physiol. 39(5): 851-856, 1975.

32. Prentice A.M, A.E. Black, W.A. Coward, H.L. Davies, G.R. Goldberg, P.R. Murgauroyd, J. Ashford, M. Sawyer, and R.G. Whitehead. High levels of energy expenditure in obese women. Brit. Med. J. 292; 983-987, 1986.

33. Randle P.J., OP.B. Garland, C.N. Hales, and E.A. Newsholme. The glucose-fatty acid cycle. Its role in insulin sensitivity and the metabolic disturbances of diabetes mellitus. Lancet i: 785-789, 1963.

34. Raz I., A. Katz, and M.K. Spencer. Epinephrine in hibits insulin-mediated glycogenesis but entrances glycolysis in human skeletal muscle. Am. J. Physiol. 260 (Endocrinol. Metab. 23): E430-E435, 1991.

35. Ravussin E., S. Lillioja, W.C. Knowler, L. Cristin, D. Freymond, W.G.H. Abbou, V. Boyce, B.V. Howard, and $\mathrm{C}$. Bogardus. Reduced rate of energy expenditure as a risk factor for body weight gain,. New Engl. J. Med. 318: 467-472, 1988.

36. Sanders Williams R. Adrenergic receptors of skeletal muscle. Biochenistry of exercise XI, ed B. Saltin. Int series on sport sciences 16. Human Kinetics Publishers, Champaign, 1986.

37. Saumet J.L., D.L. Kellog, W.F. Taylor, and J.M. Johnson. Cutaneous Laser Doppler flowmetry: infiluence of underlying muscle blood flow. J. Appl. Physiol. 65(1):478-481, 1988.

38. Segal K.R., A. Edano, and M.B. Tomas. Thermic effect of a meal over 3 and 6 hours in lean and obese men. Metabolism 39: 985-992, 1990.

39. Siri W.E. The gross composition of the body. Adv. Biol. Med. Physiol. 1956; 4: 239-180.

40. Sejrsen P. blood flow in cutaneous tissue studied by washout of radioactiwe xenon. Circ. Rest. XXV: $215-229,1969$

41. Smedes F., J.C. Kraak, and H. Poppe. Simple and fast solvent extraction system for selective and quantitative isolation of adrenaline, noradrenaline and dopamine from plasma and urine. $J$. Chromalogr. 231: 25-39, 1982

42. Spencer M.K., A. Katz, and I. Raz. Epinephrine increases tricarboxylic acid cycle intermediates in human skeletal muscle. Am. J. Physiol. 260 (Endocrinol. Metab. 23): E436-E439, 1991.

43. Terjung R.L., and B.M. Engbretson. Blood flow to different rat skeletall muscle fiber type sections during isometric contractions in situ. Med. Sci. Sports Exerci. 20 (no 5, suppl) : S124-\$130, 1988.

44. Vernet O., C.A. Nacht, L. Christin, Y. Schut, E. Danforth, and E. Jequier. Badrenergíc blockade and 


\section{Chapter 6}

intravenous nutrient-induced themogenesis in lean and obese women. Am. J. Physiol. 253 (Endocrinol. Mctab. 16): E65-E71, 1987.

45. Wade A.J., M.M. Marbut, and J.M. Round. Muscle fibre type and aetiology of obesity. Lancet 335 : $805-808,1990$.

46. Walker M., G.R. Fullcher "C. Catalano, G. Petranyi, H. Orskov, and K.G.M.M. Alberti. Physiological levels of plasma non esterified faty acids impair forearm glucose uptake in normal man. Clin. Sci. 79 : $167-174,1990$.

47. Weir J.B. New methods for calculating metabolic rate with special reference to protein metabolism. J. Physial. 109: 1-9, 1949.

48. Welle S., G.B. Forbes, M. Statt, R.R. Barnard, and J.M. Amatruda. Energy expenditure under freeliving conditions in normal weight and overweight women. Am. J. Clin. Nutr. 55: 14-21, 1992.

49. Whitrey R.J. The measurement of volume changes in human limbs. J. Physiol 121:1-27, 1953.

50. Zurlo F., S. Lilioja, A. Esposito-Del Puente, B.L. Nyomba, I. Raz, M.F. Saad, B.A. Swinburn, W.C. Knowler, C. Bogardus, and $\mathrm{E}$. Ravussin. Low ratio of fat to carbohydrate oxidation as predictor of weight gain: study of 24-h RQ. Am. I. Physiol. 259 (Endocrinal. Metab. 22): E650-E657, 1990. 


\title{
CHAPTER 7
}

\section{Beta-adrenergically mediated thermogenic and heart rate response: effect of obesity and weight loss}

\author{
E.E. Blaak, M.A.van Baak, A.D.M. Kester* and W.H.M. Saris
}

Department of Human Biology and * Department of Methodology and Statistics, Uniwersity of Limburg, Maastricht, The Netherlands

Submitted to J. Clin. Invest.

\section{Abstract}

The $B$-adrenergically mediated thermogenic and heart rate response, as assessed by means of stepwise intravenous infusion of the B-agonist isoprenaline (ISO), were evaluated by means of partial correlation analysis in a group of men with a wide range of adiposity $(n=30)$ and in a subgroup of 16 obese males after weight loss. The B-adrenergically mediated thermogenesis (open circuit ventilated hood system) was blunted in obese subjects, as reflected by a significant positive correlation between \% body fat (hydrostatic weighing) and the plasma ISO concentration to increase resting energy expenditure by $15 \%$ ( $\mathrm{P}<0.001$ ). The magnitude of the $\mathrm{B}$-adrenergically mediated heart rate response was (negatively) associated with the basal plasma norepinephrine concentration (NE, $\mathrm{P}<0.001)$. Weight reduction resulted in a significant increase in the thermogenic and heart rate response in obese subjects to similar values as in lean subjects. Furthermore, the increase in thermogenic response as result of weight loss was negatively related to the average magnitude of thermogenic response $(\mathrm{P}<0.01)$ and positively related to the initial $\%$ body fat $(\mathrm{P}<0.05)$. The increase in heart rate response as result of weight loss was positively related to the decrease in basal $\mathrm{NE}(\mathrm{P}<0.01)$ and the change in $\%$ body fat $(\mathrm{P}<0.05)$. In conclusion, the degree of adiposity was shown to be negatively related with the magnitude of the B-adrenergically mediared thermogenesis, whereas the heart rate response was merely related to basal NE. Since weight loss resulted in a significant increase in the thermogenic response, the blunted thermogenic response does not seem to be a primary factor contributing to the development of obesity.

\section{Introduction}

Obesity has previously been reported to be associated with a blunted sympathetically mediated thermogenesis $(1,13)$, which may be a factor contributing to an increased 
efficiency of energy expenditure and may thereby be of importance in the development and maintenance of excess body weight. However, data on an impaired sympathetically mediated thermogenesis in obesity are not consistent. Several recent studies suggest a similar thermogenic response in lean and obese subjects after infusion of catecholamines (10) or a B-agonist (4). The possibility exists that there are small differences in the sympathetically mediated thermogenesis between lean and obese subjects which are hard to detect, but may be of physiological significance over longer periods of time.

Weight reduction, as well as merely the hypocaloric state, has been shown to decrease various indexes of basal sympathetic actvity in obese subjects, such as norepinephrine appearance rate (19) and circulating plasma norepinephrine (3). A diminished basal sympathetic activity is expected to be associated with the development of supersensitivity to agonist stimulation and upregulation of adrenoceptor numbers (16). However, both diminished (11) and increased (3) sympathetically mediated physiological responses have been reported in obese subjects as result of weight loss. It remains to be clarified by what factors the (change in) $B$-adrenergically mediated thermogenesis as result of weight loss is determined and how this relates to the initial $\mathbb{B}$-adrenergic thermogenesis in obese subjects.

The present study was intended to investigate the B-adrenergically mediated thermogenesis and heart rate response in a relatively large group of subjects with a wide range of adiposity to increase the probability of detecting small differences between lean and obese subjects. Several other factors that may have an impact on the B-adrenergic sensitivity, like age and basal sympathetic activity (as reflected by the basal plasma norepinephrine concentration, 22), were also taken into account. In addition, the effect of weight reduction on the B-adrenergically mediated thermogenesis and heart rate response was evaluated.

\section{Subjects and method's}

In this study, body composition and the B-adrenergically mediated heart rate and thermogenic response were determined in a group of lean males $(n=9, \%$ body fat $5-20)$, obese males ( $n=13$, \% body fat $25-30$ ) and very obese males ( $n=8, \%$ body fat $30-40) .16$ obese males were also studied after a period of weight reduction. Physical characteristics of the subjects are indicated in table 1. All subjects were normotensive and in good health as assessed by a medical history and physical examination. The study protocol was reviewed and approved by the Ethics Committee of the University of Limburg and all subjects gave their written consent.

\section{Body composition}

Body composition was determined by hydrostatic weighing with simultaneous lung volume measurement (Volugraph 2000, Mijnhardt, the Netherlands). Body composition was calculated according to the formula of Siri (20). 
Table 1. Physical characteristics of the subjects.

\begin{tabular}{|c|c|c|c|}
\hline & $\begin{array}{r}\text { Iean mrales } \\
n=9\end{array}$ & $\begin{array}{r}\text { obese males } \\
\mathrm{n}=13\end{array}$ & $\begin{array}{l}\text { very obese males } \\
\qquad n=8\end{array}$ \\
\hline Age $(y)$ & $21.6 \pm 0.5$ & $32.6 \pm 1.38$ & $33.9 \pm 2.08$ \\
\hline Weight (kg) & $73.7 \pm 4.3$ & $100.0 \pm 2.0 \$$ & $110.4 \pm 9.1 \$$ \\
\hline Body mass index $\left(\mathrm{kg} / \mathrm{m}^{2}\right)$ & $22.3 \pm 1.0$ & $31.0 \pm 0.4 \S$ & $33.6+2.38$ \\
\hline \% Body fat & $11.6 \pm 1.3$ & $26.9 \pm 0.5 \S$ & $36.9 \pm 1.8 \mathrm{~s}$ \\
\hline Fat mass (kg) & $8.9 \pm 1.4$ & $26.5 \pm 0.7 \S$ & $39.0 \pm 4.8 \$$ \\
\hline Fat free mass $(\mathrm{kg})$ & $64.6 \pm 3.3$ & $72.2 \pm 1.2^{*}$ & $71.3 \pm 5.1 *$ \\
\hline
\end{tabular}

Means \pm SEM: Unpaired t-lest: lean vs obese, very obese: ${ }^{*}=\mathrm{P}<0.05, \xi=\mathrm{P}<0.001$, obese vs very obese: $q=\mathrm{P}<0.01, * \mathrm{P}<0.001$.

\section{ISO-Infusion test}

For the measurement of B-adrenergic sensitivity, the subjects were fasted from 8.00 P.M. the evening before and were allowed to drink water freely. The experiments started at 8.00 A.M., and the subjects came to the laboratory by car or bus. Room temperature was kept between $23-25^{\circ} \mathrm{C}$. After $30 \mathrm{~min}$ baseline measurement, the $B_{1}-$, $B_{2}$-agonist isoprenaline (ISO) was infused in increasing doses of $6,12,23$ and $46 \mathrm{ng} / \mathrm{kgFFM}_{\mathrm{Fmin}}$, each dose for $30 \mathrm{~min}$. The dose in the text is related to $1 S O$ sulphate, $69 \%$ of which corresponds to ISO free base. Whole body energy expenditure was determined by an open circuit ventilated hood system (Oxycon Beta, Mijnhardt, The Netherlands). Energy expendiure was calculated according to the abbreviated formula of Weir (23). After 15 min in each infusion period, a blood sample was taken in heparinized syringes and was put into a glutathione containing tube in ice. The sample was immediately centrifuged at $3000 \mathrm{rpm}$ at $4{ }^{\circ} \mathrm{C}$ and the plasma was stored at $-50{ }^{\circ} \mathrm{C}$. In the plasma samples concentrations of $I S O$ and $\mathrm{NE}$ were determined by high performance liquid chromatography (21). During the experiments heart rate was recorded continuously. When heart rate had risen 30 beats/min the infusion was stopped.

\section{Diet}

16 out of the 21 obese males subsequently followed a very low calorie diet of 2000 $\mathrm{kJ} / \mathrm{day}$, which provided $52 \mathrm{~g}$ protein, $50 \mathrm{~g}$ carbohydrate, $7 \mathrm{~g} \mathrm{fat,} 1.3 \mathrm{~g}$ sodium/day and a micronutrient content which meets the Dutch recommended daily allowances. In the fifth week the subjects returned in 2-3 days to their habitual eating pattern. The measurements of body composition and B-adrenergic sensitivity were repeated in the sixth week. Sodium concentrations in 24-h urine, collected before and after diet under conditions near energy balance, were determined by flame photometry. 


\section{Chapter 7}

\section{Calculations and Statistics}

Data in the text are presented as means \pm SEM. For each dose, energy expenditure and heart rate responses reached a steady state after $10 \mathrm{~min}$ ISO-infusion. Therefore, mean values of the last $20 \mathrm{~min}$ were taken as being representative for that dose. The respiratory exchange ratio (RER) reached a steady state after 20 min infusion after a rapid initial increase at the start of the infusion, as described before (5). The steady state value for RER was, therefore, taken as the mean of the last 10 min infusion.

B-Adrenergic sensitivity was defined as the dose or plasma concentration to increase resting energy expenditure by $15 \%$ for energy expenditure responses (Dose $\triangle E E=15 \%$ vs Conc $\triangle E E=15 \%$, respectively). In addition, the decrease in RER was determined at $\triangle \mathrm{EE}=15 \%$ (defined as $\triangle \mathrm{RER}(\triangle \mathrm{EE}=15 \%)$ ). The sensitivity for heart rate responses was defined as the dose or plasma ISO concentration to increase resting heart rate by 25 beats/min ( $\mathrm{CD} 25$ vs $\mathrm{CC} 25$, respectively). These values were determined by linear regression of response vs dose or plasma concentration. The relationship between the thermogenic and heart rate responses and body composition, age and basal norepinephrine concentration was evaluated by means of partial regression analysis. Mean vallues of body composition and B-adrenergic sensitivity between groups were compared by means of an unpaired t-test.

The effect of weight reduction on the B-adrenergically mediated heart rate and thermogenic response was evaluated in 16 obese subjects. Furthermore, we related the change in thermogenic and heart rate response to the magnitude of these variables. To avoid an artificial correlation (6) we took for this magnitude the average values before and after diet. Body composition and parameters of $B$-adrenergic sensitivity before and after diet were compared with a Student's paired $t$-test. A P-value smaller than 0.05 was regarded as statistically significant.

\section{Results}

As result of ISO-infusion there were dose- and plasma ISO concentration-related increases in heart rate and energy expenditure in all subjects, as reported before (5). As shown in table 2, resting energy expenditure (EE) and basal heart rate were significantly higher in (very) obese males as compared to lean males, whereas the respiratory exchange ratio (RER) and the basal plasma norepinephrine concentration (NE) were not significantly different between the groups. The Conc $\Delta \mathrm{EE}=15 \%$ en $\mathrm{CC} 25$ were significantly higher in very obese as compared to lean males, whereas the thermogenic and heart rate response related to the administered dose of ISO were not significantly different between groups. The decrease in the respiratory exchange ratio during ISOinfusion ( $\triangle \mathrm{RER}(\triangle \mathrm{EE}=15 \%)$ ) was significantly less in obese and very obese males as compared to lean males $(\mathrm{P}<0.05)$. 
Table 2. Resting energy expenditure (EE), respiratory exchange ratio (RER), basal plasma norepinephrine (NE), basal theart rate (HR) and B-adrenergic sensitivity in lean, obese and very obese males.

\begin{tabular}{|c|c|c|c|}
\hline & $\begin{array}{l}\text { leam males } \\
n=9\end{array}$ & $\begin{array}{r}\text { obese males } \\
n=13\end{array}$ & $\begin{array}{l}\text { very obese malles } \\
\qquad \mathbf{n}=\mathbf{8}\end{array}$ \\
\hline $\mathrm{EE}(\mathrm{kJ} / \mathrm{min})$ & $5.62 \pm 0.19$ & $6.38 \pm 0.181$ & $6.65 \pm 0.42 *$ \\
\hline RER & $0.81 \pm 0.01$ & $0.82+0.01$ & $0.83 \pm 0.01$ \\
\hline basal NE (pg/ml) & $135 \pm 13$ & $136 \pm 15$ & $162 \pm 18$ \\
\hline basal HR (beats/min) & $53.6 \pm 0.9$ & $62.5 \pm 2.7 \S$ & $67.7 \pm 4.28$ \\
\hline Dose $\triangle E E=15 \%(\mathrm{ng} / \mathrm{kgFFM} \mathrm{min})$ & $19.6 \pm 2.2$ & $22.0 \pm 2.0$ & $22.1 \pm 4.0$ \\
\hline Conc $\triangle \mathrm{EE}=15 \%(\mathrm{pg} / \mathrm{mI})$ & $108 \pm 11$ & $156 \pm 16$ & $207 \pm 23$ \\
\hline$\triangle \mathrm{RER}(\triangle \mathrm{EE}=15 \%)$ & $-0.05 \pm 0.02$ & $-0.01 \pm 0.01 *$ & $0.01 \pm 0.01 *$ \\
\hline $\mathrm{CD} 25(\mathrm{ng} / \mathrm{kgFFM} \mathrm{min})$ & $19.4 \pm 2.0$ & $24.2 \pm 2.2$ & $24.5 \pm 6.2$ \\
\hline $\mathrm{CC} 25(\mathrm{pg} / \mathrm{ml})$ & $116 \pm 16$ & $184 \pm 23$ & $230 \pm 39 *$ \\
\hline
\end{tabular}

Means \pm SEM: Unpaired t-test: lean vs obese, very obese:* $=\mathrm{P}<0.05, \xi=\mathrm{P}<0.01,1=\mathrm{P}<0.001$. The dose or plasma concentration of isoprenaline to increase resting energy expenditure by $15 \%$ is indicated as Dose $\triangle E E=15 \%$ or Conc $\triangle E E=15 \%$, respectively; The change in the respiratory exchange ratio (RER) at $\triangle E E=15 \%$ is indicated as $\triangle R E R(\triangle E E=15 \%)$; The dose or plasma concentration of isoprenaline to increase heart rate by 25 beats/min are indicated as $\mathrm{CD} 25$ or $\mathrm{CC} 25$, respectively.

Table 3 indicates partial correlations between the thermogenic and heart rate response and percentage body fat, basal NE and age, each with adjustment for the other two. Percentage body fat (adjusted for basal NE and age) was (negatively) correlated with the $B$-adrenergically mediated thermogenic response, as reflected by a significant positive correlation between the \% body fat and Conc $\triangle E E=15 \%$. Notably, this correlation was not seen when the thermogenic response was related to the administered dose of isoprenaline. Figure 1 shows the unadjusted correlation between $\%$ body fat and the plasma ISO concentration to increase energy expenditure by $15 \%$.

The basal norepinephrine concentration (adjusted for $\%$ body fat and age) was the only variable with a significant (negative) partial correlation with the $\beta$-adrenergically mediated heart rate response, as indicated by the positive partial correlation between basal $\mathrm{NE}$ and the plasma concentration or dose of isoprenaline to increase heart rate by 25 beats/min (CC25 or CD25, respectively). Partial correlations between the decrease in $\operatorname{RER}(\triangle E E=15 \%)$ and percentage body fat, basal $N E$ and age did not reach statistical significance. 
Chapter 7

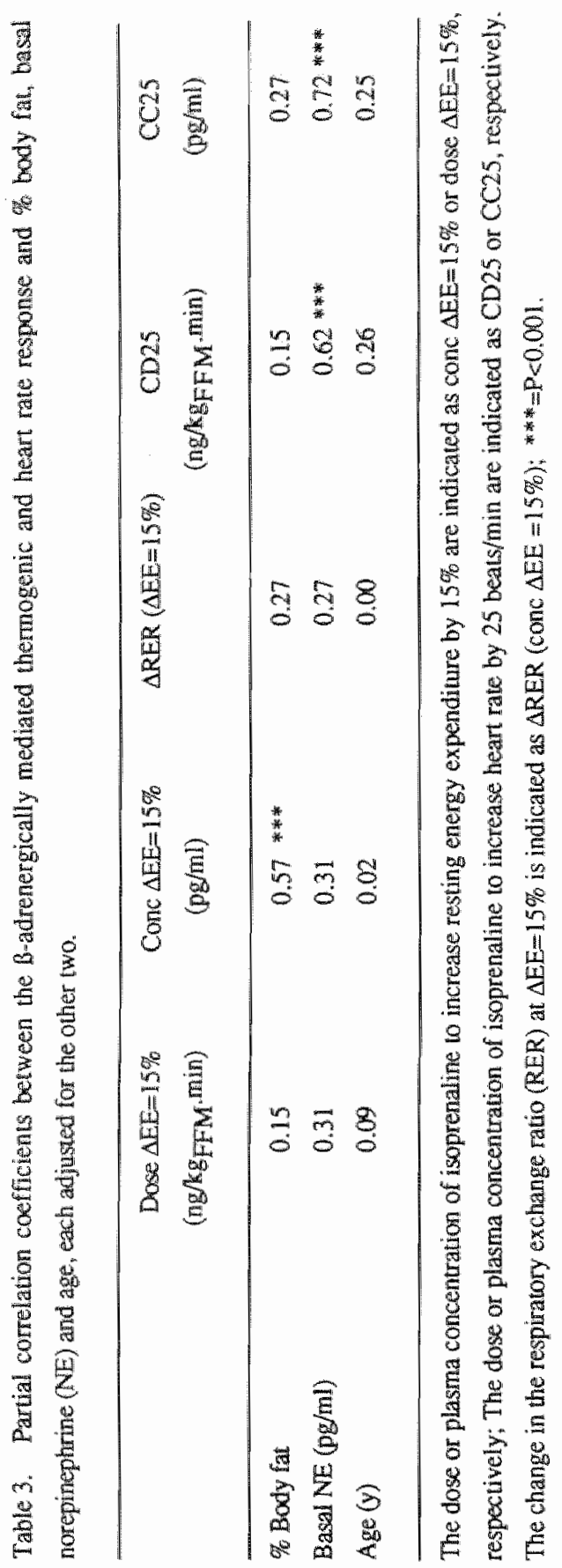




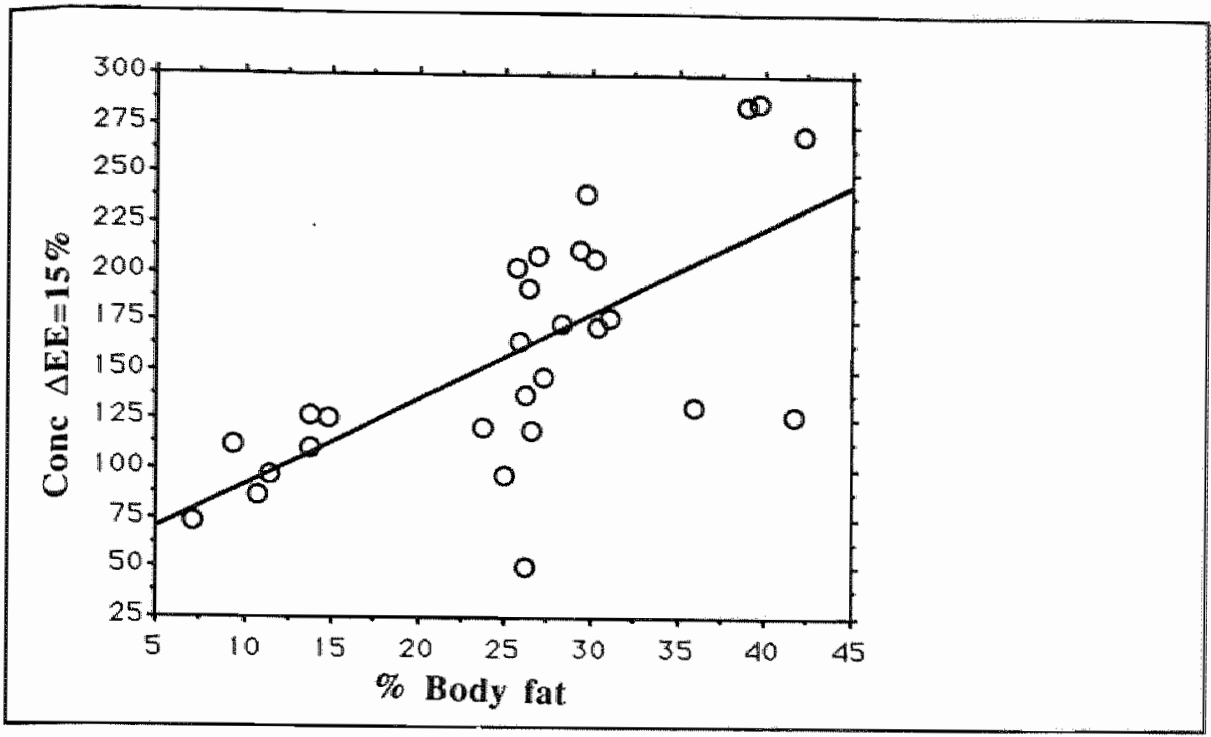

Fig 1. Simple (unadjusted) correlation between \% body fat and the plasma isoprenaline concentration to increase resting energy expenditure by $15 \%$ (conc $\Delta E E=15 \%$ ), $n=30, r=0.68, P=0.001$, standard error of estimate: $47 \mathrm{pg} / \mathrm{ml}$.

Table 4 indicates the changes in body composition, resting energy expenditure and indices of basal sympathetic activity and 3 -adrenergic sensitivity as result of weight loss. There was an average weight loss of $10 \mathrm{~kg}$, which can be explained for $70 \%$ by loss of fat mass and for $30 \%$ by loss of fat free mass. Resting metabolic rate decreased by $10 \%$ as result of weight loss. Basal norepinephrine concentration tended to be lower after weight reduction $(P=0.11)$. Basal heart rate significantly decreased as result of weight loss, whereas the B-adrenergically mediated thermogenesis and heart rate response were significantly higher after weight reduction as compared to before. There was no significant difference in the change in the respiratory exchange ratio at $\triangle E E=15 \%$ before as compared to after diet. The sodium excretion in 24-h urine was comparable before and after weight reduction and amounted $157 \pm 12 \mathrm{mmol} / 24 \mathrm{~h}$ vs $166 \pm 18 \mathrm{mmol} / 24 \mathrm{~h}$, respectively.

Table 5 indicates the partial correlations between the changes in the B-adrenergically mediated thermogenic and heart rate response and the (changes) in body composition and basal norepinephrine (NE), each adjusted for the other variables. The initial body fat percentage and the magnitude of Conc $\triangle \mathrm{EE}=15 \%$ (see methods) appeared to be positively correlated with the change in ISO-induced thermogenic response. Furthermore, the change in \% body fat and in basal NE appeared to be positively correlated with the change in $\mathrm{CC} 25$. 
Table 4. Body composition, resting energy expenditure (EE), basal plasma norepinephrine (NE), basal heart rate (HR) and B-adrenergic sensitivity before and after weight loss in obese males

\begin{tabular}{|c|c|c|}
\hline & Before & After \\
\hline Weight (kg) & $104.8 \pm 4.4$ & $94.3 \# 4.5$ \\
\hline Body fat & $29.7 \pm 1.2$ & $25.7 \pm 1.3$ \\
\hline Fat mass (kg) & $31.1 \pm 2.6$ & $23.7 \pm 2.7$ \\
\hline Falt free mass $(\mathrm{kg})$ & $72.5+2.3$ & $69.4 \pm 2.4$ \\
\hline $\mathrm{EE}(\mathrm{kJ} / \mathrm{min})$ & $6.48 \pm 0.23$ & $5.81 \pm 0.17$ \\
\hline Basa NE (pg/mi) & $149 \pm 14$ & $117 \pm 9$ \\
\hline Basal HR (beais/min) & $64.6 \pm 2.6$ & $55.5 \pm 1.6$ \\
\hline Conc $\Delta E E=15 \%(\mathrm{pg} / \mathrm{ml})$ & $165 \pm 17$ & $104 \pm 7 \S$ \\
\hline$\triangle \mathrm{RER}(\triangle \mathrm{EEE}=15 \%)$ & $-0.01 \pm 0.01$ & $-0.02 \pm 0.01$ \\
\hline $\mathrm{CC} 25(\mathrm{pg} / \mathrm{ml})$ & $217 \pm 31$ & $165 \pm 21 *$ \\
\hline
\end{tabular}

Means $\pm S E M, n=16$; The plasma concentration of isoprenaline to increase resting energy expenditure by $15 \%$ is indicated as conc $\triangle E E=15 \%$; The plasma concentration of isoprenaline to increase theart rate by 25 beats/min is indicated as $\mathrm{CC} 25$. The change in the respitatory exchange ratio (RER) at $\triangle E E=15 \%$ is indicated as $\triangle R E R(\triangle E E=15 \%)$. Student's paired t-test, before vs after: $*=P<0.05, \xi=P<0.01, \uparrow=\mathbb{P}<0.001$.

Table 5. Partial correlation coefficients between the changes in B-adrenergically mediated thermogenesis and heart rate response and (changes in) body composition and basal norepinephrine (NE) as result of weight lloss, each adjusted for the other variables.

\begin{tabular}{lcc}
\hline & $\begin{array}{c}\Delta \text { conc } \triangle \mathrm{EE}=15 \% \\
\text { (before minus afier) }\end{array}$ & $\begin{array}{c}\Delta \mathrm{CC} 25 \\
\text { (before minus after) }\end{array}$ \\
\hline \% Body fat before & $0.55 *$ & 0.09 \\
Mean level (conc $\triangle \mathrm{EE}=15 \%$ or $\mathrm{CC} 25$ ) & $0.70 \%$ & 0.34 \\
Basal NE before (pg/mi) & 0.11 & -0.05 \\
$\Delta$ \% body fat (before minus after) & 0.12 & $0.64 *$ \\
$\Delta$ basal NE (before minus after) & 0.13 & $0.76 \$$ \\
\hline
\end{tabular}

The plasma concentration of isoprenaline to increase resting energy expenditure by $15 \%$ is indicated as cone $\triangle E E=15 \%$. The dose or plasma concentration of isoprenaline to increase heart rate by 25 beats/min is indicated as $\mathrm{CC} 25 . *=\mathrm{P}<0.05, \xi=\mathrm{P}<0.01 ; \%=$ mean of values conc $\triangle \mathrm{EE}=15 \%$ or $\mathrm{CC} 25$ before and after diet. 


\section{Discussion}

The issue whether a possible metabolic efficiency in obesity is associated with a diminished thermogenic response as result of infusion of sympathomimetics is still a matter of debate $(10,13)$. The results of the present study indicate a diminished $B$ adrenergic thermogenic response in obesity, as reflected by the significant positive correlation between percentage body fat (adjusted for basal NE and age) and the plasma isoprenaline concentration needed to increase resting energy expenditure by $15 \%$. In a previous study (4) we found no difference in the B-adrenergically thermogenesis between lean and obese subjects (mean \% body fat lean vs obese: 17 vs 32 ), which is consistent with another study using epinephrine infusion (10). This apparent discrepancy may be due to the fact that the relatively small differences in thermogenesis are only detectable when including very obese and very lean subjects into the analyses as we did in the present study (range \% body fat 5-42). Moreover, this negative partial correlation between the thermogenic response and degree of adiposity was not detected when relating the thermogenic response to the administered standardized dose of isoprenaline. This indicates that using individual plasma isoprenaline concentration-response curves instead of dose-response curves improves the accuracy of the determination of $B$ adrenergic sensitivity, as reported before (15).

The determinant factor for the magnitude of the $\beta$-adrenergically mediated thermogenesis probably is the degree of stimulation of energy requiring processes, which implicates that obesity is associated with a blunted activation of these processes. Processes that have been reported to be stimulated during adrenergic activation are the $\mathrm{Na}^{+} \mathrm{K}^{+}$pump activity (8) and the actvity of futile cycles (17). There is, however, no conclusive evidence that supports a relationship between the rate of substrate cycling or the $\mathrm{Na}^{+} \mathrm{K}^{+}$pump activity and the lowered adrenergic thermogenesis in obese subjects. Another possibility is that the magnitude of the $B$-adrenergically mediated thermogenesis is determined by the capacity to induce changes in substrate metabolism. An indication for differences in B adrenergically mediated substrate metabolism comes from the finding that the decrease in respiratory exchange ratio as result of ISO-infusion was significantly higher in lean than obese, which indicates a higher fat oxidation in lean subjects. Moreover, in a previous study (4) we have found that the ability to mobilize and oxidize fat as result of Badrenergic stimulation may be impaired in obesity. B-Adrenergic stimulation resulted in an increased muscle fatty acid uptake and probably oxidation in lean subjects, whereas in obese subjects glucose seemed to be the preferred substrate as reflected by an increased skeletal muscle glucose uptake and lactate release. Furthermore, a diminished thermogenic response to glucose ingestion has been reported in insulin resistant subjects $(12,18)$, which suggests that insulin resistance may also be of importance in the ability to increase glucose metabolism during B-adrenergic stimulation. It requires, however, further research to elucidate what mechanisms are of importance in explaining the blunted $B$-adrenergically mediated thermogenesis in obesity.

The magnitude of the B-adrenergically mediated heart rate response was negatively associated with the basal norepinephrine concentration (adjusted for \% body fat and age). This may indicate that the level of basal sympathetic activity is a determinant factor for 


\section{Chapter 7}

the magnitude of B-adrenergically induced tachycardia. An explanation for this phenomenon may lie in the fact that due to a decreased basal sympathetic activity an increase in adrenoceptor number or supersensitivity to agonist stimulation may occur (16), which will result in increased physiological responses as result of agonist stimulation.

Weight loss resulted in a significant increase in the "soprenaline-induced heart rate and thermogenic response. Furthermore, the magnitude of the thermogenic response (for definition see methods) and the initial \% body fat (both adjusted for the other variables indicated in table 5) were, respectively, negatively and positively related to the change in this response as result of weight loss. These data suggest that the origins of obesity are unlikely to be sought in a lowered B-adrenergically mediated thermogenesis. In addition, weight reduction seemed to produce a $B$-adrenergic supersensitivity with respect to the thermogenic response in the (reduced)-obese subjects: the mean value for conc $\triangle \mathrm{EE}=15 \%$ after weight loss was not only lower than before diet but was similar to the value of lean subjects, despite the still considerably higher \% body fat in the reducedobese. This relatively increased $B$-adrenergic thermogenesis seems to be in accordance with the previously reported increased contribution of the sympathetic nervous system to 24 h energy expenditure in weight stable reduced-obese subjects (7) and in post-obese subjects consuming a high-carbohydrate diet (2) in comparison to lean subjects. The present study offers no explanation for the underlying mechanism for the increased contribution of the 3 -adrenergic system to $24 \mathrm{~h}$ energy expenditure in the reduced-obese subjects.

The increase in heart rate response as result of weight loss was positively related to the decrease in basal norepinephrine concentrations, independent of the other variables indicated in table 5. As suggested above, a larger decrease in basal plasma norepinephrine concentration may reflect a more pronounced decrease in basal sympathetic activity, which may be related to a larger upregulation of the number of adrenoceptors or increased sensitivity to agonist stimulation. Furthermore, the increase in heart rate response was positively associated with the magnitude of decrease in percentage body fat (adjusted for other variables indicated in table 5). The exact mechanism for this is not clear. It may be speculated that the decrease in percentage body fat is negatively related to an increase in adrenoceptor number or sensitivity and may thereby be negatively related to the heart rate response.

In several studies $(9,15)$ a decreased heart rate response as result of ISO-infusion was found with increasing age within a very narrow age range $(20-40 \mathrm{y})$. In agreement with this, the Pearson's product-moment correlation coefficients between age and the conc $\triangle \mathrm{EE}=15 \%$ and $\mathrm{CC} 25$ were statistically significant (both: $\mathrm{P}<0.01$ ). However, the partial correlation coefficient between age (adjusted for \% body fat and basal NE) and the conc $\triangle \mathrm{EE}=15 \%$ and the $\mathrm{CC} 25$ did not reach statistical significance. This may be explained by the fact that a strong correlation exists between \% body fat and age $(\mathrm{P}<0.001)$, which indicates that, implicit linearity between the variables in the regression model, the previouslly reported association between age and sympathetically mediated physiological responses is mainly due to differences in adiposity.

In conclusion, the degree of adiposity was shown to be negatively associated with the magnitude of the isoprenaline-induced thermogenic response, whereas the heart rate 
response seems to be merely related to the basal sympathetic activity. Since weight loss resulted in a significant increase in the B-adrenergically mediated themogenesis, the blunted thermogenic response does not seem to be a factor related to the origins of obesity. It is, however, possible, that a decrease in the B-adrenergically mediated thermogenesis as result of increasing fat stores may be a factor involved in the further development and maintenance of the obese state.

\section{References}

1. Astrup A.. T. Andersen, N.I. Christensen, J. Bülow, J. Madsen, L. Breum, and F. Quaade. Impaired glucose-induced thermogenesis and arterial norepinephrine response persist after weight reduction in obese humans. Am. J. Clin. Nutr. 51: 331.317, 1990.

2. Astrup A., B. Buemann, N.J. Christensen, and J. Madsen. 24-Hour energy expenditure and sympathetic activity consuming a high-carbohydrate diet. Am. J. Physiol. 262 (Endocrinol. Metab. 25): E282 E288, 1992.

3. Berlin I., M. Berlan, B. Crespo-Laumonnier, C. Landault, C. Payan, A.J. Puech, and G. Turpin. Alterations in $\mathbb{B}$-adrenergic sensitivity and platelet $\alpha_{2}$-adrenoceptors in obese women: effect of exercise and caloric restriction. Clin. Sci. 78: 81-87, 1990.

4. Blaak E.E., M.A. van Baak, G.J. Kemerink, M.T.W. Pakbiers, G.A.K. Heidendal, and W.H.M. Saris. Effect of beta-adrenergic stimulation on whole body energy expenditure and forearm sketetal muscle metabolism in obese men: a comparison with lean men. Submitted to Am. J. Physiol. (Endocrinol. Metab).

5. Blaak E.E., M.A. van Baak, K.P.G. Kempen, and W.H.M. Saris. Role of $\alpha$ - and B-adrenoceptors in the sympathetically-mediated thermogenesis. Am. J. Physiol. 264 (Endocrinol. Metab. 27): E1 1-E17, 1993.

6. Bland J.M., and D.G. Altman Statistical Methods for assessing agreement between two methods of clinical measurement. The Lancet, February 8: 307-310, 1986.

7. Buemann B., A. Astrup, J. Madsen, and N.J. Christensen. A 24-h energy expenditure study on reduced-obese subjects and nonobese women: eflect of B-blockade. Am. I. Clin. Nutr. 56: 662 670 . 1992.

8. Clausen T. Adrenergic control of $\mathrm{Na}^{+} \mathrm{K}^{+}$homeostasis. Acta Med. Scand. Suppl 672: 111-115, 1983.

9. Cleaveland C.R., R.E. Rangno, and D.G. Shand. A standardized isoproterenol sensitivity test. The effects of sinus arrhythmia, atropine and propranolol. Arch. Intern. Med. 130:47-52, 1972.

10. Connacher A.A., W.M. Bennet, R.T. Jung, D.M. Bier, C.C.T. Smith, C.M. Scrimgeour, and M.J. Rennie. Effect of adrenaline infusion on fatty acid and glucosc turnover in lean and obesc humans in the postabsorptive and fed states. Clin. Sci. 81: 635 644, 1991.

11. Finer N., P.C. Swan, and F.T. Mitchell. Suppression of the notepinephrine induced thermogenesis in human obesity by diet and weight loss. Int. J. Obes. 9: 212-216, 1985.

12. Golay A., Y. Schutz, H.U. Meyer, D. Thiebaud, B. Curchod, E. Maeder, J.P. Felber, and E Jequier. Glucose-induced thermogenesis in nondiabetic and diabetic obese subjects. Diabetes 31: 1023-1028, 1982.

13. Jung R.T., P.S. Shetty, W.P.T. James, M. Barrand, and M. Callingham. Reduced thermogenesis in obesity. Nature (London) 279: 322.323, 1979. 
14. Lovejoy J., F.D. Newby, S.S.P. Gebhar, and M. DiGiralamo. Insulin resistance in obesity is associated with elewated basal lactate levels and diminished lactate appearance following intravenous glucose and insulin. Metabolism 41: 22-27, 1992 .

15. Martinsson $A_{n,}$ K. Lindvall, A. Melcher, and P. Hjehmdahl B-adrenergic receptor responsiveness to isoprenaline in humans: concentration-effect, as compared with dose-effect evaluation and influence of antonomic reflexes. Brit. J. Clin. Pharmacol. 28: 83-94, 1989.

16. Motulski H.J., and P.A. Insel. Adrenergic receptors in man. Direct identification, physiological regulation and clinical alterations. New Engl. J. Med. 64: 18-29, 1982.

17. Newsholme E.A. A possible metabolic basis for the control of body weight. New Engl. J. Med. 302 (7): $400-405,1980$.

18. Ravussin E., C. Bogardus, R.S. Schwartz, D.C. Robbins, R.R. Wolfe, E.S. Horton, E. Danforth, and E.A.H. Jr \& Sims. Thermic effect of infused glucose and insulin in man. Decreased response with increased insulin resistance in obesity and non-insulin dependent diabetes mellitus. J. Clin. Invest. 72: $893.902 ; 1983$.

19. Schwartz R.S., L.F. Jaeger, R.V. Veith, and S. Lakshiminarayan. The effect of diet and exercise on plasma norepinephrine kinetics in moderately obese young men. Int. J. Obes. 14: 11-11, 1990.

20. Siri W.E. The gross composition of the body. Adw. Biol. Med. Physiol. 4: 239-280, 1956.

21. Smedes F, J.C. Kraak, and H. Poppe. Simple and fast solvent extraction system for selective and quantitative isolation of adrenaline, noradrenaline and dopamine from plasma and urine. J. Chromatogr 231: $25-39,1982$.

22. Wallin B.G., G. Sundlof, B.-M. Eriksson, P. Dominiak, H. Grobecker, and L-E. Linblad Plasma noradrenaline concentration correlates to sympathetic muscle nerve activity in normotensive man. Acta. Physiol. Scand. 111: 69-73, 1981.

23. Weir J.B. New methods for calculating metabolic rate with special reference to protein metabolism. J. Physiol. Lond. 109: 1-9, 1949. 


\title{
CHAPTER 8
}

\section{Beta-adrenergic stimulation and skeletal muscle metabolism in relation to weight reduction in obese men}

\author{
E.E. Blaak, M.A. van Baak, G.J. Kemerink**, M.T.W. Pakbiers* ,G.A.K. Heidendal* \\ and W.H.M. Saris.
}

Department of Human Biology, Uniwersity of Limburg, Maastricht and Hepartment of Radiology and * Department of Nuclear Medicine, University Hospital Maastricht, the Netherlands

Submitted to Am. J. Physiol. (Endocrinol. Metab.)

\section{Abstract}

In previous studies $(5,6)$ we found that during infusion of the $B_{1}$ - and $B_{2}$-agonist isoprenaline (ISO), obese males have a lower fat utilization as compared to lean males, reflected by a lower ISO-induced rise in arterial glycerol and non-esterified fatty acids (NEFA) and a lower muscle NEFA oxidation. The present study was intended to investigate whether a period of weight reduction would alter this impaired fat utilization in obesity. The obese males (age $31.1 \pm 1.7 \mathrm{y}, \%$ body fat $32.3 \pm 2.3$ ) followed a very low calorie diet (VLCD) for four weeks and returned to a situation of energy balance in the fifth week. Before and after this five-week intervention period skeletal muscle metabolism was investigated during infusion of the $B_{1}-$ and $B_{2}$-agonist ISO with and without simultaneous infusion of the $B_{1}$-blocker atenolol (AT). After 30 min of supine rest, ISO- or ISO+AT-infusion, skeletal muscle blood flow and arterio-venous concentration differences of various metabolites across muscle were determined. The changes in skeletal muscle blood flow were determined by measuring total forearm-, skin-, and subcutaneous adipose tissue- blood flow and forearm composition. As result of VLCD, there was a $8.1 \mathrm{~kg}$ body weight loss, which can be accounted for $79 \%$ by loss of fat mass and for $21 \%$ by loss of fat free mass. The increase in arterial NEF $A$ and glycerol concentrations as result of ISO-infusion were not significantly different before and after weight reduction. The increase in arterial $B$-hydroxybutyrate with $1 S O$ was significantly lower after weight reduction in comparison to before $(P<0.05)$, which may reflect a lowered ketogenesis as result of weight loss. Muscle NEFA uptake did not change as result of ISO- or ISO+AT-infusion both before and after diet, whereas muscle glucose uptake and lactate release tended to be more pronounced after weight reduction. These data suggest that a diminished capacity to utilize fat may rather be a primary factor leading to the development of overweight than a secondary factor as result of the obese state. 


\section{Introduction}

Experience indicates that the reduced obese state is a limited accomplishment, since in most subjects weight regain occurs within measurable time. A factor responsible for this quick weight regain may be that some subjects have a (genetic) predisposition for developing overweight. This predisposition has been suggested to lie in a lowered metabolic rate (21) or a reduced fat to carbohydrate oxidation ratio $(22,27)$, which makes individuals prone to obesity when consuming a high fat diet as in the Western world. The sympathetic nervous system is one of the mediators of energy and substrate metabolism, exerting its effect on thermogenesis via $B_{1}$ - and $B_{2}$-adrenoceptors (4). In addition, catecholamines may play an important role in the mobilization and use of the fat stores $(2,5)$. Several recent studies suggest that obesity may be associated with an impaired ability to oxidize fat $(18,27)$, which may result in the maintenance or development of large fat stores. In agreement with this we showed in previous studies $(5,6)$ that during $B$ adrenergic stimulation the utilization of fat seems to be impaired in obese men. This was reflected by a decreased mobilization of non-esterified fatty acids (NEFA) and glycerol from adipose tissue and a decreased skeletal muscle NEFA uptake (6). However, it is difficult to assess the pathophysiological abnormalities leading to obesity when the obese state has already developed, since then it is impossible to differentiate between primary and secondary factors. In order, to obtain more insight in the etiology of obesity, the previously studied obese subjects were restudied after a period of weight reduction. In the present study data on skeletal muscle substrate utilization were compared in obese subjects before and after a period of weight reduction by a very low calorie diet.

\section{Subjects and methods}

This study was performed in 6 obese male volunteers, aged $31.1 \pm 1.7 \mathrm{y}$, all of which were normotensive and in good health as assessed by a medical history and physical examination. Subject's characteristics are indicated in table 1: The study protocol was reviewed and approved by the Ethics Committee of the University of Limburg and all volunteers accepted a written consent. The subjects followed a very low calorie diet for four weeks and returned in the fifth week in 2-3 days to a situation of energy balance. Before and after this five-week intervention period, measurements were done on $B$ adrenergic thermogenesis, body composition and skeletal muscle metabolism. In a previously reported experiment (3), the $B_{1}$ - and $\beta_{2}$-agonist isoprenaline (ISO) was infused in increasing standardized doses and during each infusion period plasma concentrations of ISO and whole body energy expenditure were determined. In the present study forearm skeletal muscle metabolism was investigated during ISO-infusion with and without simultaneous infusion of the $B_{1}$-blocker atenolol in 6 subjects of the first study. To improve the accuracy of the skeletal muscle experiment, the dose of ISO infused in this experiment was individually determined from the data of the first experiment as the dose that increased plasma ISO to a fixed concentration of $165 \mathrm{pg} / \mathrm{ml}$, known to increase energy expenditure by about $15 \%$ (4). The dose in the text is related to ISO sulphate, 
$69 \%$ of which corresponds to ISO free base.

Table 1. Physical characteristics of the subjects before and after weight loss.

\begin{tabular}{lrrr}
\hline & Before & After & \\
\hline Weight $(\mathrm{kg})$ & $112.3 \pm 10.4$ & $104.2 \pm 10.6$ & $* * *$ \\
Body Mass Index $\left(\mathrm{kg} / \mathrm{m}^{2}\right)$ & $33.3 \pm 2.8$ & $30.9 \pm 2.9$ & $* *$ \\
\% Body fat & $32.3 \pm 2.3$ & $28.3 \pm 2.9$ & $* * *$ \\
Fat mass $(\mathrm{kg})$ & $37.3 \pm 6.4$ & $30.9 \pm 6.8$ & $* * *$ \\
Fat free mass $(\mathrm{kg})$ & $75.0 \pm 4.3$ & $73.3 \pm 4.1$ & $*$ \\
\hline
\end{tabular}

Means \pm SEM, obese $n=6$; Student's paired t-test: *P<0.05, **P<0.01,*** $<<0.001$.

\section{Body composition}

Body density was determined by means of hydrostatic weighing with simultaneous lung volume measurement (Volugraph 2000, Mijnhardt, The Netherlands). Body composition was calculated according to the equation of Siri (23).

Diet

The first four weeks of the diet period the subjects followed a very low calorie diet of $2000 \mathrm{~kJ} / \mathrm{day}$, which provided $52 \mathrm{~g}$ protein, $50 \mathrm{~g}$ carbohydrate, $7 \mathrm{~g}$ fat, $1.3 \mathrm{~g}$ sodium/day and a micronutrient content which meets the Dutch recommended daily allowances. In the fifth week the subjects returned in 2-3 days to their habitual eating pattern. The measurements on forearm metabolism were repeated in the sixth week after the subjects had been weight stable 4-5 days.

\section{Forearm muscle experiment}

\section{Design}

Forearm sikeletal muscle metabolism was investigated with infusion of the $B_{1}$ and $B_{2}$ " agonist ISO with and without simultaneous infusion of the $B_{1}$-blocker atenolol (AT). After $30 \mathrm{~min}$ supine rest, skeletal muscle blood flow and arterio-venous concentration differences of various metabolites across muscle were determined (see under clinical and biochemical methods). After the control period, the ISO-infusion was started for 60 min with AT added on to the last $30 \mathrm{~min}$. The above mentioned measurements were repeated after $30 \mathrm{~min}$ ISO-infusion and after $30 \mathrm{~min}$ of simultaneous ISO and AT infusion. For each subject, a dose of $1 S O$ (per $\mathrm{kg}_{\text {fat free mass }}$ min) corresponding to a plasma concentration of $165 \mathrm{pg} / \mathrm{ml}$ was infused. The mean infusion rate of $1 S O$ was $19.8 \pm 1.7$ $\mathrm{ng} / \mathrm{kgFF}_{\mathrm{FF}} \cdot \mathrm{min}$ before and $21.2 \pm 3.6$ after diet. Before the simultaneous infusion of ISO 
and AT $\left(0.11 \mathrm{mg} / \mathrm{kg}_{\mathrm{FFM}}\right.$, h) started, a priming dose of AT $\left(0.08 \mathrm{mg} / \mathrm{kg}_{\mathrm{FFM}}\right)$ was administered within five minutes. The changes in forearm skeletal muscle blood flow were determined by measuring total forearm-, skin- and subcutaneous adipose tissueblood flow and forearm composition.

\section{Clinical methods}

Before the start of the experiment, three canulas were inserted. For sampling of arterial blood a canula was inserted in the radial artery of the forearm under local anesthesia. In the same arm, a second canula was inserted in a forearm antecubital vein for the infusion of ISO and AT. In the contralateral arm, a catheter was inserted in retrograde direction of the antecubital vein of the forearm for sampling of deep venous blood.

Forearm blood flow was measured by venous occlusion plethysmography (28) with a mercury strain gauge (Periflow 0699, Janssen Scientific Instruments, Belgium). The strain gauge was placed around the forearm, which contained the deep venous catheter. Because this method measures percent change in volume, the blood flow is related to 100 $\mathrm{ml}$ of forearm tissue. Prior to measuring forearm blood flow, the hand circulation was occluded by inflating a pediatric sphygnomanometer cuff, placed around the wrist, to a pressure of $200 \mathrm{~mm} \mathrm{Hg}$. In this way forearm blood flow could be assessed without interference from the hand circulation. The venous occlusion cuff, placed around the upper arm, was automatically inflated (and deflated) to a pressure of $40 \mathrm{~mm} \mathrm{Hg}$. Forearm blood flow was recorded approximately every four seconds (depending on heart rate) for $1.5 \mathrm{~min}$ and the consecutive (stable) values during the last $\mathrm{min}$ were averaged.

Subcutaneous adipose tissue blood flow was measured after a subcutaneous deposition of ${ }^{133}$ xenon on the dorsal side of the forearm about $10 \mathrm{~cm}$ proximal to the wrist joint (16). A dose of $5.5 \mathrm{MBq}(150 \mu \mathrm{Ci}){ }^{133}$ xenon was dissolved in saline $(0.1-0.15 \mathrm{ml})$ and was injected subcutaneously with a very fine needle $(0.5 \times 16 \mathrm{~mm})$. The arm was placed in a fixed position close to a large field of view gamma camera (Technicare large field 438 HR, General Electrics, Utrecht). The registration of the ${ }^{133}$ xenon disappearance was started 45 min after injection in order to obtain a monoexponential washout. Fat tissue blood flow was calculated from the disappearance constant of ${ }^{133}$ xenon over the last 20 min of each infusion period. It was assumed that the blood-tissue partition coefficient of xenon was $8 \mathrm{ml} / \mathrm{gram}$ in obese subjects before and after weight loss, a value reported for normal weight volunteers ( 8 ). Although it has been suggested that this coefficient varies with differences in degree of adiposity (7), a study in rats could not confirm this (20). However, variation in this coefficient within the range reported by Bülow et al $(7,8)$ would not change the conclusions of this study. For the conversion of adipose tissue blood flow values from $100 \mathrm{~g}$ to $100 \mathrm{ml}$ of tissue, the density of adipose tissue was assumed to be $0.9 \mathrm{~g} / \mathrm{ml}$ both before and after diet $(10,23)$.

Before the measurement of total forearm blood flow, skin blood flow was determined by the laser doppler technique (Periflux PF3, Perimed, Sweden) with an occluded hand circulation. The probe was placed on the ventral side of the forearm near the wrist joint. This method gives a linear measure of the flux of red cells in the outer layer of the skin and is only suitable to measure changes in blood flow, when there is no change in diameter of the underlying skin blood vessels. A major change in skin vessel diameter 
can be excluded since intravenous isoprenaline infusion (100 $\mathrm{ng} / \mathrm{kg} \cdot \mathrm{min}$ ) has been reported to cause a weak but transient vasodilatation of skin vessels, which returned to basal levels within 10 minutes after the initiation of the infusion (9). Since the laser doppler method only gives flow in relative units, for callculating absolute blood flow the resting skin blood flow was assumed to be $5 \mathrm{ml} / 100 \mathrm{ml}$.min (24).

The amounts of subcutaneous fat, bone and muscle of the forearm were determined before and after diet by a cross-sectional amalysis at the site of the greatest circumference of the forearm with magnetic resonance imaging (Gyroscan T5, Philips Medical Systems, the Netherlands). In our MRI images, we could not detect the amount of forearm skin or distinguish between muscle and tendons. Therefore, the relationship between the total amount of forearm skin and the total area of muscle and subcutaneous fat was assumed to be constant and was assumed to be as described by Cooper et al (10). The amount of tendon was calculated in a similar way by relating its amount to the amount of muscle. Under the heading of fat and muscle are also grouped nerves and blood vessels within the tissues.

\section{Biochemical methods}

Blood samples were taken simultaneously from the artery and the deep forearm vein after the blood flow measurement, while the hand circulation was still occluded. Triplicate samples of arterial and deep venous blood were immediately deproteinized with ice cold sulphosalicylic acid (SSA, 3.5\% w/v) in a ratio of $1: 2$, respectively. The samples were centrifuged at $3000 \mathrm{rpm}$ at $4{ }^{\circ} \mathrm{C}$ In the supernatant concentrations of glucose, pyruvate, lactate, $\mathrm{B}$-hydroxybutyrate $(\mathrm{BOH})$, glutamate, alanine and glutamine were determined with enzymatic assays automated on the Cobas BIO centrifugal analyzer at $355 \mathrm{~nm}$ (11). All these assays were carried out using $0.2 \mathrm{M}$ tris-hydrazine buffer, $\mathrm{pH} 9.2$, except for pyruvate which was done with $1 \mathrm{M}$ phosphate buffer, $\mathrm{pH} 7$. Plasma non-esterified fatty acids (NEFA) and glycerol were measured using standard enzymatic techniques automated on the Cobas Bio centrifugal analyzer.

The concentration of hemoglobin $(\mathrm{Hb})$ in blood and the percentage saturation of $\mathrm{Hb}$ with $\mathrm{O}_{2}$ were measured with a hemoximeter (OSM2 hemoximeter, VA Howe Radiometer, Copenhagen). The hematocrit was determined using a microcapillary system.

\section{Calculations and Statistics}

Skeletal muscle blood flow (SMBF) was calculated by the following formula:

$T B F=$ amount of muscle $x S M B F+$ amount of $\sin \times S B F+$ amount of fat $x A T B F$.

amount of tissue: $\%$ of total forearm area/100

units blood flow: $\mathrm{mL} / 100 \mathrm{ml}$ tissue.min

The exchange of metabolites across muscle (nmol/100 ml muscle tissue min) was calculated by multiplying the arterio-venous difference of metabolites $(\mu \mathrm{mol} / \mathrm{l})$ by muscle blood flow $(\mathrm{ml} / 100 \mathrm{ml}$ muscle tissue.min). The exchange of NEFA and glycerol was 


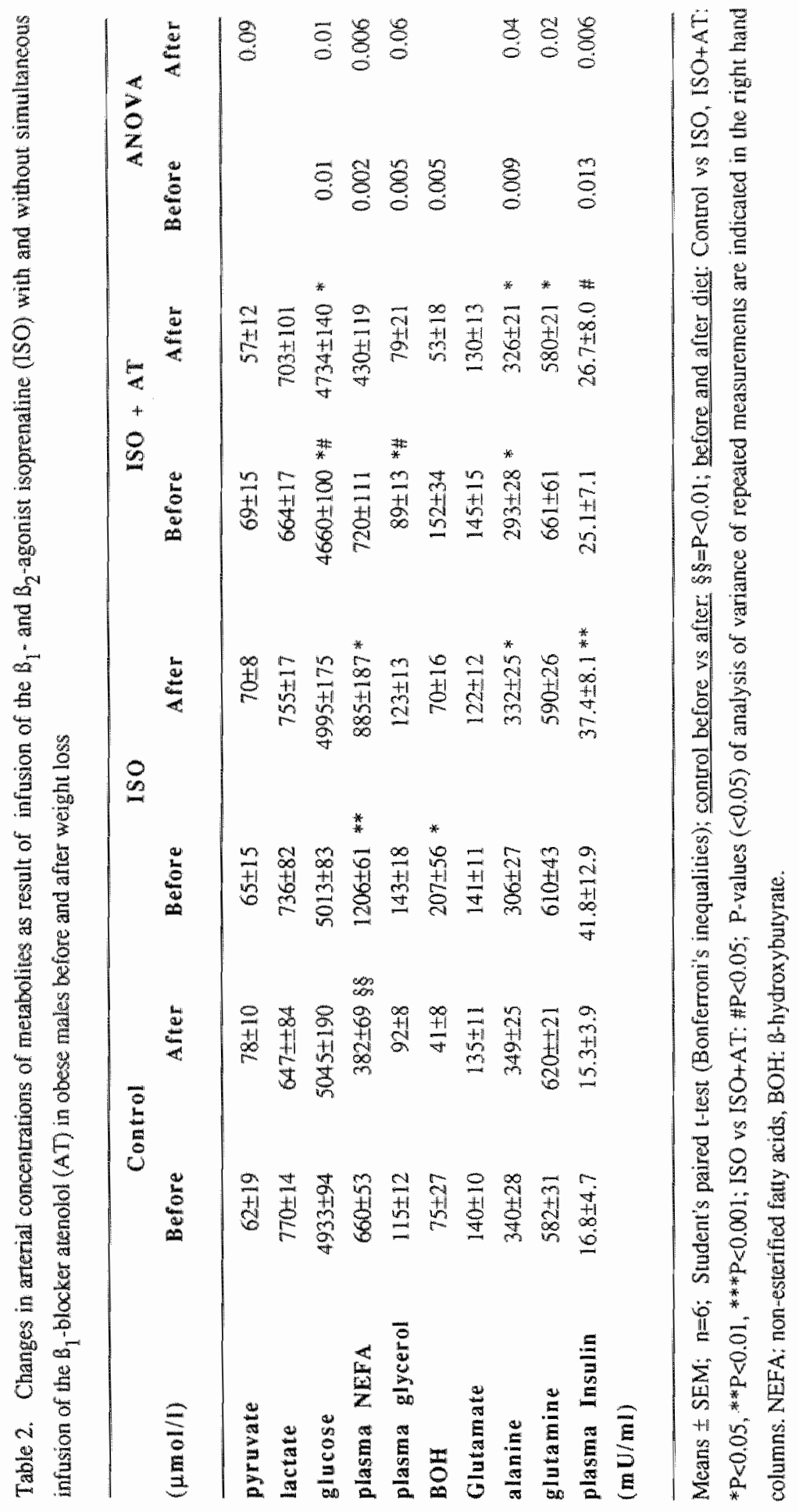


calculated by multiplying their plasma A-V difference by plasma flow [total blood flow (1-H/100)]. A positive flux indicates uptake.

Data are represented as means \pm SEM. Both before and after diet the effect of the ISOand ISO+AT infusion on various parameters was analyzed with repeated measurements ANOVA. Post hoc testing was done with a Student's paired t-test and the P-values of the post-hoc comparisons were corrected according to Bonferroni's inequalities

Comparisons between values before and after diet were done with a Student's paired $t$ test. A P-value smaller than 0.05 was regarded as statistically significant.

\section{Results}

\section{Body composition}

As indicated in table 1 ( $p$ 107), there was a significant decrease in body weight, fat mass and fat free mass as result of the very low calorie diet. The $8.1 \mathrm{~kg}$ body weight loss can be accounted for $79 \%$ by loss of fat mass and for $21 \%$ by loss of fat free mass.

\section{Heart rate}

Basal heart rate tended to be lower after diet $(62 \pm 5 \mathrm{vs} 55 \pm 3$ beats/min, $\mathrm{p}=0.10)$. The absolute ISO-induced increase in heart rate was higher after diet in comparison to before, although these differences did not reach statistical significance (before $v \mathrm{~s}$ after, ISO: $18.9 \pm 2.0$ vs $26.6 \pm 4.3$ beats $/ \mathrm{min}$ and ISO+AT: $6.2 \pm 2.3$ vs $10.6 \pm 2.8$ beats $/ \mathrm{min}$ ). In addition, the \% increase in heart rate with ISO and ISO+AT tended to be higher after diet than before (before vs after; ISO: $30.3 \pm 3.1$ vs $49.6 \pm 10.2 \%, p=0.13$; ISO+AT: $10.0 \pm 3.6$ vs $19.9 \pm 6.3 \%$, respectively).

\section{Intermediary metabolltes}

Changes in arterial concentrations of metabolites are indicated in table 2 . The change in lactate concentration with ISO and ISO+AT was signifcantly higher after diet than before, as shown in fig 1 . Before and after diet glucose concentration decreased with ISO+AT compared to control. The basal concentration of NEFA was signifcantly lower after diet, whereas the increase in NEFA with ISO was not significantly different before and after diet, irrespective whether it is expressed as absolute increase or increase per $\mathrm{kg}$ fat mass. With ISO+AT the plasma NEFA values returned to baseline both before and after diet. Basal glycerol values and the change in glycerol values during ISO and ISO+AT were not significantly different before and after weight reduction. The increase in whole blood $\mathrm{BOH}$ with ISO was significantly lower after weight reduction in comparison to before $(\mathrm{P}<0.05$, fig 1$)$ and tended to be lower during ISO+AT $(\mathrm{P}=0.11)$. There were no significant differences in glutamate concentration before and after diet. After weight reduction, alanine concentration tended to decrease less with ISO and with ISO+AT than before. Before diet there were no significant changes in glutamine 
concentration, whereas after diet glutamine concentration tended to decrease with ISO and significantly decreased with ISO+AT.
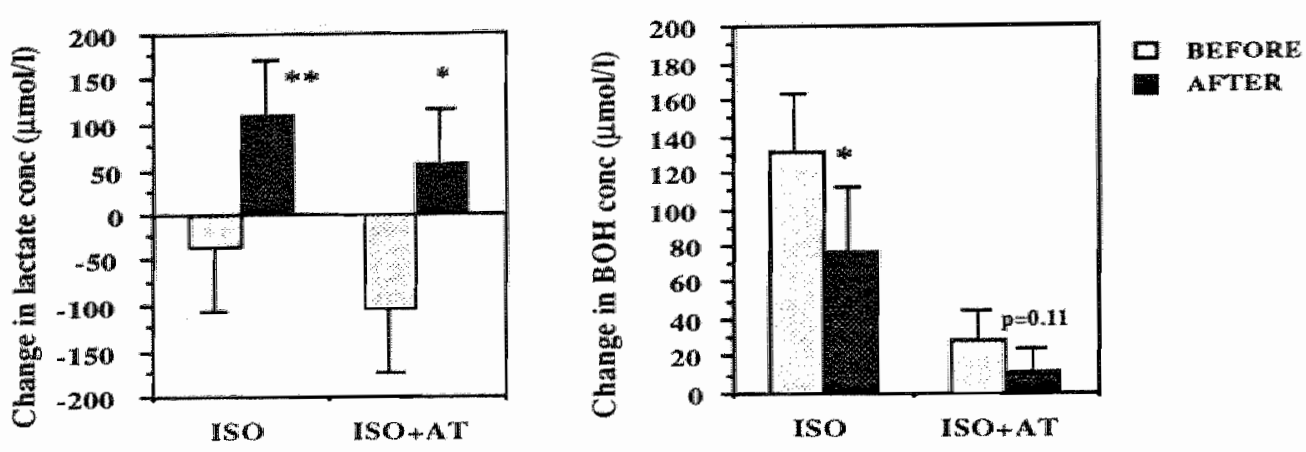

Fig 11 . Changes in arterial lactate and B-hydroxybutyrate concentrations as result of infusion of the $B_{1}$. and $B_{2}$-agonist isoprenaline ( $\mathbb{S S O}$ ) with and without sumultameous infusion of the $B_{1}$-blocker atenolol (AT) before and after weight loss. Means $\pm S E M, n=6$; Paired $t$-test (Bonferroni): $* P<0.05,{ }^{*} * \mathrm{P}<0.01$.

\section{Composition forearm}

The composition of the forearm, expressed as $\%$ of total forearm area, is indicated in fig 2. The total forearm area was significantly lower after diet than before (before vs after $8394 \pm 445$ vs $8179 \pm 496 \mathrm{~mm}^{2}, \mathrm{P}<0.01$ ). The absolute amount of fat to forearm tissue decreased as result of weight loss (before vs after $1659 \pm 105$ vs $1467 \pm 120 \mathrm{~mm}^{2}, P<0.01$ ), while also the relative amount of fat was significantly decreased after diet (before vs after: $19.8 \pm 1.1$ vs $17.9 \pm 0.9 \%, \mathrm{P}<0.01)$. The absolute amount of muscle did not change as result of diet (before vs after: $5119 \pm 308$ vs $5116 \pm 324 \mathrm{~mm}^{2}$ ), whereas the relative amount tended to be higher after weight reduction $(\mathrm{P}=0.09)$. The absolute or relative amounts of bone, tendon and skin did not significantly change as result of weight reduction.

\section{Blood flow}

Basal total forearm blood flow and skeletal muscle blood flow were not significantly different before in comparison to after weight reduction (table 3, p 114), whereas fat tissue blood flow was significantly lower after diet. The changes in blood flow through the different forearm tissues with ISO and with ISO+AT were similar before and after weight loss. 


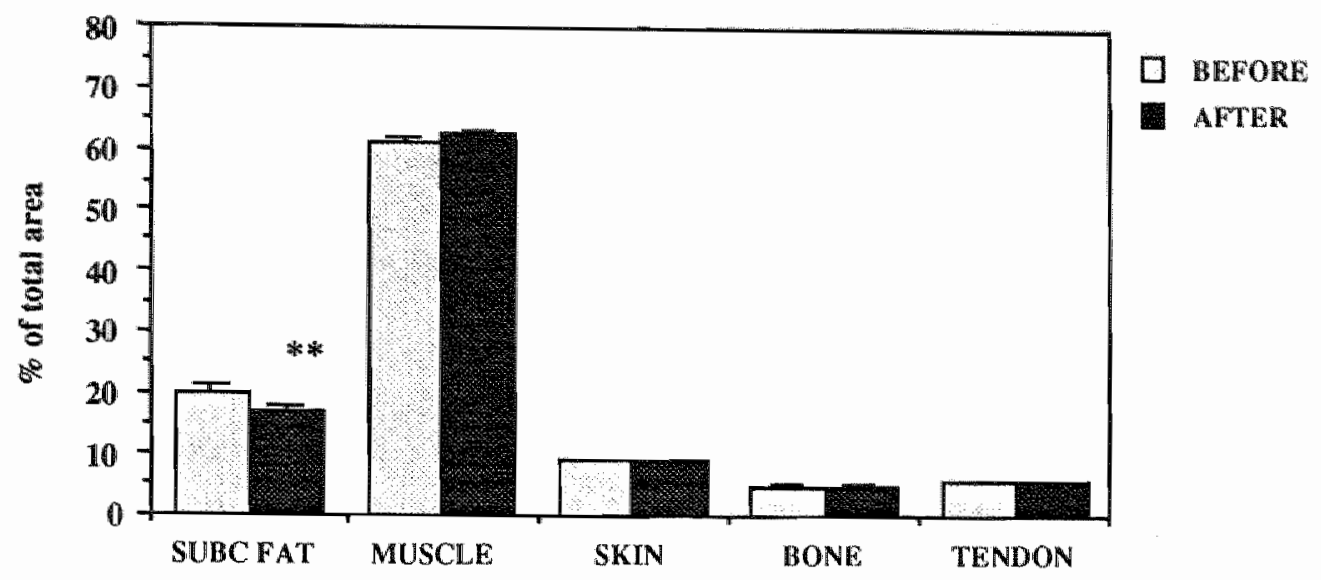

Fig 2. The forearm composition before and after weight reduction, expressed as percentage of total forearm area. Means $\pm S E M, n=6$; Paired t-test * $* 0.01$, ***P<0.001.

\section{Skeletal muscle substrate fluxes}

Basal skeletal muscle glucose uptake tended to be lower after diet than before ( $\mathrm{P}=0.13)$. Pyruvate uptake tended to increase before diet during ISO and ISO+AT, whereas after diet there was a significant decrease in pyruvate uptake. As result of weight loss skeletal muscle glucose uptake tended to be higher with ISO (table 4, p 115), whereas lactate release tended to be more pronounced. During ISO+AT, there were no significant changes in glucose or lactate flux as result of weight reduction. NEFA and glycerol flux did not change as result of ISO or ISO+AT infusion both before and after diet. BOH uptake tended to be more pronounced before than after weight reduction during ISO and ISO+AT. Before and after weight reduction there were no significant changes in glutamate, alanine and glutamate fluxes. 


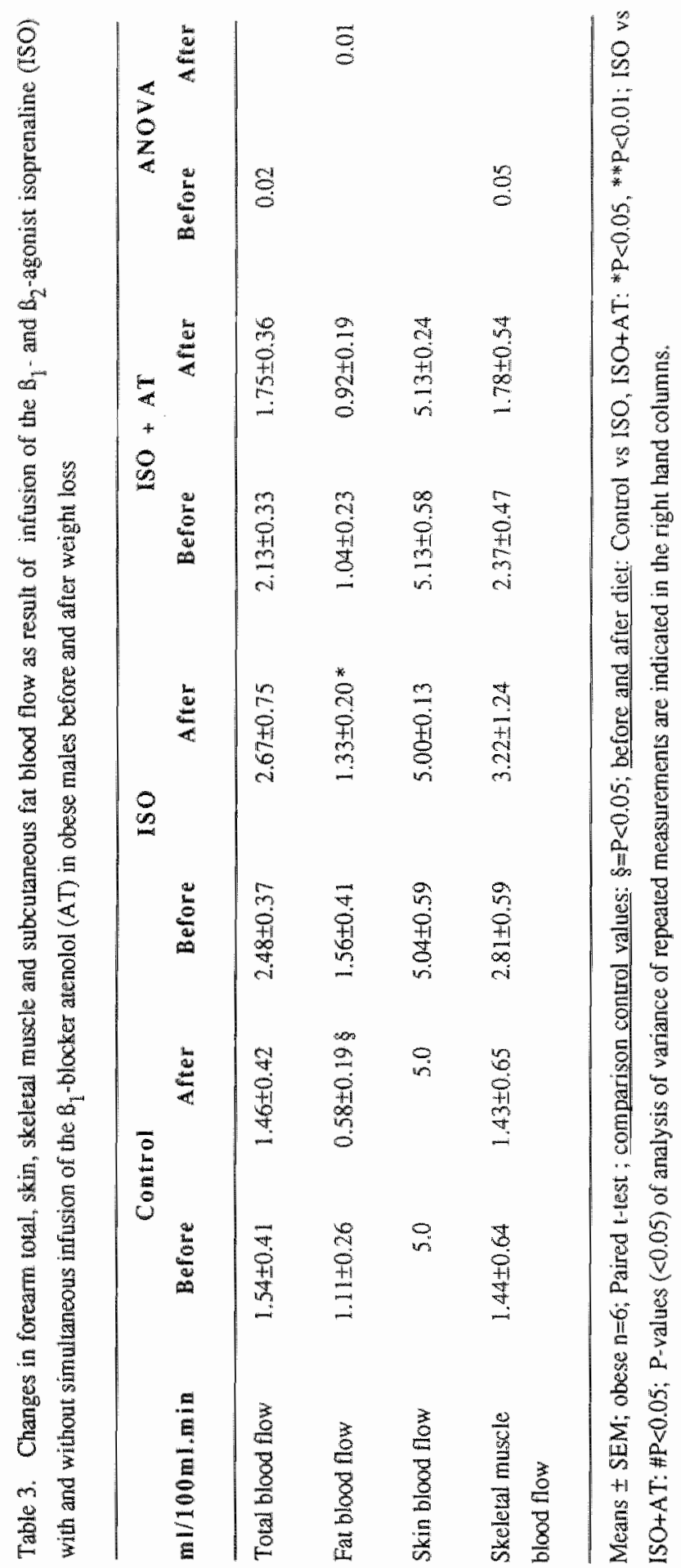




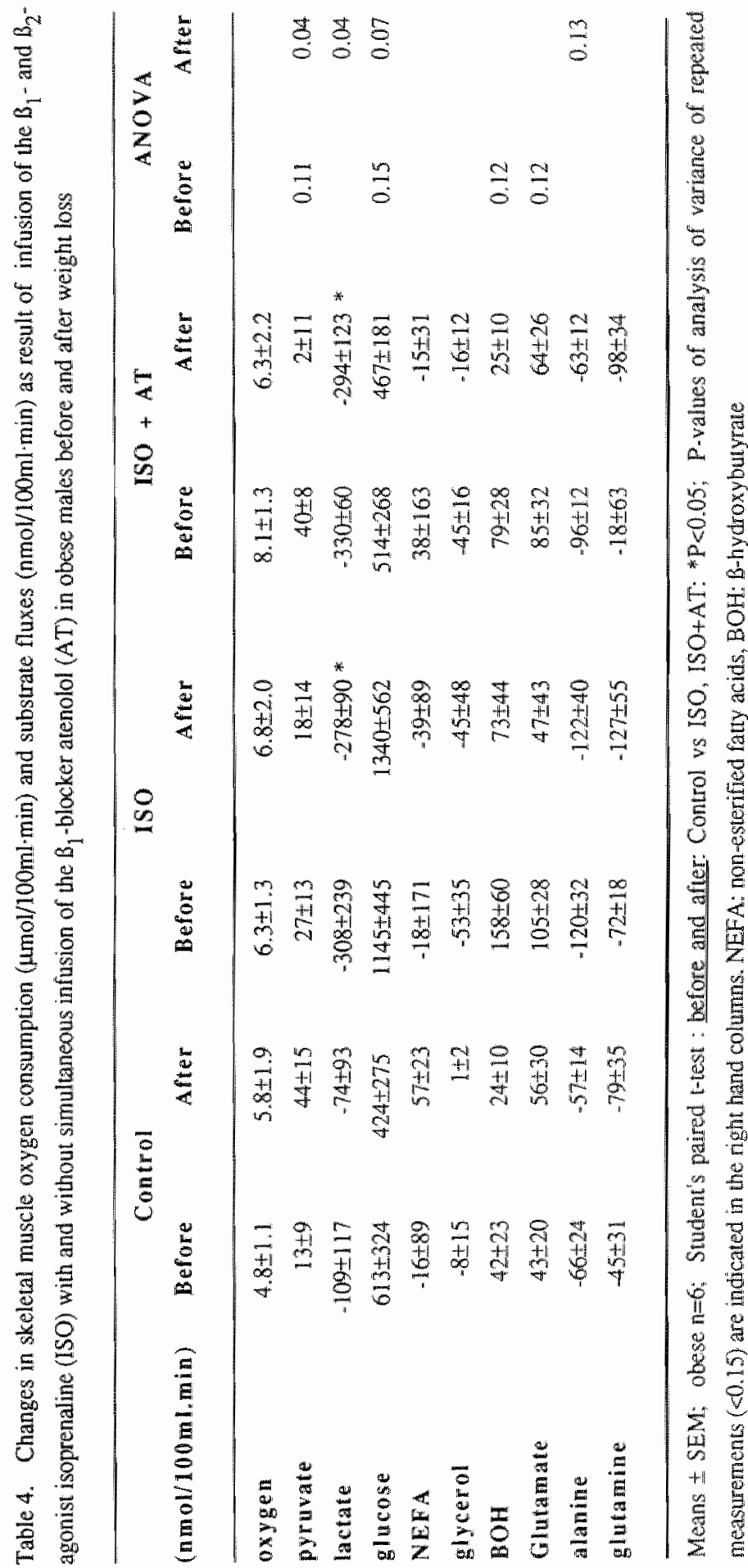




\section{Discussion}

Recent research indicates that one of the factors contributing to the development of obesity may be an impaired ability to use fat $(18,27)$. In previous studies $(5,6$, table 4$)$ we found that during ISO obese subjects have a lower fat utilization as compared to lean subjects, which was reflected by a lower ISO-induced rise in arterial NEFA and glycerol and in a lower muscle NEFA uptake. The main finding of the present study is that weight loss does not result in an improvement of the ISO-induced lipolysis and muscle NEFA uptake.

The increase in arterial NEFA and glycerol during ISO are similar before and after weight loss, irrespective whether expressed as absolute increase or as increase per $\mathrm{kg}$ fat mass. These ISO-induced increases in NEFA and glycerol were still significantly lower as values previously reported in lean subjects (5). In addition, the rise in arterial Bhydroxybutyrate (BOH) was significantly lower after weight loss than before and was also considerably lower than the rise previously reported in lean subjects $(5)$, which indicates a lowered ketogenesis in the reduced-obese state. Since the B-adrenergically mediated ketogenesis is mainly determined by the supply of NEFA to the liver $(2,15)$, these data suggest rather a trend towards a worsening than to an improvement of the lipolytic capacity in the reduced-obese state. These findings seem to be in contradiction with data of Leibel et al (17), who reported an increased lipolytic response to epinephrine infusion in reduced-obese subjects. In the latter study the lipolytic response was expressed as \% increase in basal glycerol concentration, whereas we expressed the lipolytic response both as absolute increase or as increase per $\mathrm{kg}$ fat mass. However, expressing our glycerol data as \% increase from baseline also yields similar values before and after weight reduction.

As previously reported ISO-infusion resulted in an increased muscle NEFA uptake and probably oxidation in lean subjects (5), whereas in the obese glucose was the preferred substrate and NEFA uptake did not change $(6$, table 4$)$. In the reduced obese state NEFA uptake was still unchanged, which indicates no improvement in the impaired capacity of muscle to take up or oxidize NEFA. In contrast, skeletal muscle glucose uptake tended to be higher after diet as compared to before, which rather indicates a shift towards an improved glucose metabolism in the reduced-obese state. The similar basal and stimulated insulin concentrations in combination with a tendency towards an increased skeletal muscle glucose uptake may suggest an increased insulin sensitivity after weight reduction. Indeed, weight reduction by low calorie diets has been reported to increase insulin sensitivity and to improve glucose metabolism $(12,13)$. Weight loss has been reported to increase glucose utilization mainly by enhancing glucose oxidation (13). However, the significantly higher increases in arterial lactate concentrations and the somewhat more pronounced muscle lactate release during ISO and ISO+AT after weight reduction as compared to before, may suggest an additional slight increase in nonoxidative glucose disposal.

Beside the differences in muscle NEFA oxidation in lean and (reduced)-obese subjects, it has previously been reported that skeletal muscle contributes more to the B-adrenergically induced thermogenesis in lean subjects $(5,6$, table 4$)$. In lean subjects the ISO-induced 
increase in muscle oxygen consumption was sufficient to explain the rise in whole body thermogenesis (5), whereas in the obese the ISO-induced rise in muscle oxygen consumption did not reach statistical significance as compared to control values $(6$, table 4). Skeletal muscle oxygen consumption during rest, ISO and ISO+AT was similar before and after weight reduction, which indicates that skeletal muscle is still of considerably less importance in the sympathetically mediated thermogenesis in reducedobese than lean subjects. This implicates that in reduced-obese and obese subjects an important part of the B-adrenergically mediated thermogenesis must be localized in other tissues, such as adipose tissue through a possibly increased triglyceride-fatty acid cycling (25).

As mentioned in the methods section, we described elsewhere the ISO-induced whole body thermogenesis in these reduced-obese subjects (3). From these data, it appeared that there was an increase in B-adrenergically mediated thermogenesis and in heart rate responses as result of weight loss. Although the mean increases in heart rate during ISO and ISO+AT were not significantly after diet in the present study, the individual responses were increased after weight reduction in five out of six subjects, which suggests an increased B-adrenergic sensitivity in accordance with the previous data. The tendency towards an increased skeletal muscle glucose uptake in the reduced-obese subjects combined with a previously reported association between increased sympathetic activity and increased glucose oxidation in post-obese women (1), may suggest that skeletal muscle is of importance in the increased $B$-adrenergically mediated thermogenesis after weight reduction. The data of the present study give, however, not enough evidence to draw any definite conclusion on this.

Taken together, the impaired utilization of fat in obesity, as reflected by a decreased ISOinduced lipolysis and muscle fat oxidation, does not improve as result of weight reduction. These data suggest that the diminished capacity to use fat may rather be a primary factor leading to the development of overweight than a secondary factor as result of the obese state. Since five out of six of our reduced-obese subjects were still overweight one has to be careful in drawing any definite conclusions from the present study. However, weight reduction rather resulted in a worsened than improved fat utilization, as reflected by the lowered ketogenesis and improved muscle glucose uptake during ISO, which makes it most unlikely that more severe weight loss would result in a reversal of this trend. The main finding of the present study is in accordance with several other studies in literature, where a diminished fat oxidation has been reported in subjects predisposed to obesity $(22,26)$. One explanation for this diminished capacity to oxidize fat may be a lowered lipolysis, as indicated by the above mentioned lower ISO-induced increase in NEFA and glycerol values in the reduced-obese as compared to lean subjects, which may result in a lowered NEFA uptake by muscle (14). The background for the diminished fat utilization in our obese and reduced-obese subjects as compared to normal-weight controls may also lie in a relatively low proportion of slow-twitch, type 1 , oxidative muscle fibres, utilizing mainly fatty acids, and a relatively high proportion of their fast-twitch glycolytic counterparts $(19,27)$. The mechanisms that may be responsible for the differences in substrate utilization require further research. 


\section{References}

1. Astrup A., B. Buemann, N.J. Christensen, and J. Madsen, 24-hour energy expenditure and sympathetic activity in poswbese women consuning a high carbohydrate diet. Am. J. Physiol (Endocrinol. Metab. 25): E282-E288, 1992.

2. Awogaro A., P.E. Cryer, and D.M. Bier. Epinephrine's ketogenic effect in humans is mediated principally by lipolysis. Am. J. Physiol. 263 (Endocrinol. Metab. 26): E250-E260, 1992.

3. Blaak E.E. M.A. van Baak, A.D.M. Kester, and W.H.M. Saris. B-adrenergically mediated changes in energy expendiure and heart rate: effect of obesity and weight reduction. Submitted to J. Clin. Invest.

4. Blaak. E.E, M.A. van Baak, K.P.G. Kempen, and W.H.M Saris. Role of alpha and beta adrenoceptors in the sympathetically-mediated thermogenesis. Am. J. Physiol. 264 (Endocrinol. Metab. 27): E11E17, 1993.

5. Blaak E.E., M.A. van Baak, G.J. Kemerink, M.T.W. Pakbiers, G.A.K. Heidendal, and W.H.M. Saris. Effect of beta-adrenergic stimulation on forearm skeletal musle metabolism. Submitted to Am. $\mathrm{J}$. Physiol. (Endocrinol. Metab.)

6. Blaak E.E., M.A. van Baak, G.J. Kemerink, M.T.W. Pakbiers, G.A.K. Heidendal, and W.H.M. Saris. effect of beta-adrenergic stimulation on whole body energy expenditure and forearm skeletal muscle metabolism in obese men: a comparison with lean men. Submitted to Am. J. Physiol. (Endocrinol. Metab).

7. Bulow J. Adipose tissue blood flow during exercise. Dan. Med. Bull. 30: 85-100, 1983.

8. Bülow J., R. Jelnes, A. Astrup, and J. Madsen. Tissue-blood partition coefficients for xenon in warious adipose tissue depots in man. Scand. J. Clin. Lab. Invest. 47: 1-3, 1987.

9. Cobbald A.F., J. Ginsburg, and A. Paton. Circulatory, respiratory and metabolic responses to isopropylnoradrenaline in man. J. Physiol. 151: 539-550, 1960.

10. Cooper K.E., O.G. Edholm, and R.F. Mottram. The blood flow in skin and muscle of the human forearm. J. Physiol. 128: 258-267, 1955.

11. Ellia M., P. Folmer, A. Schlatman, A. Goren, and S. Austen. Carbohydrate, fat and protein metabolism. in muscle and in the whole boly after mixed meal ingestion. Metabolism 37: 542-551, 1988 .

12. Eliahou H.E., J. Laufer, A. Blau, and L. Shuiman. Effect of low-calorie diets on the sympathetic nervous system, body weight, and plasma insulin in owerweight hypertension. Am. J. Clin. Nutr. 56: $175 \mathrm{~S}-8 \mathrm{~S}_{8} 1992$.

13. Fransilla-Kallunki A., A. Rissanen, A. Ekstrand, A. Ollus, and L. Groop. Weight loss by very-lowcalorie diets: effects on substrate oxidation, energy expenditure and insulin sensitivity in obese subjects. Am. J. Clin. Nutr. 56: 247S-8S, 1992.

14. Hagenfeldt L., and J. Wahren. Human forearm muscle metabolism during exercise. II. Uptake, release and oxidation of individual FFA and glycerol. Scand. J. Lab. Invest. 21: 263-276, 1.968.

15. Keller U., M. Lustenberger, I. Muller-Brand, P.P.G. Gerber, and W. Stauffacher. Human ketone body production and utilization studies using tracer techniques: regulation by free fatty acids, insulin, catecholamines, and thyroid hormones. Diabetes Metab. Rev. 5: 285-298, 1989.

16. Larsen O.A., N.A. Lassen, and F, Quaade. Blood flow through human adipose tissue determined with radioactive xenon. Acta Physiol. Scand. 66: 337-345, 1966.

17. Leibel R.L., E.M. Berry, and J. Hirsch. Metabolic and hemodynamic responses to endogenous and exogenous catecholamines in formerly obese subjects. Am. J. Physiol. 260 (Regulatory Integrative Comp. Physiol. 29): R785-R791, 1991. 
18. Lillioja S., J. Foley, C. Bogardus, D. Mott, and B.V. Howard. Free fatty acid metabolism and obesity in man: in vivo and in vitro comparisons. Metabolism 35: 505-514, 1986.

19. Lillioja S., A.A. Young, C.L. Culter, J.L. Ivy, W.G.H. Abbot, J.K. Zawadzki, H. Yki-Järvinen, L. Christin, T.W. Secomb, and C. Bogardus. Skeletal muscle capillary density and fiber type are possible determinants of in vivo insulin resistance in man. J. Clin. Invest. $80: 415424,1987$

20. Madsen J., A. Malcow-Moller, and S. Waldorff. Continuous estimation of adipose tissue blood flow in rats by ${ }^{133}$ Xe elimination. J. Appl. Physiol. 39(5): 851-856, 1975.

21. Ravussin E., S. Lillioja, W.C. Knowler, L. Cristin, D. Freymond, W.G.H. Abbott, V. Boyce, B. V. Howard, and C. Bogardus. Reduced rate of energy expenditure as a risk factor for body weight gain, New Engl. J. Med. 318: 467-472, 1988.

22. Seidell J.C., D.C. Muller, J.D. Sorkin, and R. Andres. Fasting respiratory exchange ratio and resting metabolic rate as predictors of weight gain: the Baltimore Longitudinal study on aging. Int. J. Obes, 16: $667-674,1992$.

23. Siri W.E. The gross composition of the body. Adv. Biol. Med. Physiol. 4: 239-280, 1956.

24. Sejrsen P. blood flow in cutaneous tissue studied by washout of radioactive xenon. Circ. Res. XXV: 215-229, 1969.

25. Tagliaferro A.R., S. Dobbin, R. Curi, B. Leighton, L.D. Meeker, and E.A. Newsholme. Effects of diet and exercise on the in vivo rates of triglyceride-fatty acid cycle in adipose tissue and muscle of the rat. Int. J. Obes. 14: $957-971,1990$.

26. Zurlo F., S. Lilioja, A. Esposito-Dell Puente, B.L. Nyomba, I. Raz, M.F. Saad, B.A. Swinburn, W.C. Knowler, $\mathrm{C}$. Bogardus, and $\mathrm{E}$. Ravussin. Low ratio of fat to carbohydrate oxidation as predictor of weight gain: study of 24-h RQ. Am. J. Physiol. 259 (Endocrinol. Metab. 22): E650-E657, 1990.

27. Wade A.J., M.M. Marbut, and J.M. Round. Muscle fibre type and aetiology of obesity. Lancet 335: 805-808, 1990.

28. Whitney R.J. The measurement of volume changes in human limbs. J. Physiol 121: 1-27, 1953. 



\title{
Beta-adrenergic stimulation and abdominal subcutaneous fat blood flow in lean, obese and reduced-obese subjects
}

\author{
E.E. Blaak, M.A. van Baak, G.J. Kemerink*\#, M.T.W. Pakbiers*, G.A.K. Heidendal* \\ and W.H.M. Saris.
}

Department of Human Biology University of Limburg, Maastricht, *Department of Nuclear Medicine and \# Department of Radiology, University Hospital Maastrich, The Netherlands

Submitted to Clin. Sci.

\section{Abstract}

The present study was intended to investigate whether the Bwadrenergically mediated blood flow response of abdominal subcutaneous adipose tissue (per unit weight) was altered in obesity and to study the effect of weight reduction on this response. Body composition (underwater weighing) and fat blood flow were determined in a group of lean $(n=9$, \% body fat $11.6 \pm 3.9)$ and obese subjects $(n=9, \%$ body fat $28.3 \pm 1.8)$. In 7 of the obese subjects measurements were also performed after a four-week period of weight reduction by a very low calorie diet (\% body fat after diet $23.4 \pm 3.3$ ). After an overnight fast, abdominal subcutaneous fat blood flow was determined by means of the ${ }^{133}$ xenon washout technique during a 30 -min period of supine rest and during $30 \mathrm{~min}$ periods of infusion of the $B_{1}$-and $B_{2}$-agonist isoprenaline (ISO) with and without simultaneous infusion of the $B_{1}$-blocker atenolol (AT). Basal abdominal fat blood flow was significantly higher in lean as compared to obese subjects, whereas weight reduction significantly increased basal fat blood flow (obese vs reduced-obese, $\mathrm{P}<0.05$ ). There was a significant increase in abdominal fat blood flow as result of ISO-infusion in lean and in obese subjects before and after weight reduction. During ISO+AT infusion abdominal fat blood flow was still significantly increased as compared to control walues in lean and obese subjects. The increase in blood flow during ISO was significantly higher in lean than obese subjects, whilst the $I S O+A T$-induced blood flow response was comparable. These data suggest that especially the $B_{1}$-mediated blood flow response is blunted in obese subjects. Although the increase in ISO-induced blood flow response was not significantly different after as compared to before diet, there was a significant positive relationship between the decrease in \% body fat and the change in the ISO-mediated abdominal blood flow as result of weight loss ( $\mathrm{P}<0.05)$. In conclusion, the present study shows that the beta-adrenergically mediated abdominal fat blood flow response (expressed per unit weight) is diminished in obesity. This lowered blood flow response tended to change in a direction rowards the condition seen in lean subjects after partial weight reduction. 


\section{Introduction}

Adipose tissue blood flow may play an important role in adipose tissue metabolism by delivering substrates, lipolytic hormones and carrier proteins, responsible for the transport of fatty acids in the bloodstream, to the tissue $(6,11,13)$. Since the mobilization of fatty acids is the principal metabolic event in adipose tissue, the relationship between adipose tissue blood flow and lipolysis is of special interest. By means of the ${ }^{133}$ xenon clearance technique it has been shown that in several metabolic situations characterized by an increased mobilization of the fat stores, such as fasting (12), exercise (4) or infusion of epinephrine (14), adipose tissue blood flow is increased.

Previous studies have shown that adipose tissue blood flow (per unit weight) may be decreased in obesity $(12,15,18)$. In addition, a blunted abdominal adipose tissue blood flow response to glucose ingestion has been reported in obese subjects (15). In previous studies we found that the lipolytic response as a result of infusion of the $B_{1}-$ and $B_{2}$ agonist isoprenaline (ISO) is lower in obese than lean subjects, as reflected by lower ISO-induced rises in arterial fatty acid and glycerol levels $(1,2)$. This may favor the maintenance (and perhaps development) of large fat stores. The impaired lipolytic response in obesity may be associated with a lowered blood flow per unit weight, since a diminished blood flow response may affect the delivery of ISO and transport proteins for fatty acids to adipose tissue $(6,13)$. In addition, a model has been proposed which raises the possibility that the release and reuptake of fatty acids by adipocytes within adipose tissue, may be controlled by adipose tissue perfusion (11).

The present study was intended to investigate whether the adipose tissue blood flow response as result of $B_{1}-$ and $B_{2}$-adrenergic stimulation was altered in obesity and to study the effect of weight reduction on this response.

\section{Subjects and methods}

In this protocol, body composition and abdominal subcutaneous fat blood flow were determined in lean $(n=9)$ and obese males $(n=9)$. In 7 of the obese subjects measurements were also performed after weight reduction $(n=7$, reduced-obese subjects). Physical characteristics are indicated in table 1 ( $\mathrm{p}$ 125). All subjects were in good health as assessed by a medical history and physical examination. The study protocol was reviewed and approved by the Ethics Committee of the University of Limburg and all volunteers were asked for written consent. During the experiments room temperature was kept between $21-23^{\circ} \mathrm{C}$.

\section{Body composition}

Body density was determined with hydrostatic weighing with simultaneous lung volume measurement (Volugraph 2000, Mijnhardt, The Netherlands). Body composition was calculated according to the formula of Siri (23). 


\section{Dlext}

The first four weeks of the diet period the subjects followed a very low calorie diet of $2000 \mathrm{~kJ} / \mathrm{day}$, which provided $52 \mathrm{~g}$ protein, $50 \mathrm{~g}$ carbohydrate, $7 \mathrm{~g}$ fat, $1.3 \mathrm{~g}$ sodium/day and a micronutrient content which meets the Dutch recommended daily allowances. In the fifth week the subjects returned in 2-3 days to a situation near energy balance. The blood flow measurements took place in the sixth week after the subjects had been weight stable for $4-5$ days.

\section{Blood flow measurements}

After an overnight fast, the blood flow through abdominal subcutaneous adipose tissue was investigated during a $30 \mathrm{~min}$-period of supine rest and during $30 \mathrm{~min}$-periods of infusion of the $B_{1}$ - and $B_{2}$-agonist isoprenaline (ISO) with or without simultaneous infusion of the $B_{1}$-blocker atenolol (AT). After the resting period, the intravenous infusion of ISO was started for $60 \mathrm{~min}$ with AT added on to the last $30 \mathrm{~min}$. In a prestudy for each subject ISO dose-plasma concentration response curves had been determined in order to infuse in the present experiment a standardized dose of ISO, which was known to increase the plasma ISO concentration to a value of $165 \mathrm{pg} / \mathrm{ml}$. The mean infusion dose of ISO was $20 \mathrm{ng} / \mathrm{kg}_{\text {fat free mass }}{ }$ min in lean, obese and reduced obese subjects.

Subcutaneous adipose tissue blood flow was measured by the ${ }^{133}$ xenon washout method on the abdomen a little distal and lateral from the umbilicus (18). A dose of ${ }^{133}$ xenon, dissolved in saline, was injected subcutaneously with a very fine needle $(0.5 \times 16 \mathrm{~mm})$. A probe with NaI-detector (Atomic Products Corporation, Intequip, Almere, The Netherlands) was placed in a fixed position $15 \mathrm{~cm}$ above the abdomen. The registration of ${ }^{133}$ xenon was started $45 \mathrm{~min}$ after the injection at which moment the washout is usually mono-exponential. From the regression of count rate against time, the rate of disappearance of ${ }^{133}$ xenon over the last 20 min of each measurement period was determined.

\section{Tissue-blood partition coefficient}

For the calculation of quantitative values of fat blood flow (per $100 \mathrm{~g}$ tissue), the relative solubility of xenon between tissue and blood, i.e., the partition coefficient, must be known. The highest solubility coefficients for xenon are found for lipids and hemoglobin, which implicates that the magnitude of the partition coefficient will mainly depend on the lipid content of adipose tissue and the hematocrit value of the blood perfusing it $(4,7)$. In a study of Martin et al (20), the relationship between \% adiposity and lipid fraction ( $V$ ) of adipose tissue was determined by means of underwater weighing of all portions of adipose tissue of human cadavers (range \% body fat 17.8-43.9) and was as follows:

(1) $V=0.327+0.0124 x \%$ adiposity $(\mathrm{r}=0.95, \mathrm{P}<0.005)$

Given that the solubility of xenon in a tissue equals the weighted mean of the solubility in 
the individual tissue components (26), the following equations can be given on basis of data of Chen et al (7):

(2) $S B=H t S C+(1-H t) S P$, whereby

$s_{\mathrm{B},} \mathbb{s}_{\mathrm{C},}, \mathrm{S}_{\mathrm{p}}$ : solubility in blood, red blood cells, and plasma, respectively.

Ht: hematocrit

Assuming that the solubility of xenon in water and protein within adipose tissue equals that of plasma yields the following equation:

(3) $S_{A}=V S_{L}+(I-V) S_{p}$, whereby

$\mathrm{S}_{\mathrm{A}}, \mathrm{S}_{\mathrm{L}}, \mathrm{S}_{\mathrm{p}}:$ solubility in adipose tissue, in lipid and in plasma, respectively

$\mathrm{V}$ : lipid fraction of adipose tissue.

The tissue-blood partition coefficient of xenon for adipose tissue $(\lambda)$ can then be expressed as:

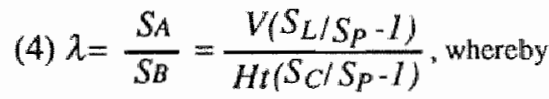

$\mathrm{Sp}_{\mathrm{p}}: \quad 0.0939 \mathrm{ml} / \mathrm{ml}$

$S_{L:} \quad 2.9134 \mathrm{ml} / \mathrm{g}$

$S_{\mathrm{C}}: \quad 0.2710 \mathrm{ml} / \mathrm{ml}$.

On basis of equation 1 and 4 , the tissue blood partition coefficient was calculated for each individual. The hematocrit value was assumed to be $45 \%$, a value previously found for both lean and obese men (2)

\section{Statistics}

Data are represented as means $\pm S E M$. Blood flow values within groups were tested by means of repeated measurements ANOVA. Post-hoc testing was done with a Student's paired $t$-test and $P$-values of the post-hoc comparisons were corrected according to Bonferroni's inequalities. Differences between lean and obese were tested with a one-way analysis of variance. Comparisons between values before and after weight reduction were done with a Student's paired t-test. A P-value smaller than 0.05 was regarded as statistically significant. 


\section{Results}

\section{Body composition}

As result of diet there was a $8.7 \mathrm{~kg}$ weight loss which can be accounted for $67 \%$ by fat mass and $33 \%$ by fat free mass (table 1 ).

Table 1. Characteristics of lean, obese and reduced-obese males.

\begin{tabular}{|c|c|c|c|c|c|c|}
\hline & $\begin{array}{r}\text { lean } \\
(n=9)\end{array}$ & $\begin{array}{l}\text { obese } \\
(n=9)\end{array}$ & & $\begin{array}{l}\text { obese } \\
(n=7)\end{array}$ & & $\begin{array}{l}\text { reduced-obese } \\
\qquad(n=7)\end{array}$ \\
\hline Age $(y)$ & $22.2 \pm 0.7$ & $33.0 \pm 1.8$ & $* *$ & $33.7 \pm 1.3$ & $* *$ & $33.7 \pm 1.3 * *$ \\
\hline Weight $(\mathrm{kg})$ & $73.3+3.9$ & $103.5 \pm 2.9$ & $* *$ & $98.4 \pm 2.9$ & $* *$ & $89.6 \pm 2.7 * * \#$ \\
\hline $\mathrm{BMI}\left(\mathrm{kg} / \mathrm{m}^{2}\right)$ & $22.3 \pm 1.0$ & $32.5 \pm 1.2$ & $* *$ & $31.4 \pm 0.9$ & $* *$ & $27.6 \pm 0.5 * *$ \\
\hline$\%$ Body fat & $11.6 \pm 3.9$ & $28.3 \pm 1.8$ & $* *$ & $27.1 \pm 1.2$ & $* *$ & $23.4 \pm 3.3 * * 4$ \\
\hline Fat mass $(\mathrm{kg})$ & $9.0 \pm 1.4$ & $29.5 \pm 2.5$ & ** & $27.0 \pm 0.6$ & $* *$ & $21.1 \pm 1.3 *$ *\#妌 \\
\hline Fat free mass $(\mathrm{kg})$ & $64.60+3.4$ & $74.0 \pm 2.2$ & * & $73.3 \pm 11.6$ & $*$ & $68.6 \pm 1.2 *$ \\
\hline Lipid fraction adipose tissue & $0.47 \pm 0.02$ & $0.68 \pm 0.02$ & $* *$ & $0.67 \pm 0.02$ & $* *$ & $0.62 \pm 0.01 * *$ \\
\hline Partition coefficient xenon & $5.3 \pm 0.2$ & $7.4 \pm 0.2$ & $* *$ & $7.2 \pm 0.1$ & $* * *$ & $6.7 \pm 0.1 * *$ \\
\hline
\end{tabular}

Means $\pm S E M$; lean, obese: $n=9$, (reduced)-obese: $n=7$; lean vs (reduced)-obese (Unpaired $t$-lest): ${ }^{*}=\mathrm{P}<0.01, * *=\mathrm{P}<0.001$; obese vs reduced-obese (Student's paired t-test): $\#=\mathrm{P}<0.01, \# \#=\mathrm{P}<0.001, \|=\mathbb{B}$ ody mass index.

\section{Blood flow measurements}

As indicated in table 1 the calculated lipid fraction of adipose tissue was significantly higher in obese as compared to lean subjects. As expected, weight reduction resulted in a significant decrease in the lipid content of adipose tissue. The estimated values for the tissue-blood partition coefficient for adipose tissue were significantly higher in obese as compared to reduced-obese and lean subjects and significantly higher in reduced-obese than lean subjects.

The abdominal subcutaneous adipose tissue blood flow in normal weight, obese and reduced-obese subjects is indicated in table 2 . The basal abdominal fat blood flow was significantly higher in lean than obese subjects, whereas weight reduction in obese subjects resulted in an increase in basal abdominal fat blood flow (obese vs reducedobese, $\mathrm{P}<0.05$ ). There was a significant negative relationship berween $\%$ body fat and basal fat blood flow in the total group $(r=0.51, P<0.05)$.

There was a significant increase in abdominal fat blood flow as result of ISO-infusion in lean and obese and reduced-abese subjects. During ISO+AT infusion, fat blood flow 


\section{Chapter 9}

Table 2. Abdominal subcutancotis adipose tissue blood flow (ml/100 g.min) during rest and during infusion of the $B_{1}$ - and $B_{2}$-agonist isoprenaline (ISO) with and without simultaneous infusion of the $B_{1}$ blocker atenolol (AT) in lean, obese and reduced-obese males.

\begin{tabular}{lcccc}
\hline & Conirol & ISO & ISO+AT & ANOVA \\
\hline lean & $2.60 \pm 0.65$ & $10.57 \pm 2.45 * *$ & $5.50 \pm 1.33 * * * 4$ & 0.001 \\
obese $(\mathbf{n}=9)$ & $1.02 \pm 0.21 \&$ & $3.95 \pm 0.57 * \%$ & $3.25 \pm 0.42 * *$ & 0.001 \\
obese $(\mathbf{n}=7)$ & $0.85 \pm 0.16 \%$ & $4.00 \pm 0.71 * \%$ & $3.26 \pm 0.53 * *$ & 0.001 \\
reduced-obese & $2.06 \pm 0.661$ & $6.11 \pm 1.41 * *$ & $4.25 \pm 1.12$ & 0.003 \\
\hline
\end{tabular}

Means \pm SEM, lean, obese: $n=9$, (reduced)-obese: $n=7$; Comparisons between control values: lean vs obese or reduced-obese (Unpaired t-test): $\$=P<0.05$, obese ws reduced obese (Student's paired t-test): I=P $<0.05$; Within-group comparisons: Control vs ISO or ISO+AT (Student's paired 1-test, Bonferroni): $* \mathrm{P}<0.05, * * \mathrm{P}<0.01$, ISO vs ISO+AT: $\#=\mathrm{P}<0.05$; Values for Repeated Measurements ANOVA are indicated in the right-hand column.

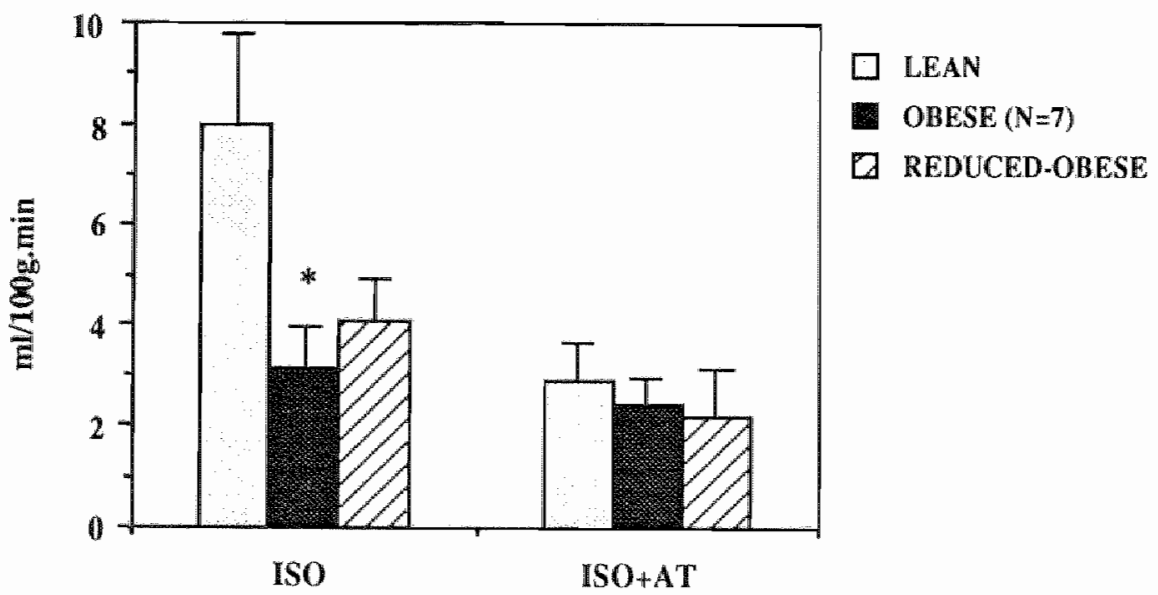

Fig 1. Changes in abdominal subcutaneous fat blood flow during infusion of the $B_{1}$ - and $B_{2}$-agonist isoprenaline (ISO) with and without simultaneous infusion of the $B_{1}$-blocker atenolol (AT). Means \pm SEM, lean: $n=9$, (reduced)-obese $n=7$; Unpaired l-test: lean ws obese ${ }^{*} P<0.05$. 
was still significantly increased as compared to control values in lean and obese subjects, whereas in reduced-obese subjects this value tended to be higher than control values $(\mathrm{P}=0.10)$. With ISO, absolute abdominal fat flow (table 2$)$ and the change in abdominal fat flow from control (fig 1) were significantly higher in lean than obese subjects, whereas with ISO+AT there were no significant differences between both groups. Furthermore, there was a significant negative relationship between \% body fat and the increase in blood flow during ISO in the total group ( $\mathrm{r}=0.53, \mathrm{P}=0.03)$.

During ISO and ISO+AT absolute values for the abdominal fat blood flow and the change in abdominal flow from control were not significantly different in reduced-obese as compared to lean or obese subjects. However, there was a positive relationship between the decrease in \% body fat and the weight loss-induced change in the ISO mediated abdominal blood flow values (indicated in fig 2).

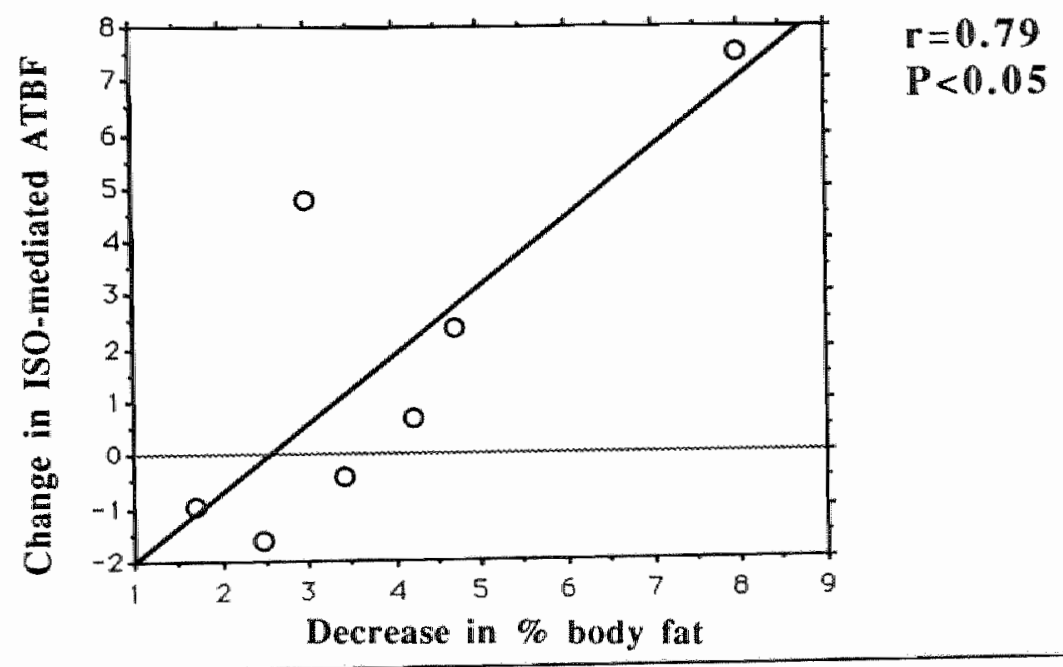

Fig 2. Relationship between the decrease in $\%$ body lat and the weight loss-induced change in abdominal subcutaneous adipose tissue blood flow (ATBF) during infusion of the $B_{1}$ - and $B_{2}$-agonist isoprenaline (ISO); (reduced)-obese: $n=7$; slandard error of estimate for $1 S 0: 2.43 \mathrm{ml} / 100 \mathrm{~g} \cdot \mathrm{min}$.

\section{Discussion}

The main purpose of the present study was to investigate whether the B-adrenergically stimulated abdominal subcutaneous fat blood flow was altered in obesity and if so how weight reduction would affect this. For calculating quantitative blood flow values from the washout curves of ${ }^{133}$ xenon, the adipose tissue blood partition coefficient must be known. The highest solubility coefficients for xenon are found for lipids and hemoglobin, 
which implicates that the lipid content of adipose tissue and the hematocrit value of the blood perfusing it will be major determinants of the partition coefficient. The hematocrit value was assumed to be $45 \%$ as found previously for both lean and obese men (2). Although the variation in lipid content of human subcutaneous adipose as reported by Martinsson et al (21) would only slightly affect the magnitude of partition coefficient, Builow et al (5) reported a much higher variation in lipid content. In both studies, exact data on the percentage adiposity of the subjects are, however, not given. The relationship between $\%$ adiposity and the lipid content of total adipose tissue in the study of Martin et al (20) has, as far as we are aware of, not previously been reported. Since subcutaneous adipose tissue comprises approximately two thirds of total adipose tissue (8), it may be assumed that the magnitude and the variation of the lipid content of total adipose tissue gives a reasonable representation of the lipid content in subcutaneous adipose tissue. Moreover, the range in lipid content we found (0.40-0.85) seems comparable to the range reported by Bülow et al (5) for subcutaneous adipose tissue on the abdomen and thigh. Basal abdominal adipose tissue blood flow was significantly higher in lean than obese subjects, as previously reported $(12,15,18)$. Furthermore, the ISO-induced increase in abdominal fat blood flow was significantly higher in lean as compared to obese subjects (fig 1). Moreover, there was a negative relationship between the increase in blood flow as result of ISO-infusion and the \% body fat. A blunted peripheral blood flow response has been reported before in obesity $(2,15,17)$. Laakso et al (17) found that the insulinmediated increase in skeletal muscle muscle blood flow was impaired in obese subjects during a hyperinsulinemic, euglycemic clamp, whereas Jansson et al (15) found a blunted adipose tissue blood flow response to glucose ingestion in obese subjects. In addition, we have recently found a diminished skeletal muscle blood flow response during Badrenergic stimulation in obese as compared to lean subjects (2). It has been previously reported that catecholamines may influence human adipose tissue blood flow (14). However, the blunted response to $\mathbb{B}$-adrenergic stimulation in abdominal subcutaneous adipose tissue in obese subjects has, as far as we are aware of, not previously been reported.

Weight reduction resulted in a significant increase in basal blood flow and a tendency towards an increase in the ISO-induced change in blood flow. Although the mean Badrenergically mediated increase in blood flow was not significantly different before as compared to after weight reduction, there was a linear relationship between the decrease in $\%$ body fat and the change in ISO-induced blood flow response as result of weight loss (fig 2). These data suggest that the biunted blood flow response as result of $\mathbb{B}$-adrenergic stimulation in obese subjects is secondary to the expanded fat mass, with a constant or decreased blood flow per adipose cell $(10,22)$, and it is hypothesized that it will return towards the condition seen in lean subjects after more severe weight reduction. However, since our obese subjects were still slightly overweight, we cannot exclude that postobese subjects, totally normalized in body weight, still have a defect in the blood flow response. In lean and obese subjects, the blood flow response was higher during ISO $\left(B_{1}-\right.$ and $B_{2}$ adrenergic stimulation) than during ISO+AT-infusion (mainly $B_{2}$-adrenergic stimulation), whereas the blood flow during ISO+AT was still significantly elevated as compared to control values. Since the administered dose of the $B_{1}$-blocker atenolol was sufficient for 
an effective $(9,24)$ and selective (19) $G_{1}$-blockade, this indicates that both $B_{1}$ - and $B_{2}$. adrenoceptors are involved in the blood flow response as result of isoprenaline. Furthermore, whilst the ISO-induced increase in ATBF was significantly higher in lean than obese subjects, the ISO+AT induced increase in ATBF was comparable, which suggests that especially the $B_{1}$-mediated blood flow response is blunted in obese subjects. A factor that may have biased our data is the significant age difference. There was a significant positive relationship between age and $\%$ body fat in our lean and obese subjects which might have affected the relationship between \% body fat and blood flow. However, a study of Larsen et al (18) reported no association between age and abdominal subcutaneous adipose tissue blood flow, which implicates that age was no confounding factor in the present study.

In previous studies $(1,2)$ we have found that the lipolytic response as result of infusion of the $B_{1}$ - and $B_{2}$-agonist ISO is lowered in obese subjects, as reflected by lower ISOinduced rises in arterial fatty acid and glycerol levels. This impaired lipolytic response in obesity may be related to the lowered blood flow response per unit weight, since a lower blood flow may diminish the delivery of ISO (13) and transport proteins for fatty acids (6) to adipose tissue and may increase the rate of fatty acid reesterification (11). However, in another study (3) we found that weight reduction did not change the impaired lipolytic response during isoprenaline-infusion in obese subjects, but rather decreased the release of NEFA from (visceral) adipose tissue as suggested by a lowered ketogenesis. This might suggest than mechanisms other than the blunted blood flow response are responsible for the impaired lipolysis in (reduced)-obese subjects. However, no firm conclusions on the role of blood flow in the impaired lipolytic response in the (reduced)-obese subjects can be drawn from the present study, since the blood flow and lipolytic response as result of $B$-adrenergic stimulation were measured in different groups of subjects and the observed changes in blood flow response were relatively small.

Recently, interdepot adipose tissue analyses have become more common since regional differences in the metabolism of adipose tissue may be one of the factors involved in the cardiovascular risk of obesity. It has been shown that the lipolytic and the blood flow response (per unit weight) to fasting (12), glucose ingestion (16) or catecholamine infusion (25) may be more pronounced in abdominal subcutaneous tissue than in other subcutaneous fat depots such as femoral and gluteal fat. In accordance with these findings we found that the blood flow response in the abdominal adipose tissue was much higher than the previously reported values on forearm subcuraneous fat flow in lean and obese subjects $(1,2)$.

In summary, the present study shows that the beta-adrenergically mediated blood flow response (per unit weight) is diminished in obesity. The lowered blood flow response in adipose tissue in obese subjects tended to change in a direction towards the conditions seen in lean subjects after partial weight reduction. 


\section{References}

1. Blaak E.E. M.A. van Baak, G.J. Kemerink, M.T.W. Pakbiers, G.A.K. Heidendal, and W.H.M. Saris. Effect of beta-adrenergic stimulation on forcarm skeletal musle metabolism. Submitted to Am. I. Physiol. (Endocrinol. Metab.)

2. Blaak E.E. M.A. wan Baak, G.J. Kemerink, M.T.W. Pakbiers, G.A.K. Heidendal, and W.H.M. Saris. Effect of beta-adrenergic stimulation on whole body energy expenditure and forearm skeletal muscle metabolism in obese men: a comparison with lean men. Submitted to Am. I. Physiol. (Endocrinol. Metab).

3. Blaak E.E., M.A. van Baak, G.J. Kemerink, M.T.W. Pakbiers, G.A.K. Heidendal, and W.H.M. Saris. Beta-adrenergic stimulation and skeletal muscle metabolism in relation to weight reduction in obese man. Submitted to Am. J. Physiol. (Endocrinol. Metab.)

4. Bullow J. Adipose tissue blood flow during exercise. Dan. Med. Bul1. 30: 85-100, 1983.

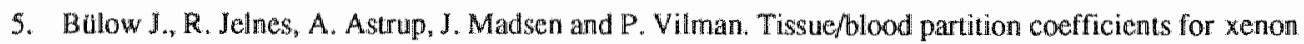
in various adipose tissue depots in man. Scand. J. Lab. Invest. $47: 1.3,1987$.

6. Builow J. and J. Madsen. Influence of blood flow on fatty acid moblization from lipolytically active adipose tissue. Pflugers Arch. 390: 169-174, 1981.

7. Chen R.Y., F. Fan., S. Kim, K. Jan, S. Usami, and S. Chien. Tissue-blood partition coefficient for xenon: temperaiure and hematocrit dependence. J. Appl. Physiol. 49(2): $178-183,1980$.

8. Chien S., M.T. Peng, K.P. Chen., T.F. Huang, C. Chang and H.S. Fang. Longitudinal studies on adipose tissue and its distribution in human subjects. J. Appl. Physiol. 39: 825-830, 1975.

9. Conway F.J. Human pharmacokinetic and pharmacodynamic studies on atenolol ICI 66082. Brit. J. Pharmacol. 3: 267.272, 1976

10. Crandall D.L., and M. DiGirolamo. Hemodynamic and metabolic correlates in adipose tissue: pathophysiologic considerations. FASEB J. 4: 141-147, 1990

11. Edens N.K. R.L. Leibel, and J. Hirsch. Mechanism of free fatty acid reesterification in human adipocytes in witro. J. Lip. Res. 31: 1423-1431, 1990.

12. Engfeldt $P$, and B. Linde. Subcutaneous adipose tissue blood flow in the abdominal and femoral regions in obese women: effect of fasting. Int. J. Obes. 16: 875-879, 1992.

13. Hjehmdahl $\mathrm{P}$, and B.B. Fredholm. Influence of adipose tissue blood flow on the lipolytic response to circulating noradrenaline at normal and reduced pH. Acta Physiol. Scand. 98: 74-79, 1976.

14. Hjehmdatl $P$. and $B$. Linde. Influence of circulating NE and Epi on adipose tissue vascular resistance and lipolysis in bumans. Am. J. Physiol. 245 (Heart Cire. Physiol. 14): H447 H452, 1983.

15. Jansson P., A. Larsson. U. Smith, and P. Lonnroth. Glycerol production in subcutaneous adipose tissue in lean and obese humans. J. Clin. Inwest. 89: 1610-1617, 1992.

16. Jansson P., U. Smith, and P. Lonroth. Interstitial glycerol measured by microdialysis in two subcutancous regions in humans. Am. J. Physiol. 258 (Endocrinol. Metab. 21): E918-E922, 1990.

17. Laakso M., S. Edelman, G. Brechtel, and A.D. Baron. Decreased effect of insulin to stimulate skeletal muscle blood flow in obese man: A nowel mechanism for insulin resistance. J. Clin. Invest. 85: 1844. $1852,1990$.

18. Larsen O.A. N.A. Lassen, and F. Quade. Blood flow through human adipose tissue determined with radioactive xenon. Acta Physiol. Scand. 66: 337-345, 1966.

19. Lipworth B.I., L.C. Mc Farlane, W.J. Coutie, and D.G. Mc Devitt. Evaluation of the metabolic response to inhaled salbutamol in the measurement of $B_{2}$-adrenoceptor blockade. Eur. J. Clin. 
Pharmacol. 37: 297-300, 1989.

20. Martin A.D., D.T. Drinkwater, and J.P. Clarys. Adipose tissue density, estimated lipid fraction and whole body adiposity in 6 male cadavers. Int. II. Sports Med. 25 (5, Suppl): $\$ 5,1993$.

21. Martinsson A. On the composition of human adipose tissue. Acta Med. Scand. 182: 795-803, 1967.

22. Rosell S., and E. Belfrage. Blood circulation in adipose tissue. Physiol. Rev. 59(4): 1078-1104, 1979.

23. Siri W.E. The gross composition of the body. Adv. Biol. Med. Physiol. 4: 239-280, 1956.

24. Thörne A., and J. Wahren. B-adrenergic blockade does not influence the thermogenic response to a mixed meal in man. Clin. Physiol. 9: 321-332, 1989.

25. Wahrenberg H., F. Lönnqvist, and P. Amer. Mechanisms underlying regional differences in lipolysis in human adipose tissue. J. Clin. Invest. 84: 458-467, 1989.

26. Yeh S.Y., and R.E. Peterson. Solubility of kryption and xenon in blood, protein solutions, and tissuce homogenates. J. Appl. Physioll. 20 (5): 1041-1047, 1965. 


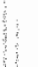




\section{CHAPTER 10}

\section{DISCUSSION}

The research in the present thesis was focussed on the role of the sympathetic nervous system in the regulation of energy expenditure in man, with emphasis on processes that may lead to the development or maintenance of the obese state. The first steps in this project were to elucidate the adrenoceptor populations involved in the sympathetically mediated thermogenesis and to evaluate the techniques used to study skeletal muscle metabolism. The next step was to investigate the importance of skeletal muscle as site of localisation for the sympathetically induced thermogenesis in healthy lean males. Subsequently, differences in sympathetically mediated changes in resting energy expenditure and substrate metabolism were evaluated in lean and obese males. Finally, the question was posed whether the observed differences in metabolism between lean and obese subjects may be a cause or consequence of the obese state.

\section{Involvement of adrenoceptor populations in human thermogenesis}

It was concluded in the studies, described in chapter 2, that in healthy lean males both $B_{1}$ - and $B_{2}$-adrenoceptors are involved in the adrenergically mediated thermogenesis, whereas $\alpha_{1}$ and $\alpha_{2}$ adrenoceptors do not play a role of significance.

The concept of an atypical $B_{3}$-adrenoceptor got new impetus with the isolation of a series of human $B_{3}$-adrenoceptor clones, from which one was expressed in chinese ovary hamster cells (20). An indication on the physiological significance of $B_{3}$-adrenoceptors in the sympathetically mediated thermogenesis may be obtained from the in chapter 2 described protocols, where the catecholamines norepinephrine (NE) and epineplurine (E) were infused in the presence of propranolol. Simultaneous infusion of $\mathrm{NE}$ and $\mathrm{E}$ in the presence of propranolol did not change energy expenditure (as compared to infusion of propranolol only). If in this situation a considerable stimulation of the atypical $B_{3}$ a adrenoceptors occurred, this may indicate a minor role for $\mathbb{B}_{3}$-adrenoceptors in human energy metabolism. However, for drawing definite conclusions on the significance of $B_{3}$ adrenoceptors on basis of these protocols several conditions have to stand. A first prerequisite is that the circulating concentrations of the catecholamines must have been high enough for exerting a $B_{3}$-adrenergic effect. As already discussed in chapter 2 we may assume that certainly the circulating concentration of NE must have been sufficient for a significant $B_{3}$-adrenergic stimulation. Secondly, the concentration of the classical $B-$ blocker propranolol must have been sufficient for a complete $B_{1}$ - and $B_{2}$-adrenoceptor blockade without blocking the $B_{3}$-adrenergic receptors. With a similar infusion protocol, we previously found steady state plasma concentrations of propranolol of approximately $1-2 \cdot 10^{-7} \mathrm{M}(9)$. This concentration is in the same order of magnitude as in vitro data on the $\mathrm{pA}_{2}$ for propranolol antagonism of the isoprenaline-induced increase in brown adipose tissue lipolysis in rats (2), which may suggest that part of the $B_{3}$-mediated effects 
were blocked in our study. In contrast, in vitro studies with chinese ovary hamster cells transfected with human $B_{3}$-genes, have shown that a propranolol concentration three orders of magnitude higher than used in our study only inhibits $\pm 20 \%$ of the isoprenalineinduced $\mathrm{C}-\mathrm{AMP}$ accumulation (20). Thus, although controversial we cannot exclude that part of the $B_{3}$-mediated effects of $N E$ and $E$ were blocked in the present study by propranolol. Data that may support this come from recent studies in man $(48,49)$, where isoprenaline- and BRL35135-induced thermogenesis were still increased when the $B_{1}$ and $B_{2}$ - effects were blocked with the $B_{1}$ - and $B_{2}$-blocker nadolol, suggesting a role for $B_{3}$-adrenoceptors in thermogenesis. The divergence between these and our results may be due to a higher $B_{1}$ - and $B_{2}$ - selectivity of nadolol than propranolol (20), which suggests that the former $B$-antagonist may be more suitable in discriminating between $B_{1} / B_{2}$ and $B_{3}$-adrenoceptor responses. However, although these nadolol studies suggest a role for $B_{3}$-adrenoceptors in human thermogenesis, the physiological significance of the atypical adrenoceptors in man remains an issue of debate. A study with human adipocytes reported that part of the lipolysis may be mediated by $B_{3}$-adrenoceptors (30), but these findings are not consistent (33). Furthermore, in a recent study (32) $B_{3}$-adrenoceptor mRNA was detected in several human fat depots, the gallbladder and colon, but another study could not confirm this (45). In summary, although there seems to be no consistent evidence to support the involvement of $B_{3}$-adrenoceptors in human energy metabolism, conclusive evidence to exclude a significant role for $B_{3}$-adrenoceptors in man is also lacking.

If $B_{3}$-adrenoceptors significantly contribute to the sympathetically mediated thermogenesis in man, the in chapter 2 described role for $B_{2}$-adrenoceptors in the isoprenaline and salbutamol-induced thermogenesis may be (partly) due to $B_{3}$-adrenergic stimulation. However, in a recent study (49) it was shown that the salbutamol-induced thermogenesis was completely abolished by $B_{1}$ - and $B_{2}$-blockade by nadolol, which indicates that the thermogenic effect of salbutamol can be mainly attributed to $B_{2}$ adrenergic stimulation. From the above discussion, we can conclude that both $B_{1}$ - and $B_{2}$ adrenoceptors are involved in the sympathetically mediated thermogenesis, whereas the role of $B_{3}$-adrenoceptors remains uncertain.

\section{Methodologicall considerations}

\section{Healling procedure for obtaining arterialized blood}

Skeletal muscle metabolism was studied by determining arterial(ized)-venous concentration differences of various metabolites across muscle in combination with a measurement of blood flow (forearm model). Arterialized blood, obtained by heating a dorsal hand vein, is often used as an alternative for arterial blood in forearm balance studies. Previously, the use of warming blankets as heating device has been criticized since it may affect core temperature and the hemodynamics of the contralateral arm and it may thereby introduce errors in the skeletal muscle flux calculations (7). In chapter 3, we showed that hand heating by means of a warm air box, which circulates air at $60^{\circ} \mathrm{C}$, had no effect on body temperature and caused less hemodynamic disturbance than the 
warming blanket. The differences between both heating procedures are likely due to differences in the efficiency of heat transfer to the body. The heat transfer with the warming blanket may be greater than with the warm air box because conduction between surfaces is more efficient than transfer of heat from warmed air (22). These data implicate that the warm air box is a better method for obtaining arterialized blood in forearm balance studies than the warming blanket. However, a drawback of using arterialized blood in tissue balance studies is that the value for the oxygen saturation of hemoglobin is an underestimation of the real arterial value. This may bias data on oxygen flux across muscle (or other tissues) especially when a small arterio-venous oxygen difference is accompanied by a relatively high tissue blood flow. For this reason, the arterialized oxygen saturation in the forearm experiment, described in chapter $\mathbf{5}$, was assumed to be equivalent to the value found for arterial blood of $97 \%$, whereas in the subsequent studies (chapter 6,8 ) instead of arterialized blood arterial blood was used.

\section{Skeletal musclle and adipose tissue blood flow}

For estimating skeletal muscle blood flow in forearm balance studies, often a measurement of total forearm blood flow by means of venous occlusion plethysmography is taken as being representative for skeletal muscle blood flow. Although skeletal muscle may account for $60 \%$ or more of the forearm tissues (17), a significant contribution of other forearm tissue, like subcutaneous fat and skin, cannot be excluded. This may especially be important when comparing skeletal muscle metabolism in lean and obese subjects since the contribution of subcutaneous fat blood flow to total blood flow may be different between these groups due to a higher fat content and a possibly lower blood flow (per unit weight) in obese subjects as compared to the lean (34). A prerequisite for calculating absolute values for adipose tissue blood flow from the washout constant of ${ }^{133}$ xenon, is that the adipose tissue-blood partition coefficient of xenon must be known. The major determinants of the adipose tissue-blood partition coefficient are the lipid. content of adipose tissue and the hematocrit value of the blood perfusing it $(10,13)$. In the blood flow studies described in chapter 4 and 9 , individual values for the tissue blood partition coefficient were calculated by correcting for the lipid content of adipose tissue and the blood hematocrit values on basis of data of Chen et al (13). The lipid content was estimated by means of a recently reported linear relationship between \% adiposity and the lipid fraction of adipose tissue (38). In the forearm studies described in chapter 5,6 , and 8 , the partition coefficient was assumed to be $8 \mathrm{ml} / \mathrm{g}$ in both lean and obese subjects, as previously reported for normal weight volunteers (10). However, a variation in the lipid content of adipose tissue as calculated in chapter 4 and 9 and as reported by Bülow et al (10,11) would not affect the conclusions of these studies

The data of the study, shown in chapter 4 , indicate that during rest the contribution of subcutaneous fat blood flow to total forearm blood flow was significantly higher in lean than obese subjects (18 vs $11 \%$, respectively). The implication of this finding is that in the study of skeletal muscle blood flow (and substrate exchange) it may be necessary to take the contribution of subcutaneous fat flow into account, especially when comparing lean and obese subjects. 


\section{B-adrenergic stimulation and skeletal muscle metabolism}

In rats, brown adipose tissue has been shown to be an important site of localisation for the sympathetically mediated thermogenesis $(27,44)$. In chapter 5 , we showed that skeletal muscle is the most important site of localisation in healthy male volunteers, which is in agreement with other studies $(5,43)$. The rise in skeletal muscle oxygen consumption during infusion of the non-selective $\mathbb{B}$-agonist isoprenaline (ISO) was sufficient to explain the rise in whole body energy expenditure. However, one has to be careful in drawing definite quantitative conclusions on the contribution of muscle to total thermogenesis, since several assumptions were made for estimating skeletal muscle blood flow. For this reason, we cannot exclude a relatively small contribution of other tissues to thermogenesis, as suggested by Simonsen et al (43) for abdominal subcutaneous adipose tissue and heart.

As result of non-selective B-adrenergic stimulation (ISO-infusion) there was an increase in lipolysis in adipose tissue, as reflected by a threefold increase in plasma non esterified fatty acids (NEFA) and a twofold increase in plasma glycerol (chapter 5). Furthermore, there was a significant increase in plasma B-hydroxybutyrate (BOH), which indicates an increased ketogenesis in the liver. The increased lipolysis and ketogenesis were accompanied by an increased uptake and oxidation of NEFA and BOH by skeletal muscle. During simultaneous infusion of ISO with the selective $B_{1}$-blocker atenolol (AT), lipolysis, ketogenesis and muscle NEFA and $\mathrm{BOH}$ uptake were no longer increased, whereas there was an increase in skeletal muscle lactate release. This indicates an increased glycolysis (conversion from glucose to pyruvate), which may be accompanied by an increased glycogen breakdown and glucose oxidation, as reported with epinephrine infusion (40). Since the adrenoceptor population of skeletal muscle mainly consists of $B_{2^{-}}$ adrenoceptors in man (35), this glycolytic effect can most likely be attributed to $B_{2}$ adrenergic stimulation.

The present thesis gives an indication which substrates are involved in the increased muscle thermogenesis during $B$-adrenergic stimulation. The energy requiring processes behind this increased substrate oxidation remain, however, to be determined. In rats, it has been shown that an unique proton conductance pathway is operative in the mitochondria from brown adipocytes stimulated by norepinephrine (27). Activation of this pathway uncouples substrate oxidation and ATP formation, with a marked increase in substrate oxidation that is no longer dependent on the generation of ADP. It seems, however, most unlikely that an uncoupling of oxidation and phosphorylation in muscle mitochondria is the primary aim of sympathetic stimulation in humans. A number of mechanisms that may be responsible for the B-adrenergically mediated muscle thermogenesis in man can be proposed. Firstly, adrenergic stimulation has been reported to result in a fall in plasma $\mathrm{K}^{+}$concentrations (5), which may be related to a stimulation of the rate of active $\mathrm{Na}^{+}-\mathrm{K}^{+}$transport in skeletal muscle, predominantly mediated by $\mathrm{B}_{2}-$ adrenergic mechanisms (15). However, it has been reported that intact muscle requires at most $6 \%$ of its basal energy production for active $\mathrm{Na}^{+} \mathrm{K}+$ transport (14), which makes a major contribution of these pumps to the thermogenic effect of sympathomimetics unlikely. Secondly, futile cycling of substrates has been suggested to be responsible for 
part of the sympathetically mediated thermogenesis $(36,37)$. A futile cycle is defined as a cycle in which ATP is wsed to form a phosphorylated product, which is then dephosphorylated with loss of non-utilizable energy. These cycles could have a major role in increasing the sensitivity of processes that control the rates of degradation and synthesis of fuels. It has been reported that the rate of triglyceride-fatty acid cycling may increase by B-adrenergic stimulation (50), but the rate of this cycle probably is of minor importance for skeletal muscle thermogenesis (37). A substrate cycle that may give the largest contribution to muscle thermogenesis is probablly the fructose-6phosphate/fructose biphosphate cycle (36). Since during $B_{2}$-adrenergic stimulation (simultaneous ISO and AT infusion), glycolysis and probably also glycogen breakdown were increased, it may be speculated that this situation was accompanied by an increased rate of this 'glycolytic' cycle. The amount of energy lost in this cycle is, however, relatively small. This implicates that if this cycle is operating at rates so far reported under different physiological conditions (37), the contribution of this cycle to thermogenesis is negligible. Finally, it is possible that muscle tremor, a $B_{2}$-adrenoceptor mediated effect (3), is responsible for part of the $\beta_{2}$-adrenergically mediated increase in energy utilization. The processes responsible for the increased energy utilization in skeletal muscle during $B$-adrenergic stimulation require, however, further research.

\section{Obesity}

\section{Resting metabolic rate}

To compare resting energy expenditure (EE) in lean and obese subjects and in obese subjects before and after weight loss, metabolic rate has to be standardized to some estimate of metabolic size, i.e. fat free mass (FFM). However, expressing EE per $\mathrm{kg}$ FFM may not be appropriate since the regression line of EE on FFM has a non-zero intercept (26,39). A more complicated statistical analysis often requires large numbers of subjects. In our studies absolute values for $\mathrm{EE}$ were significantly higher in the obese as compared to lean subjects (lean, $n=9: 8078 \pm 274 \mathrm{~kJ} / 24 \mathrm{~h}$ vs obese $\mathrm{n}=21: 9331 \pm 273 \mathrm{~kJ} / 24 \mathrm{~h}, \mathrm{P}<0.02$ ). Due to the small number of subjects in the lean group it seems not realistic to perform a standardization for fat free mass, which implicates that no conclusion about standardized differences in resting energy expenditure between lean and obese subjects can be drawn from studies in the present thesis. By means of multiple regression analysis we could, however, determine a relationship between FFM, fat mass (FM) and EE in the total group of lean and obese subjects $(n=30)$. The equation is:

\section{$\mathrm{EE}(\mathrm{kJ} / 24 \mathrm{~h})=2401+80.7 * \mathrm{FFM}+36.2 * \mathrm{FM}$}

The $t$ and $P$-values for the different independent variables are as follows FFM: $t=7.318$, $\mathrm{P}<0.0001$; FM: $\mathrm{t}=4.317, \mathrm{P}<0.0002$, standard error of estimate $(\mathrm{SEE})=477 \mathrm{~kJ} / 24 \mathrm{~h}$. This two-variable equation explains $84 \%$ of the variance in EE. In addition, this equation indicates that beside FFM, FM is an important variable in the prediction of the magnitude 
of resting energy expenditure. The contribution of FM to EE amounts $36 \mathrm{~kJ} / \mathrm{kg}$ fat mass per $24 \mathrm{~h}$, which is comparable to several other studies $(23,29)$.

In total, we had data on body composition and resting energy expenditure in 16 obese subjects before and after weight loss (chapter 9). Absolute values of resting energy expenditure were significantly lower after diet as compared to before $(9331+331 \mathrm{vs}$ $8366 \pm 245$ kJday, $\mathrm{P}<0.001$ ). Partial correlation coefficients were calculated between the change in resting energy expenditure ( $\triangle E E)$ and the change in fat free mass $(\triangle F F M)$, fat mass $(\triangle F M)$ and basal venous norepinephrine concentration ( $\triangle N E)$, each adjusted for the other two variables. There were significant partial correlations between $\triangle \mathrm{EE}$ and $\triangle F F M$ $(r=0.61, P<0.02)$ and between $\triangle E E$ and $\triangle N E(r=0.63, P<0.02)$, whereas the partial correlation between the $\triangle \mathrm{EE}$ and $\triangle F M$ did not reach statistical significance $(r=0.32, N S)$. The equation expressing the relation between $\triangle \mathrm{EE}$ and $\triangle \mathrm{FFM}, \triangle \mathrm{FM}$, and $\triangle \mathrm{NE}$ within subjects is as follows:

$\Delta E E(\mathrm{~kJ} / 24 \mathrm{~h})=-262+170 \times \Delta \mathrm{FFM}(\mathrm{kg})+75 \times \Delta \mathrm{FM}(\mathrm{kg})+4.3 \Delta \mathrm{NE}(\mathrm{pg} / \mathrm{ml})$

The $t$ and $P$ values for the different independent variables are as follows: $\triangle F F M t=2.1$, $\mathrm{P}<0.04 ; \Delta \mathrm{FM} t=1.01 ; \mathrm{P}=0.30, \Delta \mathrm{NE} \mathrm{t}=2.5, \mathrm{P}<0.04 ; \mathrm{SEE}=461 \mathrm{~kJ} / 24 \mathrm{~h}$. This three-variable equation explains $55 \%$ of the variance in $\triangle \mathrm{EE}$. Furthermore, this equation indicates that beside the decrease in fat free mass, the decrease in basal norepinephrine concentration is an important variable contributing to the decrease in EE as result of weight reduction. This finding suggests that a diminished basal sympathetic activity may contribute to the previously suggested increased efficiency of cellular metabolism after weight loss (41). However, since our measurements of resting energy expenditure took place directly after the period of weight reduction, it is not known whether this effect will persist over longer periods of time.

\section{B-adrenerglcally mediated thermogenesis}

It has been suggested that a blunted thermogenesis after infusion of catecholamines (31) or a blunted activation of the sympatheric nervous system after a meal (4) may contribute to an increased metabolic efficiency in obesity, but these data are not consistent $(16,46)$. In chapter 6 we found that the whole body thermogenic response as result of infusion of the $B_{1}$ - and $B_{2}$-agonist isoprenaline was not significantly different between lean and obese subjects, which is consistent with another study using epinephrine infusion (16). However, in chapter 7 data are presented of the B-adrenergically mediated thermogenesis of 30 subjects with a wide range of adiposity (from 6 to $42 \%$ ). The results of this analysis show a significant negative relationship between \% body fat (adjusted for age and basal norepinephrine concentrations) and the magnitude of the isoprenaline induced thermogenic response, when this response is related to the plasma isoprenaline concentration. These findings suggest a blunted B-adrenergically mediated thermogenesis in obesity, which is only detectable when studying subjects with a wide range of adiposity and when the accuracy of individual values for the thermogenic response is optimized by using plasma concentration-response curves. The difference in B- 
adrenergically mediated thermogenesis between lean and obese subjects is relatively small, but may be of physiological significance, if persisting over prolonged periods of time, when the increase in body weight is calculated on basis of the classical law of thermodynamics: change in energy stores= energy intake - energy expenditure.

It is, however, hard to distinguish between causes and consequences of obesity when the obese state has already developed. To obtain an indication whether a lowered Badrenergically mediated thermogenesis may be an important factor contributing to the development of the obese state, the obese subjects were restudied after a period of slimming. As result of weight reduction there was a significant increase in the thermogenic response in the obese subjects, and this increase was negatively correlated to the average magnitude of thermogenic response (chapter 7). These data implicate that the origins of obesity are unlikely to be sought in a blunted B-adrenergically mediated thermogenesis. However, it is possible that a decrease in the B-adrenergically mediated thermogenesis as result of increasing fat stores may be a factor involved in the further development or maintenance of the obese state.

At present, it is becoming still more evident that a situation of energy balance can only be achieved in the case of macronutrient balance and that carbohydrate, protein and fat balance are regulated separately $(6,21)$. Achievement of macronutrient balance in turn requires that the fuel mix oxidized by the body is equivalent to the average nutrient composition of the diet. It has been proposed that the regulation of fat balance is less precise than the regulation of carbohydrate or protein balance and that not all individuals may be capable to adjust their oxidation pattern to a change in fat content of the diet. We found that as result of isoprenaline infusion there was a significant decreased in the respiratory exchange ratio in lean subjects but not in the obese, indicating a higher fat oxidation in lean subjects (chapter 6). This difference in fat oxidation between lean and obese subjects will be discussed more extensively in the following paragraphs.

\section{B-adrenergically mediated lipolysis}

When comparing the effect of $B$-adrenergic stimulation on intermediary metabolism in lean and obese subjects, the obese state appeared to be associated with an impaired ability to utilize fat. This impaired ability to use fat in obesity was reflected in a lowered Badrenergically mediated rise in arterial fatty acids and glycerol and a lowered muscle fatty acid oxidation (chapter 6). Weight reduction did not improve the impaired lipolytic response (chapter 8 ). In contrast, although the rise in arterial fatty acids and glycerol was similar before and after weight reduction the increase in the arterial concentration of $B$ hydroxybutyrate was significantly lower after weight loss, which may indicate a lowered ketogenesis. Since the only determinant factor for ketogenesis during B-adrenergic stimulation probably is the supply of fatty acids to the liver (8), these data suggest a worsened rather than improved lipolytic response after weight loss. These findings indicate that the impaired release of fatty acids and glycerol from adipose tissue may be a cause rather than a consequence of the obese state. Since our reduced-obese subjects were still slightly overweight, no definite conclusion about cause and consequence can be drawn from the present data. However, the tendency towards a worsened lipolysis after 
weight loss makes it very unlikely that after more severe weight loss a reversal of this trend will occur.

The lower rise in arterial fatty acids and glycerol may indicate an impaired B-adrenergic sensitivity of adipose tissue of obese subjects. A second possible explanation that may contribute to the impaired release of fatty acids and glycerol from adipose tissue may be a stronger inhibition of the lipolysis by insulin in obese subjects, since the rise in plasma insulin was significantly higher in obese than lean subjects during isoprenaline infusion. Considering the role of insulin, we also have to take into account that the insulin resistance of adipose tissue may be higher in obese than lean subjects, as suggested in obese subjects after meal ingestion (18). In addition to this, in lean volunteers it has recently been shown that the effect of insulin on lipolysis in vivo may be strongly counteracted by $B$-adrenergic stimulation (25). Thus, whether the different degrees of hyperinsulinemia in lean and obese subjects are of importance in explaining the differences in stimulated lipolysis remains questionable. A third factor that may contribute to the release of glycerol and fatty acids into the blood stream may be the magnitude of blood flow response during B-adrenergic stimulation. In chapter 9 , it is shown that the increase in abdominal subcutaneous adipose tissue blood flow during Badrenergic stimulation is much less pronounced in obese than in lean subjects. The lowered blood flow response in obese subjects may have resulted in a diminished mobilization of fat stores by decreasing the delivery of isoprenaline to the tissue (28), as well as carrier proteins for the transport of fatty acids in the bloodstream (12). In addition, a model has been proposed which raises the possibility that the rate of reuptake and reesterification of fatty acids within adipose tissue may be controlled by adipose tissue perfusion (19). Weight reduction, however, resulted in a trend towards a worsened lipolytic response and a trend towards an increased blood flow response (chapter 9). These data may suggest that factors other than the impaired blood flow response are responsible for the lowered release of fatty acids and glycerol from adipose tissue in (reduced)-obese subjects. However, care has to be taken in interpreting this since the blood flow and lipolytic response were measured in different group of subjects and the observed changes in these responses were very small.

\section{a-adrenerglically mediated skeletal muscle metabolism}

During $\mathbb{B}$-adrenergic stimulation there was an increase in fatty acid uptake and probably oxidation in forearm muscle in lean subjects, whereas the obese showed an increased glucose uptake and lactate release (chapter 6). Weight reduction did not improve this diminished fat uptake by muscle in obesity but tended to shift substrate use towards an increased muscle glucose uptake (chapter 7). These findings indicate that an impaired ability to utilize fat may contribute to the development of the obese state, by favoring the storage of fat and contributing thereby to the development and maintenance of large fat stores. A factor responsible for the lower muscle fatty acid oxidation in obesity may be simply the lower arterial concentrations of fatty acids in (reduced)-obese as compared to lean, which may result in a lower fatty acid uptake by muscle (24). Also, it has been suggested that obese subjects, due to a relatively lower proportion of slow twitch type 1 
muscle fibres, using mainly fatty acids as fuel, are unable to oxidize fatty acids as efficiently as lean subjects (47). A recent study could, however, not confim a difference in muscle fibre pattern between lean and obese subjects (42). Furthermore, it has been shown that the membrane transport of Jong chain fatty acids may be under B-adrenergic control (1). However, it remains to be determined whether this transport may be of importance in explaining differences in muscle fatty acid uptake between lean and obese subjects.

Beside the differences in skeletal muscle substrate metabolism in lean and obese subjects, the rise in muscle oxygen consumption during isoprenaline infusion is more pronoumced in lean subjects, which indicates that skeletal muscle is of more importance in the Badrenergically mediated thermogenesis in lean than obese subjects. As mentioned above, the increase in muscle oxygen consumption in lean subjects during isoprenaline infusion was sufficient to explain the total rise in whole body themogenesis, whereas in the obese the increase in muscle oxygen consumption did not reach statistical significance. What other tissues are of importance in the adrenergic thermogenesis in obese subjects remains to be elucidated. It is possible that part of the $B$-adrenergically mediated whole body thermogenesis in obese subjects may be located in the liver (increased B-adrenergically mediated NEFA oxidation, gluconeogenesis and glycogenolysis) or in adipose tissue (increased rate of fatty-triglyceride cycling), but at present, data are lacking to speculate further on this.

In summary, on basis of the research in the present thesis, several mechanisms that may be of importamce in the relationship between the sympathetic nervous system and (the development of) obesity can be proposed. Although the blunted B-adrenergically thermogenesis in obesity does not seem a primary factor related to the origins of obesity: the decrease in thermogenesis with increasing fat stores may be a factor involved in the further development or maintenance of the obese state. Secondly, the impaired $B$ adrenergically mediated lipolysis, possibly related to a decreased $\mathbb{B}$-adrenergic sensitivity of adipose tissue, is hypothesized to be a factor contributing to the development of the obese state, since weight reduction does not result in an improvement of this impaired response. Thirdly, the B-adrenergically stimulated uptake or oxidation of fatty acids by skeletal muscle is lowered in obese and reduced-obese subjects, which may speculated to be associated with, beside a lower supply of fatty acids to skeletal muscle, a defect in the B-adrenergically mediated transport of fatty acids across the cell membrune. These findings combined with evidence that the sympathetic nervous system is involved in several components of daily energy and substrate metabolism indicate that the sympathetic nervous system plays a significant role in the development and maintenance of the obese state. 


\section{References}

1. Abumrad N.A, C.R. Park, and R.R. Whitesell. Catecholamine activation of the membrane transport of long chain fatty acids in adipocytes is medliated by cyclic AMP and protein kinase. J. Biol. Chem. 261: $13082-13086,1986$.

2. Arch J.R.S. A.T. Ainsworth, M.A. Cawthorne, V. Piercy, M.V. Sennit, V.E. Thody, C. Wilson, and S. Wilson. Atypicall b-adrenoceptor on brown adipocytes as target for anti-obesity drugs. Nature 309: 163-165, 1984.

3. Arnold J.M.O., P.C. O'Connor, J.C. Riddel,D.W.G. Harron, R.G. Shaniks, and D.G. McDevitt. Effects of the $B_{2}$-adrenoceptor antagonist ICI 118,551 on exercise tachycardia and isoprenaline-induced $B$ adrenoceptor responses in man. Brit. J. Clin. Pharmacol. 19:619-630, 1985.

4. Astrup A., T. Andersen, N.J. Christensen, J. Bülow, J. Madsen, L. Breum, and F. Quaade. Impaired glucose-induced thermogenesis and arterial norepinephrine response persists after weight reduction in obese humans. Am. J. Clin. Nutr. 51: 331-337, 1990.

5 Astrup A., J. Bülow, J. Madsen, and N.J. Christensen. Contribution of BAT and skeletal muscle to thermogenesis induced by ephedrine in man. Am J Physiol 248 (Endlocrinol Metab 11): E507-E515, 1985 .

6. Astrup A., and A. Raben. Obesity: an inherited deficiency in the control of macronutrient balance. Eur. J. Clin. Nutr. 46: 611-620, 1992.

7. Astrup A., L. Simonsen, J. Bülow, and N.J. Christensen. Measurement of forearm oxygen consumption: role of heating of the contralateral hand. Am. J. Phystol. 255 (Endocrinol. Metab. 13): E572-E578, 1988.

8. Awogaro A., P.E. Cryer, and D.M. Bier. Epinephrine's ketogenic effect in humans is mediated principally by lipolysis. Am. J. Physiol, 263 (Endocrinol. Metab. 26): E250-E260, 1992.

9. van Baak M.A., J.M.V. Mooy and P.F.M. Schiffers. Exercise and the pharmokinetics of propranolol, verapamil and atenolol. Eur. J. Clin. Pharmacol.43:547-550, 1992.

10. Butlow J. Adipose tissue blood flow during exercise. Dan. Med. Bulli. 30 (2): 85-100, 1983.

11. Bullow J., R. Jelnes, A. Astrup, J. Madsen, and P. Vitmann. Tissue/blood partition coefficient for xenon in various adipose tissue depots in man. Scand. J. Lab. Invest. 47: 1-3, 1987.

12. Bullow I., and J. Madsen. Influence of blood flow on fatly acid moblization from lipolytically active adipose tissuc. Phingers Arch. 390: 169\%174, 1981.

13. Chen R.Y., F. Fan, S. Kim, K. Jan, S. Usami, and S. Chien. Tissue blood partition coefficient for xenon: temperaure and hematocrit dependence. J. Appl. Physiol. 49(2): 178-183, 1980.

14. Chinet A., T. Clatusen, and L. Giradier. Microcalorimeiric determination of energy expenditure due to active sodium-potassium transport in the soleus muscle and brown adipose tissue of the rat. J. Physiol 265: 43-61, 1977.

15. Clausen $T$, and $J$. Flatman. $B_{2}$-adrenoceptors mediate the stimulating effect of adrenalline on active electrogenic Na-K-transport in rat soleus muscle. Brit. J. Pharmacol. 68: 749-755, 1980.

16. Connacher A.A. W.M. Bennet, R.T. Jung, D.M. Bier, C.C.T. Smith, C.M. Scrimgeour, and M.J. Rennie. Effect of adrenaline infusion on fatty acid and glucose tumover in lean and obese human subjects in the postabsorptive and fed states. Clin. Sci. 81: 635-644, 1991.

17. Cooper K.E., O.G. Edholm, and R.F. Mottram. The blood llow in skin and muscle in human forearm. J. Physiol, 128: 258-267, 1955 .

18. Coppack S.W., R.D. Evans, R.M. Fisher, K.N. Frayn, G.F. Gibbons, S.M. Humphreys, M.L. Kirk, J.L. 
Potts, and T.D.R. Hockaday. Adipose tissue metabolism in obesity: lipase action in vivo before and after a mixed meal. Metabolism 41: 264-272, 1992.

19. Edens N.K.. R.L. Leibel, and J. Hirsch. Mechamism of free fatty acid reesterification in human adipocytes in vitro. J. Lip. Res. 31: 1423-1431, 1990.

20. Emorine L.J., S. Marullo, M. Briend-Sutren, G. Patey, K. Tate, C. Delavier-Klutchko, and D.A. Strosberg. Molecular characterization of the human $\mathrm{B}_{3}$-adrenergic receptor. Science $245: 1118-1121$, 1989.

21. Flatt J.P. Dietary fat, carbohydrate balance, and weight maintenance: effects of exercise. Am. J. Clin. Nutr. 45: 296-306, 1987.

22. Gallen I.W., and I.A. MacDonald. Effect of iwo methods of hand heating on body temperature, forearm blood flow, and deep venous oxygen saturation. Am. J. Physiol. 259 (Endocrinol. Metab. 22): $\mathrm{E} 639-\mathrm{E} 643,1990$.

23. Garby L., J.S. Garrow, B. Jørgenson, O. Lammert, K. Madsen, P. Sørensen, and J. Webster. Relation between energy expenditure and body composition in man: specific energy expenditure in vivo of fat and fat-free tissue. Eur. J. Clin Nutr 42: 301-305, 1988.

24. Hagenfeldt $\mathrm{L}$., and J. Wahren. Human forearm muscle metabolism during exercise. II. Uptake, release and oxidation of indiwidual FFA and glycerol. Scand. J. Lab. Invest. 21: 263-276, 1968.

25. Hagström-Toft E., P. Amer, U. Johannsson, L.S. Eriksson, U. Ungerstedt, and J. Bolinder. Eerfect of insulin on human adipose tissue metabolism in situ. Interactions with beta-adrenoceptors. Diabetologica 35: 664-670, 1992.

26. Heshka. S., M. Yang, P. Burt, and F. Xavier Pi-Sunyer. Weight loss and change in resting metabolic rate. Am. J. Clin. Nutr. 52: 981-986, 1990.

27. Himms-Hagen J. Brown adipose tissue thermogenesis and obesity. Prog. Lipid Res, 28: 67-11.5, 1989.

28. Hjehmdahl P., and B.B. Fredholm. Influence of adipose tissue blood flow on the lipolytic response to circulating noradrenaline at normal and reduced pH. Acta Physiol. Scand. 98: 74-79, 1976.

29. Hoffmans M., W.A. Pfeifer, B.L Gundlach, H.G.M. Nijkrake, A.J.M. Oude Ophuis, and J.G.A.J Hautvast. Resting metabolic rate in obese and normal weight women. Int. J. Obes. 3: 111-118, 1979.

30. Hollenga C.H., F. Brouwer, and J. Zaagsma. Three B-adrenoceptor subuypes mediate lipolysis int human adipocyses. Thesis: Beta-3, beta-2 and beta-1. adrenoceptors in human and animal adipocytes. Gromingen, The Netherlands, 1990.

31. Jung R.T., P.S. Shety, W.P.T. James, M. Barrand, and M. Callingham. Reduced thermogenesis in obesity. Nature (London) 279:322.323, 1979.

32. Krief S., F. Lönnquist, S. Rambault, B. Baude, A. van Spronsen, P. Arner, A. D. Strosberg, D. Ricquier, and L.J. Emorine. Tissue disuribution of B3-adrenergic receptor mRNA in man, J. Clin. Invest. $91: 344-349,1993$.

33. Langin D., M.P. Portillo, J. Saulnier-Blache, and M. Lafontan. Coexistence of three B-adrenoceptor subtypes in white fat cells of various mammalian species. Eur. J. Pharmacoll. 199:291-301, 1991.

34. Larsen O.A., N.A. Lassen, and F. Quaade. Blood flow through human adipose tissue determined with radioactive xenon. Acta Physiol. Scand. 66 (3): 337-345, 1966.

35. Ligget S.B., S.D. Shah, and P.E. Cryer. Characterization of B-adrenergic receptors of human skelctal muscle obtained by needle biopsy. Am. J. Physiol. 254 (Endocrinol. Metab. 17): E795-E798, 1988.

36. Newsholme E.A. A possible basis for the control of body weight. New Engl. J. Med. 302: 400-405, 1980.

37. Newsholme E.A., and R.A.J. Challis. Metabolic-control-logic: its application to thermogenesis, insulin 
sensitivity and obesity. In: Obesity, Björntorp P., and B.N. Brodoff, editors. J.B. Lippincon Company, Philadelphia 145-161, 1992.

38. Martin A.D., D.T. Drinkwater, and J.P. Clarys. Adipose tissue density, estimated lipid fraction and whole body adiposity in 6 male cadavers. Int. J. Sports Med. 25 (5, suppl): S5, 1993.

39. Ravussin E., and C. Bogardus. Relationship of genetics, age and physical fitness to daily energy expendiure and fuel utilization. Am. J. Clin. Nutr. 49:968-975, 1989.

40. Raz 1., A. Katz, and M.K. Spencer. Epinephrine inhibits insulin-mediated glycogenesis but enhances glycolysis in human skeletal muscle. Am J. Physiol. 260 (Endocrinol. Metab. 23): E430-E435, 1991

41. Shetty P.S. Physiological mechanisms in the adaptive response of the metabolic rates to energy restriction. Nutr. Res. Rev، 3: 49-74, 1990.

42. Simoneau J.A., and C. Bouchard. Skeletal rouscle metabolism in normal weight and obese men and women. Int. J. Obes. (17, suppl. 2): 31 (Abstract).

43. Simonsen L., J, Bülow, J. Madsen, and N.I. Christensen. Thermogenic response to epinephrine in the forearm and abdominal subcutaneous adipose tissue. Am. J. Physiol. 263 (endocrinol. Metab. 26): E850-E855, 1.992.

44. Stock M.J., and N.J. Rothwell. Factors influencing brown fat and the capacity for diet -induced themogenesis. Int. J. Obes. 9:9-15, 1985.

45. Thomas R.F., and S.B. Ligget. Lack of $B_{3}$-adrenergic receptor mRNA expression in adipose tissue and other metabolic tissues in the adult human. Mol. Pharmacol. 43: 343-348, 1993.

46. Vernet O., C.A. Nach», I. Christin, Y. Schutz, E. Danforth and E. Jequier. B-adrenergic blockade and intravenous nutrient-induced thermogenesis in lean and obese women. Am. J. Physiol. 253 (Endocrinol. Metab. 16): E65-E71 "1987.

47. Wade AJ., M.M. Marbut, and J.M. Round. Muscle fibre type and aetiology of obesity. Lancet 335: $805.808,1990$.

48. Wheeldon N.M., D.G. McDevitt, L.C. McFarlane, and B.J. Lipworth. Evaluation of putative $B_{3}$ adrenoceptors mediating the metabolic response to isoprenaline. Brit. J. Clin. Pharmacol. 35 (5): $555 \mathrm{P}$, 1993 (Abstract).

49. Whceldon N.M., D.G. McDevit, L.C. McFarlane, and B.J. Lipworth. B-adrenoceptor subtypes mediating the metabolic responses to BRL 35135 in man. Proceedings Brit. Pharmacoll. Soc., Bradford 14-16 July, 1993 (Abstract).

50. Wolfe R.R., D.N. Herndorn, F. Jahoor, H. Miyoshi and M. Wolfe. Effect of severe burn on substrate cycling by glucose and fatty acids. New Engl. J. Med. 317: 403-408, 1987. 


\section{Summary}

The sympathetic nervous system plays a role of importance in human energy and substrate metabolism. The catecholamines, norepinephrine and epinephrine, have a central role in the regulation of energy expenditure since they increase cellular oxygen uptake and stimulate the conversion of complex fuels in readily available substrates through processes of lipolysis, glycolysis and gluconeogenesis. The studies described in this thesis were intended to obtain more information on the role of the sympathetic nervous system in human energy metabolism with emphasis on processes that may be of importance in the development or maintenance of the obese state.

To obtain more information on the different adrenoceptor populations involved in the sympathetically mediated thermogenesis several infusion studies were performed which are described in chapter 2 . From these studies it can be concluded that both $B_{1}$ - and $B_{2}$ adrenoceptors are involved in the adrenergically mediated thermogenesis, whereas $\alpha_{1}$ and $\alpha_{2}$-adrenoceptors do not play a role of significance. Although there seems to be no consistent evidence to support the involvement of atypical adrenoceptors $\left(B_{3}\right)$ in human thermogenesis, data to exclude a significant role of $B_{3}$-adrenoceptors in man are also lacking.

Whilst in rats the sympathetically mediated thermogenesis occurs matinly in brown adipose tissue, there are indications that skeletal muscle is an important site of localization for human thermogenesis. Chapter 3 and $\mathbf{4}$ are dealing with the techniques to study forearm skeletal muscle metabolism in man. Skeletal muscle metabolism was studied by means of the determination of arterio-venous concentration differences of several metabolites in combination with a measurement of muscle blood flow. Arterialized blood, obtained by heating a dorsal hand vein, is often used as an alternative for arterial blood in forearm balance studies. The method of hand heating by warming blankets has been criticized since it may to some extent affect core temperature and metabolism of the contralateral arm and may thereby introduce errors in skeletal muscle flux calculations. In chapter 3 , it was shown that hand heating by means of a warm air box, which circulates air at $60^{\circ} \mathrm{C}$, has no effect on body temperature and no or little effect on skin temperature, deep venous oxygen saturation and forearm blood flow of the contralateral arm. These data indicate that the warm air box is a better method for obtaining arterialized blood in forearm balance studies than the warming blanket.

A generally applied method for estimating skeletal muscle blood flow is venous occlusion plethysmography. This method, however, measures only total forearm blood flow (TBF) and not the flow through the individual parts like muscle, fat tissue and skin. In chapter 4 , the contribution of forearm subcutaneous adipose tissue blood flow (ATBF, xenon washout technique) to TBF was evaluated in lean and obese males during rest and during intravenous infusion of the non-selective B-agonist isoprenaline (ISO). The data of this study showed that, although the overall contribution of ATBF to TBF was relatively small (on average $15 \%$ ), the significance of this contribution may vary with degree of adiposity (during rest; lean ws obese: 18 vs $11 \%, \mathrm{P}<0.05$ ). In addition, in lean volunteers the percentage contribution of ATBF to TBF was significantly higher during rest than during ISO-infusion (18 vs $10 \%$, respectively, $\mathrm{P}<0.05$ ), which suggests that in 
intervention studies where muscle blood flow is stimulated the blood flow measurement during the intervention may not be comparable to the baseline measurement. The implication of this finding is that in the study of forearm muscle metabolism, it may be necessary to take the contribution of subcutaneous fat blood flow to total blood flow into account, especially when comparing lean and obese subjects.

In chapter 5, skeletal muscle metabolism was studied with the above described techniques in healthy male volunteers during rest and during infusion of the non-selective $B$-agonist ISO with and without simultaneous infusion of the $B_{1}$-blocker atenolol (AT). As result of ISO-infusion there was an increase in lipolysis in adipose tissue as indicated by a threefold increase in plasma non-esterified fatty acids (NEFA) and a twofold increase in plasma glycerol, whilst during ISO+AT plasma NEFA and glycerol returned to control values. During non-selective $B$-adrenergic stimulation (ISO) an important part of whole body thermogenesis was localized in skeletal muscle, which can be accounted for by an increased fatty acid oxidation. During ISO+AT, muscle fatty acid uptake returned to control values, whereas skeletal muscle lactate release was increased. These findings suggest that skeletal muscle is of importance in both the $B_{1}$ - and $B_{2}$ adrenergically mediated thermogenesis.

To investigate whether the sympathetically mediated thermogenesis and sympathetically induced changes in metabolic pathways and skeletal muscle metabolism are altered in obesity, a comparison of these processes was made in lean and obese healthy males. In chapter 6 , it was shown that the whole body thermogenic response as result of ISOinfusion was not significantly different in a group of lean and obese subjects. However, in chapter 7, data of 30 subjects with a wide range of adiposity (6-42\%) showed a significant negative correlation between \% body fat (adjusted for age and basal plasma norepinephrine concentration) and the magnitude of the ISO-induced thermogenic response, when this response is related to the plasma ISO concentration. These findings suggest a blunted B-adrenergically mediated thermogenesis in obesity which is only detectable when studying subjects with a wide range of adiposity and when the accuracy of individual values for the thermogenic response is optimized by using plasma concentration-response curves. As result of weight reduction there was a significant increase in the thermogenic response in obese subjects (chapter 7), and this increase was negatively correllated to the average magnitude of thermogenic response. These data implicate that the origins of obesity are unlikely to be sought in a blunted Badrenergically mediated thermogenesis. Furthermore, we found a significant decrease in respiratory exchange ratio as result of ISO-infusion in lean subjects but not in the obese, indicating a higher fat oxidation in lean subjects.

When comparing the effect of B-adrenergic stimulation on intermediary metabolism in lean and obese men (chapter 6), the obese state appeared to be associated with an impaired ability to utilize fat, which was reflected in a lowered B-adrenergically mediated rise in arterial non-esterified fatty acids (NEFA) and glycerol and in a lowered muscle fatty acid uptake. Weight reduction did not improve this impaired lipolytic response (chapter 8). In contrast as result of weight reduction the ISO-induced rise in arterial Bhydroxybutyrate $(\mathrm{BOH})$ was lower than before, which indicates a lowered ketogenesis probably caused by a lower supply of NEFA to the liver. These data suggest that the 
lowered B-adrenergically mediated lipolytic response may be a cause rather than a consequence of obesity.

A factor that may be of importance in the release of NEFA and glycerol into the blood stream is adipose tissue blood flow. In chapter 9, it was shown that the increase in abdominal subcutaneous adipose tissue blood flow as result of ISO-infusion was much less pronounced in obese as compared to lean subjects. Weight reduction, however, resulted in a trend towards an increased blood flow response (chapter 9), which indicates that factors other than a blunted blood flow response may contribute to the diminished lipolysis in (reduced)-obese subjects.

During B-adrenergic stimulation there was an increase in muscle fatty acid uptake and probably oxidation in lean subjects, whereas the obese showed an increased glucose uptake and lactate release (chapter 6). Weight reduction did not improve this diminished muscle fat uptake in obesity but tended to shift the substrate use towards an increased muscle glucose uptake (chapter 8 ). These findings indicate that an impaired ability to utilize fat may contribute to the development of the obese state by favoring the storage of fat and contributing thereby to the development and maintenance of large fat stores. In conclusion, the above findings combined with evidence that the sympathetic nervous system is involved in several components of daily energy expenditure and substrate metabolism indicate that the sympathetic nervous system plays a role of importance in the development and maintenance of the obese state. 



\section{Samenvatting}

Het sympathische zenuwstelsel speelt een belangrijke rol bij het humane energie- en substraatverbruik. De catecholaminen, noradrenaline en adrenaline, spelen een centrale rol bij de regulering van het energieverbruik omdat zij de cellulaire zuurstofconsumptie verhogen en de omzetting van opgeslagen brandstof in snel beschikbare substraten bevorderen door middel van processen als lipolyse, glycolyse en gluconeogenese. Het onderzoek dat beschreven is in dit proefschrift was bedoeld om meer inzicht te verkrijgen in de rol van het sympatische zenuwstelsel bij de regulering van het energieverbruik van de mens, met nadruk op de processen die een rol kunnen spelen bij de ontwikkeling van obesitas.

Om meer informatie te verkrijgen over de verschillende adrenoceptor populaties die betrokken zijn bij de sympaticus gemedieerde thermogenese werden de in hoofdstuk 2 beschreven studies uitgevoerd. Uit deze studies kan geconcludeerd worden dat het effect van het sympathische zenuwstelsel op de thermogenese gemedieerd wordt door $B_{1}$ - en $B_{2}$ receptoren, terwijl de $\alpha_{1}$ - en $\alpha_{2}$-receptoren geen rol van betekenis spelen. De fysiologische betekenis van de atypische adrenoceptoren $\left(\beta_{3}\right)$ voor het humane energieverbruik bijft nog steeds een discussiepunt, aangezien eenduidig bewijs ontbreekt om een rol voor $B_{3}$-receptoren te bevestigen of te verwerpen.

Terwijl bij de rat de sympaticus gemedieerde thermogenese voornamelijk plaatsvindt in het bruine vetweefsel, zijn er aanwijzingen dat bij de humane thermogenese de skeletspier een belangrijke rol speelt. In hoofdstuk 3 en 4 wordt ingegaan op de technieken om het metabolisme van de skeletspier van de onderarm te bestuderen bij de mens. Het spiermetabolisme werd onderzocht door het bepalen van arterio-veneuze concentratieverschillen van verschillende metabolieten over de onderarmspier in combinatie met een meting van de spierdoorbloeding. Als alternatief voor arterièel bloed wordt in onderarm studies vaak gebruik gemaakt van gearterializeerd bloed, dat verkregen wordt door het verwarmen van een dorsale hand vene. De methode van het verwarmen van de hand met behulp van warme doeken is in het verleden bekritiseerd, aangezien deze effect kan hebben op de lichaamstemperatuur en het metabolisme van de contralaterale arm, wat kan resulteren in fouten in de berekening van de afgifte of opname van metabolieten door de spier. In hoofdstuk 3 werd aangetoond dat het verwarmen van de hand met behulp van een hete lucht 'box' $\left(60^{\circ} \mathrm{C}\right)$ geen effect heeft op de lichaamstemperatuur en weinig of geen effect op de huidtemperatuur, de diepe veneuze zuurstofsaturatie en de doorbloeding van de onderam van de contralaterale arm. Deze resultaten geven aan dat het verwarmen van de hand met de hete luchr 'box' een betere methode is voor het verkrijgen van gearterializeerd bloed dan het verwarmen met de warme doeken.

Een algemeen gebruikte methode voor het schatten van de spierdoorbloeding is veneuze occlusie plethysmografie. Met deze methode meet men echter alleen de doorbloeding van de totale onderarm en niet de doorbloeding van de individuele delen van de arm zoals spier, huid en vetweefsel. In hoofdstuk 4 werd de bijdrage van de subcutane vetweefseldoorbloeding (ATBF, ${ }^{133}$ xenon 'washout' techniek) aan de totale onderarmdoorbloeding (TBF) bepaald bij mannen met normaal gewicht en bij mannen 
met overgewicht tijdens rust en tijdens intraveneuze infusie van de $\mathbb{B}$-agonist isoprenaline (ISO). De resultaten van deze studie toonden aan dat, alhoewel de gemiddelde procentuele bijdrage van ATBF aan TBF relatief klein is, deze bijdrage hoger kan zijn bij normaal gewich dan bj overgewicht (18 vs $11 \%, \mathrm{P}<0.05$ ). Verder werd gevonden dat bij mannen met normaal gewicht de procentuele bijdrage van ATBF aan TBF tijdens rust significant hoger was dan tijdens 150 -infusie (18 vs $10 \%, P<0.05$ ). Dit suggereert dat het mogelijk is dat in interventie studies waarbij de spierdoorbloeding gestimuleerd wordt, de meting van de totale doorbloeding tijdens de interventie niet vergelijkbaar is met de rustmeting. De implicatie van deze bevinding is dat het bij de bestudering van het spiermetabolisme van de onderarm nodig kan zijn om rekening te houden met de bijdrage van de subcutane vetweefseldoorbloeding aan de totale doorbloeding.

In hoofdstuk 5 werd het skeletspiemetabolisme bestudeerd met de hierboven beschreven rechnieken bij mannen met normaal gewicht tijdens rust en tijdens infusie van de $B$ agonist $\mathbb{I S O}$ met en zonder gelijktijdige infusie van de $\mathbb{B}_{1}$-blokker atenolol (AT). Als gevolg van ISO infusie was er een vermeerdering van de lipolyse in het vetweefsel wat blijkt uit de drievoudige vermeerdering van de arteriële concentraties van vrije vetzuren en een tweevoudige stijging van de arteriële concentratie van glycerol, terwijl tijdens ISO+AT deze concentraties niet significant verschilden van de controlewaarden. Tijdens ISO-infusie was een belangrijk deel van de stijging van het lichaamsenergieverbruik gelokaliseerd in de skeletspier, die zijn energieverbruik verhoogde door een verhoogde vetoxidatie. Tijdens ISO+AT was de vetzuuropname van de spier niet langer verhoogd, maar was er een vermeerderde afgifte van laktaat door de spier. De bovenstaande gegevens suggereren dat de skeletspier van belang is bij zowel de $B_{1^{-}}$als de $B_{2}$ gemedieerde thermogenese.

Vervolgens werden de sympaticus gemedieerde thermogenese en de sympaticus gemedieerde veranderingen van het substraat metabolisme vergeleken bij mannen met normal gewicht en mannen met overgewicht. In hoofdstuk 6 werd gevonden dat de stijging van het lichaamsenergieverbruik als gevolg van ISO-infusie niet significant verschillend was bij normaal gewicht en overgewicht. In hoofdstuk 7 werd echter aangetoond dat er bij een groep van 30 mannen met een grote spreiding van het lichamasvetpercentage $(6-42 \%)$, een signifikante negatieve correlatie was tussen lichaamsvetpercentage en de grootte van de ISO-geinduceerde thermogenese, wanneer de thermogene respons gerelateerd werd aan de plasma ISO concentratie. Deze bevindingen tonen aan dat de $\mathrm{b}$-adrenerge thermogenese verminderd is bij mannen met overgewicht Dit verschil is alleen te detecteren bij de bestudering van proefpersonen met een grote spreiding van het vetpercentage en wanneer de thermogene respons bepaald wordt met behulp van plasma ISO concentratie-respons curves. Als gevolg van gewichtsreductie was er een stijging van de B-adrenerge thermogenese bij obese mannen (hoofdstuk 7), die afhankelijk was van de grootte varn de thermogene respons. Deze gegevens impliceren dat de oorsprong van obesitas niet zozeer gezocht moet worden in een verminderde Badrenerge thermogenese. Als gevolg van ISO-infusie was er een significante daling van het respiratoir quotiënt bij normaal gewicht terwijl bij overgewicht dit quotiënt niet veranderde. Dit geeft aan dat mannen met normaal gewicht meer vet verbranden als gevolg van ISO-infusie dan mannen met overgewicht. 
Ook bij de vergelijking van het effekt van B-adrenerge stimulering op het intermediaire metabolisme bij normaal gewicht en overgewicht (hoofdstuk 6) kwam naar voren dat mannen met overgewicht minder vet verbruiken. Dit kwam tot uiting in een lagere Badrenerge gemedieerde stijging van de arteriële concentraties van vrije vetzuren (NEFA) en glycerol en in een lagere vetverbranding van de onderarmspier bij overgewicht dan bij normaal gewicht. Gewichtsvermindering verbeterde de verlaagde lipolytische respons bij obese mannen niet (hoofdstuk 8). Er was een lagere stijging in de arteriële concentratie van B-hydroxybutyratat als gevolg van gewichtsreductie, wat een aanwijzing is voor een verlaagde ketogenese en dus een verminderde toevoer van NEFA naar de lever. Deze bevindingen suggereren dat de verlaagde lipolytische respons eerder een oorzaak dan een gevolg van overgewicht is.

Een factor die van belang kan zijn bij de afgifte van NEFA en glycerol vanuit vetweefsel naar het bloed is de vetweefseldoorbloeding. In hoofdstuk 9 werd aangetoond dat de vermeerdering van de abdominale vetweefseldoorbloeding als gevolg van ISO-infusie duidelijk lager was bij mannen met overgewicht dan bij normaal gewicht. Gewichtsvermindering resulteerde echter in een tendens tot een vermeerderde ISO geïnduceerde doorbloedingsrespons, wat aangeeft dat andere factoren dan een verlaagde doorbloeding waarschijnlijk verantwoordelijk zijn voor de verminderde $B$-adrenerge lipolyse bij overgewicht.

Tijdens B-adrenerge stimulering nam de vetoxidatie van de onderarmspier toe bij mannen met normaal gewicht, terwijl de onderarmspier van mannen met overgewicht een verhoogde glucose-opname en laktaatafgifte vertoonde (hoofdstuk 6). Gewichtsreductie verbeterde deze verlaagde vetopname door de spier bij obesen niet, maar stuurde het substraatverbruik van de spier in de richting van een verbeterde glucose opname (hoofdstuk 8). Deze bevindingen geven aan dat het onvermogen om vet te oxideren eerder een oorzaak dan een gevolg van obesitas lijkt. Het verlaagde vetverbruik van obesen kan bijdragen aan de ontwikkeling van obesitas door de opslag van vet en de handhaving van grote vetvoorraden te bevorderen.

Concluderend kan gesteld worden dat de hierboven beschreven bevindingen, in kombinatie met aanwijzingen dat het sympathische zenuwstelsel een rol speelt bij het dagelijks energie- en substraatverbruik, aangeven dat het sympathische zenuwstelsel een belangrijke rol kan spelen bij de ontwikkeling en het in stand houden van overgewicht. 


\section{Abbreviations}

\begin{tabular}{|c|c|}
\hline ANOVA & analysis of variance \\
\hline $\mathrm{AT}$ & atenolol \\
\hline$A-V$ difference & arterio-venous concentration difference \\
\hline ATBF & adipose tissue blood flow \\
\hline BMI & body mass index \\
\hline BW & body weight \\
\hline $\mathrm{BOH}$ & B-hydroxybutyrate \\
\hline $\mathrm{Hb}$ & hemoglobin \\
\hline $\mathrm{Ht}$ & hematocrit \\
\hline $\mathrm{E}$ & epinephrine \\
\hline $\mathrm{EE}$ & resting energy expenditure \\
\hline FM & fat mass \\
\hline FFM & fat free mass \\
\hline $\mathrm{h}$ & hour \\
\hline HR & heart rate \\
\hline ISO & isoprenaline \\
\hline Kact & activation constant \\
\hline MAP & mean arterial pressure \\
\hline MRI & magnetic resonance imaging \\
\hline $\mathrm{n}$ & number \\
\hline $\mathrm{NE}$ & norepinephrine \\
\hline NEFA & non esterified fatty acids \\
\hline NS & not significant \\
\hline PE & phenylephrine \\
\hline RER & respiratory exchange tratio \\
\hline $\mathrm{SatO}_{2}$ & oxygen saturation of hemoglobin \\
\hline $\mathrm{SEE}$ & standard error of estimate \\
\hline SEM & standard error of the mean \\
\hline SBF & skin blood flow \\
\hline SMBF & skeletal muscle blood flow \\
\hline SSA & sulphosalicylic acid \\
\hline TBF & total forearm blood flow \\
\hline $\mathrm{VLCD}$ & very low calorie diet \\
\hline$y$ & years. \\
\hline
\end{tabular}





\section{Nawoord}

Het onderzoek beschreven in dit proefschrift is tot stand gekomen dankzij de medewerking en het enthousiasme van weel mensen. Een aantal mensen wil ik met name noemen.

Allereerst wil ik Marleen van Baak en Wim Saris bedanken, die mij de mogelijkheden hebben geboden om dit onderzoek uit te voeren. Marleen, die bijna te allen tijde tijd vrij wist te maken voor discussie over onderzoeksresultaten en wiens heldere en kritische visie op het onderzoek van groot belang zijn geweest bij het tot stand komen van dit proefschrift. En natuurlijk niet te vergeten al de samen uitgevoerde experimenten, die om practische redenen vaak 's morgens wel erg vroeg moesten begimen. Wim wil ik bedanken voor de goede inhoudelijke suggesties en de stimulerende discussie over het verloop van het onderzoek. Alsmede voor zijn enthousiasme voor het onderzoek, wat ik zeer heb gewaardeerd.

Ik zou graag de leden van de beoordelingskommissie, Prof. A.C. Nieuwenhuijzen Kruseman, Prof. A. Astrup, Prof. M.J. Stock, Prof. H. Kuipers and Prof. H.A.J. Struijker Boudier, willen bedanken woor de beoordeling van het proefschrift. Especially, I would like to thank Prof. Astrup and Prof. Stock for the critical evaluation of my thesis and for being present on the day of the defence of my thesis.

Zonder de medewerking van de afdeling Nucleaire Geneeskunde van het AZM had het grootste deel van dit proefschrift niet tot stand kunnen komen. G. Heidendal wil ik bedanken voor de mogelijkheid om experimenten wit te voeren op de afdeling Nucleaire Geneeskunde en voor het kritisch doornemen van de artikelen. Gerrit Kemerink wil ik bedanken voor de hulp bij het opzetten van de xenon-metingen en het uitvoeren van de MRI metingen, alsmede voor de hulp bij het analyseren van de resultaten en de discussie over het onderzoek. Marie-Therese Pakbiers voor de samenwerking bij de uitvoering van de xenon metingen en voor de analyse van de xenon metingen.

Verder wil ik alle mensen bedanken die bijgedragen hebben tot een gowde uitvoering van het practische gedeelte van de in dit proefschrift beschreven experimenten en die hierboven nog niet genoemd zijn:

-de Röntgen afdeling van het AZM voor het beschibaar stellen van hun MRI apparatuur voor de plaatjes van de onderarmen.

-C. Langenberg voor het inbrengen van de arteriële infusen

-Loek Wouters en Paul Schoffelen voor de hulp bij technische problemen.

-Ed Beckers voor het veelvuldig inbrengen van infusen in de beginperiode van het onderzoek

- Amnemie Gijsen voor de hulp bij uitwoering van de vele COBAS bepalingen.

-alle proefpersonen voor deelname aan de vaak invasieve proeven

-alle mensen van de vakgroep die proefpersoon zijn geweest bij het valideren van apparatuur en het oefenen van technieken (en ik realiseer me nu dat dit bijna de hele vakgroep is).

Alle collega's van Humane Biologie wil ik bedanken voor de collegialiteit en hun bijdrage aan de werkomstandigheden waaronder dit proefschrift tot stand is gekomen. 
Met name wil ik mijn (ex)-kamergenoten noemen, in chronologische volgorde:

* Monique en Anita wil ik vooral bedanken voor de gezellige eerste periode, waarbij ik de gezellige sfeer op de kamer alsmede de gezamelijke etentjes erg leuk heb gevonden.

* Nancy en Daphne voor de goede onderlinge sfeer, zowel op het werk als tijdens de regelmatige sauna bezoeken.

* Kitty en Jos voor de goede werksfeer gedurende het laatste jaar. Kitty, we hebben in dat jaar tot een optimale combinatie tussen hard werken en gezelligheid kunnen komen, wat ik zeker zal missen.

Verder wil ik alle mensen in de privésfeer bedanken voor hun interesse in mijn werk en hun bijdrage aan een goede balans van werk en privéaktiviteiten. En tot slot Jan Paul, die door mij te volgen naar Maastricht de belangrijkste bijdrage aan deze balans heeft gegeven. 


\section{Curriculum vitae}

Ellen E. Blaak werd op 17 december 1964 in Vught geboren. In 1983 behaalde zij haar VWO diploma op het Develsteincollege te Zwijndrecht. Vanaf 1983 tot 1989 studeerde zij Humane Voeding aan de Landbouwuniversiteit te Wageningen. Tijdens haar studie deed zij een afstudeervak Klinische Voeding uitgevoerd bij de Rijksuniversiteit Limburg en het VU ziekenhuis te Amsterdam (Dr. H. Bilo). Tevens deed zij een afstudeervak Dierfysiologie bij de vakgroep Fysiologie van mens en dier van de Landbouwuniversiteit Wageningen (Dr. V.V.A.M. Schreurs). Van november 1988 to mei 1989 werd een stageperiode doorgebracht bij het 'Dunn Clinical Nutrition Centre' te Cambridge (Dr. M. Elia). In september 1992 behaalde zij het diploma van landbouwkundig ingenieur, waarna zij in dienst trad als assistent in opleiding bij de vakgroep Humane Biologie van de Rijksuniversiteit Limburg, alwaar het in dit proefschrift beschreven onderzoek werd uitgevoerd (Dr. M.A. van Baak, Prof, dr. W.H.M. Saris). In mei 1993 heeft zij een stipendium toegewezen gekregen van de Nederlandse Organisatie van Wetenschappelijk Onderzoek, waarmee zij een half jaar onderzoek (februari-augustus 1994) zal doen bij het Huddinge Ziekenhuis, Karolinski Instituut te Zweden (Dr. P. Arner). 



\section{List of publications}

\section{Articles}

* Bilo H.J.G, G.H. Schaap, E.E. Blaak, R.O.B. Gans, P.L. Oe, and A.J.M. Donker. Effect of chronic and acute protein administration on renal function in patients with chronic renal insufficiency. Nephron 53: 181-187, 1989.

* Blaak E.E., K.R. Westerterp, O. Bar-OT, L.J.M. Wouters, and W.H.M. Saris. Training in relationship to total energy expenditure and spontaneous activity in obese boys. Am. J. Clin. Nutr. 55: 777-782, 1992.

* Blaak E.E, M.A. van Baak, K.P.G. Kempen, and W.H.M. Saris. The effect of hand heating on $\mathrm{O}_{2}$ consumption of the contralateral arm. J. Appl. Physiol, 72(6): 2364-2368, 1992.

* Blaak E.E., M.A. van Baak, K.P.G. Kempen, and W.H.M. Saris Role of alpha and beta adrenoceptors in the sympathetically mediated thermogenesis. Am. J. Physiol. 264 (Endocrinol. Metab. 27): E11-E17, 1993.

* Blaak E.E., W.H.M. Saris, and M.A. van Baak. Adrenoceptor subtype mediating catecholamineindwce thermogenesis in man. Int. J. Obes. 17 (Suppl. 3), 1993, in press.

* Blaak E.E., M.A. van Baak, K.P.G. Kempen and W.H.M. Saris. Weight reduction and the Badrenergically mediated thermogenesis in obese men. Obesity in Europe 1993, in press.

* Blaak E.E., M.A. van Baak, G.J. Kemerink, M.T.W. Pakbiers, G.A.K. Heidendal, and W.H.M. Saris. Effect of beta-adrenergic stimulation on forearm skeletal muscle metabolism in man. Subminted to Am. J. Physiol. (Endocrinol. Metab.)

* Blaak E.E., M.A. van Baak, G.J. Kemerink, M.T.W. Pakbiers, G.A.K. Heidendal and W.H.M. Saris. Total forearm blood flow as indicator of skeletal muscle blood flow: effect of subcutaneots adipose tissue blood flow. Submitted to Clin Sci.

* Blaak E.E., M.A. van Baak, G.J. Kemerink, M.T.W. Pakbiers, G.A.K. Heidendal, and W.H.M. Saris. Beta adrenergic stimulation of whole body energy expenditure and skeletal muscle metabolism in obese men: a comparison with lean men. Submitted to Am. J. Physiol. (Endocrinol. Metab.)

* Blaak E.E., M.A. van Baak, G.J. Kemerink, M.T.W. Pakbiers, G.A.K. Heidendal and W.H.M. Saris. Beta-adrenergic stimulation and skeletal muscle metabolism in relation to weight reduction in obese men. Submitted to Am. J. Plyysiol. (Endocrinol. Metab.)

* Blaak E.E., M.A. van Baak, A.D.M. Kester, and W.H.M. Saris. Beta-adrenergically thermogenic and heart rate response: effect of obesity and weight loss. Submitted to J. Clin. Invest.

* Blaak E.E., M.A. van Baak, G.J. Kemerink, M.T.W. Pakbiers, G.A.K. Heidendal and W.H.M. Saris. Beta-adrenergic stimulation and abdominal subcutaneous fat blood flow in lean, obese and reducedobese subjects. Submithed to Clin. Sci.

\section{Abstracts}

* Blaak E.E., K.R. Westerterp, O. Bar-Or, L.J.M. Wouters, and W.H.M. Saris. Effect of training on total energy expenditure and spontancous activity in obese boys. Int. J. Obes. 14 (suppl 2): 86, 1990.

* Blaak E.E., K.R. Westerterp, O. Bar-Or, L.M.M. Wouters, and W.H.M. Saris. Effect of VLCD on daily energy expenditure and body composition in obese boys. Int J. Obes. 14 (suppl. 2): 86, 1990. 
* Blaak E.E., M.A. van Balak, K.P.G. Kempen, and W.H.M. Saris. Role of alpha and beta adrenoceptors in the sympathetically mediated thermogenesis. Int. J. Obes. 15 (suppl. 1): 62, 1991

* Blaak E.E., M.A. wan Baak, K.P.G. Kempen, and W.H.M. Saris. Role of alpha and beta adrenoceptors in the sympathetically mediated thermogenesis. Eur. J. Physiol. 418: R144, 1991.

* Blaak E.E.M.A. van Bask, K.P.G. Kempen, and W.H.M. Saris. The effect of hand heating on $\mathrm{O}_{2}-$ consumption of the contralateral arm. Int. J. Obes 15 (suppl 1): 63, 1991.

* Blaak E.E, M.A. van Baak, K.P.G. Kempen, and W.H.M. Saris. The effect of hand heating on $\mathrm{O}_{2}-$ consumption of the contralateral arm. Eur. J. Physiol. 418: R144, 1991.

* Blaak E.E., M.A. van Baak, G.J. Kemerink, M.T.W. Pakbilers, G.A.K. Heidendal, and W.H.M. Saris. Effect of beta-adrenergic stimulation on whole body energy expenditure and forearm skeletal muscle metabolism. Int. J. Obes. 16 (suppl. 1), 1992.

* Blaak E.E., M.A. van Baak, and W.H.M. Saris. Role of B -adrenoceptors in the sympatheticallymediated energy expenditure. Int. J. Obes. 16 (suppl. 1): 227, 1992.

* Blaak E.E., M.A. van Baak, G.J, Kemerink, M.T.W. Pakbiers, G.A.K. Heidendal, and W.H.M. Saris. The effect of beta adrenergic stimulation on whole body energy expenditure and skeletal muscle metabolism in lean and obese men. Int. J. Obes. 17 (suppl. 2) 25, 1993

* Blaak E.E., W.H.M. Saris, K.P.G. Kempen, and M.A. van Baak. Effect of weight reduction on the Badrenoceptor mediated thermogenesis. Int. J. Obes. 17 (suppl. 2) 25, 1993.

* Kempen K.P.G., E.E. Blaak, M.A. van Baak, and W.H.M. Saris. Relation between lymphocyte and skeletal muscle $B_{2}$-adrenoceptors in obese female subjects. Int. J. Obes. 17 (suppl. 2): 28, 1993.

* Kempen K.P.G., E.E. Blaak, M.A. wan Baak, and W.H.M. Saris. Effect of weight reduction on acute response to exercise of adrenoceptors in obese subjects. Int. J. Obes. 17 (suppl. 2): 106, 1993.

* Kempen K.P.G., J.H.C.H. Stegen, E.E. Blaak, M.A. van Baak, and W.H.M. Saris. Relation between weight reduction and beta-adrenergic stimulation in obese women. Int.J. Obes 16 (suppl. 10): 238, 1992.

* Kempen K.P.G., J.H.C.H. Stegen, E.E. Blaak, M.A. van Baak, and W.H.M. Saris. Weight cycling has no effect on beta-adrenergic stimulation in obese women. Int. J. Obes. 16 (suppl. 1): 239, 1992.

* Schreurs V.V.A.M. , H.A. Boekholt, E.E. Blaak, P.J.M. Weys, and R.E. Koopmanschap. Post-exercise leucine catabolism in relation to the nutritional state. Int. J. Sports Med. 23 (suppll.) 469, 1991. 